\title{
Assessing Basic Education Service Delivery in the Philippines
}

The Philippines Public Education Expenditure Tracking and Quantitative Service Delivery Study

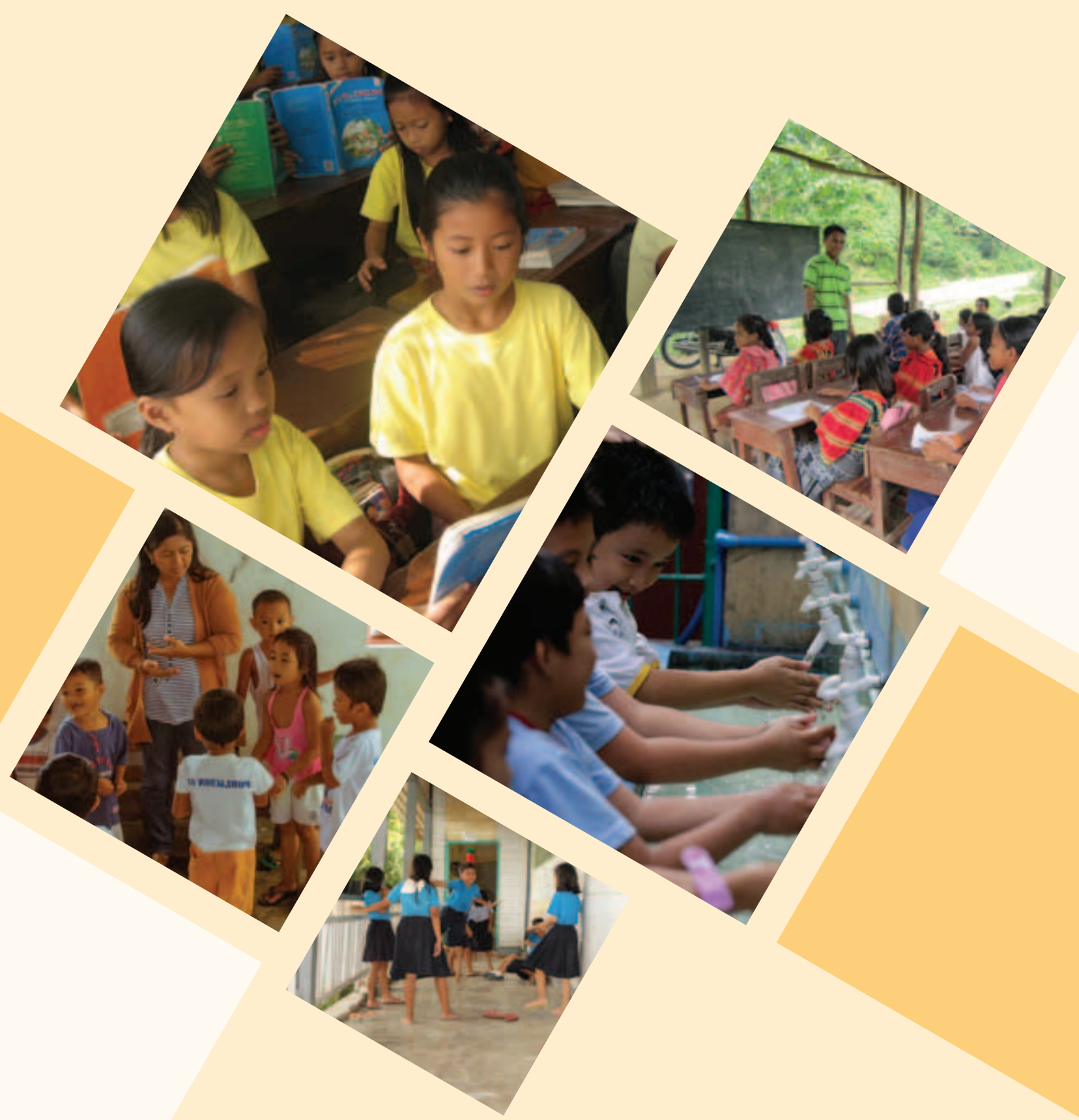

(4) WORLD BANK GROUP

Australian

Aid ए 



\section{Assessing Basic Education Service Delivery in the Philippines}





\section{Assessing Basic Education Service Delivery in the Philippines}

The Philippines Public Education Expenditure Tracking and Quantitative Service Delivery Study 
Report No: AUS6799 | June 2016

\section{Standard Disclaimer:}

This volume is a product of the staff of the International Bank for Reconstruction and Development/ The World Bank. The findings, interpretations, and conclusions expressed in this paper do not necessarily reflect the views of the Executive Directors of The World Bank or the governments they represent. The World Bank does not guarantee the accuracy of the data included in this work. The boundaries, colors, denominations, and other information shown on any map in this work do not imply any judgment on the part of The World Bank concerning the legal status of any territory or the endorsement or acceptance of such boundaries.

\section{Copyright Statement:}

The material in this publication is copyrighted. Copying and/or transmitting portions or all of this work without permission may be a violation of applicable law. The International Bank for Reconstruction and Development/The World Bank encourages dissemination of its work and will normally grant permission to reproduce portions of the work promptly.

For permission to photocopy or reprint any part of this work, please send a request with complete information to the Copyright Clearance Center, Inc., 222 Rosewood Drive, Danvers, MA 01923, USA, telephone 978-750-8400, fax 978-750-4470, http://www.copyright.com/.

All other queries on rights and licenses, including subsidiary rights, should be addressed to the Office of the Publisher, The World Bank, 1818 H Street NW, Washington, DC 20433, USA, fax 202-522-2422, e-mail pubrights@worldbank.org. 


\section{Table of Contents}

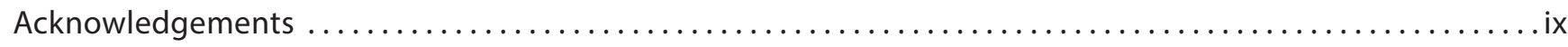

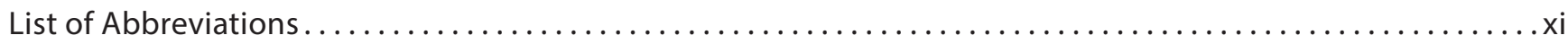

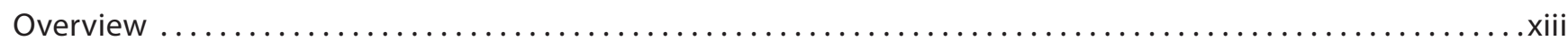

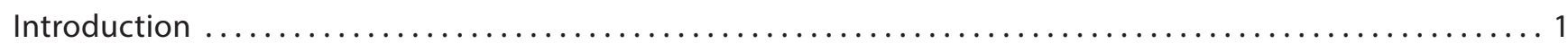

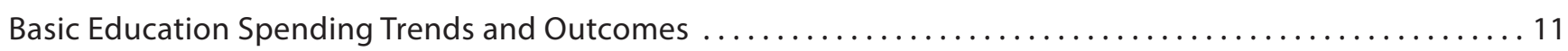

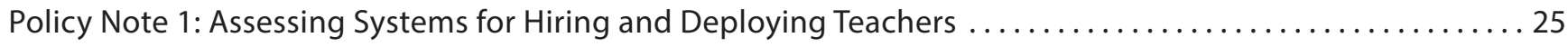

Policy Note 2: Developing a Proficient and Motivated Teacher Workforce $\ldots \ldots \ldots \ldots \ldots \ldots \ldots \ldots \ldots \ldots \ldots$

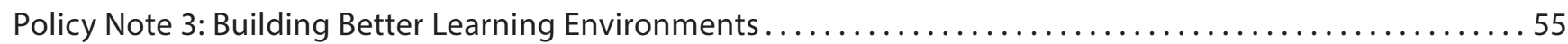

Policy Note 4: Assessing School-based Management ................................. 71

Policy Note 5: Providing Schools with Enough Resources to Deliver Quality Education................ 87

Policy Note 6: Assessing the Role Played by Local Government in Supporting Basic Education ........... 103

Policy Note 7: Understanding the Drivers of Public School Performance and Efficiency .............. 115

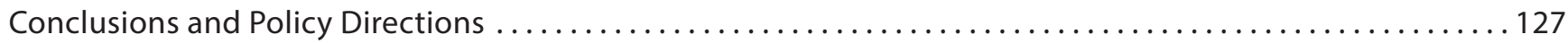

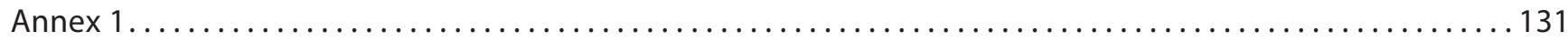

\section{Figures}

\section{Overview}

Figure 1: Annual GDP per capita growth rate (1960-2000) and student learning outcomes across countries . . . . . . . . xiii

Figure 2: Government spending on basic education, 2003 to 2015 (in 2014 constant prices) . . . . . . . . . . . . . xiv

Figure 3: National achievement test scores and school annual revenue per student, 2013/14 . . . . . . . . . . . . xvi

Figure 4: Primary/elementary teacher absenteeism rates in selected countries, various years . . . . . . . . . . . .xvii

Figure 5: Percentage of teacher posts allotted for the 2013 school year where newly hired teachers were in post by the final quarter of the 2014 calendar year. . . . . . . . . . . . . . . . xviii

Figure 6: Percentage of questions answered correctly by the median teacher (binary scoring method), 2014 . . . . . xviii

Figure 7: Appropriations, allotments, obligations, and utilization rates for HRTD funds

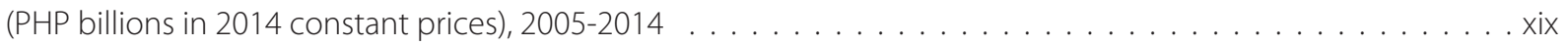

Figure 8: Indicators of classroom quality from direct classroom observation $\ldots \ldots \ldots \ldots \ldots \ldots \ldots \ldots \ldots \ldots$

Figure 9: Completion and satisfaction rates for 2013 school infrastructure projects, 2014 . . . . . . . . . . . . . xxi

Figure 10: Annual school revenue by type and source, $2013 / 14$ school year. . . . . . . . . . . . . . . . . . xxiii

Figure 11: Percentage of parents of elementary and high school students

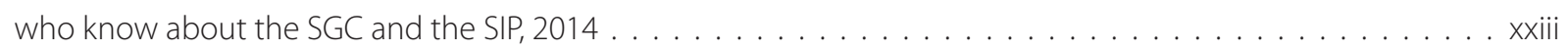

Figure 12: Percentage of school principals reporting an engagement with Check My School (CMS) in 2013 or 2014 . . . xxiv

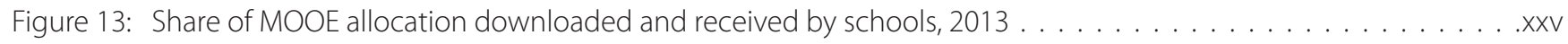

Figure 14: Percentage of schools that received input from stakeholders about MOOE funds, 2014 SY . . . . . . . . . . xxvii

Figure 15: Percentage of schools that report receiving cash or in-kind contributions from local governments and average levels of support, $2013-14 \ldots \ldots \ldots \ldots \ldots \ldots$. . . . . . . . . . . . . . . . . . . . . . .

Figure 16: Percentage of schools that failed to meet DepEd service standards, $2014 \ldots \ldots \ldots \ldots \ldots \ldots \ldots$. . . . . . . . . . . . 


\section{Introduction}

Figure 1: Breakdown of the Department of Education (DepEd) budget, $2015 \ldots \ldots \ldots \ldots \ldots \ldots$

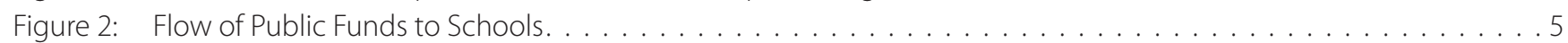

\section{Basic Education Spending Trends and Outcomes}

Figure 1: Government Spending on Basic education, 2003 to 2015 (in 2014 constant prices) . . . . . . . . . . . . . . . . 12

Figure 2: Per Capita Government Spending on Basic Education by Region and Province and Poverty Incidence, 2012 . . 13

Figure 3: Public Spending on Education as a Share of GNP and Total Government Spending, Selected Countries, 2012 . 14

Figure 4: Government Spending on Education as a Share of GNP, Selected Countries, 2012 . . . . . . . . . . . . 15

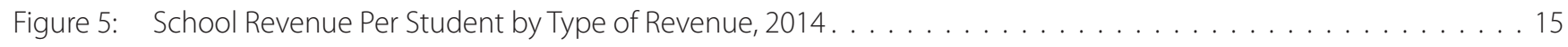

Figure 6: Public Student-teacher and Student-classroom Ratios, 2005-2013 . . . . . . . . . . . . . . . . . . . 16

Figure 7: Student-teacher and Student-classroom Ratios and Per Capita Basic Education Spending, 2012 . . . . . . . . 17

Figure 8: Gross and Net Enrollment Rates and Completion rates, 2005-2012 . . . . . . . . . . . . . . . . . . . 18

Figure 9: National Achievement Test Scores by Region (\%), $2011 \ldots \ldots \ldots \ldots \ldots$

Figure 10: Budget Execution Rates for Basic Education Spending, 2006-2013 . . . . . . . . . . . . . . . . . . . . . . . 20

\section{Policy Note 1: Assessing Systems for Hiring and Deploying Teachers}

Figure 1: Student-teacher ratios (STRs) and teacher numbers in basic education, 2006-2014 . . . . . . . . . . . . . 26

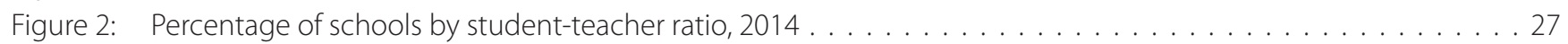

Figure 3: Percentage of high school principals reporting subject specialist teacher shortages

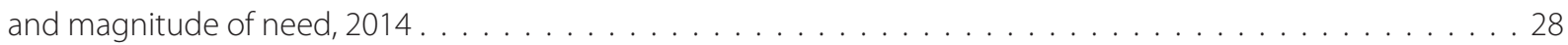

Figure 4: Primary/elementary teacher absenteeism rates in selected countries, various years . . . . . . . . . . . . . . 29

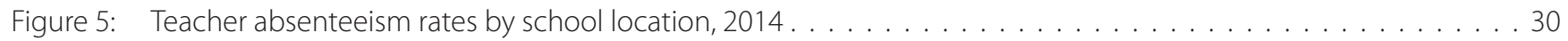

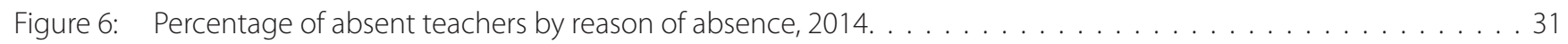

Figure 7: Proportionate increase in the stock of school teachers in 2013 and 2014

compared to 2012 school-level student-teacher ratios . . . . . . . . . . . . . . . . . . . . . 32

Figure 8: Percentage of schools by student-teacher ratio, 2012 and 2014 school years . . . . . . . . . . . . . . . 33

Figure 9: Percentage of teacher posts allotted for the 2013 school year where

newly hired teachers were in post by the final quarter of the 2014 calendar year . . . . . . . . . . . . . . 35

\section{Policy Note 2: Developing a Proficient and Motivated Teacher Workforce}

Figure 1: Percentage of questions answered correctly by the median teacher (binary scoring method), 2014 . . . . . . 40

Figure 2: $\quad$ Percentage of Grade 10 science teachers by their responses to easy and hard test questions, $2014 \ldots \ldots$. . . 42

Figure 3: Average self-assessment scores on national competency-based standards, 2014 . . . . . . . . . . . . 43

Figure 4: Percentage of teachers receiving in-service training and duration of all training received, 2013 . . . . . . . . 44

Figure 5: Percentage of Grade 10 high school teachers by the type of additional support that they most need to improve their classroom teaching, $2014 \ldots \ldots \ldots \ldots \ldots \ldots \ldots \ldots \ldots$

Figure 6: Percentage of school staff completing professional development plans and the time since one was completed . . 46

Figure 7: Appropriations, allotments, obligations, and utilization rates for HRTD funds

(PHP billions in 2014 constant prices), 2005-2014 . . . . . . . . . . . . . . . . . . . . . . . 47

Figure 8: Amounts of HRTD funds received by DepEd regional offices and transferred to DepEd division offices, 2013 . . . 48

Figure 9: Percentage of division offices receiving 2013 HRTD funds by the quarter during which it was received . . . . 49

Figure 10: Elementary school teacher salaries as a percentage of per capita GDP, $2010 \ldots \ldots \ldots \ldots$

Figure 11: Percentage of teachers whose salary payments were late, $2014 \ldots \ldots \ldots \ldots \ldots$

\section{Policy Note 3: Building Better Learning Environments}

Figure 1: Availability of key facilities in elementary and high schools, $2014 \ldots \ldots \ldots \ldots \ldots \ldots$

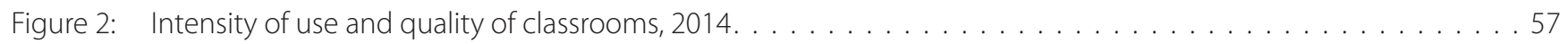

Figure 3: Indicators of classroom quality from direct classroom observation . . . . . . . . . . . . . . . . 58

Figure 4: Trends in government school infrastructure spending, 2005-2015 . . . . . . . . . . . . . . . . . 60

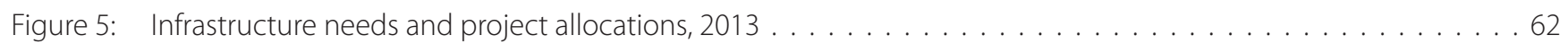


Figure 6: School infrastructure fund allotments, obligations, and utilization rates, 2005-2014 . . . . . . . . . . 63

Figure 7: Completion and satisfaction rates for 2013 school infrastructure projects, 2014 . . . . . . . . . . . . 63

Figure 8: Receipt of project list and first sub-allotment at DPWH district engineering offices . . . . . . . . . . . . . 64

Figure 9: Common problems faced by the DPWH in implementing school infrastructure projects, $2014 \ldots \ldots$. . . . . 65

\section{Policy Note 4: Assessing School-based Management}

Figure 1: Percentage of schools by latest self-assessed SBM implementation level, 2014 . . . . . . . . . . . . . . . . . 72

Figure 2: Percentage of schools reporting weaknesses in key SBM dimensions, $2014 \ldots \ldots \ldots \ldots$

Figure 3: Annual school revenue by type and source, 2013/14 school year. . . . . . . . . . . . . . . . . . . . . . 74

Figure 4: Percentage of SGCs by type of membership, $2014 \ldots \ldots \ldots \ldots \ldots \ldots \ldots \ldots \ldots \ldots$

Figure 5: Percentage of parents of elementary and high school students who know about the SGC and the SIP, 2014 . . 76

Figure 6: Frequency of PTA meetings and percentage of parents reporting

that they attended regularly in $2013 / 14$ school year . . . . . . . . . . . . . . . . . . . . . . . 77

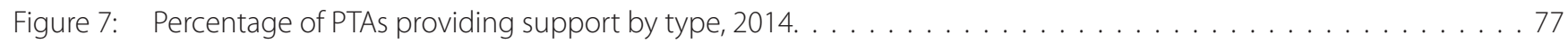

Figure 8: Percentage of schools with a transparency board and types of information posted on the boards, 2014 . . . . 78

Figure 9: Percentage of school principals reporting any involvement with Check My School (CMS) in 2013 or 2014 . . . 79

Figure 10: Average number of visits to schools in the first half of $2014 / 15$ school year and issues covered. . . . . . . . . . 80

\section{Policy Note 5: Providing Schools with Enough Resources to Deliver Quality Education}

Figure 1: Total and per student appropriations for school MOOE, 2005-2015 (in 2014 constant prices) . . . . . . . . . . . 88

Figure 2: Percentage of stakeholders who are aware of MOOE funding and its components . . . . . . . . . . . . . 89

Figure 3: Share of MOOE allocation downloaded and received by schools, $2013 \ldots \ldots \ldots \ldots$. . . . . . . . . . . 90

Figure 4: Reasons why DepEd division offices retain MOOE funds (\% of divisions), $2013 \ldots \ldots \ldots$. . . . . . . . . . . 91

Figure 5: Timing of first MOOE advance and share of overall allocation received, $2013 \ldots \ldots \ldots \ldots$. . . . . . . . . 92

Figure 6: Challenges experienced by schools in spending MOOE funds, 2013/14 school year . . . . . . . . . . . . . 93

Figure 7: Average hours spent on MOOE administration per week by schools' distance to division office, 2014 school year . 94

Figure 8: Elementary school per student funding by source, 2013 and 2013/14 school years . . . . . . . . . . . . . . 95

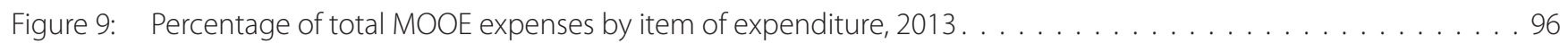

Figure 10: Percentage of schools that had transparency board displaying MOOE information in $2014 \ldots \ldots$. . . . . . . 96

Figure 11: Percentage of schools that received input from stakeholders about MOOE funds, 2014 SY. . . . . . . . . . . . 97

\section{Policy Note 6: Assessing the Role Played by Local Government in Supporting Basic Education}

Figure 1: Total and per student public basic education spending, 2003-2013 . . . . . . . . . . . . . . . . . . . . . 104

Figure 2: Total and per student local government education spending by region, $2013 \ldots \ldots \ldots$

Figure 3: Percentage of schools that report receiving cash or in-kind contributions from

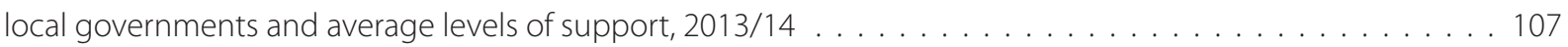

Figure 4: Composition of school funding for all schools and only schools that receive some LGU support, 2013/14 _ . 107

Figure 5: Composition of LGU cash and in-kind contributions to schools (PHP), 2013/14 . . . . . . . . . . . . . . 108

Figure 6: Total and per student LGU spending on basic education by region and poverty incidence, 2012-13 . . . . . 109

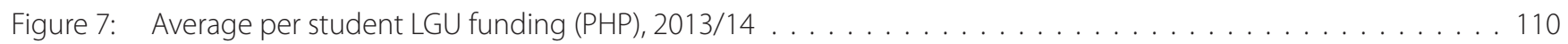

Figure 8: Percentage of schools where LGUs reported providing some funding but schools reported receiving none . . 111

\section{Policy Note 7: Understanding the Drivers of Public School Performance and Efficiency}

Figure 1: A Framework for Understanding School Performance . . . . . . . . . . . . . . . . . . . . . . . . . . 117

Figure 2: Average student enrollment and location for schools ranked

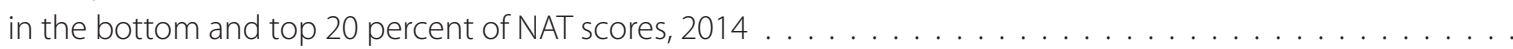

Figure 3: Average proportion of parents who are members of the PTA and percentage of schools

that do not receive all of their MOOE funds from the DepEd division offices. . . . . . . . . . . . . . 121

Figure 4: National achievement test scores and school annual revenue per student, 2013/14 . . . . . . . . . . . . . 122

Figure 5: Average estimated efficiency scores and standard deviations for

school attendance and NAT results in elementary and high schools. . . 


\section{Tables}

Overview

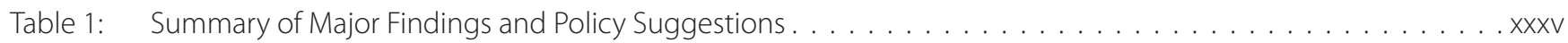

\section{Introduction}

Table 1: Examples of Education Tracking and Service Delivery Surveys. . . . . . . . . . . . . . . . . . . 4

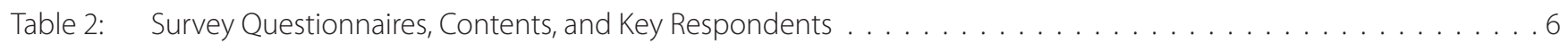

Table 3: $\quad$ Planned and Final Sample Sizes . . . . . . . . . . . . . . . . . . . . . . . . . . . . 7

Policy Note 1: Assessing Systems for Hiring and Deploying Teachers

Table 1: Benchmarks and Actual Timing of Key Steps in the Teacher Hiring Process, 2013 . . . . . . . . . . . . . . 34

Table 2: $\quad$ Strengthening Systems to Hire and Deploy Teachers . . . . . . . . . . . . . . . . . . . . . . 37

Policy Note 2: Developing a Proficient and Motivated Teacher Workforce

Table 1: Strengthening Teacher Support Systems . . . . . . . . . . . . . . . . . . . . . . . . . . 53

\section{Policy Note 3: Building Better Learning Environments}

Table 1: $\quad$ Percentage of Schools that Failed to Meet DepEd Service Standards, $2014 \ldots \ldots \ldots \ldots$. . . . . . . . . . . . . . 59

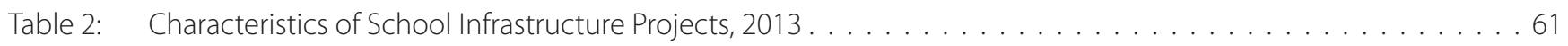

Table 3: Strengthening Government Systems for School Infrastructure Improvements . . . . . . . . . . . . . . . . 69

Policy Note 4: Assessing School-based Management

Table 1: Strengthening School-based Management . . . . . . . . . . . . . . . . . . . . . . 84

Policy Note 5: Providing Schools with Enough Resources to Deliver Quality Education

Table 1: Components of the MOOE Allocation Formula . . . . . . . . . . . . . . . . . . . . . . . . . . 89

Table 2: $\quad$ Allowed and Prohibited Spending Categories for MOOE Funds . . . . . . . . . . . . . . . . . . . . . . . . 95

Table 3: Strengthening Systems to Provide Operational Funding to Schools . . . . . . . . . . . . . . . . . . . . . . 100

Policy Note 6: Assessing the Role Played by Local Government in Supporting Basic Education

Table 1: Improving Local Government Support for Basic Education. . . . . . . . . . . . . . . . . . . . . . . . 113

Policy Note 7: Understanding the Drivers of Public School Performance and Efficiency

Table 1: School National Achievement Test Results and Student Attendance Rates, 2014 . . . . . . . . . . . . . . 116

Table 2: Characteristics Used to Measure the Key Aspects of the Performance Framework . . . . . . . . . . . . . . 118

Table 3: School Performance and Leadership Indicators . . . . . . . . . . . . . . . . . . . . . . . . . . . 120

Annex 1

Table 1: Details of the Field Visits Carried Out during the Development of the Survey Instruments . . . . . . . . . . 132

Table 2: Description of Questionnaires . . . . . . . . . . . . . . . . . . . . . . . . . . . . . . 134

Table 3: Planned and Final Samples. . . . . . . . . . . . . . . . . . . . . . . . . . . . . . . . . 138

Table 4: $\quad$ Outline of the PETS-QSDS Sampling Strategy . . . . . . . . . . . . . . . . . . . . . . . . . . . . . . . . . 140

Table 5: Schedule and Coverage of Field Visits . . . . . . . . . . . . . . . . . . . . . . . . . . . . . 143

Table 6: Other Data Sources Used in the Policy Notes . . . . . . . . . . . . . . . . . . . . . . . . . . . . . . 146 


\section{Boxes}

Overview

Box 1: $\quad$ The Philippines Public Education Expenditure Tracking and Quantitative Service Delivery Study . . . . . . . . . xv

Policy Note 1: Assessing Systems for Hiring and Deploying Teachers

Box 1: $\quad$ Procedures for Measuring Teacher Absenteeism through Observation . . . . . . . . . . . . . . . . . . . . . . . . 29

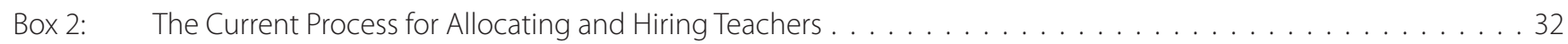

Policy Note 2: Developing a Proficient and Motivated Teacher Workforce

Box 1: PETS-QSDS Approach to Assessing Teachers. . . . . . . . . . . . . . . . . . . . . . . . . . 41

Box 2: Indonesia's Integrated Framework for Teacher Accountability . . . . . . . . . . . . . . . . . . . . . 52

\section{Policy Note 3: Building Better Learning Environments}

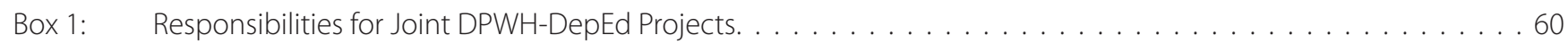

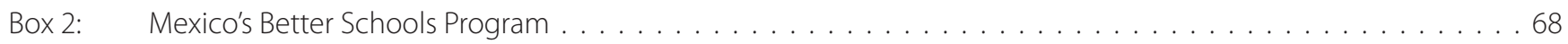

\section{Policy Note 4: Assessing School-based Management}

Box 1: Measuring the Implementation of School-based Management in the Philippines _ . . . . . . . . . 73

Box 2: An Evaluation of School-based Management Training Activities in Indonesia . . . . . . . . . . . . . 81

Box 3: An Evaluation of School-based Management Training Activities in Uganda . . . . . . . . . . . . . . . . 83

Policy Note 5: Providing Schools with Enough Resources to Deliver Quality Education

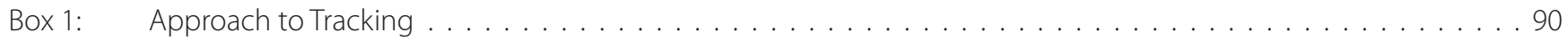

Box 2: The Pupil Premium in England. . . . . . . . . . . . . . . . . . . . . . . . . . . . . . . . 100

Policy Note 6: Assessing the Role Played by Local Government in Supporting Basic Education

Box 1: Legal Framework for the Role Played by LGUs and their Local School Boards in Basic Education . . . . . . . . 106

Box 2: The Seal of Good Local Governance . . . . . . . . . . . . . . . . . . . . . . . . . . . . . . . . . . . . . . 112

Annex 1

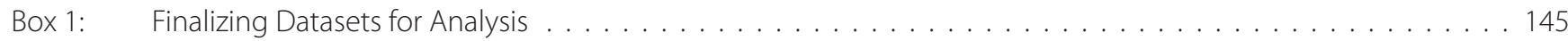




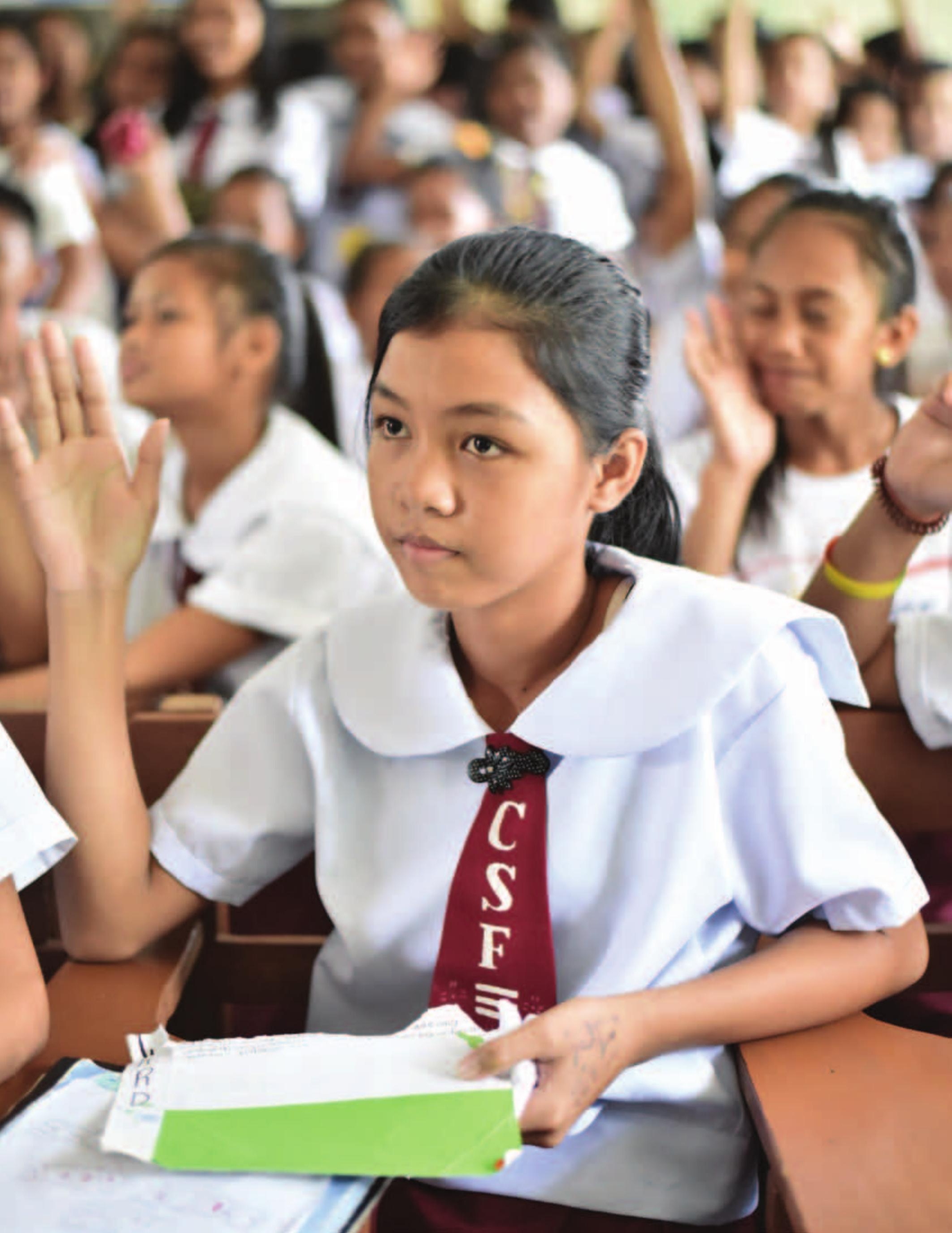




\section{Acknowledgements}

The team is grateful to officials and staff in the Department of Education for their overall support of this study. Special thanks go to Secretary Br. Armin A. Luistro and Undersecretaries Reynaldo Laguda and Dina Ocampo for their advice and guidance. We are also grateful to Roger Masapol, Anna Bautista, Zaida Briones, Kat Lejara, and Mary Jane Feliciano from Planning Services and to Selwyn Briones and Gilbert Murong from Finance Services for their support and help in data collection and survey implementation. More generally we would like to acknowledge the welcome given to our team in many regional and divisional offices and schools across the Philippines. We are indebted to all DepEd staff for their patience in answering the many, many questions that we had.

Our thanks also go to Undersecretary Laura Pascua and her team at the Department of Budget and Management for their feedback throughout the study.

The Public Education Expenditure Tracking and Quantitative Service Delivery Survey was implemented by Taylor, Nelson, and Sofres (TNS). The team are grateful for the enormous effort of the team at TNS (J. Flores, C. de Jesus, Y. Tolentino, M. Raquedan, C. Gemaol, G. Bautista, J. Adeja, A. Agregado, J. dela Cruz, J. Virginio, D.A. Diaz, R. Olivares, J. Amin, G. Orpilla, and $S$ Kakade) in planning, implementing, and coding this complex survey. Thanks also go to the army of enumerators who interviewed thousands of respondents across the Philippines. Their dedication and commitment to conducting the survey was central to the depth and breadth of the results reported.

Thanks also go to the team at the Research Center for Teacher Quality (RCTQ) at the Philippine Normal University (Marilyn Balagtas, Jenny Jocson, John Pegg, and Ken Vine) for developing the teacher assessments used as part of the study and for supporting the implementation of the survey. Our collaboration was an important part of the study, and RCTQ's guidance and assistance on the analysis of teacher quality was vital to many of the main findings of the study.
Lynnette Perez (former World Bank Senior Education Specialist) began discussions on this study with the Government of the Philippines and was an invaluable source of help and guidance at all stages. We are very appreciative of the support provided by Robyn Biti, Lea Neri, and Tess Felipe at the Department of Foreign Affairs and Trade of the Government of Australia.

The World Bank team was led by Samer Al-Samarrai (Senior Economist, GED02) and consisted of Vandana Sipahimalani Rao (ST Consultant), Jason Alinsunurin (ST Consultant), Himdat Bayusuf (Education Specialist, GED02), Corinne Bernaldez (Team Assistant, EACPF), Vicky Catibog (ST Consultant), Marie Jo Cortijo (ST Consultant), Jesus Galvan (ST Consultant), Judith Kom (ST Consultant), Alma Mariano (ST Consultant), Unika Shrestha (ST Consultant), and Marianne Joy Vital (ST Consultant). Juan Munoz provided assistance in developing the overall sampling methodology and computing the sampling weights used in the study. The report and policy notes were edited by Fiona Mackintosh and laid out by Bill Pragluski at Critical Stages.

We are grateful to the many DepEd staff and teachers who provided useful comments in the workshops that were held to share the study's preliminary findings. Comments were also provided on various parts of the report by Honesto Nuqui (University of the Philippines) and Rosario Manasan (Philippines Institute of Development Studies). The peer reviewers for the report were Fadila Caillaud (Senior Economist, GED01), Deon Filmer (Lead Economist, DECHD) and Ken Vine (SiMERR, University of New England, Adelaide).

Finally, the team would like to acknowledge the unswerving support and guidance that we received from the late Undersecretary Francisco Varela. His insights and enthusiasm for the study were invaluable.

The report was conducted by the Department of Education and the World Bank with the support of the Australian Government through the Australia-World Bank Philippines Development Trust Fund. 



\section{List of Abbreviations}

\begin{tabular}{|c|c|c|c|}
\hline ANSA & Affiliated Network for Social Accountability & MOOE & Maintenance and Other Operating Expenses \\
\hline APIS & Annual Poverty Indicators Survey & NAT & National Achievement Tests \\
\hline AusAID & Australian Aid & NCR & National Capital Region \\
\hline ARMM & Autonomous Region in Muslim Mindanao & NCBTS & National Competency-Based Teacher Standards \\
\hline $\mathrm{BOS}$ & Bantuan Operasional Sekolah & NEDA & National Economic and Development Authority \\
\hline BEFF & Basic Education Facilities Fund & NGO & Non-Governmental Organization \\
\hline BSP & Better Schools Program & NOSCA & Notice of organization, staffing and \\
\hline BLGF & Bureau of Local Government Finance & & compensation action \\
\hline $\mathrm{CO}$ & Central Office & OFSTED & Office for Standards in Education, \\
\hline CMS & Check My School & & Children's Services and Skills \\
\hline COA & Commission on Audit & PT & Parent-Teacher Association \\
\hline CAR & Cordillera Administrative Region & PCF & Performance Challenge Fund \\
\hline DEA & Data Envelopment Analysis & PBB & Performance-based Bonus \\
\hline DBM & Department of Budget and Management & PHP & Philippine Pesos \\
\hline DBMR & Department of Budget and Management & PNU & Philippines Normal University \\
\hline & Regional Office & PFSED & Physical Facilities and Schools Engineering Division \\
\hline DepEd & Department of Education & PMT & Proxy Means Testing \\
\hline DPWH & Department of Public Works and Highways & PETS-QSDS & Public Education Expenditure Tracking and \\
\hline DSWD & Department of Social Welfare and Development & & \\
\hline DILG & Department of the Interior and Local Government & & Public Schools District Supervisor \\
\hline DO & Division Office & $D P$ & Public-private Partnership \\
\hline DPFC & Division Physical Facilities Coordinator & $\mathrm{RO}$ & Regional Office \\
\hline EBEIS & Enhanced Basic Education Information System & RQA & Registry of Qualified Applicants \\
\hline FC & Field Coordinator & RCTQ & Research Center for Teacher Quality \\
\hline FTL & Field Team Leader & SBP & School Building Program \\
\hline FY & Financial Year & SGC & School Governing Council \\
\hline GAA & General Appropriations Act & SIP & School Improvement Plan \\
\hline GF & General Fund & SY & School Year \\
\hline GPTA & General Parent-Teacher Association & SBM & School-based Management \\
\hline GASTPE & Government Assistance for Students and & SDS & Schools District Superintendent \\
\hline & Teachers in Private Education & SDE & Schools Division Engineer \\
\hline GDP & Gross Domestic Product & SARO & Special Allotment Release Order \\
\hline GNP & Gross National Product & SPED & Special Education \\
\hline HUCs & Highly Urbanized Cities & SEF & Special Education Fund \\
\hline HRIS & Human Resource Information System & $\mathrm{SAOB}$ & Statement of Allotments, Obligations and Balances \\
\hline HRTD & Human Resource Training and Development & STR & Student-teacher Ratio \\
\hline IU & Implementing Unit & Sub-ARO & Sub-Allotment Release Order \\
\hline IPPD & Individual Plan for Professional Development & TPMS & Teacher Professional Management System \\
\hline INSET & In-Service Training & TSNA & Teachers' Strengths and Needs Assessment \\
\hline KVP & Kindergarten Volunteer Program & TALIS & Teaching and Learning International Survey \\
\hline LGC & Local Government Code & TIMSS & Trends in International Mathematics and \\
\hline LGU & Local Government Unit & & Science Study \\
\hline LSB & Local School Board & $\begin{array}{l}\text { INS } \\
\text { WATSAN }\end{array}$ & $\begin{array}{l}\text { ylor, Nelson, and Sotres } \\
\text { Water and Sanitation }\end{array}$ \\
\hline & & & \\
\hline
\end{tabular}




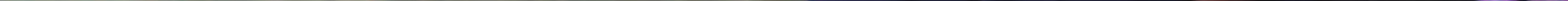




\title{
Assessing Basic Education Service Delivery in the Philippines
}

\author{
Overview
}

\section{Introduction}

Building a strong and inclusive basic education system has been a central strategy for improving economic growth in many East Asian countries. Research from around the world has shown that increasing access to good quality basic education raises productivity and can improve long-term per capita economic growth rates (Figure 1). Moreover, fast growing countries in East Asia such as China, Singapore, and South Korea have invested heavily in their education systems as part of their successful economic development strategies.

\section{Figure 1: Good Quality Education Can Improve Long- term Economic Prospects}

Annual GDP per capita growth rate (1960-2000) and student learning outcomes across countries

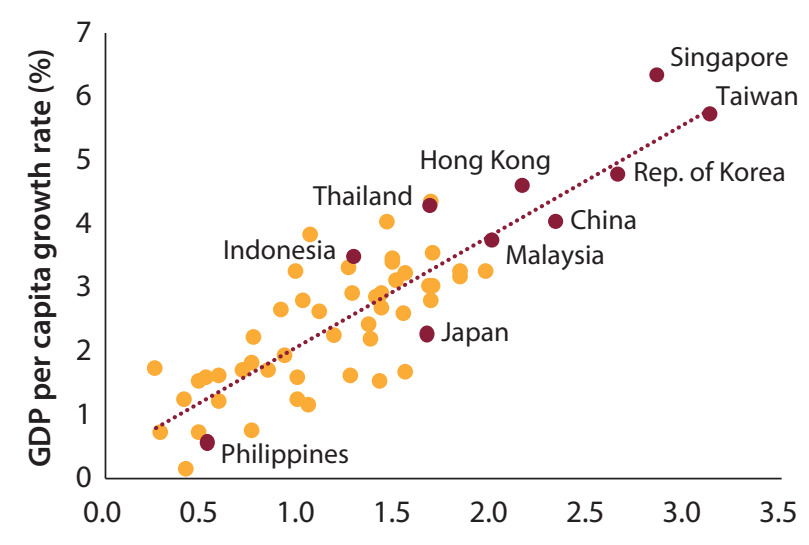

Score on international assessment of learning outcomes

Source: Hanushek, E. and L. Woessmann (2016). "Knowledge Capital, Growth, and the East Asian Miracle. Hanushek, E. A. and L. Woessmann (2016)." Science 351(6271): 344-345.

Note: The growth rate is conditional on the initial level of per capita GDP and initial years of school attainment.
Efforts to address persistent and high levels of poverty and income inequality can also be enhanced by investing in good quality basic education. Differences in educational attainment among socioeconomic groups are a key driver of income inequality. The private and social returns to education are high in the Philippines and, as a recent World Bank study showed, can provide individuals with an effective route out of poverty. Making it possible for schools to offer good quality education opportunities for all can be key to ensuring that the benefits of future economic growth are shared more widely.

Over the last five years, the Government of the Philippines has embarked on an ambitious education sector reform program aimed at reducing poverty and increasing national competitiveness. The 2013 Basic Education Act was passed in response to growing concerns about how the short length of basic education in the Philippines was constraining national competitiveness. The Act extended the basic education cycle from 10 to 13 years, an increase which, in other countries, has been associated with large economic benefits.

Recent reforms have been backed up by substantial amounts of new investment (Figure 2). Between 2010 and 2015, public spending on basic education increased by 60 percent in real terms, while per student funding levels also increased considerably.

The reform program halted a long-term decline in public basic education services. Massive school infrastructure improvements and nationwide teacher recruitment have 
Figure 2: Public Education Spending Has Risen Rapidly in Recent Years

Government spending on basic education, 2003 to 2015 (in 2014 constant prices)

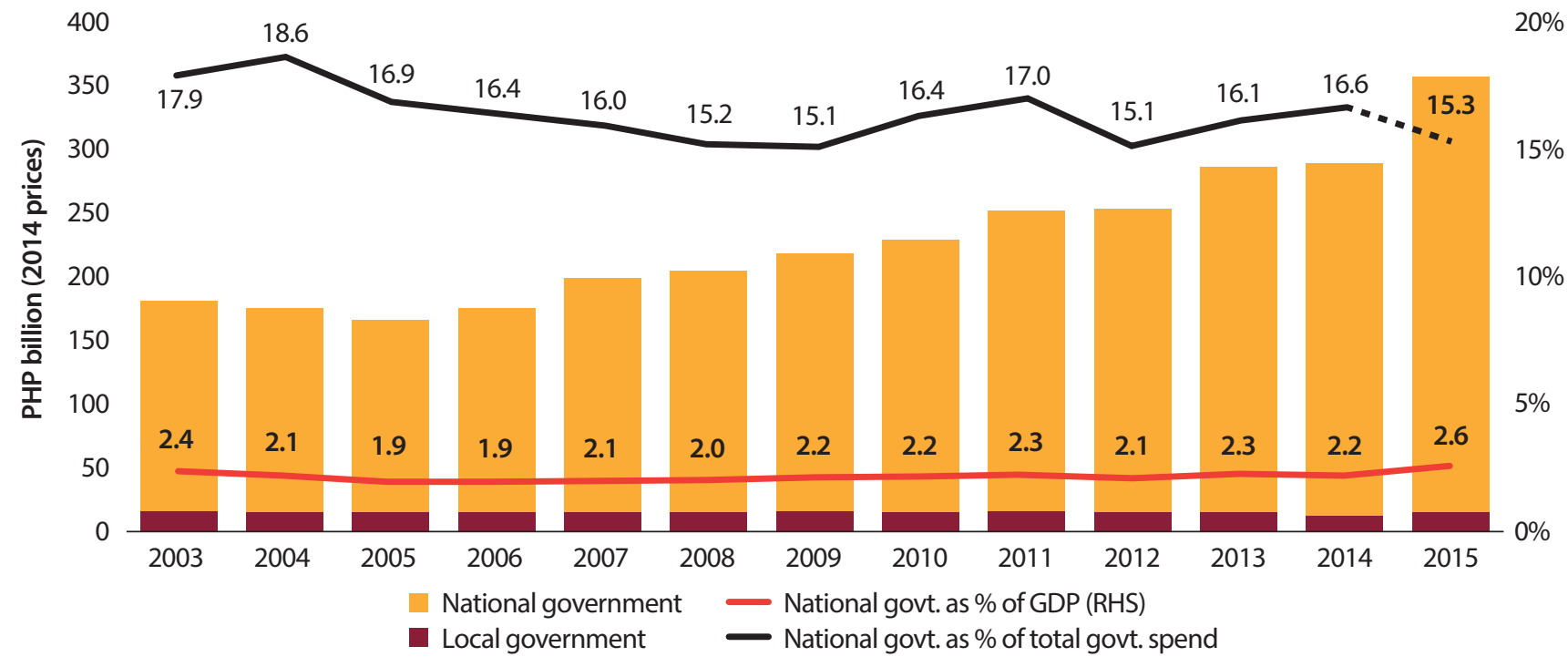

Sources: National government spending_DBM National Expenditure Program. Local government education spending-Bureau of Local Government Finance. GDP and GDP deflator-Philippines Statistics Authority.

Notes: Basic education spending data are obligations except for 2015 where adjusted amounts are reported. Basic education refers to the DepEd budget and obligations for the Philippines Science High School. Local government spending figures are obligations but from 2014 only include spending from the Special Education Fund. The total government expenditure figures used to calculate the share of education spending exclude interest payments.

improved school conditions. Key indicators of the adequacy of the number of teachers (the student-teacher ratio) and classrooms (the student-classroom ratio) in the school system have improved. For example, between 2010 and 2013, student-teacher ratios in public high schools fell from 38:1 to 29:1, while student-classroom ratios fell from 64:1 to 47:1.

Increases in the availability of key inputs have also significantly increased access to basic education. Kindergarten enrollment almost doubled in absolute terms between 2008 and 2014, and the proportion of children of school age attending basic education also increased. Poorer families benefitted most: the share of school-aged children from the poorest 20 percent of households who were attending school increased from 86 percent to 94 percent between 2002 and 2013.

However, significant challenges remain before the government's education goals can be achieved. Access to high school continues to be relatively unequal. In 2013, only 53 percent of high school aged children in the poorest 20 percent of households were attending high school compared to 81 percent of children in the wealthiest 20 percent of households. The latest completion rates also show that only three-quarters of the children that start successfully complete elementary or high school.

Improvements in the overall quality of basic education also need to be made if the potential economic benefits are to be realized. The Philippines last participated in an international learning assessment in 2003 when the results showed that only one-third of its elementary and secondary school students reached the lowest international benchmark in mathematics. More recent results of national examinations suggest that there have been only limited improvements since then.

Key to tackling these challenges will be further increases in education spending. Despite impressive recent increases, the Philippines still spends less on education than many neighboring and middle-income countries, and recent analysis has confirmed the need for more spending to meet national education norms and standards.

However, the impact of further increases in education spending will depend crucially on how effectively public 


\section{Box 1: The Philippines Public Education Expenditure Tracking and Quantitative Service Delivery Study}

The aim of the Philippines Public Education Expenditure and Quantitative Service Delivery Study has been to answer four main questions on the use of the public education budget:

1. Resource flow, management, and control. What factors prevent resources from reaching their intended destination in a timely and transparent manner?

2. Existence, use, and financing of inputs at the school level. Do schools have access to essential inputs and how effective are the systems that govern their use?

3. Equity. How do the resources available to schools and the systems that manage these resources differ among regions and socioeconomic groups?

4. School performance and resources. How and why does the performance of schools differ and what drives those differences?

The study has tracked over 80 percent of the national government education budget (including teacher salaries and training, school maintenance and operating expenses, construction, and learning materials) as well as local government spending on basic education.

In order to assess how funds flow and how they are used at the school level, the study team conducted a nationally representative survey of government institutions and public schools in the last quarter of 2014. The Autonomous Region in Muslim Mindanao was excluded from the study because government funds for this region are managed separately and flow to schools through a different mechanism. In addition, integrated schools (which offer both elementary and high school education) and schools that did not have final grade elementary and high school students were excluded from the sample, primarily because the study aimed to measure outcomes at the end of elementary school and at the end of high school.

The sample for the survey included all regional offices of the Department of Education (DepEd) and the Department of Budget and Management (DBM), 51 division and 113 district offices of DepEd, 54 district engineering offices of the Department of Public Works and Highways, 74 provincial and city/municipality local governments, 249 public elementary schools, and 200 public high schools. At the school level, interviewers administered a questionnaire to each parent-teacher association, assessed the competencies of approximately 1,500 teachers, and interviewed 2,200 student households.

The data collected were used to explore the systems that govern the use of public funds and to assess how the availability of resources differed among schools. The study team combined information on the flow of funds to schools with information on school characteristics and quality to evaluate how financing and governance affected school performance.

financial and resource management systems allocate and use these resources. Low budget execution rates driven by delays in fund releases, difficulties in managing funds and inadequate coordination have led to widespread concerns about the effectiveness of public education spending. These issues and more generally the effectiveness of government systems to manage and govern the use of education resources are key drivers of differences in the ability of schools to translate resources into improved education outcomes.
Figure 3 shows that on the whole, higher levels of annual school funding were associated with better school performance, but this relationship is not very strong. Some schools appeared to use their resources more effectively than others to improve student learning outcomes. In Figure 3, each panel is divided into quadrants that show where schools fell in relation to the average achievement score and average annual school spending per student. Schools in quadrant A were the most efficient as they spent less than the average school every year but had better than average 
Figure 3: There Are Large Differences in Performance Even Among Schools with Similar Levels of Funding National achievement test scores and school annual revenue per student, 2013/14
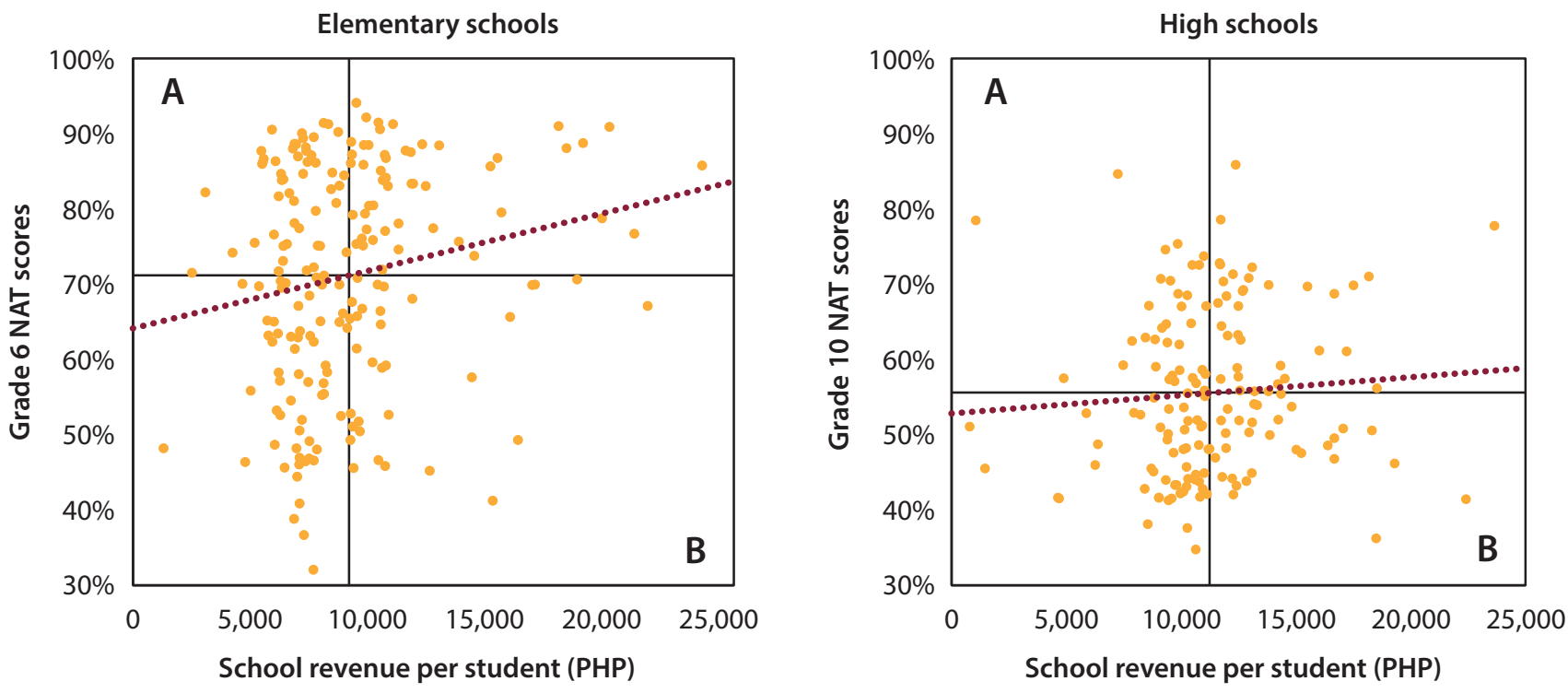

Source: PETS-QSDS national survey - school-level data.

Note: The horizontal line in the figure represents the average school NAT score while the vertical line marks the average school revenue per student.

outcomes. The schools in quadrant B were the least efficient, with levels of spending that were higher than average but with below average performance. Levels of efficiency varied greatly between schools that had similar levels of either performance or spending.

Pressure on public financial management systems will only grow with the introduction of senior high school and the need for 1.5 million additional school places. It is therefore vital that systems used to allocate resources, build new infrastructure, and recruit new teachers work effectively.

The Philippines Public Education Expenditure Tracking and Quantitative Service Delivery Study (PETS-QSDS) aimed to gather detailed evidence of the quality of basic education services and the systems used to allocate and manage resources, to provide a snapshot of the key education inputs at the school level, and to evaluate whether these resources are being distributed equitably across schools. The study emerged from a request from the Department of Education (DepEd) and the Department of Budget and Management (DBM) asking the World Bank to assess whether the large budgeted increases in public education spending were being used effectively to improve conditions in public elementary and high schools. The Bank developed the design of the study in consultation with DepEd, the DBM, the National Economic and Development Authority (NEDA), the Affiliated Network for Social Accountability (ANSA), and experts on the Philippines education system (Box 1).

\section{The Teacher Workforce}

Ensuring that schools have enough teachers to provide education in classes that are small enough to foster a good learning environment is an important first step for improving education outcomes. While the optimal size of classes and the impact of reducing class sizes continue to be debated, it is clear that very large class sizes are detrimental to learning. Moreover, evidence from recent impact evaluations in developing countries shows that, on the whole, reducing class sizes in schools improves learning.'

\section{Teacher Distribution and Presence in Schools}

In the Philippines, the Department of Education (DepEd) has class size standards for each grade in elementary and high schools. Even though good progress has been made 
towards meeting these standards, the distribution of teachers among schools remains unequal. Using DepEd norms for school-level student-teacher ratios (STRs), it can be seen that 29 percent of elementary schools and 37 percent of high schools have too few teachers, whereas many other schools have a surplus. For example, about 52 percent of all elementary schools have STRs that imply that they have too many teachers. These lower STRs are typically found in remote areas where the catchment population is too small to meet STR guidelines. Indeed, a higher proportion of schools in rural municipalities tend to have STRs that are below existing guidelines than city schools. However, a significant number of schools in more densely populated urban areas also have low STRs. It is possible that transferring teachers from these schools to schools with teacher shortages would be a more efficient option than hiring additional teachers.

Knowing how many teachers are allocated to each school is important for planning, but whether they turn up to teach every day on time is even more important for student outcomes. Using unannounced visits and conventional methods to measure teacher attendance, the PETS-QSDS study found that teacher absenteeism rates were generally low in the Philippines (Figure 4), at around 7.6 percent among elementary school teachers and 5.9 percent among high school teachers. Absenteeism was more of a problem in highly urbanized cities where almost 1 in 10 teachers was absent in 2014, a rate some 54 percent higher than the national average. This was probably a result of the larger size of schools in highly urbanized cities, transport and traffic problems, and greater demands on teachers' time.

\section{Systems to Hire, Deploy, and Transfer Teachers}

School-level data from the PETS-QSDS survey show that, while new teachers were generally allocated to schools with greater need, there is room for improving new teacher allocations. The recent recruitment drive has reduced the number of schools with a teacher shortage but has also increased the number with teacher surpluses. Also, while DepEd division offices are now filling vacancies more rapidly (an average of 5 months down from 18 months in 2007), about one-third of the new teacher positions for 2013-14 remained unfilled at the end of 2014 (Figure 5). It is likely that delays by teachers in submitting their documentation and delays by division offices in verifying this information partly explain these delays in getting new teachers into the classroom.

\section{Figure 4: Teacher Absenteeism Rates in the Philippines Are Low}

Primary/elementary teacher absenteeism rates in selected countries, various years

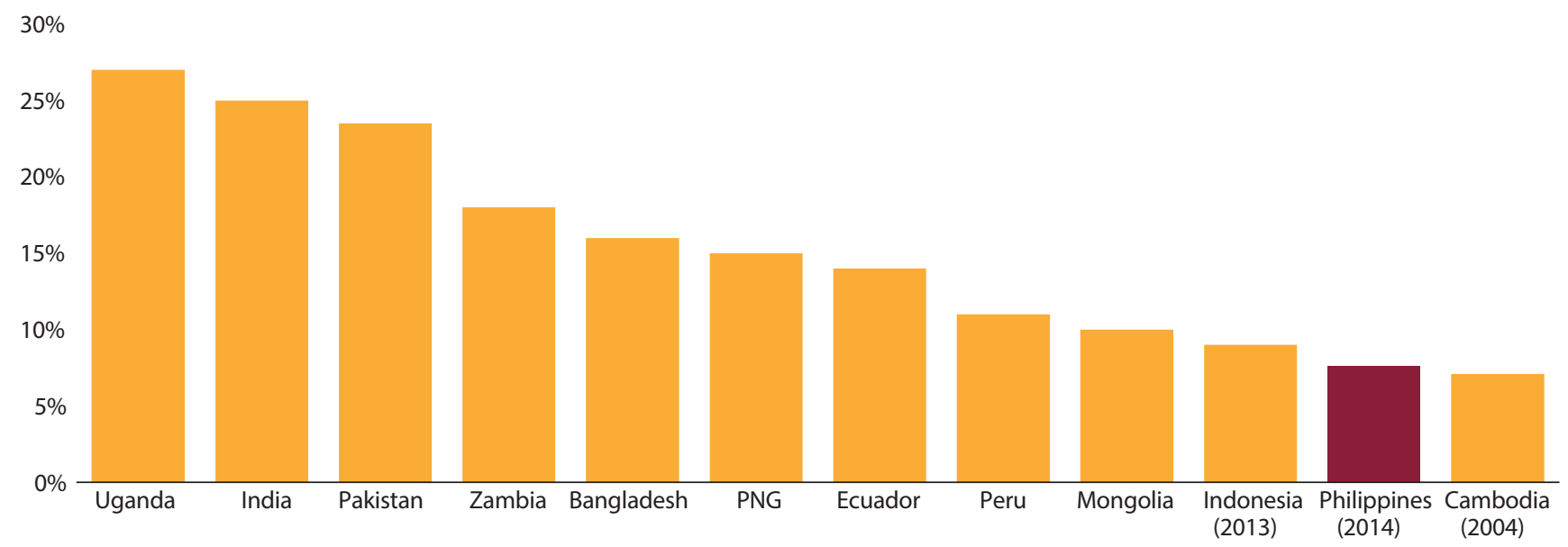

Sources: Philippines - PETS-QSDS national survey - school-level data. Data on Indonesia come from Analytical and Capacity Development Partnership (2014). "Teacher Absenteeism in Indonesia: Policy brief." Jakarta. Data for all other countries come from Rogers, F. H. and E. Vegas. (2009). "No More Cutting Class? Reducing Teacher Absence and Providing Incentives for Performance." Policy Research Working Paper. No. WPS 4847. World Bank, Washington D.C.

Notes:The Philippines study measured teacher absenteeism for teachers who were expected to be present at the beginning of the school day, whereas other studies checked teacher absenteeism at different times of the school day. All absenteeism rates are for 2002-2004 unless otherwise stated. 


\section{Figure 5: A Significant Number of Newly Hired Teachers Were Not in Post at the Beginning of the School Year}

Percentage of teacher posts allotted for the 2013 school year where newly hired teachers were in post by the final quarter of the 2014 calendar year

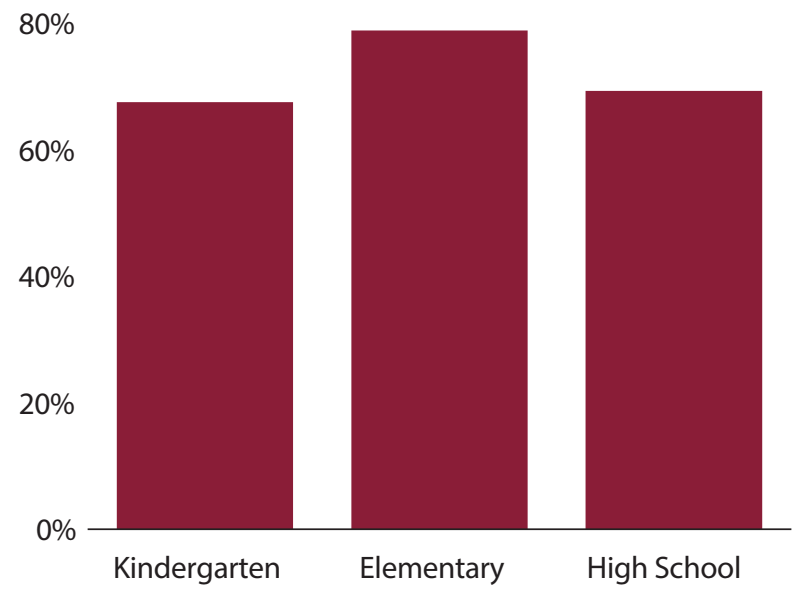

Source: PETS-QSDS national survey - DepEd division office data.

When the study tracked fund flows for newly hired teachers, it found data inconsistencies and poor record keeping. Information on the budget allocation for newly hired teachers was not available from either the DepEd division offices or the DBM regional offices. This meant that the study team was largely unable to track the flow of funds between these two sets of offices. In the rare cases where it was possible to do so, only one-third of the divisions reported receiving the amount reported by the DBM regional office.

Transferring teachers between schools can redress imbalances and increase the efficiency of public spending, but teacher transfers are rare. A nationally representative sample of Grade 6 and 10 teachers showed that fewer than 2 percent of teachers were transferred in 2013, most of them probably for personal family reasons rather than to redress imbalances in teacher distribution.

\section{The Quality of Elementary and High School Teachers}

According to the results of the PETS-QSDS assessments of teachers, knowledge of subject matter among elementary and high school teachers is low in most subjects. With the exception of English at the elementary level, the average elementary or high school teacher could answer fewer than half of the questions on the subject content tests correctly (Figure 6). Since these tests are closely aligned with the curriculum, the results suggest that teachers face significant challenges in teaching a considerable portion of the current curriculum.

However, teachers rated their own competencies in the curriculum domain highly, including subject-matter knowledge. Simple correlation coefficients showed a weak relationship between teachers' self-assessment ratings and

Figure 6: Teachers' Performance on Content Knowledge Assessments Was Poor

Percentage of questions answered correctly by the median teacher (binary scoring method), 2014

\section{Grade 6 elementary school teachers}

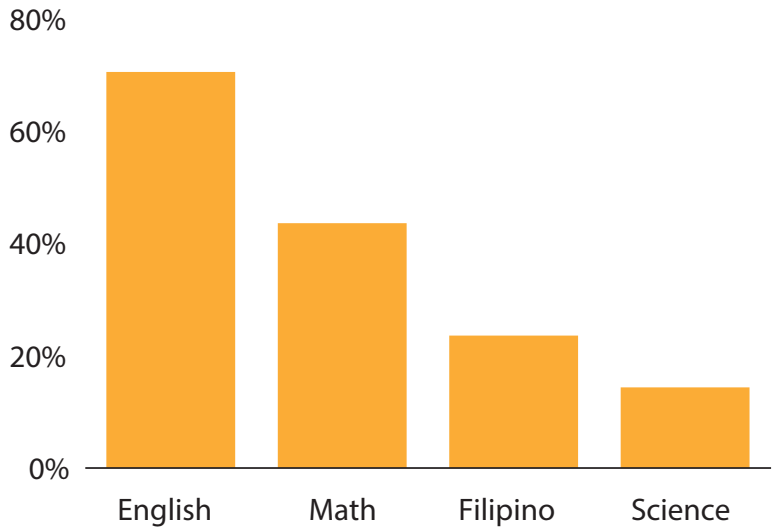

Grade 10 high school teachers

$80 \%$

$60 \%$

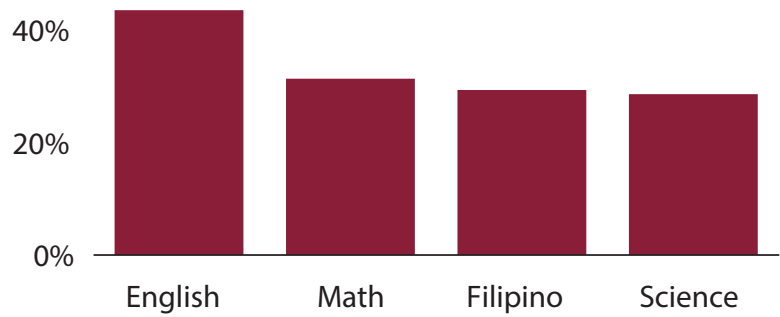

Source: PETS-QSDS teacher content knowledge assessments 
their subject-matter test scores. These findings suggest that teacher self-assessments may not be a good basis on which to plan professional development.

\section{In-service Teacher Training}

Providing teachers with good quality professional development opportunities is an effective way of increasing their competencies and improving student learning outcomes, but the professional development opportunities currently offered to teachers frequently fail to meet even minimum levels of quality and fall short of what teachers want and need. Most teachers in the Philippines received some professional development training - approximately five days of in-service training for the average Grade 10 teacher in 2013 - but this is less than in other countries. Moreover, approximately 40 percent of teachers interviewed for the PETS-QSDS study said that they needed more and better quality in-service training to improve their classroom teaching.

Systems at the school level to support teachers and identify their professional development needs are not working well. Teachers are expected to develop their own professional development plan, which school principals then aggregate and submit to division offices to organize relevant training. However, many teachers and schools, including a quarter of high school teachers, had never prepared a plan, and in many other cases the plans were out of date.

Support from school principals for teachers' professional development also varied. Only two-thirds of Grade 10 teachers in high schools reported that their school principal had spent a full period in their classroom over the course of the whole 2013 school year. When principals did observe classroom teaching, most gave written comments focused on the teaching method that was used. Only around a quarter of comments concerned the teacher's knowledge of the subject content.

DepEd has increased the budget allocation for human resource training and development (HRTD), but utilization of these funds is often low, amounting to only 57 percent of the budget in 2014 (Figure 7).

The PETS-QSDS survey also found that only a small share of the available funds is transferred from DepEd central office to its regional and division offices. Also, almost half of

Figure 7: The Budget for In-service Training Has Increased Recently but Utilization Rates Are Frequently Low Appropriations, allotments, obligations, and utilization rates for HRTD funds (PHP billions in 2014 constant prices), 2005-2014
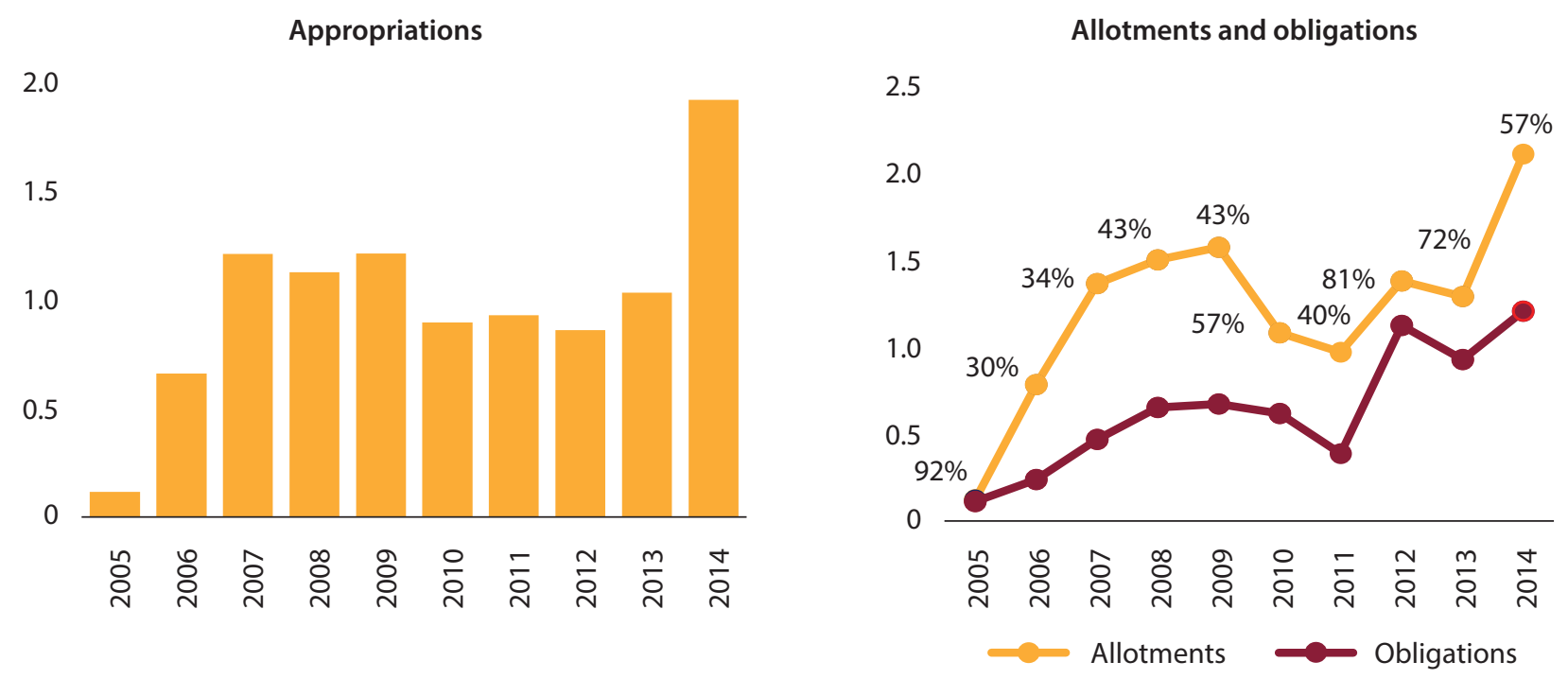

Source: Appropriations - Department of Budget and Management. All other data - DepEd Statement of Appropriations and Obligations, various years. Note: Allotments/obligations for a given year include current, continuing, and extended allotments/obligations. The utilization rate is indicated by the percentage figures in the graph and show the proportion of allotments obligated in a given year. 
HRTD funds were allocated for training activities provided at DepEd's central office, with the rest split equally between regional and division offices. Given that division offices have the closest contact with schools and are most likely to know their in-service training needs, it is surprising that a larger share of HRTD funds is not downloaded to divisions.

Little information was available on how DepEd's regional offices used their HRTD funds. The regional offices retained approximately 42 percent of all of the HRTD funds that they received from DepEd central office rather than downloading them to division offices. DepEd expects regional offices to use these funds to organize mass teacher training on, for example, the introduction of the new $\mathrm{K}$ to 12 curriculum. DepEd's guidelines governing the use of these funds require regional offices to keep detailed records on who has been trained and on the kind of training provided. However, when the PETS-QSDS study team visited all regional offices to collect this information, no such information was available. This lack of records greatly reduces the transparency of the use of these funds.

\section{School Infrastructure}

Evidence from around the world has shown that improving school infrastructure leads to better learning outcomes. ${ }^{2}$ For example, a 2011 review of the economics literature over the last 20 years showed that the availability of basic school infrastructure (such as classrooms, desks, and chairs) and facilities (such as electricity, libraries, and blackboards) is frequently associated with better student learning achievement. ${ }^{3}$ These findings have been backed up by a systematic review of recent impact evaluations, which showed that infrastructure investments have a positive impact on school enrollment rates, attendance rates, and learning achievement. ${ }^{4}$ Also, research in the Philippines has shown that reducing the number of students per classroom is associated with better student learning outcomes, particularly in rural schools. ${ }^{5}$

\section{The Current State of School Infrastructure}

Schools in more densely populated areas tend to be larger and have more congested learning environments, and high schools in particular tend to be much larger in cities and urban areas. ${ }^{6}$ For example, in 2014 the average high school in a highly urbanized city had approximately 1,700 students compared with about 1,000 and 570 students in city and municipality schools respectively. Around 30 percent of high schools in these highly urbanized cities have studentinstructional room ratios in excess of 55:1.

While most schools meet DepEd's service standards, a large proportion of those that do not are in highly urbanized cities. While 94 percent of elementary schools and 83 percent of high schools have student-classroom ratios that fall within or below the DepEd standard, some 24 percent of elementary and 30 percent of high schools in highly urbanized cities have student-classroom ratios well above the maximum set out in DepEd standards. Many also fail to meet sanitation facility standards, including the 70 percent of high schools in highly urbanized cities with more than 50 female students sharing each toilet.

To get a better picture of the real learning environment faced by students, around 7,000 classes and classrooms were observed as part of the PETS-QSDS survey. These classroom observations revealed that class sizes were smaller than official statistics suggest but that many classrooms were in a poor state of repair (Figure 8).

\section{Systems to Improve School Infrastructure}

Spending on school infrastructure has risen rapidly in recent years, and many new classrooms have been built which has eased congestion, particularly in high schools. The allocation of government infrastructure resources tends to be broadly in line with need but could be improved further: while half of all elementary schools with overcrowded classrooms were selected by DepEd for an infrastructure improvement project, so were 30 percent of schools with adequate classroom space.

Utilization rates for school infrastructure funds have been low over the last 10 years. In the 2013 budget, Congress appropriated approximately PHP 27 billion for school infrastructure improvements, but only around 70 percent of this appropriation was released in 2013. This is a particular concern given the infrastructure shortages outlined in the previous section and given the large increases for infrastructure investment planned for the coming years. 


\section{Figure 8: A Significant Proportion of Classrooms Were Observed to Be of Poor Quality}

Indicators of classroom quality from direct classroom observation

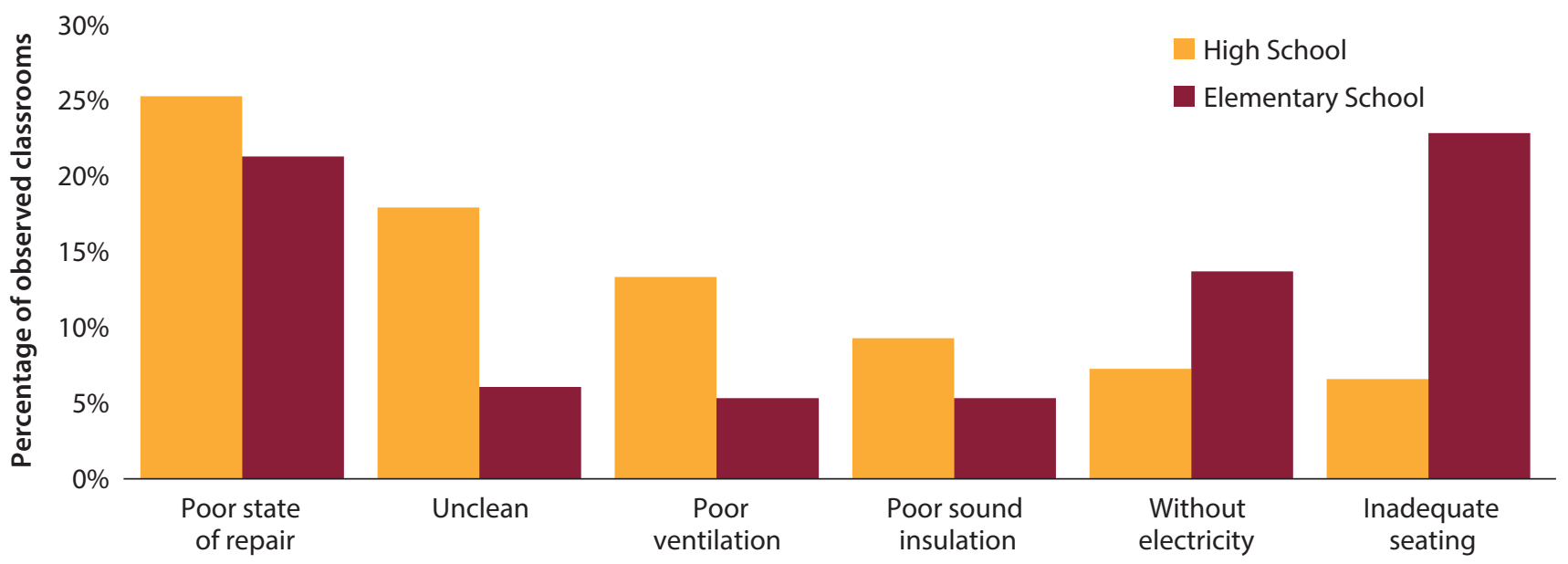

Source: PETS-QSDS national survey - classroom observations at the school level.

As many as one in five school infrastructure improvement projects started in 2013 had not been completed by late 2014 mainly due to insufficient funds, other demands on contractors' time, and design issues (Figure 9). The initial cause of delays in these projects was often a delay in the release of funds by DPWH central office to their district engineering offices but other difficulties included inflexibility in the funding of school projects (62 percent of DPWH district engineering offices reported receiving insufficient funds to remove debris while 33 percent complained of impractical costing). Over 60 percent of DPWH offices reported that there was not enough space allocated for the new infrastructure.

There were large discrepancies between the accounts given by implementing offices and schools of these infrastructure projects. First, elementary schools reported that fewer DepEd-funded projects had been implemented than was reported by DepEd and the DPWH. Second, only around half of the projects that the DepEd and DPWH offices claimed to have implemented could be verified using information provided by the schools. Only a quarter of projects reported by schools as DepEd-financed projects could be matched with information from the relevant DepEd divisional or DPWH district office. It is difficult to draw firm conclusions about whether infrastructure funds are reaching their intended destinations since not all projects recorded at the district or division level were implemented in schools, while schools also reported projects funded by DepEd that were not recorded in the DepEd or DPWH offices. It is clear that existing information and monitoring systems do not accurately record the use of infrastructure funds.

\section{Figure 9: Schools Report Low Levels of Satisfaction with Government-funded Infrastructure Projects} Completion and satisfaction rates for 2013 school infrastructure projects, 2014

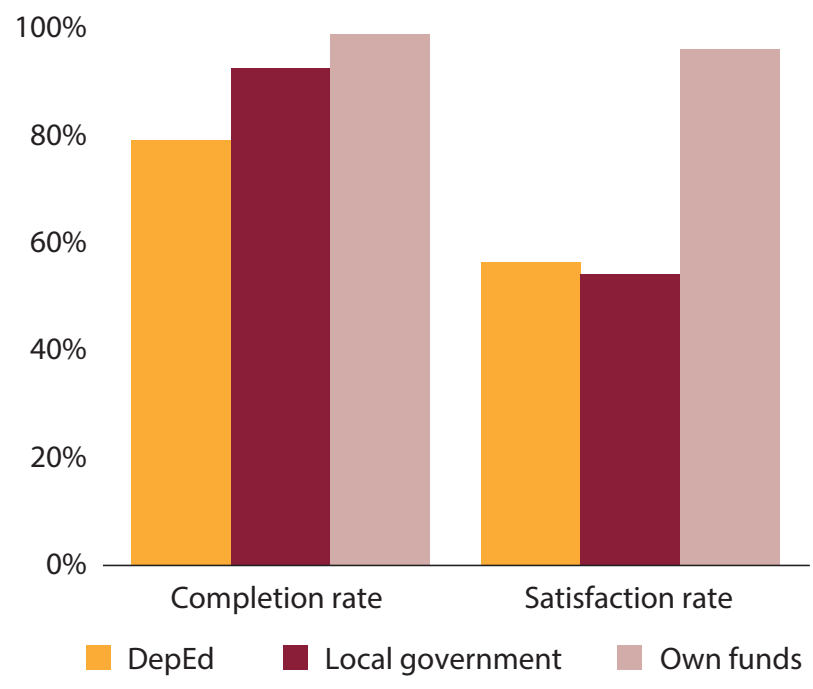

Source: PETS-QSDS national survey - infrastructure project information at the school level for all elementary and high school projects.

Note: Data relates to all school infrastructure projects in 2013. Completion rates are the proportion of 2013 projects that were completed by the last quarter of 2014. DepEd projects include those managed by the DPWH as well as major school repair and water and sanitation projects managed by DepEd Division offices. 


\section{School-based Management}

In recent times, many countries have begun to devolve authority and resources to schools in an effort to improve teaching and learning conditions. School-based management (SBM) reforms of this kind are a strategy to improve education quality by bringing decision-making closer to local communities and by strengthening accountability between schools and the parents and children that they serve.

Recent studies from many different countries have shown that school-based management can have a positive impact in terms of increasing access to education and improving learning outcomes. 'Reforms of this kind have also had a positive impact on student learning outcomes in the Philippines. ${ }^{8}$ However, the type of SBM reforms being implemented varies from country to country, the reforms can take time, and their success depends critically on parental participation, political support, and effective implementation.

In the early 2000s, the Government of the Philippines introduced school-based management reforms that have had a positive impact on student learning outcomes. A key aspect of the success of these reforms has been the provision of ever-increasing levels of operational funding to the school level coupled with the devolution to schools of greater autonomy over the use of these funds. By 2014, schools were managing significant amounts of resources and using these funds to implement their own school improvement plans. Also, in 2015, DepEd issued new guidelines drawing on past experience that aimed to strengthen school improvement planning and make it more transparent.

Most schools in the Philippines have not yet gone very far in implementing school-based management. In 2009, DepEd introduced a tool for schools to assess their own progress towards SBM. In 2014, the PETS-QSDS survey found that most elementary and high schools had put in place only the lowest level of SBM. This means that they had only a minimum number of arrangements in place for community participation and for taking action to improve learning outcomes.

\section{Autonomy}

The main weaknesses identified by school principals related to school autonomy. On the whole, more elementary school principals than high school principals highlighted weaknesses in their implementation of SBM. However, more high school principals mentioned their inability to raise sufficient resources as a major impediment to putting SBM into practice. It is likely that this also limits the ability of schools to carry out the activities included in their school improvement plans.

Schools have discretion over only a very small amount of their total revenues. The PETS-QSDS survey of school revenue and expenditure showed that the average annual revenue of an elementary school was approximately PHP 3 million, and for high schools it was PHP 8.1 million (Figure 10). Over 80 percent of school funding was devoted to teacher and staff salaries, mostly for centrally hired government teachers and staff. While school principals have some control over the day-to-day supervision of their staff, the hiring and resources used for school staffing fall outside the school's control. Only around PHP 188,000 or 7 percent of total funds is available to each elementary school to use at its own discretion. High schools have a little more flexibility in the use of their funds but only over around PHP 987,000 or 12 percent of each school's total funds are discretionary.

\section{Participation}

Effective school-based management requires parents and local community members to play a strong supporting role in school decision-making and oversight. The School Governing Council (SGC) for each school is a forum for parents, students, teachers, and community stakeholders to participate in making school improvement decisions. It takes an active role in developing the school improvement plan (SIP) and, together with the school principal, is responsible for endorsing it and sending it on to the schools division superintendent (SDS) for approval. It is also expected to participate in monitoring the implementation of the SIP. The number and type of the SGC's members and the frequency of its meetings are decided at a first meeting attended by parents and other stakeholders where the constitution and by-laws of the SGC and the election process for initial council members are agreed. 
Figure 10: Discretionary Resources at the School Level Are Low

Annual school revenue by type and source, 2013/14 school year
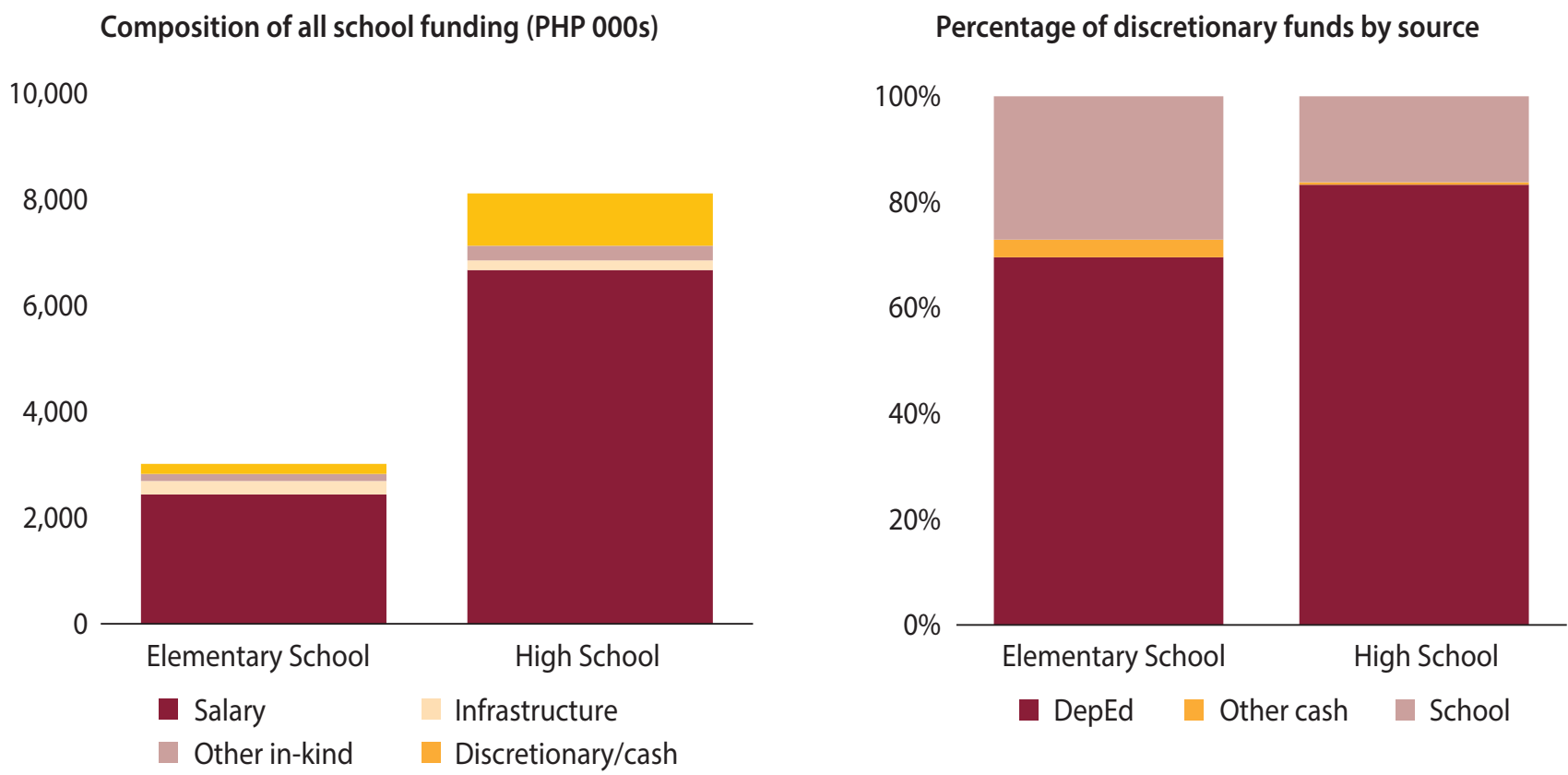

Source: PETS-QSDS national survey - school level.

Note: The averages reported in the table are for all schools even if they received zero revenue under a particular category. Other cash revenue includes cash provided to schools by parent-teacher associations, local governments, and barangays and from private sector or NGO contributions.

Nearly three-quarters of the household heads who were interviewed were unaware that their child's school had an SGC (Figure 11), and fewer than half of all parents were aware that their school had an improvement plan. Most of the parents who knew about the SIP seem to have been invited to participate directly in its preparation, but awareness beyond this group was rare. These findings raise questions about how effectively the SGCs are fulfilling their role as forums for school and community collaboration in improving learning outcomes.

\section{Accountability and Transparency}

The effective implementation of SBM depends on parents, PTAs, SGCs, and other stakeholders having access to the information needed to hold schools to account and to provide them with feedback.

Around 70 percent of elementary and high schools have some kind of notice board or transparency board where

\section{Figure 11: Few Parents Know about the SGC or Are Aware of the School Improvement Plan}

Percentage of parents of elementary and high school students who know about the SGC and the SIP, 2014

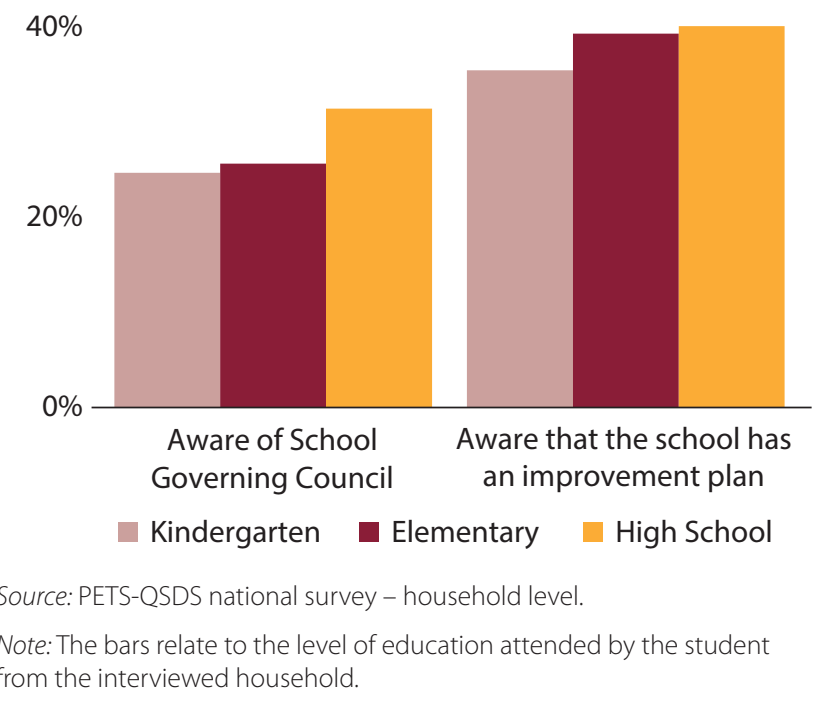


Figure 12: Social Accountability Initiatives like Check My School Do Not Work in Many Schools Percentage of school principals reporting an engagement with Check My School (CMS) in 2013 or 2014

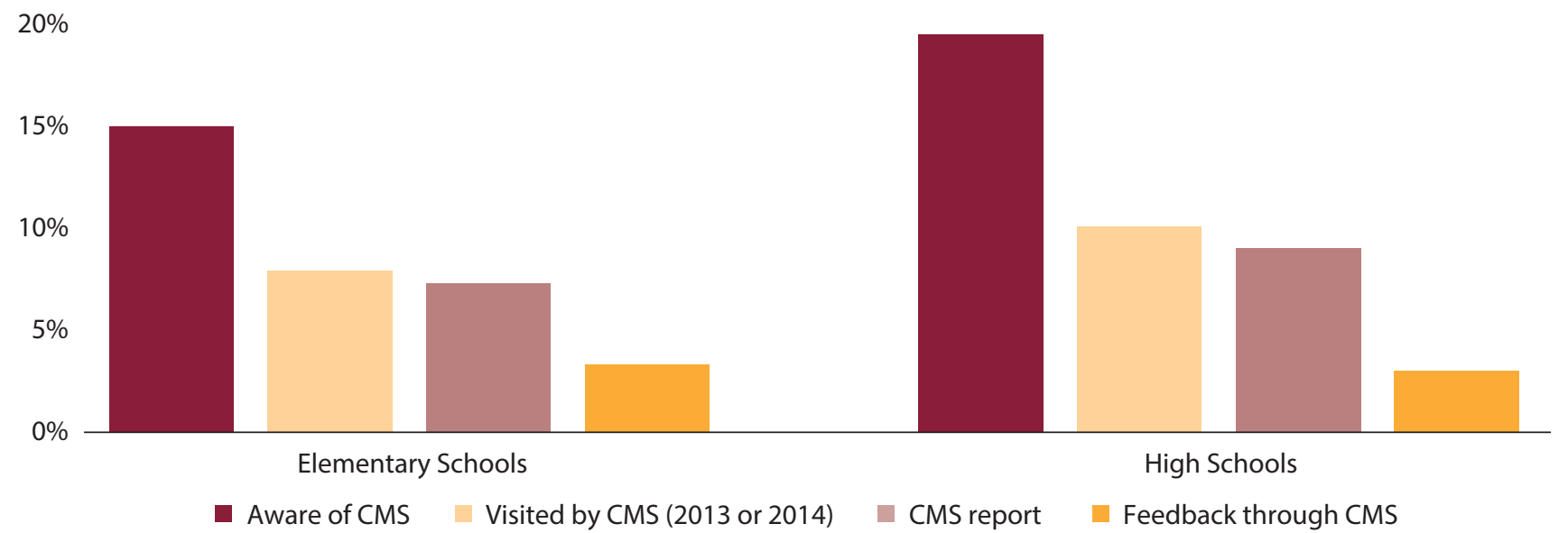

Source: PETS-QSDS national survey - school level.

information was posted, but the study team found that many were not visible to the public - including the one-third in elementary schools that were located inside the principal's office or the staff room. Schools rarely display or publish upto-date information on how they spend their discretionary resources.

The limited availability of information provided by schools helps to explain why parents appear to be unaware of the financial resources that schools receive to fund improvements. Only 40 percent of parents of elementary and high school students knew that schools received operational funding from the national government, and fewer than half of those had received information on how the funds had been allocated in the previous year.

There are few other ways by which parents and other stakeholders can access information on school performance. As part of the school improvement planning process, schools are supposed to prepare an annual school report card that includes information on key school performance indicators such as National Achievement Test (NAT) results and student progression indicators. Yet only around half of the parents of elementary and high school students said that they had been given such a card or even any information on the card in the previous two school years. A similar proportion of parents reported that they had not even received a report card on their own child's progress.
Beyond school-level institutions, social accountability initiatives like Check My School (CMS) appear to have a limited impact. CMS uses mobile and internet technology to enable communities to monitor the quality of basic education services, involving local facilitators who mobilize local communities to verify information on the status of their school. Any discrepancies between the official government data and the data collected by the CMS are then brought to the attention of DepEd. Although the initiative began in 2011, its coverage appears to be quite small. Only 15 percent of elementary school principals and 20 percent of high school principals were aware of CMS, and only a small proportion of these schools had had any direct dealings with the initiative (Figure 12). For example, fewer than 5 percent of high schools had ever provided feedback through CMS.

\section{National Government Support for School Operations}

Providing schools with direct funding to meet their operational needs is the cornerstone of the government's efforts to strengthen school-based management in the Philippines. Over the past five years, funds provided directly to schools to support their maintenance and other operating expenses (MOOE) have increased by 45 percent in real 
terms, demonstrating the government's commitment both to increasing operational funding and to providing schools with the funding that they need to implement their own improvement plans. Evidence from the Philippines and elsewhere shows that increased school funding and effective school-based management (SBM) can lead to more efficient use of resources and, ultimately, to better education outcomes.

Over recent years, school MOOE funding has increased significantly in real terms even though its share in the overall basic education budget has remained stable. For example, between 2011 and 2014, per student appropriations for elementary school MOOE increased from PHP 317 (US\$7) to PHP 566 (US\$13). Despite these increases, a detailed costing study revealed that existing levels of school MOOE are insufficient and would need to more than double to ensure that existing service standards were met.

Public schools rely heavily on the school operating funds provided by the national government. The PETS-QSDS survey collected detailed information on all types of school revenues. In 2013, MOOE allocations accounted for 68 percent of all discretionary funding received by elementary schools and for 82 percent received by high schools. In the case of over 10 percent of schools, their MOOE allocations were the only source of operational funding that they received.

\section{Tracking MOOE funds}

Only 77 percent of the total allocations for elementary and non-IU high schools ultimately reached those schools in 2013 (Figure 13). In other words, elementary and high schools received only PHP 448 of the PHP 581 allocated for each student. Given that the guidelines stipulate that all school MOOE funds should be downloaded to schools, this finding is a concern. It implies that about PHP 1.8 billion out of the PHP 8 billion MOOE budget intended to be used by schools in 2013 were not downloaded.

The retention of school MOOE by DepEd division offices is the main reason for the differences between the initial allocations and the amount of funds actually downloaded to schools. Although division offices are required to download funds to schools in full, the PETSQSDS tracking exercise indicated that over 60 percent of division offices held onto some MOOE funds in 2013

\section{Figure 13: A Significant Portion of the MOOE Allocations Do Not Reach Schools}

Share of MOOE allocation downloaded and received by schools, 2013
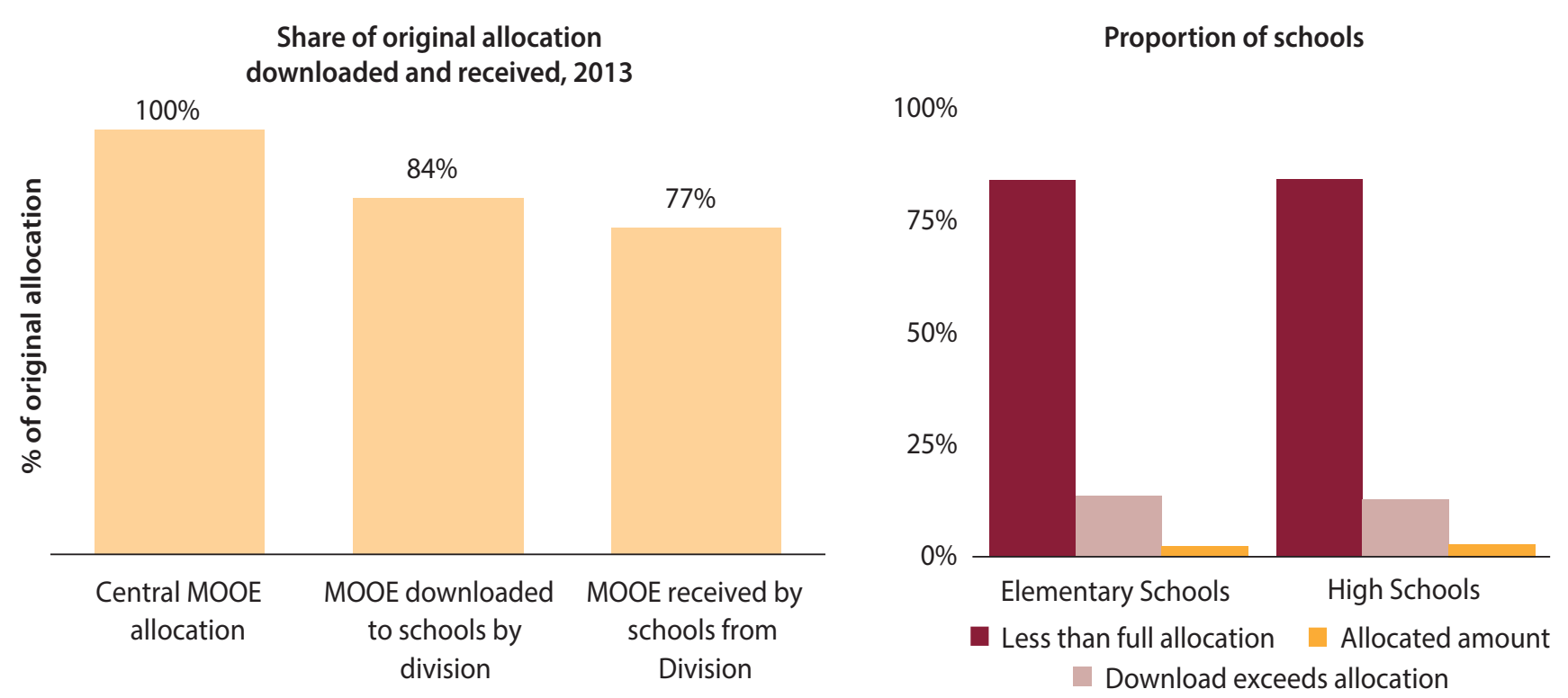

Sources: Data on allocations from DepEd central office. All other data from PETS-QSDS national survey - division and school levels. 


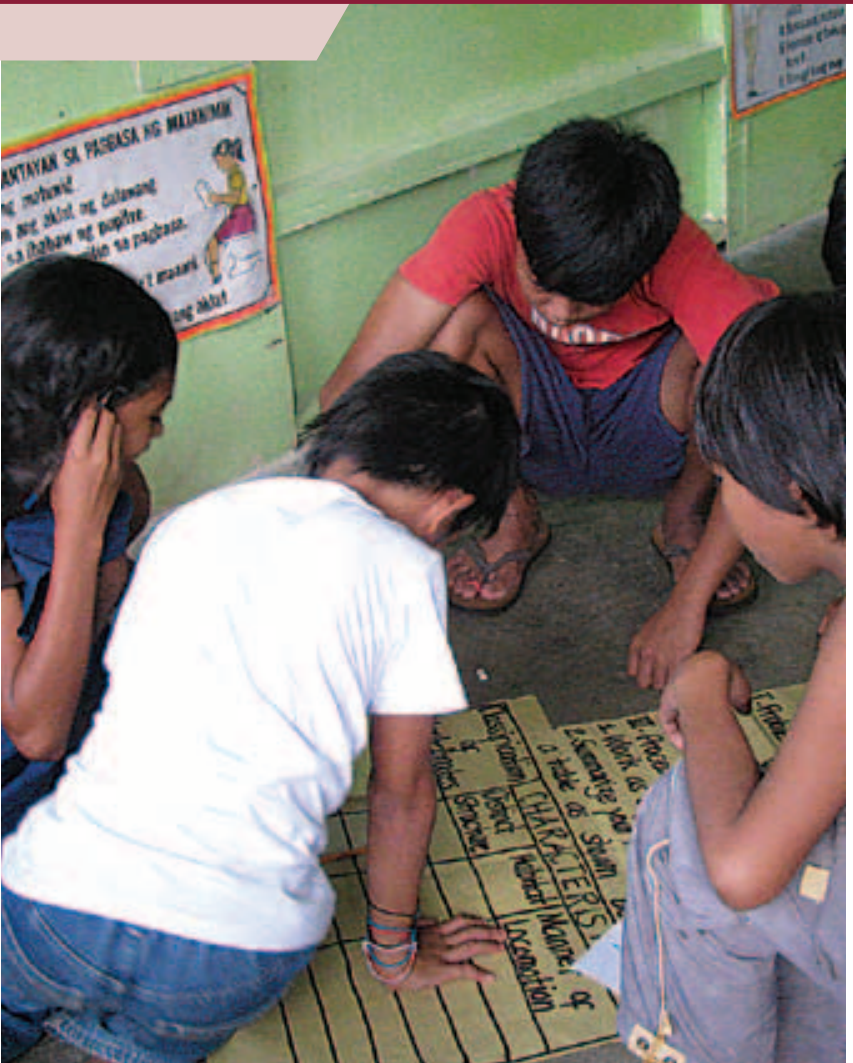

in order to procure items for schools, pay their utility bills, or fund other services for schools. This was the case even though DepEd explicitly prohibits division offices from procuring items using school MOOE funds except in extreme cases where there is a demonstrated need for the division to do the procurement. This practice reduces the amount of discretion that schools have over the use of their own MOOE funds and has the potential to limit the effectiveness of ongoing school-based management reforms.

School liquidation (utilization) reports reveal that some schools find it difficult to use all of the MOOE funds that they receive. The main reason why so many schools find it difficult to spend their entire MOOE allocation is because they have insufficient capacity and time to meet their reporting and procurement requirements. Over onethird of elementary schools and a quarter of high schools reported encountering such problems in 2013, and the most common reason they cited was lack of capacity to meet reporting requirements. The management of $\mathrm{MOOE}$ funds is particularly demanding of school principals. In the 2014 school year, principals reported spending six to eight hours a week on administrating MOOE funds, including procuring goods and services and preparing liquidation reports.
The difficulties that school principals experience in managing MOOE funds can result in significant delays in their submission of liquidation reports as well as some misreporting of data. Although schools are usually required to submit liquidation reports within 35 days of receiving an MOOE transfer, only about half of all elementary school advances and one-third of high school advances were submitted within this period. Some schools submitted reports as long as three months after receiving the initial advance.

Schools serving poorer and more marginalized groups are provided with higher levels of MOOE funding for each student. This is not because the MOOE funding formula provides additional funding to schools serving poorer groups. Instead, this is partly a reflection of the fact that wealthier students are more likely to attend schools in urban areas where student-classroom and student-teacher ratios are higher, thus leading to lower per student MOOE funding.

However, in elementary schools, the pro-poor allocation virtually disappears in terms of the amount of MOOE funding that the schools actually spend. The result is that, in practice, students from different socioeconomic groups attend schools that receive similar levels of per student MOOE despite the large differences in their original allocations. This is a missed opportunity to use school MOOE as a way to narrow the very large differences in school revenue among schools serving different socioeconomic groups.

\section{Oversight and Monitoring}

While there are regulations in place that aim to make use of MOOE funds more transparent, compliance with these regulations is low. The Anti-Red Tape Act (2007) mandates public schools to maintain a transparency board or bulletin board detailing how they are using their MOOE funds. However, as of 2014, fewer than two-thirds of schools had a transparency board containing information on MOOE expenditures. Moreover, the information posted on about one-third of transparency boards was more than three months old.

Decisions on the use of MOOE funds are largely confined to the school principal and other teachers. In 2014, over 80 percent of elementary schools reported that teachers had 
been consulted about how to use the schools' MOOE funds (Figure 14), but PTAs had an input in fewer than 30 percent of schools. This is not surprising since DepEd's current guidelines explicitly prohibit PTAs from "interfering in schools' administrative management."

Only 13 percent of elementary schools receive input from school governing councils (SGCs) even though SGCs are responsible for developing and implementing the school improvement plan (SIP), which includes activities financed by MOOE funds. This number is even lower among high schools, with SGCs, parents, and local school boards participating in MOOE decisions in fewer than 10 percent of schools. The study's interviews with parents revealed a similar picture. Only about one-third of parents reported participating in discussions about the school's use of financial resources in general and fewer than a quarter reported participating in decisions about how to use the school's MOOE funds.

\section{Local Government Support for Basic Education}

Local government funding represents a small and declining share of overall public funding for basic education. While spending on basic education by local government units (LGUs) has fluctuated considerably over the last 10 years, in real terms, it appears to have been declining since 2007. Combined with everincreasing levels of national spending, the share of public basic education funding accounted for by local government spending declined from 11 percent in 2006 to only 6 percent in 2013.

There are also large disparities in basic education spending by local governments across different regions in the Philippines. These disparities are largely driven by differences in the revenues that local governments collect for the Special Education Fund (SEF) from a 1 percent surcharge on property taxes. The National Capital Region (NCR), the region with the highest overall levels of property tax revenue, accounts for over 44 percent of total local government education funding in the Philippines. This is a very large and significant source of additional funding for the school system, equivalent to approximately PHP 3,500 in additional funding for each basic education student in the region or about 28 percent over and above per student funding from the national government. Disparities between other regions are not as stark but still exacerbate funding inequalities between schools in different locations.

Figure 14: There Is Little Participation by Local Stakeholders in Decisions about How MOOE Funds Are Used Percentage of schools that received input from stakeholders about MOOE funds, 2014 SY
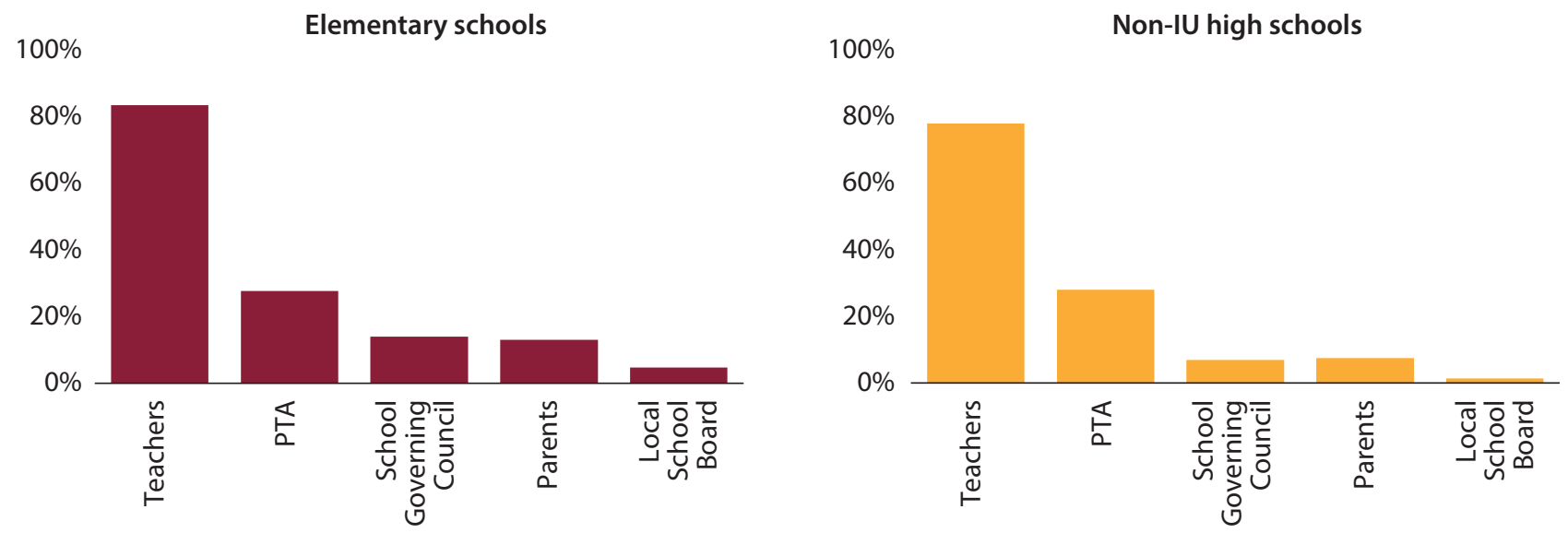

Source: PETS-QSDS national survey - school level 
Looking beyond aggregate spending figures, it can be seen that fewer than 50 percent of schools receive any kind of direct funding from local governments (Figure 15). Even when schools do receive LGU funding, it tends to make up a very small share of overall funding. For example, LGU funding represents less than 4 percent of the total cash and in-kind funding that schools receive, with the remainder largely coming from the national government.

\section{A comparison between levels of LGU direct school} funding and total LGU education spending reported at the national level suggests that significant amounts are not being spent on activities that directly benefit schools. Rough estimates by the PETS-QSDS team using finance data carefully collected during school visits suggest that LGU spending on schools amounts to approximately PHP 9 billion. This represents only 58 percent of the PHP 16 billion that LGUs reported spending on education in 2013. There was little information on how the LGU funds that were not spent at the school level were used. The study team made considerable efforts to collect such information from the local governments directly and from the DepEd supervisors who sit on local school boards. However, little information was available and, even where it was, the data were patchy and did not correlate with the official aggregate spending figures reported by the LGUs.
Data on levels of annual local government education spending was often unavailable to the survey team at the local level, and what little information they were able to find was inconsistent. This clearly limits the ability of stakeholders to hold local governments accountable. The PETS-QSDS team collected financial data on the Special Education Funds (SEFs) from the Bureau of Local Government Finance (BLGF) at the national level and from LSB offices in cities, municipalities, and provinces. The team then attempted to match these two sets of data, which revealed significant inconsistencies between the nationally and locally reported spending aggregates. The team found that the information reported at the national and local levels was consistent in the case of only 16 percent of LSBs, while, for 22 percent of LSBs, there were inconsistencies in the levels of spending reported at the national and local levels, and half of all LSBs did not report any SEF expenditure at the local level.

\section{Equity}

Ensuring access to good quality basic education is necessary if children are to be equipped with the foundational skills that they need in order to play a full and productive role in their communities. Despite recent progress in narrowing disparities between socioeconomic groups, gaps in access

Figure 15: Fewer than Half of All Schools Receive LGU Support, and the Amount of Funding Provided is Small Percentage of schools that report receiving cash or in-kind contributions from local governments and average levels of support, 2013-14
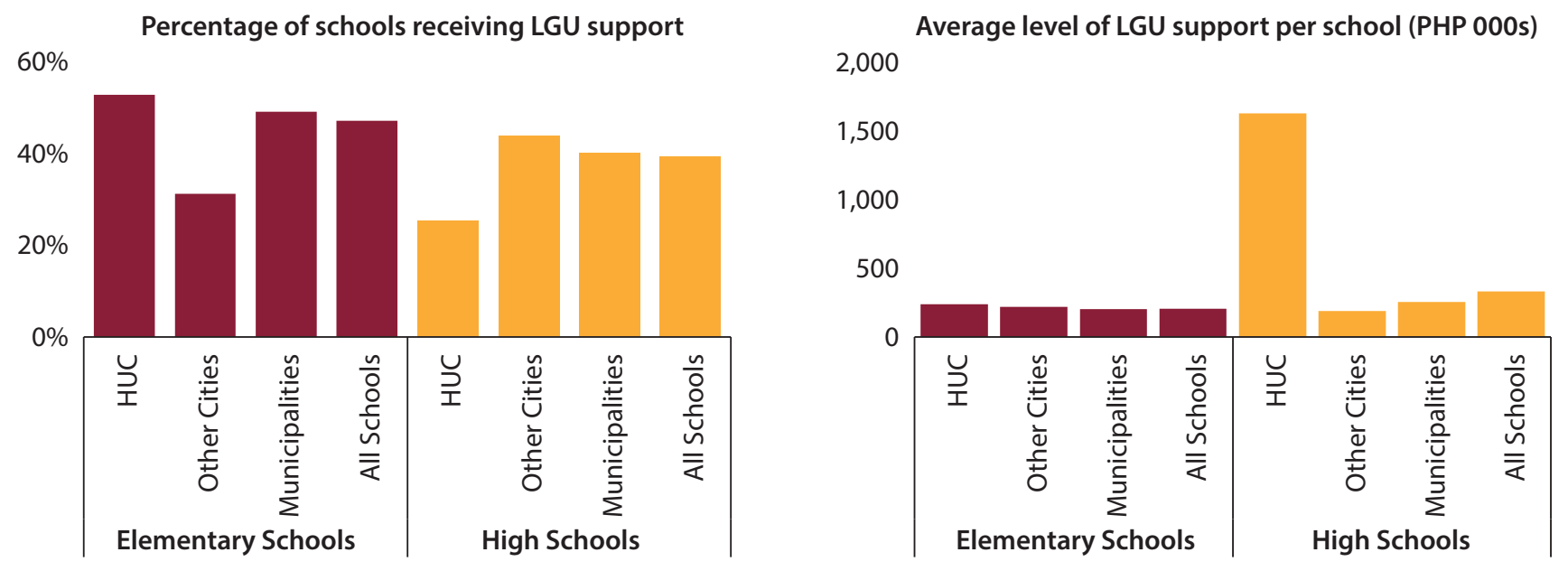

Source: PETS-QSDS national survey - school level.

Note: The average level of support is only for schools that received LGU contributions in 2012/14. 
remain large, particularly at the high school level. The PETSQSDS study also found large differences in the quality of education provision across regions, between rural and urban areas, and among schools serving different income groups.

\section{Regional Inequality}

Significant differences in levels of education spending and the quality of the learning environment exist across regions and provinces. For example, the national government's spending per school-aged child in 2012 varied from PHP 4,500 in the National Capital Region (NCR) to just over PHP 7,600 in the Cordillera Administrative Region. Moreover, regional disparities in national government spending have been growing since 2005. Local government spending on basic education tends to reinforce national government spending patterns. For example, Region II had one of the highest national and local government per student allocations in 2012, while Region VII had one of the lowest national and local government allocations.

These funding disparities result in considerable variations in the quality of school learning environments across regions. This study shows that there is a strong association between levels of per student education spending and the quality of the learning environment. In other words, regions with low levels of per student spending also tend to have the poorest learning environments. For example, low levels of national and local government funding in Region VII have resulted in very poor student-teacher and student-classroom ratios compared to national averages.

\section{Rural Urban Disparities}

Even though urban schools tend to serve wealthier populations, they tend to perform poorly compared to rural schools. National examination results tend to be lower for students of urban elementary and high schools than for students of rural schools. For example, in 2014 the average score in the Grade 6 national achievement test was 66 percent in highly urbanized cities compared to 75 percent in rural municipality schools. The PETS-QSDS study also found that urban schools, particularly high schools, tended to be less efficient than rural schools in translating their generally larger revenues into better learning outcomes.
These patterns in school performance are partly driven by differences in the quality and availability of facilities in rural and urban areas. Average school size varies enormously between urban and rural areas. In 2014, the average high school in a highly urbanized city had approximately 1,700 students compared to about 1,000 students and 570 students in city and municipality schools respectively. However, the facilities in highly urbanized city schools are frequently insufficient to accommodate these high student numbers. For example, the proportion of schools that fail to meet DepEd standards for classrooms and toilets is much higher in highly urbanized cities than in other locations (Figure 16).

Tackling deficiencies in the quality of the learning environment also appears to be more difficult in urban areas. Two-thirds of DPWH district engineering offices and all offices in urban areas reported finding it difficult to implement school infrastructure projects in urban schools. Lack of space and impractical uniform pricing policies were key reasons underlying these difficulties.

The quality of other important education inputs also tends to vary between rural and urban areas. Fewer qualified teachers appear to be available in urban areas, particularly in highly urbanized areas, than in more rural areas. For example, there is an average of 39 students for every teacher in elementary schools in highly urbanized cities compared to only 29:1 in schools located in municipalities. Differences in STRs in high schools are not as stark, but large urban schools have higher STRs than schools in rural areas.

Teacher absenteeism rates also tend to be higher in cities, particularly in highly urbanized cities. In high schools located in HUCs, almost 1 in 10 teachers was found to be absent in 2014. This absenteeism rate was 53 percent higher than the national average. However, while their absenteeism rates were high, high school teachers in HUCs and other cities had higher scores on subject content assessments conducted as part of the study than rural high school teachers.

\section{Socioeconomic Disparities}

The PETS-QSDS survey included a nationally representative sample of public elementary and high school student households. Using the information collected from these 
Figure 16: A Greater Proportion of Urban Schools Fail to Meet Infrastructure Standards than Rural Schools Percentage of schools that failed to meet DepEd service standards, 2014

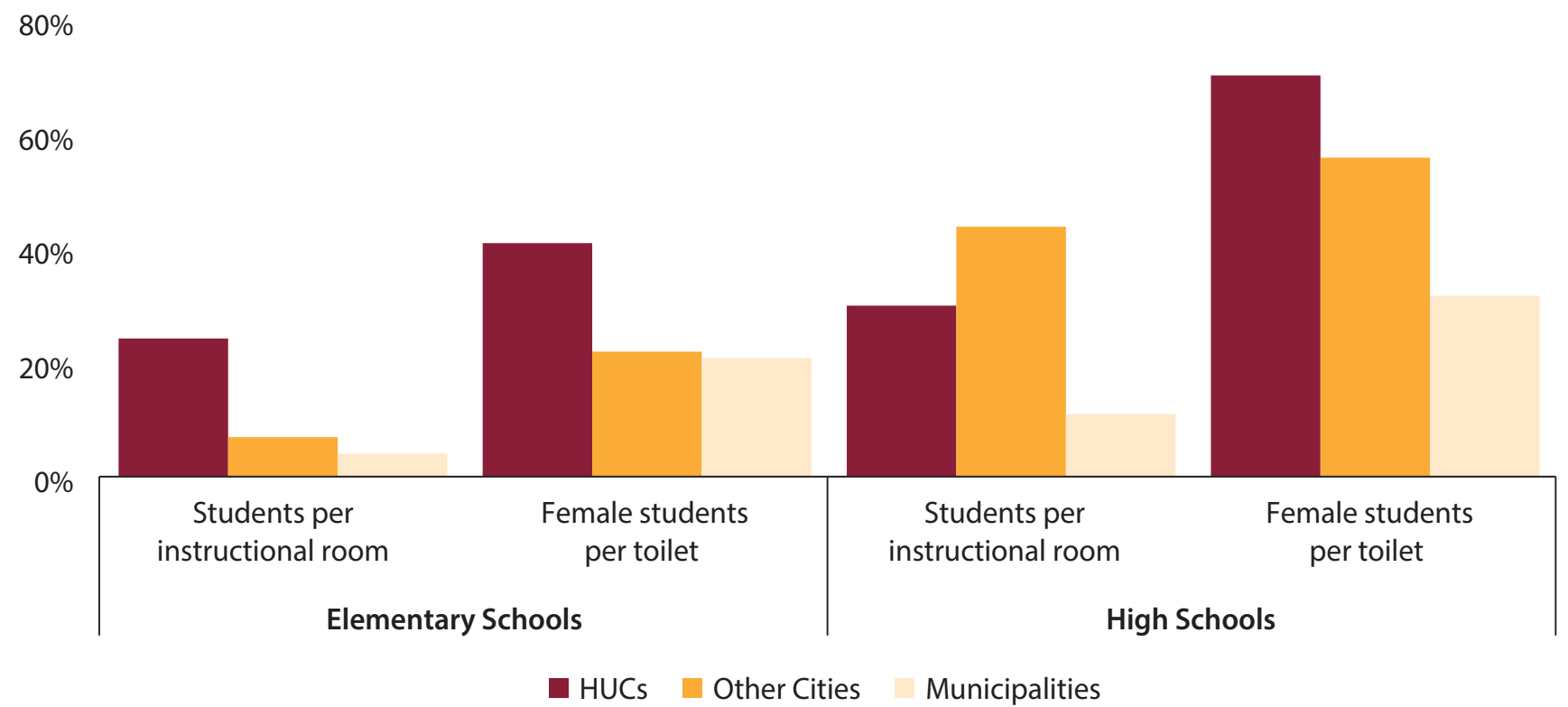

Source: PETS-QSDS national survey - school level.

survey households, it was possible to rank them by their estimated levels of per capita household consumption. This ranking was used to explore the characteristics of schools attended by different socioeconomic groups.

Schools serving poorer students tended to be more resource-constrained than wealthier schools. Schools receive discretionary funds from the national government, and these tend to be allocated relatively equitably. Schools also generate their own funds, but their ability to do so is dependent on the socioeconomic composition of their student populations. In 2014, students in the poorest quintile attended elementary schools that collected about half as much in discretionary funding as the schools attended by students in the wealthiest quintile.

Lower levels of funding are a key reason why schools serving poorer communities tend to have poorer ratings for the implementation of school-based management. The study found that students from the poorest 20 percent of households were more likely to attend elementary and high schools that had the lowest level of self-assessed SBM implementation than students from the wealthiest 20 percent of households. Other research has shown that SBM reforms have had only a limited impact in schools that serve poorer communities. The findings from the PETS-QSDS study suggest that this may be due at least in part to the fact that schools in poorer areas have less funding to support key elements of SBM, including the implementation of school improvement plans.

Differences in the availability and competency of teachers by socioeconomic group present a more mixed picture. On the whole, poorer children attend schools with lower rates of teacher absenteeism than wealthier children. This ranking reveals that students in the bottom 20 percent of households in terms of consumption tend to attend schools with lower rates of teacher absenteeism than students from the wealthiest 20 percent of households. This reflects the greater proportion of wealthier students attending schools in highly urbanized cities where rates of teacher absenteeism are higher. However, high schools serving better-off students tended to have better-performing high school teachers than high schools attended by poorer students. At the elementary level, no clear pattern emerged, although poorer students tended to be taught by teachers who performed better than average on the Filipino test. 
The mixed picture of the quality of basic education services available to different socioeconomic groups highlights the need to look at all dimensions of inequality to improve basic education services. For example, a greater proportion of poor children than wealthy children are located in rural areas where schools are less crowded and the learning environment is better. However, at least in high schools, the best teachers are working in wealthier urban areas, which puts poor students in rural areas at a disadvantage. Addressing these different dimensions of inequality is a necessary first step to ensuring that students across the many islands of the Philippines all receive an education of similar quality.

\section{Conclusions and Policy Directions}

The study has shown that, despite a renewed focus on basic education by the Philippines government, further increases in both capital and recurrent public spending are needed. The study has shown that there have been significant improvements in the learning environment that Filipino children experience every day but more still needs to be done. Many schools, particularly in urban areas, have insufficient and poor quality facilities and a shortage of teachers. Operational funding still falls short of the amounts that schools need to pay bills, undertake basic repairs, and provide the day-to-day materials their students need. And there is rarely anything left over to fund school-level initiatives to improve student learning achievement. The study has also highlighted the lack of good quality opportunities for teachers to improve their skills. Addressing these challenges will require further investments in the education sector.

It also appears that the bulk of this funding will need to be provided by the national government. The study has shown that local government funding, except in the National Capital Region, is very small and that funding from other sources, including parent-teacher associations, is also negligible. Detailed estimates suggest that over 90 percent of school funding comes from the national government. Unless there are significant policy changes in the future, this means that increases in spending will need to be found from the national government budget, either through greater revenue-raising efforts and/or by increasing the share of basic education in the overall government budget from its existing level of 15 percent.
However, the study also highlights some limitations in the existing systems that manage public basic education funds. Allocation systems have managed to target funds reasonably well, but there are still many examples of needy schools missing out on additional support while other, better-equipped schools continue to receive additional support. Moreover, delays in identifying school needs and in the budget allocation process have meant that a significant amount of funding goes unspent or has to be spent quickly or at times that disrupt school operations. Even when schools benefit from improvement projects or resources, the study has also shown that they are frequently unhappy about the quality of the resources supplied.

In the absence of efforts to address these limitations, further increases in funding are likely to have only limited impact on the challenges faced by the education sector. Moreover, the successful introduction of the senior high school program in 2016 will be jeopardized if systems managing the allocation and use of public funds are not made more effective.

Through a series of policy notes, this report has identified some of the key challenges and potential policy responses in key areas of resource management. Instead of repeating these recommendations in full, this section draws together some common policy directions that have emerged from the findings of the study as a whole. Table 1 also summarizes the major findings and policy suggestions from each policy note.

\section{Improve Allocation Mechanisms Through Better Planning}

The report makes clear that the systems currently used to allocate resources to schools could be strengthened by improved planning. While these allocation systems generally target schools with greater need, they could be improved further. For example, school infrastructure improvement projects are planned on an annual basis and project lists are frequently finalized late. This shortens the time available to implement them and compromises the ability of DepEd and DPWH offices to monitor projects adequately. Developing a two- or three-year plan that would forecast need and list all school improvement projects in each DepEd division would reduce the work involved in putting together the annual project list and accelerate the transmission of funds to the responsible implementing offices. It would also 
give implementing offices time to do some advance planning and thus avoid some of the difficulties associated with inadequate funding and site availability that were commonly cited as reasons for implementation delays. A similar approach could be adopted for teachers and the planning of other important school inputs.

More input from division offices and schools in planning could also improve allocation decisions. Funding decisions are largely taken at the central level and frequently do not take into account local conditions. For example, in the PETS-QSDS study, a considerable number of school principals and school division superintendents (SDSs) felt that existing procedures for allocating new teachers were suboptimal, and some SDSs felt that they had not been adequately consulted. Similarly, schools had only limited input into the planning and implementation of infrastructure projects. This contributes to an impression that division offices and schools have limited influence on education decision-making. Strengthening the processes for consulting schools and division offices about the decisions that affect them and making information publicly available on the decisions that are made would improve planning.

\section{Give Schools Greater Authority and Simplify Reporting Requirements}

Increasing the role played by schools and local DepEd offices in deciding on the use of education funding may also improve the quality of public education spending. The study has highlighted the limited authority that schools have over the implementation of school infrastructure projects. It has also shown the weak links between the individual professional development needs of teachers and the types of in-service training offered. Providing schools and division offices with more authority during the implementation of both infrastructure projects and teacher training could yield significant benefits. For example, giving school principals the authority alongside DepEd and DPWH officials for certifying that infrastructure projects have been satisfactorily completed might improve their quality. School principals in the Philippines have taken on roles of this kind in the past and with appropriate training could become a major driving force in improving the quality of school infrastructure projects.
Over recent years, schools have been given ever increasing amounts of discretion over how to spend their funding. This has primarily been done to support school-based management reforms by providing schools with the funds to implement their own improvement plans. Evidence from the Philippines and other countries supports the idea that giving schools more autonomy can improve education outcomes.

However, the study found that the existing system for managing school operational funding is too onerous on school principals and that there is a risk that the benefits from reforms of this kind will not materialize. Simplifying the existing requirements for the management of these funds would reduce the significant burden that this currently puts on schools. It would also give school principals more time to focus on providing academic leadership in their schools. One approach that has been adopted in other countries would be to treat operational funds as a grant. For example, this is the case in Indonesia, where these funds have much less onerous reporting requirements than required by the usual government budget and implementation systems. Schools use simplified reporting templates to report on their use of the funds and submit these forms to district offices (the equivalent of division offices in the Philippines) every quarter. Developing a similar system adjusted to take account of the specific context of the Philippines could reduce the burden that using these funds currently puts on schools.

However, if division offices, schools, and even local communities are to get more involved in decisions about how education resources are allocated and used, these spending decisions need to be more transparent. Across all of the spending areas that the PETS-QSDS survey covered, information on the transfer and use of funds was frequently missing, inaccessible, or in formats that were not easy to understand. Even where information was available, it frequently was not consistent between different administrative levels. For example, there was a discrepancy of about 8 percent between the funds that division offices reported having downloaded to schools for operational expenses and the amounts that the schools reported receiving. In most cases, it was not possible for the study team to judge accurately the extent to which these discrepancies arose from misappropriation of funding and/or incomplete reporting. 


\section{Improve Transparency of Fund Allocation and Resource Use}

Local government funding was an area that was particularly concerning. The study estimated that only around 60 percent of local government funding reached schools directly. However, records on which schools received funds and what the funds were provided for were very weak. For example, 24 percent of elementary schools to which local governments claimed to have provided in-kind support for salaries denied ever having received this support. In contrast, LGUs themselves reported providing support to only approximately 40 percent of all of the elementary schools that reported having received support from their LGU. Information on the 40 percent of funds that did not go directly to schools was even less reliable.

Developing simple reporting formats in which to record the funds allocated to divisions and schools and how these institutions use these funds would go a long way to increasing transparency. A recent initiative by the Department of the Interior and Local Government (DILG) to encourage greater accountability and transparency is one useful example of what could be done. The DILG awards the Seal of Good Local Governance to local governments that perform well in several areas as well as providing them with additional performance-based funds. This scheme has given LGUs a strong incentive to increase transparency and to improve their use of the Special Education Funds. While the awarding of the Seal is already conditional on whether the annual plan of local school boards is aligned with the plans of the schools themselves, it could also be used to encourage better reporting. For example, the category of "good financial housekeeping" could be expanded to include more detailed reporting, a requirement to publish details of how SEF funds are used, and a requirement to set targets for the proportion of funds that should reach schools.

Introducing and widely disseminating a set of standards for elementary and high schools would also increase transparency and encourage greater accountability for the use of public funds. DepEd has a number of different guidelines that set standards for elementary and high schools, which the PETS-QSDS study used to assess the adequacy of existing resource allocations. However, these guidelines are scattered across different DepEd orders and regulations, and many stakeholders are unaware of their existence.
Setting basic standards for basic education provision and ensuring that information about these standards is widely disseminated would enable parents and other stakeholders to judge the fairness of allocations and to hold the government more accountable for the provision of key education inputs like classrooms and teachers. It would also enable schools and other stakeholders to seek redress for unfair allocations or poor project implementation. Policymakers could explore the feasibility of introducing a formal grievance system that schools could use to express dissatisfaction with decisions related to all school funding, including school infrastructure projects, as this would help to make government education spending more effective and improve education services.

\section{Strengthen the Role of School Governing Councils and Parent Teacher Associations}

Parents and other community members can also play a role in improving school decision-making and overseeing how schools use public funds and resources. However, the study found that, while SGCs had been established in nearly all schools, their role was fairly limited. Giving SGCs greater responsibility for monitoring how schools use public funds could provide a useful complement to DepEd's own oversight role. For example, SGCs could become jointly responsible with the DepEd division offices for signing off on schools' fund utilization reports. However, if the SGCs are to take on an expanded role, then their members will need to receive more training and support from DepEd. Schools also need to encourage greater participation from parents and others in the SGC to strengthen their planning and oversight activities as the PETS-QSDS study found that most parents of students were unaware of the existence of SGCs or of their school's improvement plan.

A campaign to increase the awareness of parents and other education stakeholders of the role of SGCs and school improvement plans is needed. Recent evaluations in Indonesia and Pakistan have shown that it is possible to use old and new technologies to disseminate information. In Indonesia, an impact evaluation study showed that well-designed information campaigns using simple SMS text messages or school meetings can significantly increase public knowledge about schools' funding levels and 
responsibilities. It also found that this increased knowledge led to higher levels of parental participation in school affairs. In Pakistan, a similar strategy was used in a successful pilot program to disseminate information about school councils. The pilot set up a call center and used inbound and outbound calls, robot calls, and SMS text messages to transmit important information about the role played by school councils and their members. An assessment of the pilot showed that school council members' knowledge about their roles and responsibilities had increased, while school principals reported the councils had increased their participation in school affairs.

\section{Address Funding and Quality Inequalities}

The study has shown that there are substantial differences in the quality of education services across the Philippines. The factors associated with the distribution of quality vary, and there is no clear and consistent pattern. However, schools in highly urbanized areas, particularly high schools, tend to be very large and, despite getting higher levels of funding, tend to have more stressed learning environments and poorer levels of performance. The forthcoming extension of high school by two extra years is only going to add to the pressure that these schools face. A concerted effort by DepEd to address the specific issues of these schools by, for example, establishing a task force to develop a complete program of support for these schools could be an important step forward.

In some cases, the distribution of education quality reinforces existing inequalities. For example, poorer students tended to go to high schools that had teachers with more limited knowledge of their subject areas. They also tended to go to schools with lower levels of discretionary funding and those that reported having implemented only a minimal amount of school-based management.

The Philippines has a well-established funding formula for school operational funding that could be extended to include an equity component. This would be one way to reduce the large school-level funding inequalities highlighted in this report. In order to compensate those schools that receive lower funding from non-DepEd sources such as local governments, an equity component could be introduced in the allocation formula. This could go some way towards equalizing school funding and providing schools in poorer areas with the additional resources that they need to support the learning needs of marginalized students. Many other countries, like the United Kingdom, have introduced funding components of this kind. The allocations of MOOE funds could also be adjusted to take into account price differences between regions so that schools operating in high-cost areas such as remote locations where travel and transportation costs are high are able to purchase similar amounts of goods and services as those in lower-cost locations.

\section{Further Research}

The study has highlighted a number of areas where current and existing resources could be used more effectively.

However, there are a number of important gaps that further research could clarify. In particular, the PETS-QSDS study was not able to look at individual student performance and some of its important determinants. In particular, the study did not explore the quality of classroom instruction and other important factors associated with the teaching and learning process. The quantitative approach used in the PETS-QSDS study is not best suited to exploring issues of this kind, but qualitative work would be an appropriate way to add to what is known about the quality of education in the Philippines and to help DepEd to develop appropriate pre-service and in-service training.

The PETS-QSDS study collected very detailed information on the status of education service delivery across the Philippines. The report analyzed a wide range of priority issues, but the data collected in the study could provide the basis of future research into an even wider range of issues. For example, further analysis of the teacher competency assessments would be useful to provide further insights into the professional development needs of teachers. The data could also be used to categorize schools for further research. For example, schools that have better school-community relationships could be identified in the PETS-QSDS data as a starting point for more detailed qualitative work to understand why these schools have been successful in this respect. Finally, the data represent an important baseline for tracking future progress in increasing the effectiveness of public education spending and improving student learning outcomes in the Philippines. 


\section{Table 1: Summary of Major Findings and Policy Suggestions}

Findings

\section{Policy suggestions}

\section{Strengthening Systems to Hire and Deploy Teachers}

Further improvements in teacher . Further develop guidelines/norms for school-level teaching needs, particularly for distribution are needed subject-specific teachers in high schools

- Monitor the distribution of teachers more closely to ensure efficiency and develop and implement the Human Resource Information System (HRIS)

- Revise teacher transfer policy to make it a more effective tool to improve teacher distribution

Hiring and deployment systems need to be strengthened
- Strengthen the accountability of regional and divisional offices for carrying out processes in a timely way

- Improve monitoring to ensure hiring timelines are met and that teachers are in post at the beginning of the school year

- Improve coordination between the DBM and DepEd regional offices

High teacher absenteeism in highly urbanized cities
- Increase the authority of DepEd division offices and schools to deal with absenteeism

- Link teachers' attendance to their career development and performance bonuses

- Explore the potential for increasing community involvement in monitoring teacher attendance

\section{Strengthening Teacher Support Systems}

Teacher subject knowledge is generally low

Professional development opportunities are limited and delivery mechanisms are weak
- Strengthen pre-service and in-service training opportunities for all teachers (see below)

- Increase funding and opportunities for effective professional development for teachers

- Provide a greater share of this funding to division offices and schools to enable them to organize professional development activities

- Transfer HRTD funds in a more timely manner

- Increase the transparency of HRTD funds through improved reporting by DepEd region and division offices and increase central office monitoring of fund use

Systems to identify teachers' professional development needs are weak

- Revaluate existing teacher strength and needs assessments and teacher professional development planning

- Develop diagnostic teacher competency tests to identify teachers' in-service training needs

- Develop content for professional development activities that will address existing weaknesses

- Evaluate and scale up the use of school learning action cells as the main venue for inservice training

A greater need to align teacher accountability systems to raise teacher motivation and competencies
- Support a stronger alignment between professional development planning, career development and performance incentives 


\section{Table 1 continued: Summary of Major Findings and Policy Suggestions}

Findings

Policy suggestions

\section{Strengthening Government Systems for School Infrastructure Improvements}

Allocation mechanisms for school infrastructure systems need strengthening
- Establish transparent criteria for prioritizing schools based on existing facility standards

- Validate project priority list at the division level

- Increase transparency and accountability by disseminating project selection criteria and by establishing feedback/grievance mechanisms

- Expand and establish partnerships to build and improve infrastructure

- Introduce multi-year planning for school improvement projects

- Strengthen coordination between implementing institutions

- Strengthen the role of schools and school governing councils in implementation

- Increase the capacity of DepEd and DPWH to monitor projects regularly

- Increase the transparency of school infrastructure improvement activities at the division and school levels

- Empower schools to monitor projects more closely and provide effective feedback channels for all stakeholders to use

\section{Strengthening School-based Management}

Schools assess their level of SBM implementation as low

- Provide further training to school principals, school governing councils, and parentteacher associations on school-based management

- Build the capacity of district and division supervisors to mentor schools in the implementation of school-based management

- Increase central government MOOE funds to a level that will enable schools to meet existing education service standards

- Increase the authority of schools over other funds (such as school construction funding)

SBM implementation is less advanced and fewer discretionary funds are available in schools that serve poorer communities

SGCs are not functioning as they were designed to do

- Introduce an equity component into the MOOE funding formula

- Provide additional supervisory support on school-based management to schools serving disadvantaged groups

- Clarify the roles and responsibilities of SGCs and PTAs

- Establish a role for the SGC in overseeing the use of school discretionary funds

- Increase the knowledge of SGC members on their roles and responsibilities through school-level training initiatives

- Conduct an information campaign to increase public awareness of the role of SGCs and PTAs, the SIP, and the use of and the reporting requirements associated with discretionary school funds (such as MOOE funds and canteen revenues)

Transparency at the school level needs to be increased
- Strengthen monitoring by DepEd district and division offices of the production of key information (such as school report cards and student report cards) by schools

- Enforce regulations on making information publicly available on school performance and use of funds 


\section{Table 1 continued: Summary of Major Findings and Policy Suggestions}

Findings

Policy suggestions

\section{Strengthening Systems to Provide Operational Funding to Schools}

Not all schools receive their full MOOE allocation and the transfers are often not made on a predictable schedule

The management of MOOE funds within schools is difficult and timeconsuming
- Enforce existing regulations on the transfer of funds

- Introduce transfer targets for DepEd division offices tied to performance bonuses

- Make MOOE allocations and formula components for each school publicly available

- Treat school MOOE funds as a grant to simplify reporting requirements

- Reduce the frequency of downloading and increase the time allowed for schools to produce liquidation reports

- Provide additional support to schools on MOOE management from district offices and provide school-level training

- Allow schools to deposit MOOE funds in bank accounts
School-level institutions like the school governing council are relatively weak

- Review and strengthen the role of SGCs in the planning and monitoring of MOOE funds

- Disseminate information on the roles and responsibilities of SGCs to parents and the local community

- Ensure that MOOE and other school-level funds are incorporated into school improvement plans

Funding inequalities at the school level are large

\section{Improving Local Government Support for Basic Education}

A low share of local government funding reaches schools and most is provided in-kind

Local government funding is inequitable
- Raise the share of local government funding provided directly to schools

- Introduce a formula-based funding model to allocate more cash directly to schools to support their annual improvement plans

- Reduce inequalities between local school board areas by adjusting the national funding formula

- Introduce a simple and transparent local government funding formula to strengthen the link between funding and school needs

Schools are rarely involved in funding decisions

- Make better use of schools' annual improvement and procurement plans in LSB planning

- Ensure that the link to school improvement planning in the Seal of Good Local Governance is properly measured and monitored

Transparency and accountability for

- Improve reporting formats for the use of SEF funds and ensure that the results are publicly disseminated

- Build on the Seal of Good Local Governance and associated performance-based funding by, for example, requiring LSBs to report planned school level funding allocations 


\section{Endnotes}

1 See, for example, McEwan, P. (2013). "Improving Learning in Primary Schools of Developing Countries: A Meta-Analysis of Randomized Experiments." Wellesley College, Wellesley, MA.

2 Woolner, P. Hall, E. Higgins, S. McCaughey, C. and K. Wall (2007). "A Sound Foundation? What We Know about the Impact of Environments on Learning and the Implications for Building Schools for the Future." Oxford Review of Education 33(1): 47-70.

3 Glewwe, P. Hanushek, E. Humpage, S. and R. Ravina. (2011). "School Resources and Educational Outcomes in Developing Countries: A Review of the Literature from 1990 to 2010," National Bureau of Economic Research, Cambridge, MA.

4 Krishnaratne, S. White, H. and E. Carpenter. (2013). "Quality Education for All Children? What Works in Education in Developing Countries?" Working Paper 20. New Delhi: International Initiative for Impact Evaluation (3ie).

5 Yamauchi, F. and S. Parandekar (2014). "School Resource and Performance Inequality: Evidence from the Philippines." World Bank Policy Research Working Paper No. 6748, World Bank, Washington D.C.

6 Highly urbanized cities are cities with populations of more than 200,000 and with average revenues of at least PHP 50 million in 1991 prices. Other cities are urban areas that do not meet these criteria. Municipalities are the administrative units for all other areas in the Philippines.

7 AusAID ERF (2011). "Current Issues in Education: School Grants and School-based Management." Canberra; Bruns, B., D. Filmer, and H. Patrinos (2011) "Making Schools Work: New Evidence on Accountability Reforms" World Bank, Washington, D.C.; and Carr-Hill, R., C. Rolleston, T. Pherali, and R. Schendel (2014) "The Effects of School-based Decision-making on Educational Outcomes in Low- and Middle-income contexts: A Systematic Review" Institute of Education, London.

8 Khattri, N., C. Ling, and S. Jha (2010). "The Effects of School-based Management in the Philippines: An Initial Assessment Using Administrative Data" Policy Research Working Paper Series. No. 5248, World Bank, Washington, D.C. and Yamauchi, F. (2014) "An Alternative Estimate of School-based Management Impacts on Students' Achievements: Evidence from the Philippines." Journal of Development Effectiveness. 6, no. 2: 97-110. 


\section{Introduction}

\section{Introduction and Purpose}

Over the last decade, the Government of the Philippines has embarked on an ambitious education reform program to ensure that all Filipinos have the opportunity to obtain the skills that they need to play a full and productive role in society. The government has backed up these reforms, particularly over the last five years, with substantial increases in investment in the education sector. Between 2010 and 2015, spending on basic education increased by 60 percent in real terms, and per student funding levels have increased considerably.

The reform program has halted a long-term decline in public basic education services. Most of the increases in education spending have been used to address major shortfalls in education services that had built up during the early 2000 s. In particular, a massive program for improving school infrastructure and a nationwide teacher recruitment drive have significantly improved school conditions. Between 2010 and 2013, student-teacher ratios in public high schools fell from 38:1 to 29:1, and student-classroom ratios fell from 64:1 to $47: 1$ over a similar period.

Increases in the availability of key inputs have also significantly increased access to basic education. Kindergarten enrollment almost doubled in absolute terms between 2008 and 2014, and the proportion of children of school age attending basic education also increased. Poorer socioeconomic groups have benefitted the most from this trend. For example, the share of children of school age from the poorest 20 percent of households who were attending school increased from 86 to 94 percent between 2002 and 2013.

However, the reforms have so far led to only modest improvements in learning outcomes. The Philippines last participated in an international learning assessment in 2003. The results showed that the quality of education in the country was low, with only around one-third of elementary and secondary school students being able to reach the lowest international benchmark in mathematics. Since 2003, the results from national examinations suggest that there have been only limited improvements in levels of learning.

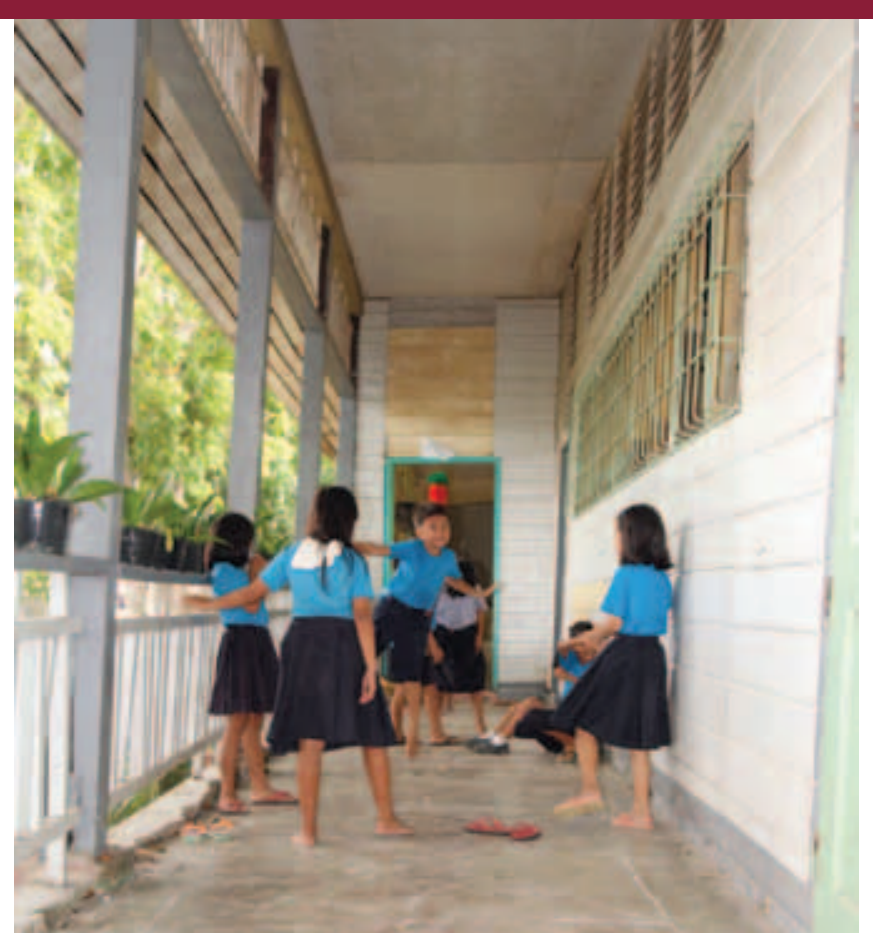

While there have been improvements in education sector outcomes, significant challenges remain if the government's goals for the education sector are to be realized. Despite some recent progress, socioeconomic disparities in access to basic education opportunities persist. For example, in 2013, 82 percent of 12 to 15 -year-old children from the wealthiest 20 percent of households attended high school compared with only 53 percent of children from households in the poorest 20 percent. Moreover, elementary and high school completion rates are relatively low, with the latest data suggesting that almost a quarter of all enrollees fail to complete. These challenges are compounded by the low quality of the basic education system. Employers frequently highlight the limitations of recent basic education graduates, and this points to the need to improve the quality of teaching and learning in elementary and high schools across the Philippines.

Key to tackling these challenges will be further increases in public education spending. While recent increases have been impressive, the Philippines still spends less on education than many of its neighbors and many other middle-income countries. In 2014, the Philippines devoted just under 3 percent of its national income to public basic education compared with an average of nearly 5 percent for lowermiddle-income countries as a whole. Recent detailed studies of education spending in the Philippines have confirmed the need for more spending to enable existing schools to meet national education norms and standards. 


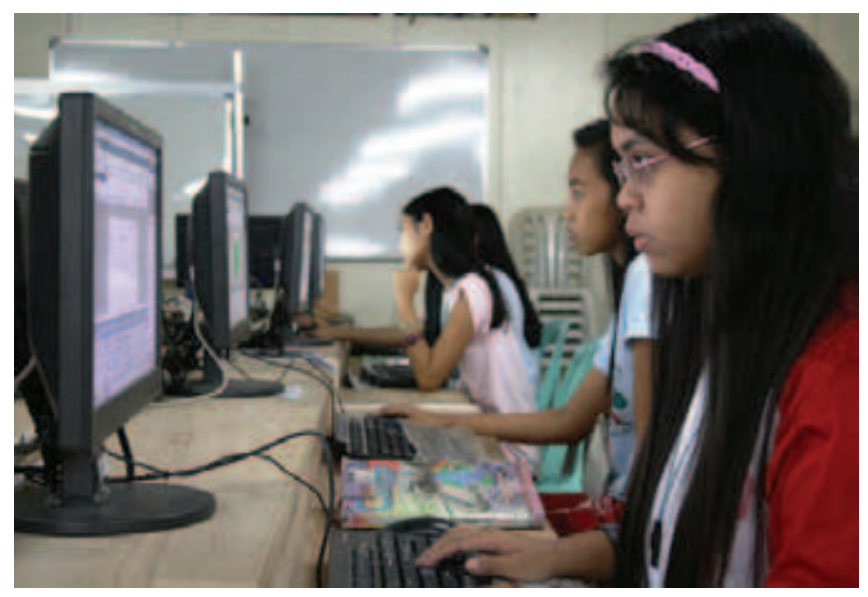

Ensuring that public systems allocate and use resources effectively will be a vital element in translating increases in public sector investment into improved education outcomes. A number of recent studies have highlighted weaknesses in these systems that may reduce the effectiveness of recent and future increases in sector spending. In 2013, budget execution rates in the education sector were lower than they were in 2009 and were very low for some key education inputs such as capital outlays, school maintenance, and operating expenses. Several factors have been identified as being behind these low execution rates including bottlenecks in the flow of funds, difficulties at the school level in managing public funds, and inadequate coordination between the relevant government agencies.

Inefficient and ineffective spending has compounded low execution rates to further weaken the impact of increased education spending on outcomes. A recent public expenditure review highlighted some possible areas of inefficiency in government education spending, including the complexity of and lack of transparency in fund allocations, rigid allocation norms, and poor school governance.' It also concluded that more detailed research was needed to estimate the magnitude of spending inefficiencies and to identify where the main bottlenecks in the government's financial managements systems lie.

The introduction of senior high school will only add to the existing pressures faced by public financial management systems. In 2016, senior high school will be introduced, and approximately 1.5 million additional school places will need to be provided for children entering Grade 11 for the first time. This will require the hiring of approximately 60,000 additional teachers and the building of a similar number of new classrooms. It is therefore vital that the systems that allocate resources, build new infrastructure, and recruit new teachers work effectively. Otherwise the success of the senior high school program and the whole $\mathrm{K}$ to 12 reform program will be jeopardized.

The purpose of this study is to assess the quality of basic education services and the systems used to allocate and manage public education resources. While small-scale qualitative studies have been conducted to look at particular public funding flows, there has been no previous attempt to comprehensively assess the strengths and weaknesses of the systems that manage and govern the use of public education funding. This study aims to fill this gap and to provide detailed evidence on the extent to which these systems are effective in handling key items of public spending. The study also aims to provide a snapshot of the availability and quality of key education inputs at the school level and to evaluate whether these resources are distributed equitably across schools.

\section{Main Research Questions and Key Education Inputs Tracked}

The Philippines Public Education Expenditure and Quantitative Service Delivery Study (PETS-QSDS) emerged from a request to the World Bank from the Department of Education (DepEd) and the Department of Budget and Management (DBM). DepEd and the DBM wanted the Bank to assess whether the large budgeted increases in public education spending were being used effectively to improve conditions in public elementary and high schools. The detailed design of the study was developed during a series of consultations between the Bank's study team and key representatives of DepEd, the DBM, the National Economic and Development Authority (NEDA), and the Affiliated Network for Social Accountability (ANSA) as well as with a range of academics working on the Philippines education system.

Through these consultations, it was agreed that the study would explore four broad issues associated with the delivery of public basic education services in the Philippines: 
1. Resource flow, management and control. What factors prevent or delay resources from reaching their intended destination in a timely and transparent manner?

2. Existence, use, and financing of inputs at school. Do schools have access to essential inputs and how effective are systems that govern their use?

3. Equity. How do the resources available to schools and the systems managing these resources differ among regions and socioeconomic groups?

4. School performance and resources. How and why does the performance of schools differ and what drives those differences?

Both the consultations with key stakeholders and practical considerations resulted in an agreement to track four key areas of the central government budget as part of the study:

- New teachers and teacher salaries

- Teacher training resources, specifically those from the Human Resource Training and Development Fund (HRTD) and In-Service Training (INSET)

- School maintenance and other operating expenses (MOOE)

- Infrastructure spending from the Basic Education Facilities Fund and the School Building Program.

The funds tracked by the study cover the bulk of national government funding for basic education (Figure 1). However, the tracking of teacher remuneration differed from more traditional public expenditure tracking exercises. It focused on whether teachers in schools were paid on time and in full rather than on identifying whether all teachers on the payroll were teaching in their assigned schools. ${ }^{3}$ Given the importance of recruiting new teachers to address existing shortfalls and to staff the senior high school program, the study also focused directly on hiring and deployment systems.

In addition to looking at central government resource flows, the study also tracked local government support to basic education. The Special Education Fund (SEF) is the source of the majority of local government spending on basic education and is funded by a 1 percent surcharge on property taxes. In 2013, local governments contributed about 6 percent of total public education funding in the Philippines.

\section{Figure 1: The Study Tracks a Large Proportion of the National Education Budget}

Breakdown of the Department of Education (DepEd) budget, 2015

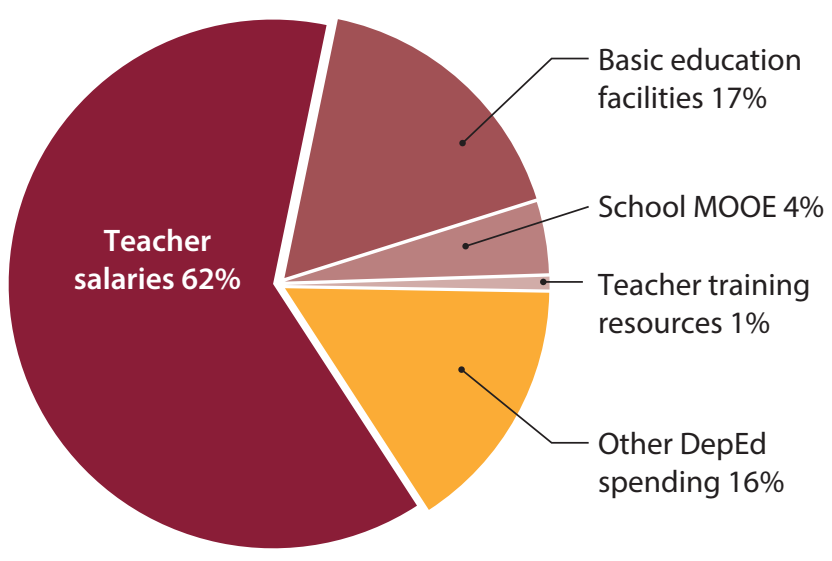

Source: DepEd Statement of Appropriations, Obligations, and Disbursements, 2015

Note: Shares are based on 2015 appropriations.

A number of other resource flows were excluded from the study for practical reasons. DepEd has a number of special programs (such as multigrade programs and special programs for science, arts, and sports) that were mentioned during consultations for the study as areas that might be tracked. However, they were excluded on the grounds that they are small in terms of the overall allocation of resources and that their impact on access and quality across the entire school age population was likely to be limited. Furthermore, including these programs and their limited number of beneficiary schools would have added to the complexity and size of the school sample for the study. Other research projects such as the series of program reviews that DepEd is currently undertaking may be better suited to assessing the effectiveness of these programs.

\section{Study Approach}

A clear diagnosis of the systems governing resource allocation decisions is a necessary first step to increasing the efficiency of public spending. ${ }^{4}$ This study combined the tracking of public resources with an assessment of the quantity and quality of education services to:

- Examine the efficiency of public education spending and the incentives associated with service delivery. 
- Identify the main weaknesses in education governance and develop strategies to increase the effectiveness of education spending.

- Support efforts to make the resource allocation system more accountable and performance-oriented.

- Act as a baseline to assess the impact of future education reforms. $^{5}$

Many countries have undertaken similar public education expenditure and quantitative service delivery studies (PETSQSDS) as can be seen in Table 1. This study draws on the tools and experiences from those many earlier studies as well as from a series of notes produced by the World Bank as guidance for implementing studies of this kind. ${ }^{6}$

A key objective of this study was to track the flow of national and local government education funding all the way down to schools (Figure 2). In order to do this, it was necessary first to identify appropriate questions and then to prepare questionnaires to collect data on the release of funds from all involved agencies, including the various offices of the Department of Education (DepEd), the Department of Budget and Management (DBM), and the Department of Public Works and Highways (DPWH). In most cases, questionnaires were prepared for the central, regional, and division/district offices of these departments (Table 2). The questionnaires were based on an analysis plan prepared by the study team through a series of field visits to many areas in the Philippines and interviews with key respondents to identify the information needed to answer the study's research questions. The team pre-tested and piloted the questionnaires as part of the final preparations for the survey. While the responses to this set of questionnaires were the main data source for the study, the team also collected information from the central offices of key government agencies (such as DepEd and the DPWH) as well as from a number of other sources to present a fuller picture of the flow of education funds?

The Research Center for Teacher Quality at the Philippines Normal University prepared a set of teacher assessments for Grade 6 and 10 teachers for the study. These assessments included subject-based content assessments to measure teachers' knowledge of $\mathrm{K}$ to 12 curriculum content in English, Filipino, Mathematics, and Science. They also included a short version of the Philippine Government's

\section{Table 1: Examples of Education Tracking and Service Delivery Surveys}

\begin{tabular}{lcl}
\hline Country & Year & \multicolumn{1}{c}{ Objectives } \\
\hline Zambia & $\begin{array}{c}\text { 2002, 2006, } \\
\text { and 2014 }\end{array}$ & $\begin{array}{l}\text { To determine the availability of key education inputs at the school level and track school } \\
\text { grants from the central government to schools }\end{array}$ \\
\hline Uganda & 1996 & To assess why increased public expenditure has not led to improved outcomes \\
\hline Mongolia & 2006 & To assess equity and regional disparities in the quality of education \\
\hline $\begin{array}{l}\text { Cambodia } \\
\text { Lapua New }\end{array}$ & 2005 & $\begin{array}{l}\text { To assess the effectiveness of the Priority Action Program in delivering resources to schools } \\
\text { in a timely manner }\end{array}$ \\
\hline $\begin{array}{l}\text { Guinea } \\
\text { Honduras }\end{array}$ & $\begin{array}{l}\text { To assess whether recent policy reforms and increases in spending have improved education } \\
\text { outcomes }\end{array}$ \\
\hline $\begin{array}{l}\text { Bangladesh } \\
\text { 2001 }\end{array}$ & $\begin{array}{l}\text { To explore incentives for front-line service delivery workers and issues of teacher } \\
\text { deployment, transfer, and attendance }\end{array}$ \\
\hline $\begin{array}{l}\text { To track public expenditure from the central government to schools and students (for } \\
\text { example, through stipend programs) and to explore the relationship between school } \\
\text { resources, leakage of funds, and school performance }\end{array}$ \\
\hline
\end{tabular}

Sources: Financial Management Reform Program (2005) "Social Sector Performance Surveys: Secondary Education in Bangladesh: Assessing Service Delivery" OPM and FMRP, Dhaka; Financial Management Reform Program (2006) "Social Sector Performance Surveys: Primary Education in Bangladesh: Assessing Service Delivery" OPM and FMRP, Dhaka; World Bank (2005). "Public Expenditure Tracking Surveys (PETS) in Primary Education” Washington D.C.; Howes, S, A. Mako, A. Swan, G. Walton, T. Webster, and C. Wiltshire (2014) "A lost decade? Service delivery and reforms in Papua New Guinea 2002 -2012", The National Research Institute and the Development Policy Centre, Canberra; World Bank (2009) "Implementing Public Expenditure Tracking Surveys for Results: Lessons from a Decade of Global Experience. Washington D.C; and World Bank (2016). "Education Sector Public Expenditure Tracking and Service Delivery Survey in Zambia"Washington, DC 


\section{Figure 2: Flow of Public Funds to Schools}

\section{LEVEL}

NATIONAL

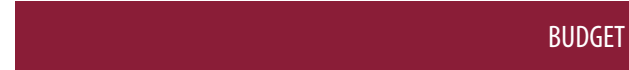

REGIONAL

PROVINCIAL/

DIVISION

SCHOOLS
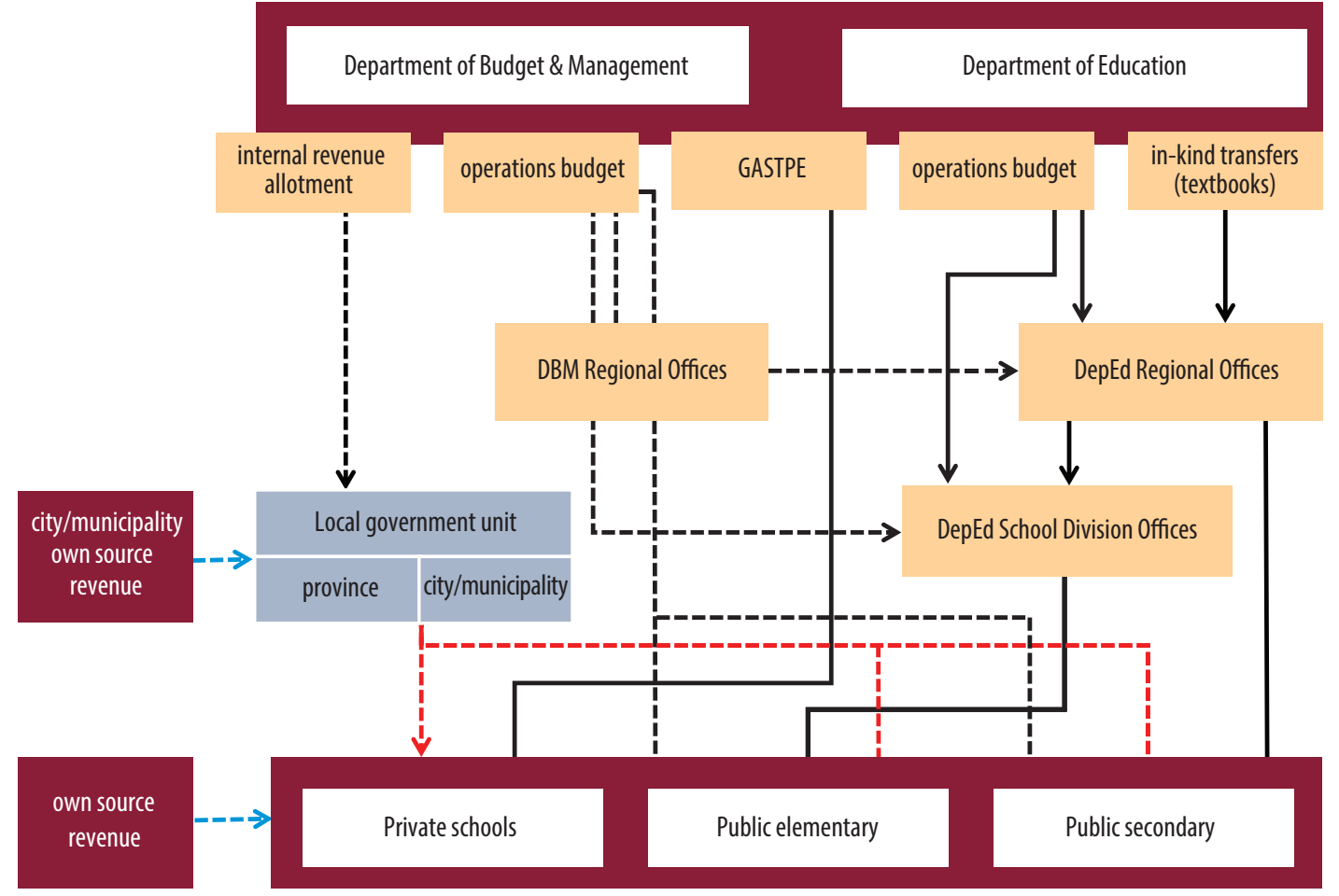

ran
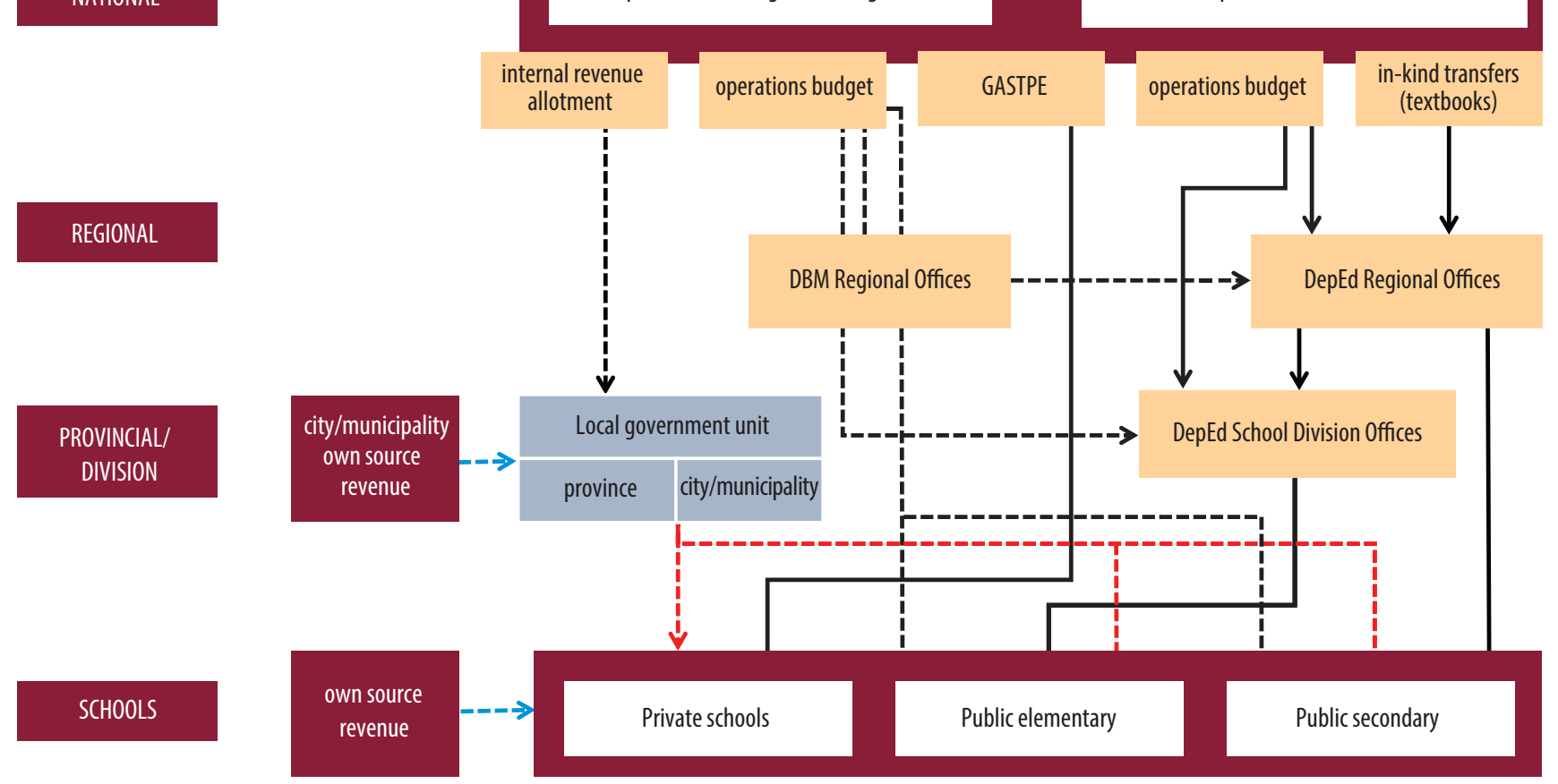

Note: GASTPE - Government Assistance for Students and Teachers in Private Education.

Teacher Strengths and Needs Assessment (TSNA) based on the National Competency Based Teacher Standards (NCBTS). The TSNA assesses teachers' perceptions of their pedagogical competence in the seven NCBTS domains; (i) social regard for learning; (ii) learning environment; (iii) diversity of learners; (iv) curriculum; (v) planning, assessing, and reporting; (vi) community links; and (vii) personal growth and development. ${ }^{8}$

A nationally representative sample of public elementary schools and high schools provided the starting point for the study. ${ }^{9}$ Schools in the Autonomous Region in Muslim Mindanao (ARMM) were excluded from the study because the public financial management system in this region differs from the norm, and a public education expenditure review had recently been completed for the region. A stratified, clustered sample was designed in which the primary sampling units were cities and municipalities. In total, 10 highly urbanized cities out of 34, (three in the National Capital Region, Davao City, and six others), 10 other cities out of 142, and 30 municipalities out of 1,339 were sampled. ${ }^{10}$ With the exception of Davao City, which was selected with certainty, all primary sampling units were selected with probability proportional to their population size. In each city or municipality, up to five elementary schools and five high schools were selected randomly from a list of eligible public schools." This sampling approach yielded a nationally representative (excluding ARMM) sample of 250 public elementary and 250 public high schools. Once the sample of elementary and high schools had been selected, the team identified the relevant local and national government offices that supported these schools in order to interview them for the survey.

A random sample of kindergarten, Grade 6, and Grade 10 teachers was also selected to be interviewed. These sampled teachers also completed a subject content test and a strengths and weaknesses assessment. A random sample of student households, stratified by a student's absence on the day of the school visit, was also selected during the school visits to verify student numbers and to collect information 
Table 2: Survey Questionnaires, Contents, and Key Respondents

\begin{tabular}{|c|c|c|}
\hline Questionnaire & Respondents & Description of Types of Information Collected \\
\hline DBM regional offices & Chief budget specialist & Fund releases for DepEd divisions and schools \\
\hline $\begin{array}{l}\text { DepEd regional } \\
\text { offices }\end{array}$ & $\begin{array}{l}\text { Regional director, payroll officer, and } \\
\text { accountant }\end{array}$ & $\begin{array}{l}\text { The receipt, transfer, monitoring, and management } \\
\text { of funds. }\end{array}$ \\
\hline $\begin{array}{l}\text { Local governments } \\
\text { (provincial and city/ } \\
\text { municipality) }\end{array}$ & $\begin{array}{l}\text { Local school board member and } \\
\text { budget officer }\end{array}$ & $\begin{array}{l}\text { Cash and in-kind resources provided to schools and in } \\
\text { coordination with DepEd. }\end{array}$ \\
\hline DepEd divisions & $\begin{array}{l}\text { School division superintendent, } \\
\text { education supervisors, accountant, } \\
\text { auditor, and other key staff }\end{array}$ & $\begin{array}{l}\text { Division office facilities and personnel, characteristics of } \\
\text { education services and financing, teacher training activities, } \\
\text { new teacher hiring, detailed information on funding (such } \\
\text { as MOOE) to the sampled schools. }\end{array}$ \\
\hline $\begin{array}{l}\text { DPWH district } \\
\text { engineering offices }\end{array}$ & $\begin{array}{l}\text { Engineer in charge of DepEd projects } \\
\text { and accountant }\end{array}$ & $\begin{array}{l}\text { Management and coordination with DepEd. Receipt } \\
\text { of school infrastructure funds and status of projects in } \\
\text { sampled schools. }\end{array}$ \\
\hline DepEd districts & Public schools district supervisor & $\begin{array}{l}\text { Coordination and effectiveness of local school boards, } \\
\text { supervision and management of the provision of textbooks } \\
\text { and learning materials. }\end{array}$ \\
\hline Schools & $\begin{array}{l}\text { School principal, custodian, physical } \\
\text { facilities officer }\end{array}$ & $\begin{array}{l}\text { School revenue and expenditure from all sources, } \\
\text { receipt and use of school MOOE funds, details of school } \\
\text { infrastructure projects, school characteristics and } \\
\text { organization, student attendance, classroom conditions. }\end{array}$ \\
\hline $\begin{array}{l}\text { Parent-teacher } \\
\text { associations }\end{array}$ & President & $\begin{array}{l}\text { Activities of the PTA and support to sampled school, } \\
\text { revenue and expenditure accounts. }\end{array}$ \\
\hline $\begin{array}{l}\text { Teachers (DepEd and } \\
\text { LGU hired) }\end{array}$ & $\begin{array}{l}\text { Kindergarten, Grade } 6 \text {, and } \\
\text { Grade } 10 \text { teachers }\end{array}$ & $\begin{array}{l}\text { Education, experience, training history, and salary } \\
\text { information. }\end{array}$ \\
\hline Teacher assessments & Grade 6 and 10 teachers & $\begin{array}{l}\text { Subject knowledge (in English, Filipino, Mathematics, and } \\
\text { Science) and teacher strength and needs assessments. }\end{array}$ \\
\hline Student households & Household head & $\begin{array}{l}\text { Socioeconomic background, student education } \\
\text { background, and the direct and indirect costs of education. }\end{array}$ \\
\hline
\end{tabular}

on the socioeconomic status of students attending the sampled schools. After the fieldwork had been completed, appropriate sample weights were calculated for each level of the survey.

Fieldwork for the study was undertaken between September and December 2014. Enumerators were trained by a team from the World Bank and the survey firm over a two-week period, which included training sessions held in the relevant government offices and schools in a pilot division. Field team leaders were responsible for ensuring the quality of the interviews and of the information collected by their teams. A series of quality control checks was included in each questionnaire to help enumerators and field team leaders to identify any inconsistencies in the data collected. One field supervisor was responsible for the survey in each of the three island groupings of the Philippines, and they also checked information from their teams regularly during the fieldwork. In addition, a team of nine "back checkers" also carried out checks on 30 percent of all of the questionnaires completed 
in the survey. Members of the survey team also conducted a number of monitoring visits to sampled municipalities and cities during the course of the fieldwork to check the quality of fieldwork and to assess progress.

The final sample ended up being similar in size to the original plan except in the case of public high schools and local governments (Table 3). A number of sampled municipalities did not have five public high schools and, in those cases, all high schools in the municipality were selected. A number of local governments were also not interviewed, primarily either because they refused to be interviewed or because the key personnel were not available to provide the necessary information.

The firm implementing the survey encoded the data collected from the fieldwork using pre-prepared data entry scripts. The resulting datasets went through a rigorous data checking and cleaning process conducted jointly by the study team and the implementing firm. The final cleaned datasets were available in November 2015. The survey team consulted with key government agencies throughout the implementation of the survey to facilitate their visits and to verify the collected data.

During the preparation for the study, the team agreed with DepEd and the DBM to present its survey results in a series of short policy notes that would each highlight a particular priority area for the government. It was also agreed that the team would present the initial findings and policy recommendations in each policy note to stakeholders in workshops in order to get feedback before finalizing each note. These workshops took place between September 2015 and March 2016. They were attended by DepEd staff from the central, regional, and division offices as well as by teachers and school principals. The DBM and NEDA staff responsible for education in the central and regional offices attended the presentations and provided feedback. Other members of the wider education community, including academics in the Philippines and researchers from other countries working on education in the Philippines, also provided feedback on the findings contained in the notes.

\section{Table 3: Planned and Final Sample Sizes}

\begin{tabular}{lcc}
\hline Questionnaire & Planned sample size & Final sample size \\
\hline DBM Regional Offices & 16 & 16 \\
\hline DepEd Regional Offices & 16 & 16 \\
\hline DepEd Division Offices & 50 & 51 \\
\hline DepEd District Offices & $* *$ & 113 \\
\hline DPWH District Offices & $* *$ & 54 \\
\hline Provincial Local Governments* & 30 & 27 \\
\hline City/Municipal Local Governments & 50 & 47 \\
\hline Public Elementary Schools & 250 & 249 \\
\hline Public High Schools & 250 & 200 \\
\hline Teachers (Kindergarten and Grade 6) & Max (1,250) & 608 \\
\hline Teachers (Grade 10) & Max (1,500) & 946 \\
\hline Parent-teacher associations & 500 & 449 \\
\hline Student households & 2,500 & 2,189 \\
\hline
\end{tabular}

Notes: * Since HUCs and other cities do not have a provincial-level local government unit (LGU), only 30 provincial LGUs were sampled. ** The sampling of district-level offices depended on which schools were selected. All DepEd and DPWH offices associated with the sampled schools were identified and interviewed. The final sample size indicates the number that can be used for analysis after accounting for adjustments and non-responses. 


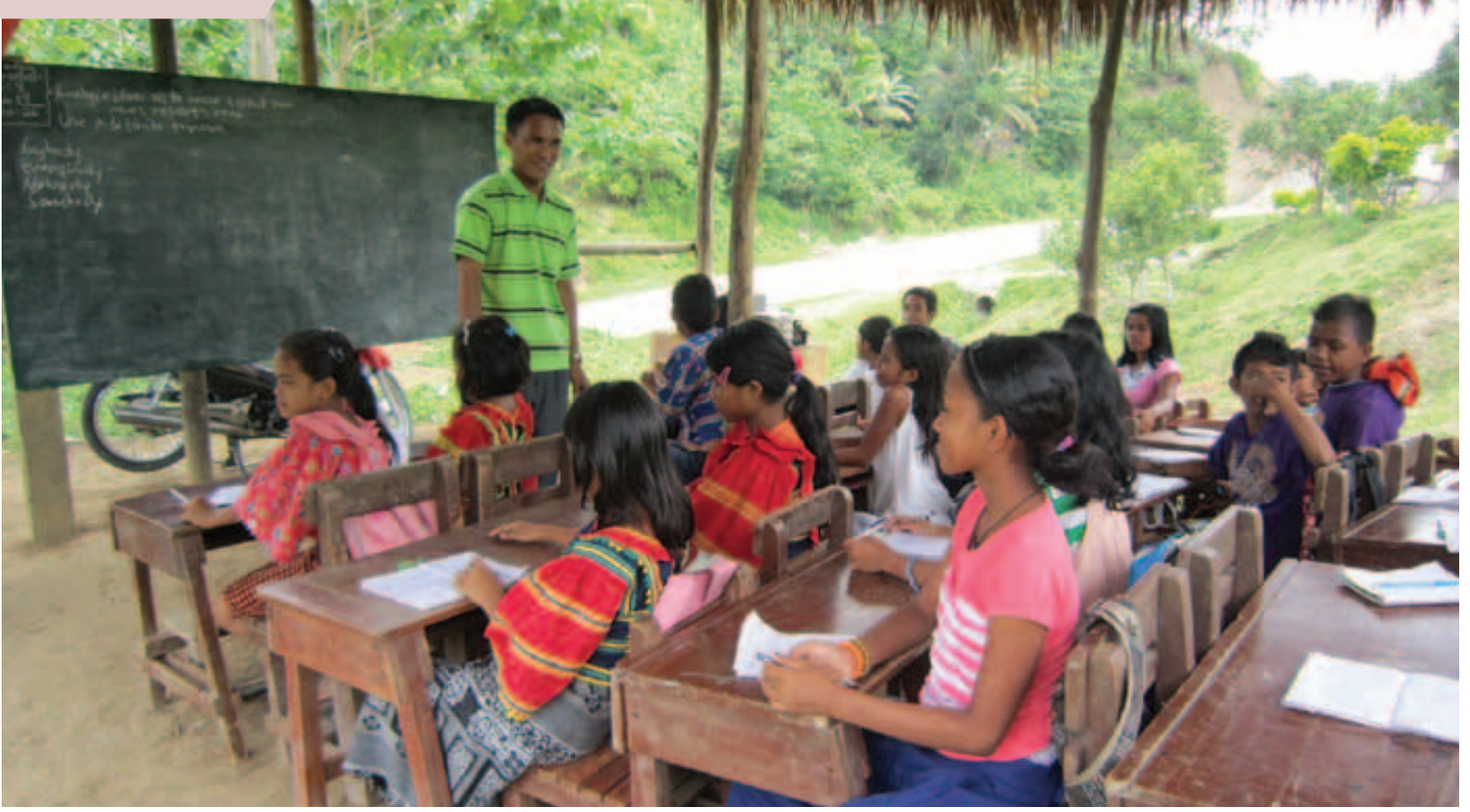

\section{Outline of the Report}

The next chapter provides the context of the study and documents recent trends in basic education spending. It also shows in detail how recent spending increases have affected education outcomes.

In line with agreements between the study team and key stakeholders while the study was being designed, the findings are presented as a series of seven policy notes:

Policy Note 1: Assessing Systems for Hiring and Deploying Teachers reports on new teacher allocations, hiring processes, and salaries.

Policy Note 2: Developing a Proficient and Motivated Teacher Workforce reports on the funds available for and the provision of professional development opportunities for teachers.

Policy Note 3: Building Better Learning Environments reports on school infrastructure spending.

Policy Note 4: Assessing School-based Management evaluates how well school-based management institutions and processes are working.
Policy Note 5: Providing Schools with Adequate Resources to Deliver Quality Education reports on the provision and use of funds to cover school maintenance and operating expenses (MOOE).

Policy Note 6: Assessing the Role Played by Local Government in Supporting Basic Education reports on the funding provided for basic education by local governments.

Policy Note 7: Understanding the Drivers of Public School Performance and Efficiency examines school efficiency and explores associations between efficiency, performance, and the explanatory factors highlighted in the other policy notes.

Finally, a short conclusion draws together the key findings and policy recommendations contained in the separate policy notes. 


\section{Endnotes}

1 World Bank and AusAID (2010). "Philippines Basic Education Public Expenditure Review." World Bank and AusAID, Manila.

2 School-based management grants were also included in the study but relatively few schools receive these grants and the data that were collected as part of the study were not representative of the grants as a whole.

3 This was partly the result of the team's discussions with the Department of Education and the Department of Budget and Management on priorities for the study. Elementary school teachers are also not allocated to specific schools so it is not possible to track teacher posts in the way that other studies of this kind have done.

4 Dehn, J., R. Reinnikka, and J. Svensson. (2003). "Survey Tools for Assessing Performance in Service Delivery" in F. Bourguignon and L. A. Pereira da Silva Evaluating the Poverty and Distributional Impact of Economic Policies. World Bank and Oxford University Press, Washington D.C.; Gauthier, B. (2006). "PETS-QSDS in SubSaharan Africa: A Stocktaking Study."World Bank, Washington D.C.; and Savedoff, W. (2008). "Public Expenditure Tracking Surveys: Planning, Implementation, and Uses." Social Insight, Maine.

5 A more detailed description of the survey methodology and approach appears in Annex 1.
6 The PETS-QSDS data portal is available at: http://pets.prognoz. com/prod/Home.aspx.

7 See Annex 1 for a full list of these additional sources.

8 Full details of the instruments, their preparation, and fieldwork organization is available in RCTQ and SiMERR (2015) "PETS-QSDS Final Report" Research Center for Teacher Quality, Manila.

9 The study team developed the sampling approach in consultation with an international expert in sampling with considerable experience of designing appropriate samples for the Living Standards Measurement Survey and other public expenditure tracking and service delivery surveys.

10 Highly urbanized cities are cities with populations of more than 200,000 and with average revenues of at least PHP 50 million in 1991 prices. Other cities are defined as cities that do not meet the criteria to be classified as highly urbanized. Municipalities are administrative units for all other areas in the Philippines.

11 Integrated schools were not included in the sample frame - there were 164 schools of this kind in 2013/14 classified as elementary schools and 568 at the high school level. Elementary or high schools that did not offer all grades were also excluded as were 350 special high schools that followed a different curriculum. 


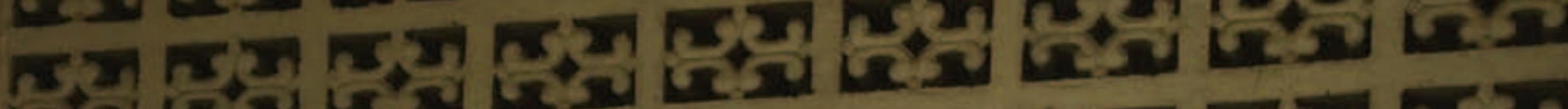

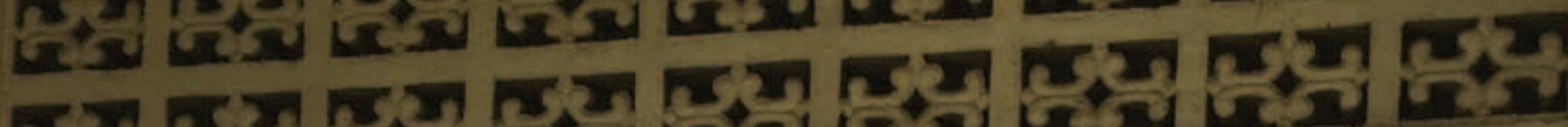

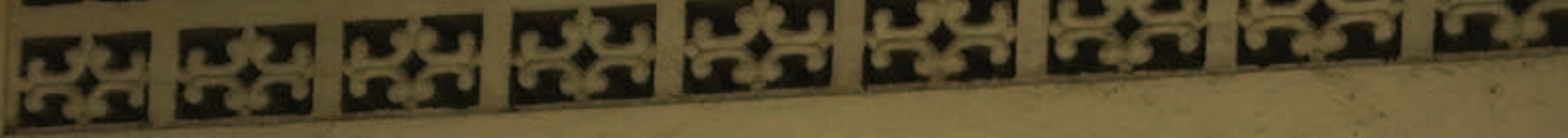
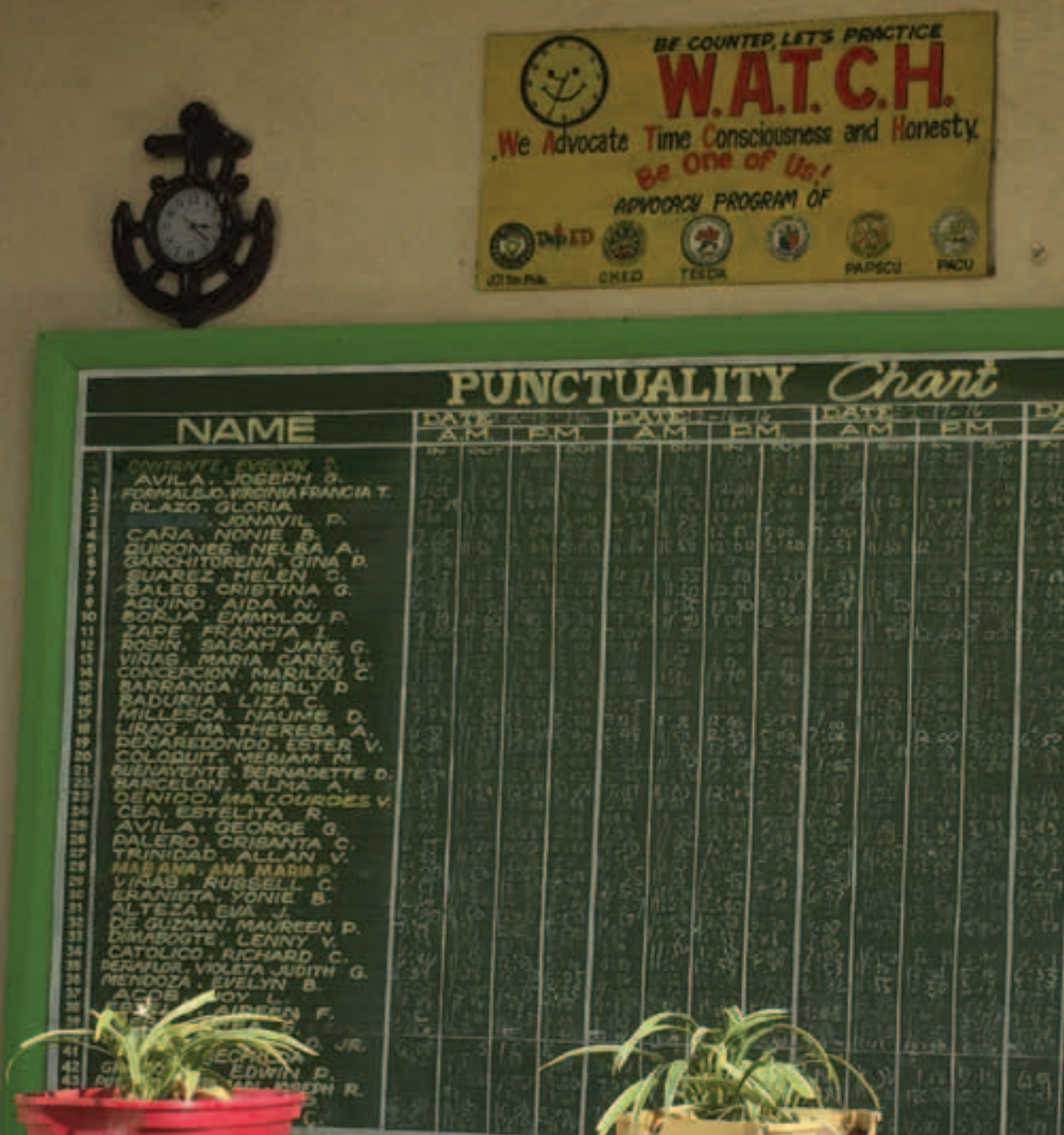

PUNCTUALITY Chant

SOHDOLYEAR:

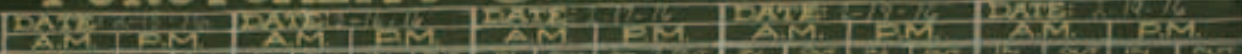

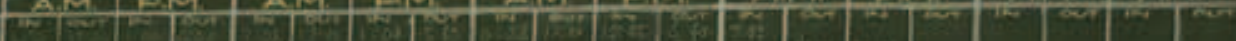
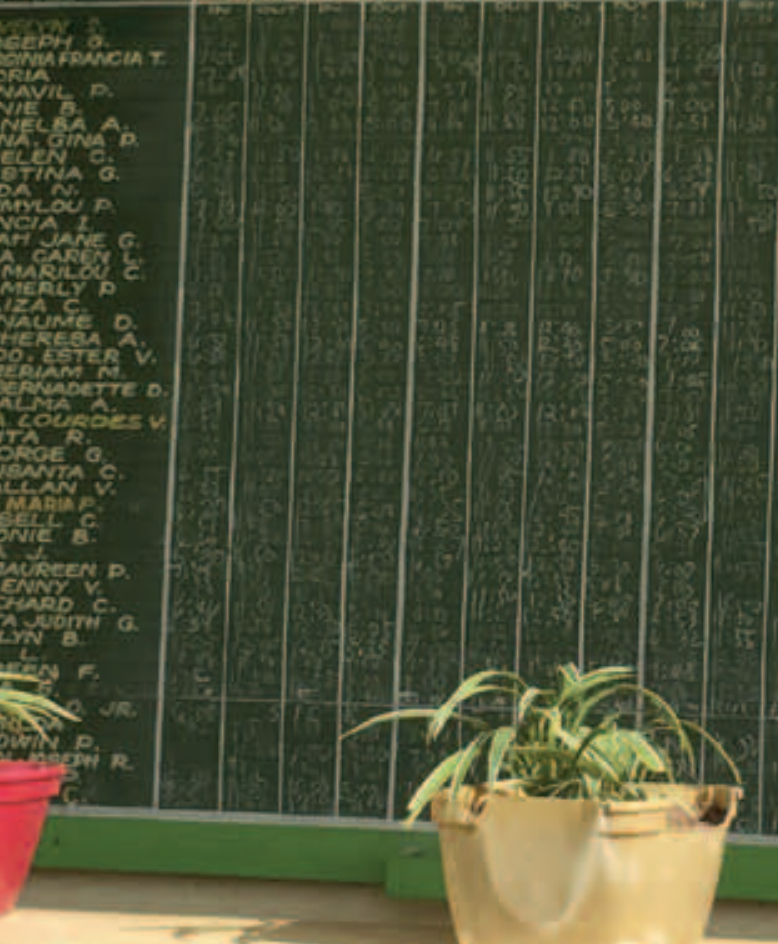


\section{Basic Education Spending Trends and Outcomes}

\section{Introduction}

Over the last decade, the Government of the Philippines has embarked on an ambitious education reform program to ensure that all Filipinos have the opportunity to obtain the skills that they need to play a full and productive role in society. The government has backed up these reforms, particularly over the last five years, with substantial increases in investment in the sector. As a result, access to basic education has increased, particularly for the poorest households, and the overall learning environment has improved.

While these improvements have halted a long-term decline in education sector outcomes, significant challenges remain. In particular, the share of national income devoted to basic education has only recently returned to the levels of the early 2000s, and spending per student in the Philippines is still low compared to spending in other middle-income countries. These relatively low levels of spending per student are likely to have limited the scope of the improvements in education outcomes over the last decade. High school completion rates remain low compared with other countries in the region, and enrollment gaps among different socioeconomic groups persist. Stakeholders frequently express concerns about the quality of the education provided and about the level and breadth of skills that children possess when they leave school.

The purpose of this note is to investigate whether the recent increases in the financing for basic education have improved education outcomes and to identify any factors that may be constraining the effectiveness of public spending. It concludes that further increases in public spending will be needed if the government's ambitious goals for the education sector for the next five years are to be achieved. However, increased investment will not be enough on its own. It will also be necessary to ensure that these resources are used effectively.

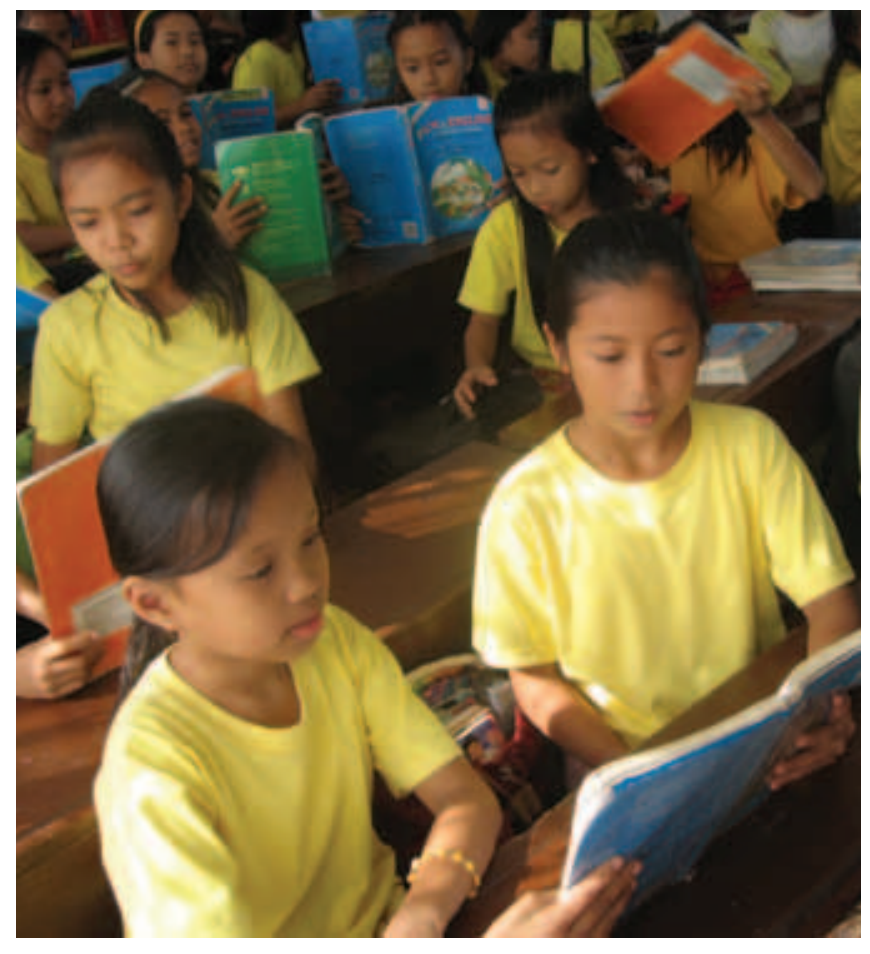

\section{How Has Public Education Expenditure Changed Over the Last 12 Years?}

In the first half of the 2000s, government spending on basic education fell in real terms. Between 2003 and 2005 basic education spending fell from PHP 166 billion to PHP 152 billion (in 2014 prices). The share of national income devoted to education also fell from 2.4 percent to 1.9 percent over the same period. Moreover, the decline in education spending led to significant drops in the level of per student funding. Between 2003 and 2005 average annual spending per public elementary and high school student fell from PHP 9,500 to PHP 8,700 in real terms.'

This downward trend was halted in 2005, and since then government spending on basic education has increased considerably. Between 2005 and 2014, national 
Figure 1: Public Education Spending Has Risen Rapidly in Recent Years

Government Spending on Basic education, 2003 to 2015 (in 2014 constant prices)

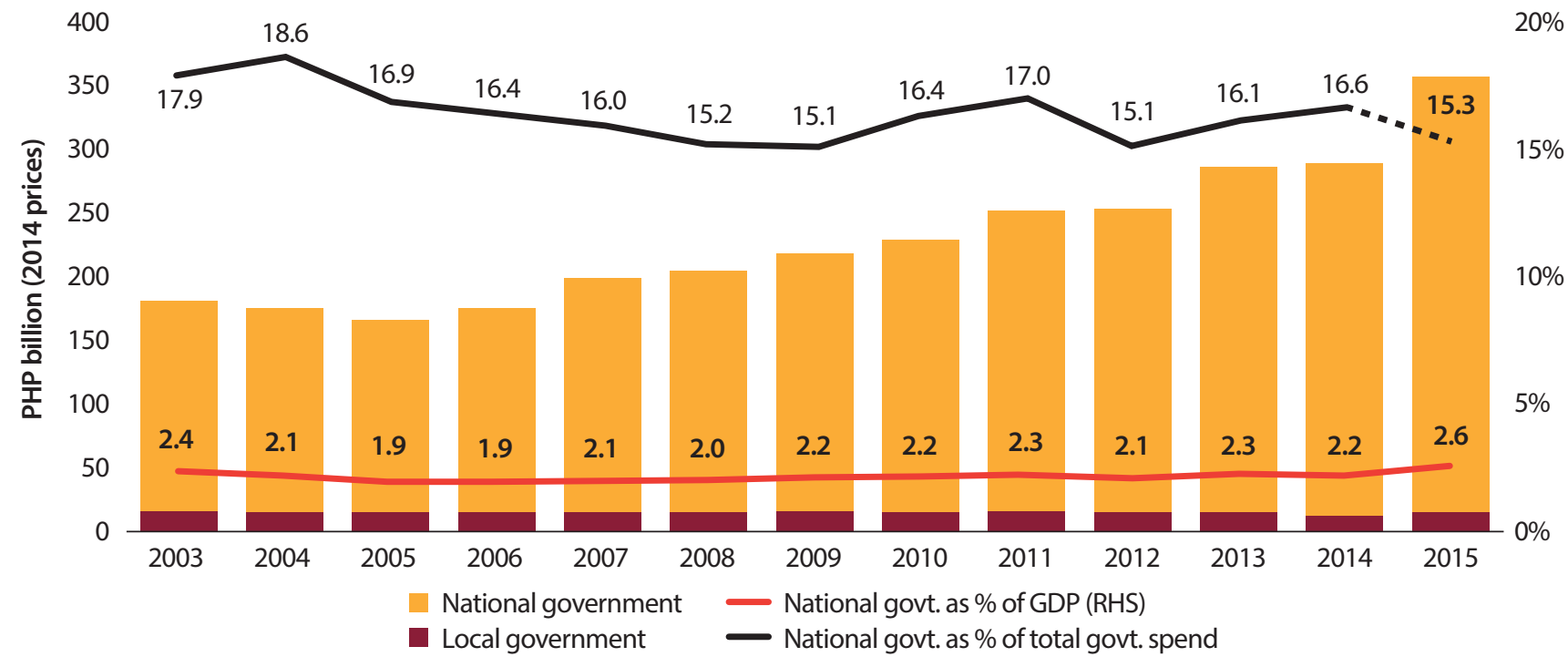

Sources: National government spending - DBM National Expenditure Program. Local government education spending - Bureau of Local Government Finance. GDP and GDP deflator - Philippines Statistics Authority

Notes: Basic education spending data are obligations except for 2015 where adjusted amounts are reported. Basic education refers to the DepEd budget and obligations for the Philippines Science High School. Local government spending figures are obligations but from 2014 only include spending from the Special Education Fund. The total government expenditure figures used to calculate the share of education spending exclude interest payments.

government spending on basic education more than doubled in real terms. The share of national income devoted to education also increased and, by 2014, had reached 2.2 percent of GDP. Spending per student followed a similar pattern; by 2013 average spending per public elementary and high school student was PHP 12,800 in real terms, an increase of almost 50 percent from the level in 2005.

The underlying factors driving the increases in basic education spending can be broken down into two distinct periods. Between 2005 and 2009, education spending rose even though the share of education in total government spending declined from 17 percent to 15 percent (Figure 1). This suggests that the budget increases were driven by rapid increases in the overall government budget rather than any renewed commitment to education itself. After 2009, the drivers of increased spending are less clear though overall budget growth and increases in the share devoted to the education budget both played a role. However, the share of the total budget devoted to basic education in 2014 was still lower than the share that prevailed in the early 2000s.

While the turnaround in government spending has been impressive, the share of national income devoted to basic education has only recently returned to the levels of the early 2000s. Budget forecasts predict that the share of national income devoted to basic education in 2015 will have exceeded 2.4 percent for the first time since 2003.

Spending by local governments makes up only a small proportion of overall basic education spending in the Philippines and has not changed much in recent times (Figure 1). ${ }^{2}$ Local government spending mostly comes from the Special Education Fund (SEF), which is financed from a 1 percent surcharge on property taxes. ${ }^{3}$ Since 2003, local governments have contributed an annual average of PHP 16 billion in basic education funding, but since central government spending has increased rapidly over the same period, local government funding as a share of total education spending has declined rapidly. Between 2003 and 2014 the share of local government spending in total public education spending fell from 9 percent to 5 percent.

Geographical disparities in public basic education spending are quite large and are not strongly associated with levels of poverty. ${ }^{4}$ For example, spending per school-aged child 
in the Philippines varies from around PHP 4,500 in the National Capital Region (NCR) to just over PHP 7,600 in the Cordillera Administrative Region (Figure 2). Moreover, on some disparity measures, these regional differences appear to have increased between 2005 and 2012. ${ }^{5}$ Regional and provincial poverty levels can sometimes provide a useful proxy for the size of educational deficits with those regions or provinces with higher levels of poverty being likely to have weaker education outcomes and thus to require greater education investments. However, in the Philippines, levels of government spending on basic education are only weakly correlated with regional and provincial levels of poverty. For example, Region 12 is one of the poorest regions in the Philippines but receives a budget for basic education that is below the national average (Figure 2).

The public basic education system is also funded by contributions from households and the private sector. Only limited information is available on household contributions to the public education system, but the available evidence suggests that these contributions may be considerable. One limitation is that household surveys cannot distinguish spending on different education levels or on public versus private schools. ${ }^{6}$
Estimates for 2006 based on available sources suggest that household spending might be as high as one-third of government education spending. Partnerships between schools and private sector corporations or NGOs may also be a significant source of funding, but little consistent information is available on these contributions. A recent survey of elementary and high schools found that community and other nongovernment sources contributed approximately 13 percent of average school-level finances in $2010 .{ }^{8}$

Despite recent increases in public education spending, the Government of the Philippines still devotes a smaller share of its national income to basic education than other middleincome countries and its regional competitors (Figure 3). ${ }^{9}$ In 2014, it devoted just under 3 percent of GNP to public education spending compared to a 2012 average for lowermiddle-income countries of nearly 5 percent. In East Asia, the Government of the Philippines devotes a similar share of its national income to education as Cambodia but significantly less than Malaysia, Thailand, and Viet Nam. The low share of national income devoted to education is partly the result of the lower priority given to education by policymakers in the Philippines than in some other countries in the region

\section{Figure 2: There are Large Disparities in Education Spending across the Philippines}

Per Capita Government Spending on Basic Education by Region and Province and Poverty Incidence, 2012
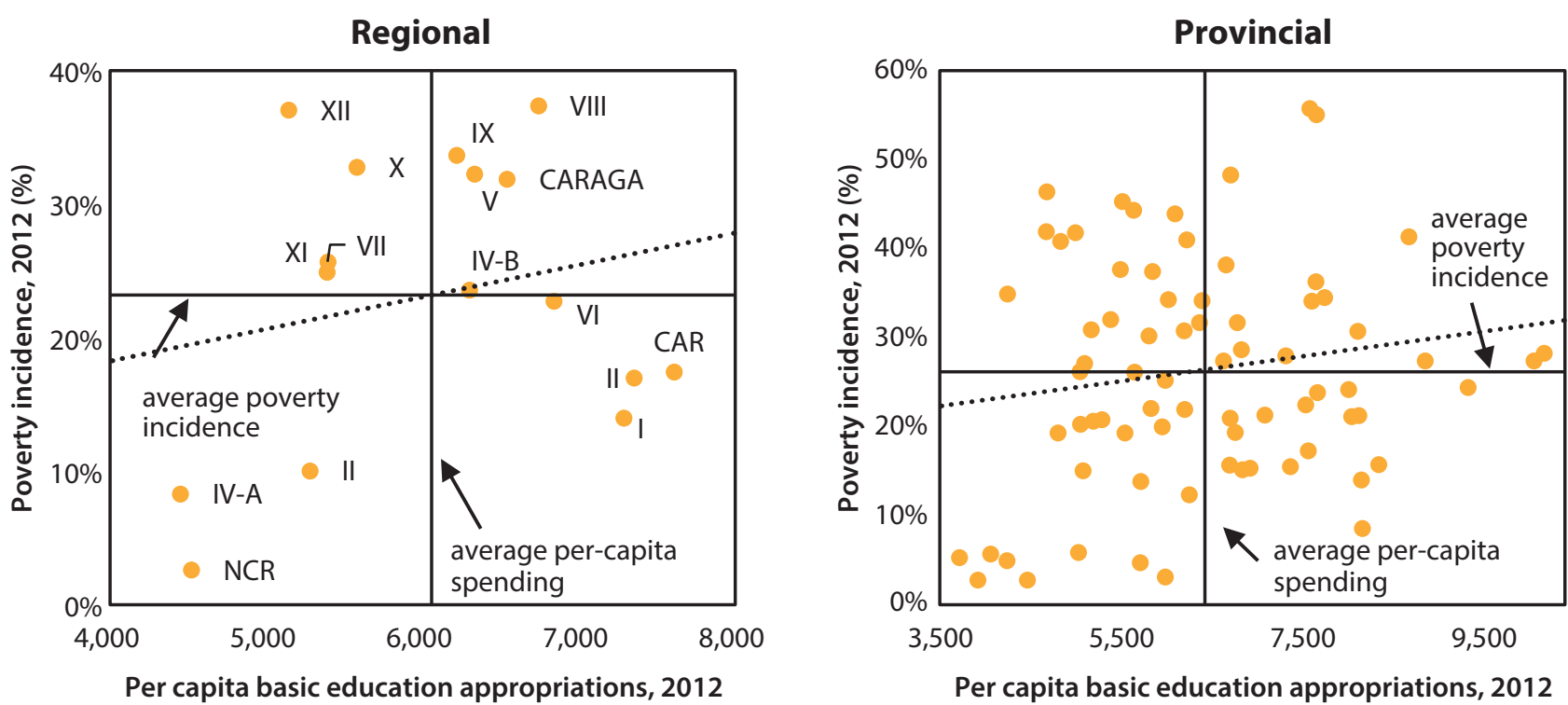

Sources: Poverty incidence and population data come from the Philippines Statistical Authority. Data on appropriations come from the General Appropriations Act.

Note: Per capita basic education appropriations are nominal appropriations per child aged between 5 and 19 . Poverty incidence and appropriations data are for 2012 and population data is for 2010. Autonomous Region in Muslim Mindanao is not included. 
(Figure 3). However, it is also due to the lower share of total government spending in national income in the Philippines than in other comparable countries.

Low overall public education spending has also translated into lower levels of per student spending than in other developing economies. The Philippines spends less per student as a share of per capita GNP than most middleincome countries (Figure 4). Per capita differences also mask significant differences in absolute levels of spending. For example, based on purchasing power parity conversions, the Philippines spent only US\$380 per elementary student compared to US\$760 in Viet Nam and US\$2,350 in Malaysia.

A recent study by the Department of Education (DepEd) explored the question of the resources that will be needed to fund various different expansion and quality improvement scenarios associated with achieving government goals for the sector. ${ }^{10}$ The study highlighted the need for a larger share of GDP to be spent on basic education if it is to be made accessible to all and to ensure modest improvements in education quality. An earlier study by the World Bank and AusAID also showed that it would take more than 6 percent of GDP to implement a broad package of quality improvements coupled with similar enrollment expansion targets as the Department of Education study."

The resources that actually reach schools also tend to be lower than national spending aggregates show. Detailed information collected for the PETS-QSDS study at the school level show that annual school revenue in 2014 was approximately PHP 11,400 (US\$262) for elementary schools and PHP 12,400 (US\$286) for high schools (Figure 5). The vast majority of school level revenue comes from the national government. In 2014, 92 percent of elementary school and 94 percent of high school funding came from the national government budget. Conversely, only around 3 percent of total school revenue comes from local school boards or local governments. Comparing per student revenue at the school level that is provided by DepEd and the overall national education budget suggests that about 80 percent of the national education budget actually reaches the school level.

\section{Figure 3: The Philippines Spends Less on Education than Many Other Countries}

Public Spending on Education as a Share of GNP and Total Government Spending, Selected Countries, 2012
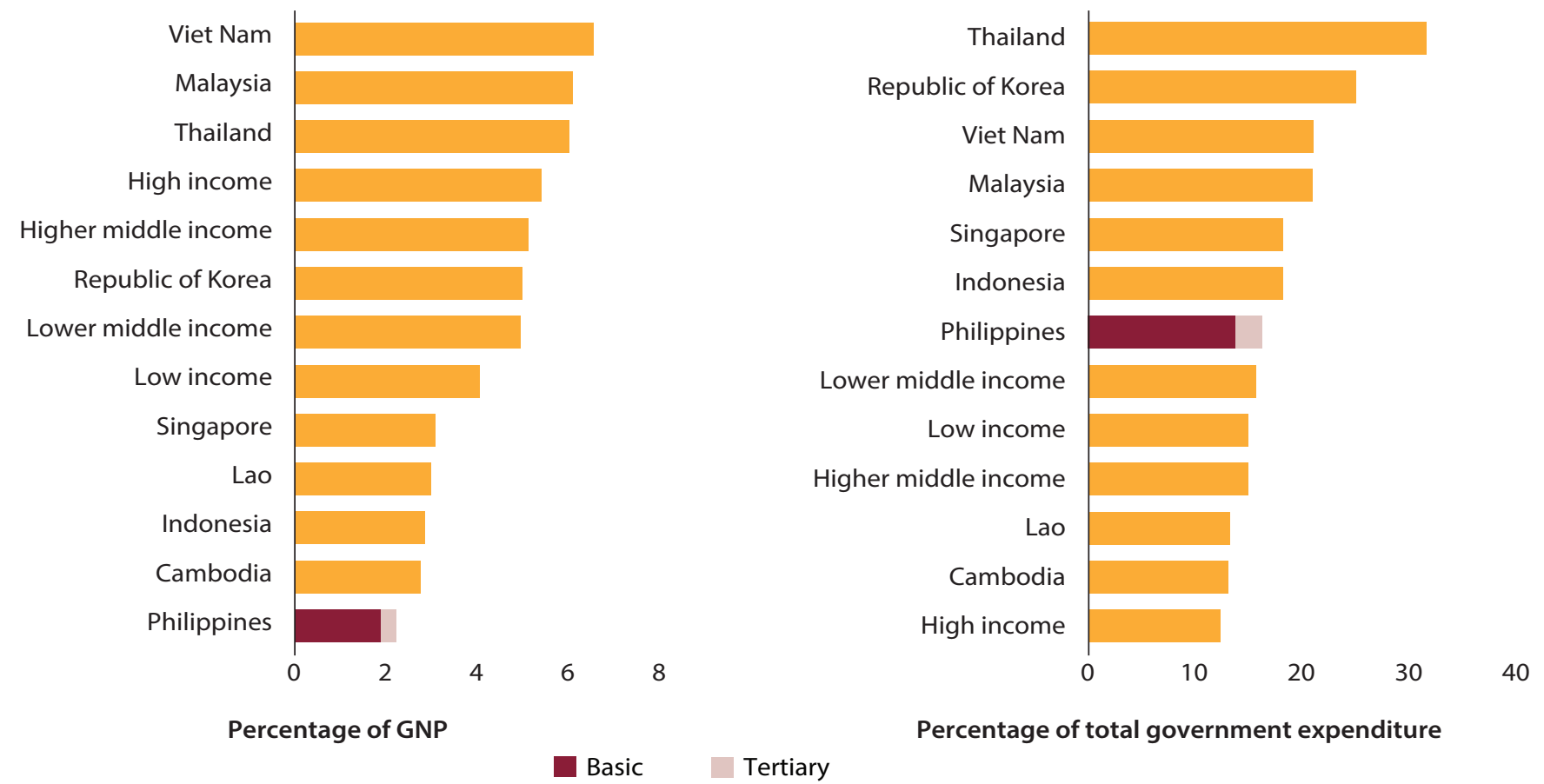

Sources: Figure 1 and UNESCO Global Monitoring Report 2015

Notes: Information for all countries is 2012 or latest year available after 2009. Philippines data are for 2014. Total government expenditure includes interest payments. 
Figure 4: Spending Per Basic Education Student in the Philippines Is Also Low

Government Spending on Education as a Share of GNP, Selected Countries, 2012

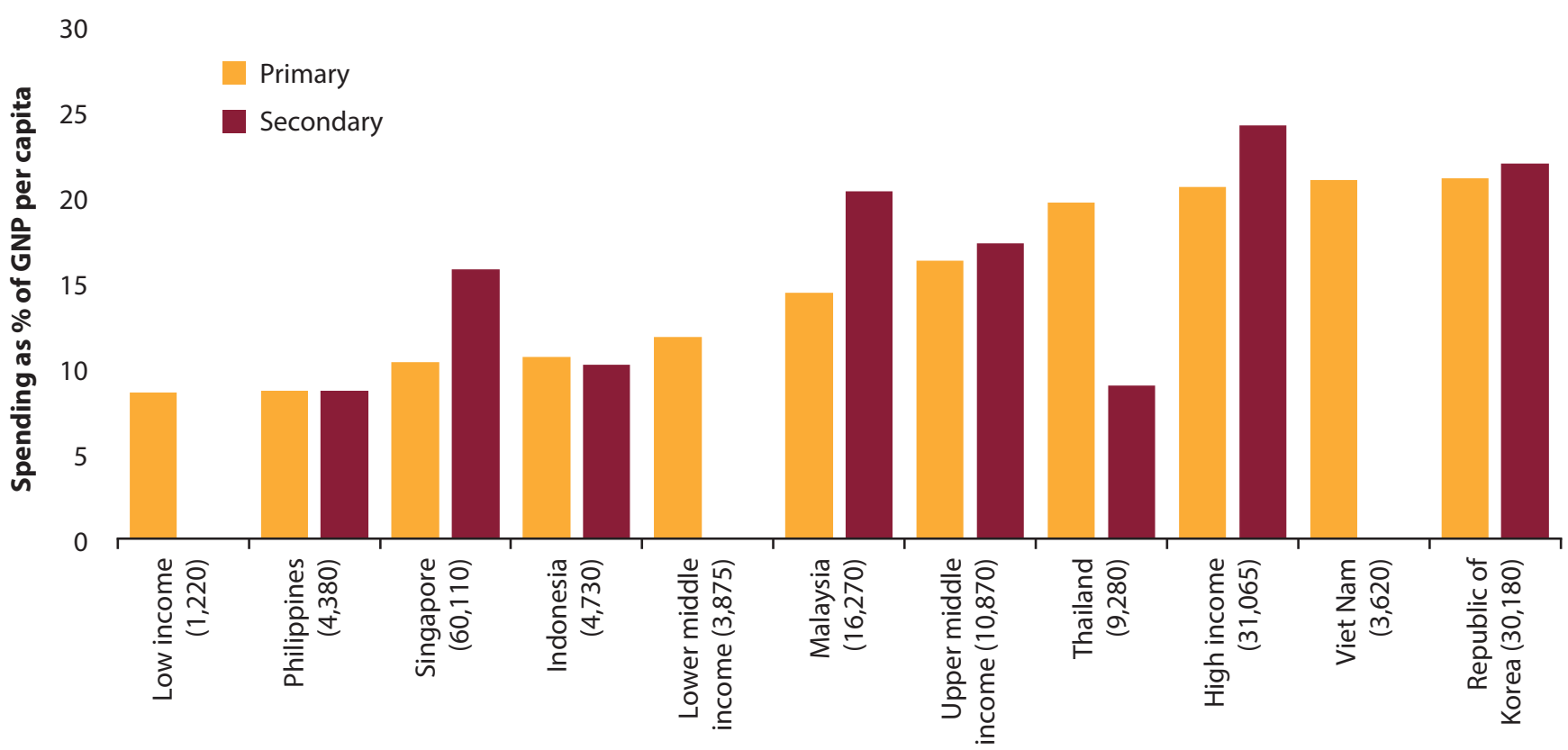

Sources: Authors' calculations and UNESCO Global Monitoring Report (2010). EFA Global Monitoring Report. Education For All 2000-2015, Achievements and Challenges. Paris, UNESCO.

Notes: Information for all countries is from 2012 or the latest year available after 2009. Philippines data are for 2013 and include all spending (recurrent and capital) whereas other countries only cover recurrent spending. Figures in parentheses are GNP per capita in 2012 based on purchasing power parity.

The proportion of funding that schools have discretion over tends to be relatively low. Elementary schools in the Philippines control about 7 percent of the resources that they receive compared to 12 percent for high schools. The remaining revenues are in-kind support either in the form of teacher and other staff salaries, infrastructure projects and other material support schools receive. While information at the school level from other countries is relatively rare, Indonesian primary schools have control over about 18 percent of the total revenue. ${ }^{12}$

\section{Figure 5: Overall Spending at the School Level Is Lower than Aggregate Figures Suggest}

School Revenue Per Student by Type of Revenue, 2014

\section{Per school (PHP 000s)}

10,000

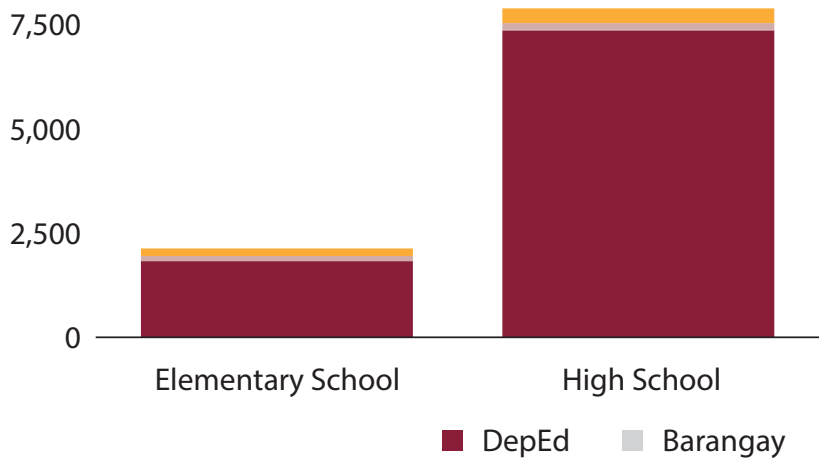

12,500

Per student

10,000

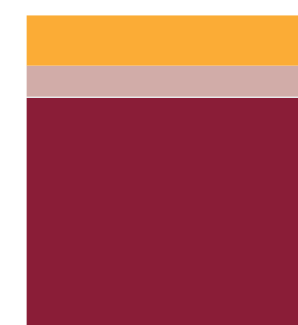

Elementary School

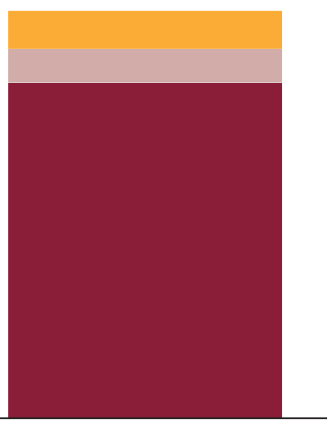

High School 


\section{What Has the Increased Investment in Basic Education Been Used For?}

A large proportion of the increased spending on basic education has been used to increase infrastructure investment and provide schools with essential inputs to improve the quality of education. These increases reflect the government's commitment to address the deteriorating condition of basic school infrastructure, the lack of adequate teachers, and the limited availability of good quality textbooks and instructional materials.

Capital spending increased from PHP 4 billion to PHP 24 billion in real terms (2014 constant prices) between 2005 and 2013, and its share in total spending increased from 2 percent to 9 percent. In practice, this yielded a large increase in the resources available for school construction and repair. Between 2005 and 2013 spending on school construction increased by a factor of five in real terms from PHP 2.8 billion to PHP 14.6 billion. ${ }^{13}$ This trend mostly became evident after 2010 and has been reflected in the declining studentclassroom ratios in both elementary and high schools across the country (Figure 6). Increased capital investment also reduced the proportion of public high schools that needed to schedule multiple shifts to accommodate students.
Preliminary data from DepEd suggests that between 2011 and 2014 the proportion of schools operating more than one shift fell from 11 percent to 6.5 percent. ${ }^{14}$ Nevertheless, the average student-classroom ratios in both elementary and high schools remain high.

While the overall share of the education budget devoted to salaries has declined, spending on teachers has increased in real terms. In 2005, approximately 90 percent of all basic education spending was spent on salaries, but by 2013 salary spending accounted for only 81 percent. ${ }^{15}$ Despite this declining share, salary spending increased in real terms from PHP 135 billion to PHP 217 billion between 2005 and 2013 (2014 prices). These increases were largely the result of schools hiring new teachers to ensure that they had adequate teachers and to reduce class sizes. New teacher hiring has had the greatest impact at the high school level where it has resulted in a decline in the student-teacher ratio from 40:1 in 2005 to 27:1 in 2014 (Figure 6). ${ }^{16}$

There have also been large increases in spending on maintenance and operating expenses in schools. Between 2005 and 2013 spending on maintenance and operating expenses increased from PHP 12 billion to PHP 28 billion in real terms. The share of this spending in the total budget increased from around 8 percent in 2005 to 10 percent in 2013. At the same time, the government transferred a greater share of operating funds directly to schools to enable

Figure 6: Increased Education Spending Has Improved the School Learning Environment Public Student-teacher and Student-classroom Ratios, 2005-2013

Student-teacher ratio

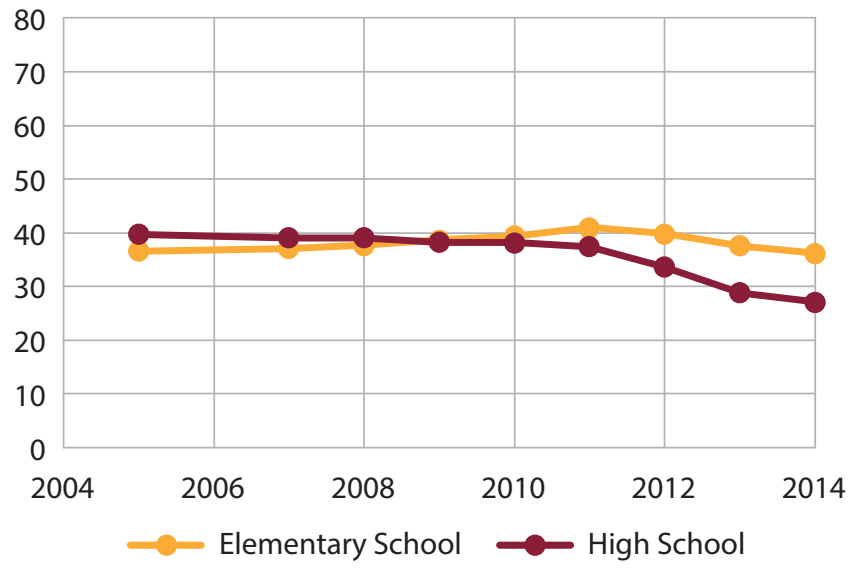

Student-classroom ratio

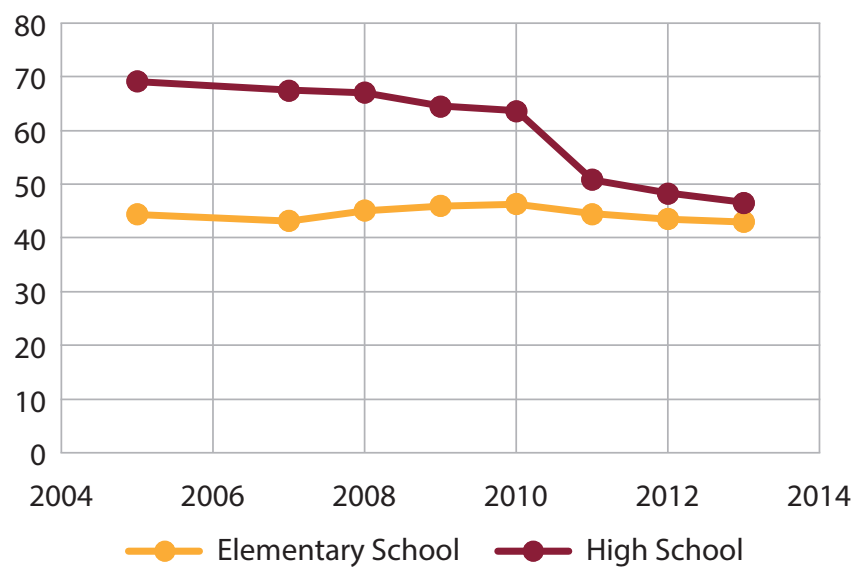

Sources: DepEd Fact Sheet and Enhanced Basic Education Information System (EBEIS)

Notes: Figures only include public enrollment and teachers although over this period local government and volunteer teachers also taught in public schools. For example, prior to 2012, all kindergarten teachers in public schools were classified as volunteer teachers and were not included in the reported data. Classroom ratios are based on the total number of rooms used for teaching rather than on the total number of rooms in the school. 
Figure 7: Regional Disparities Exist in Levels of Financing and Key Education Inputs

Student-teacher and Student-classroom Ratios and Per Capita Basic Education Spending, 2012

\section{Student-teacher ratio}

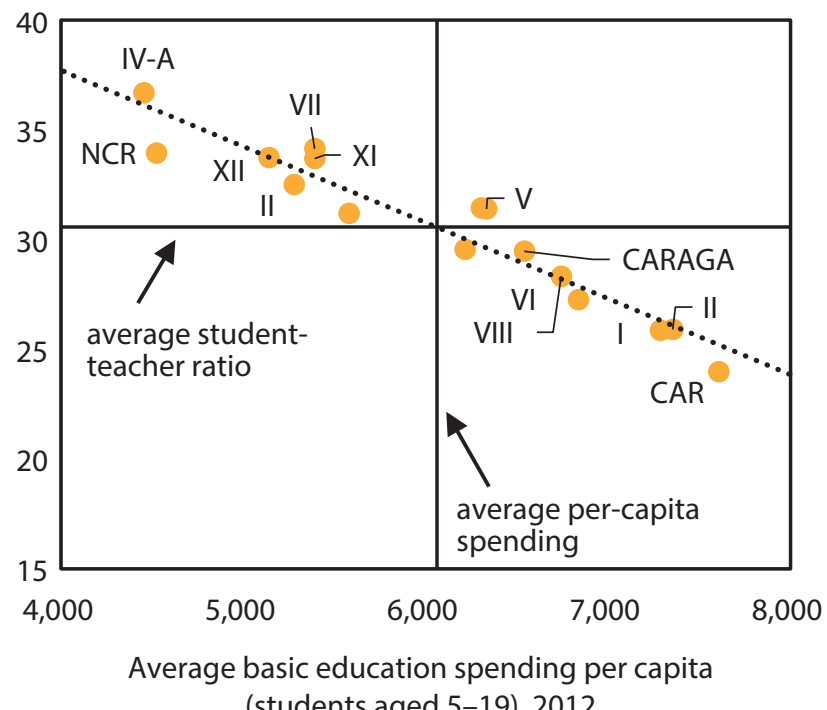

(students aged 5-19), 2012
Student-classroom ratio

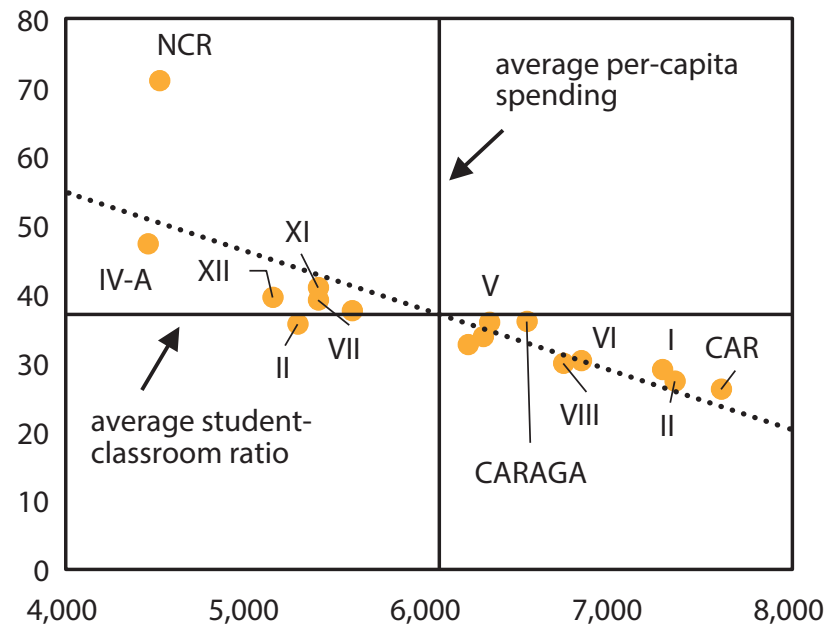

Average basic education spending per capita (students aged 5-19), 2012

Sources: DepEd Education Basic Education Information System (EBEIS) and DBM GAA

Notes: Per capita basic education spending is total regional appropriations (nominal) per child aged between 5 and 19. Autonomous Region in Muslim Mindanao (ARMM) is not included.

them to make their own spending decisions. Specifically, the government introduced the Boncodin formula in 2013 by which maintenance and operating expenses are now allocated to schools on the basis of student numbers and other school characteristics and provided to them directly. As a result, the amount of maintenance and operating funds allocated directly to schools nearly trebled in real terms between 2005 and 2013 from PHP 4 billion to PHP 12 billion. Over the same period, spending on textbooks and other instructional materials also increased, indicating the high priority that DepEd has given to critical infrastructure and quality inputs for the sector over the last decade.

The nationwide improvements documented in this section conceal significant disparities across regions in key education inputs (Figure 7). Region IV-A and NCR tend to have high student-teacher and student-classroom ratios, while those in CAR tend to be relatively low. This partly reflects differences in population density, with NCR and Region IV-A being mainly urban areas with very large schools compared to CAR, which is mainly rural with many small schools. However, differences in key inputs are also driven by differences in per capita budget funding. For example, Region IV-A has some of the poorest input ratios as well as one of the lowest per capita allocations for basic education. ${ }^{7}$

\section{How Has the Increased Investment Affected Education Outcomes?}

This section explores how the increased availability of key inputs has affected educational outcomes. It is important to keep in mind that it may take time before recent improvements in school learning environments are reflected in national education achievement averages. For example, the latest available information on national examination results is for students who started school at a time when the education system was only beginning to recover from a long-term decline in academic outcomes. Later cohorts of children are likely to benefit to a greater extent from improved funding, and it is reasonable to expect that their learning outcomes will be better than those achieved by students leaving elementary and high school today. ${ }^{18}$ 


\section{Access and School Completion Rates}

Enrollment in kindergarten has expanded rapidly since the mid-2000s, which has largely been the result of increased public sector provision. In many countries, early childhood education has yielded higher learning achievement and improved life outcomes for children when they enter the labor force. In the Philippines, kindergarten enrollment almost doubled between 2005 and 2013, and approximately two-thirds of all five year olds are now attending kindergarten. ${ }^{19}$ The largest increases in kindergarten enrollment have been concentrated among the poorest and most vulnerable sections of society. In 2008, the gross enrollment rate in kindergarten for the poorest 20 percent of the population was 33 percent, but this had increased to 63 percent by 2013. Levels of kindergarten enrollment in the Philippines now compare favorably with rates in other middleincome countries both within the region and globally.

On the whole, elementary and high school enrollment rates have been on an upward trend since the end of the first decade of the 2000s. At the beginning of the 2000s, elementary net enrollment rates continued to fall as population increases outpaced enrollment growth. However, since 2008 elementary enrollment rates have been on an upward trend (Figure 8). Between 2009 and 2012, more than half a million additional children enrolled in elementary school, and the net enrollment rate increased from 90 percent to 95 percent.

Over a similar period, high school enrollment also expanded, and by 2013 some 300,000 additional children were continuing their education beyond elementary school compared to 2005. This resulted in the net enrollment rate increasing from 60 percent to 65 percent between 2009 and 2013. ${ }^{20}$ The Philippines compares favorably with other countries in terms of enrollment in the first four years of secondary schooling. However, most other middle-income countries have already extended secondary education level to encompass six years, which the Government of the Philippines plans to follow in 2016.

Although most recent enrollment gains have been concentrated among the poorest children, socioeconomic disparities remain large at the high school level. World Bank estimates using data from the Annual Poverty Indicators

\section{Figure 8: Access and Attainment Indicators Have Shown Modest Improvements Recently}

Gross and Net Enrollment Rates and Completion rates, 2005-2012

\section{Enrollment rates}

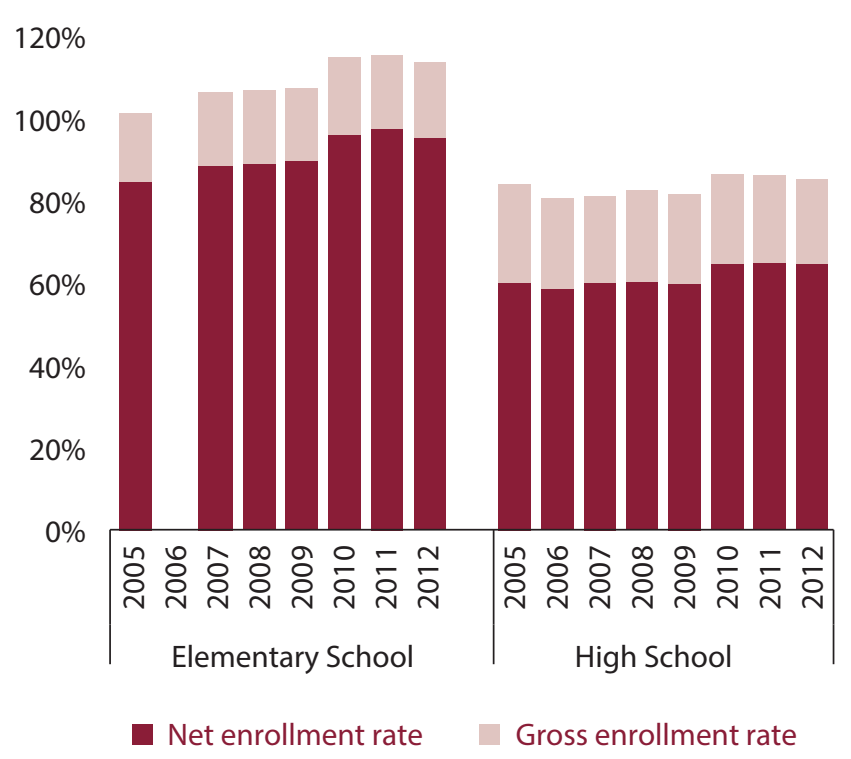

\section{Completion rates}

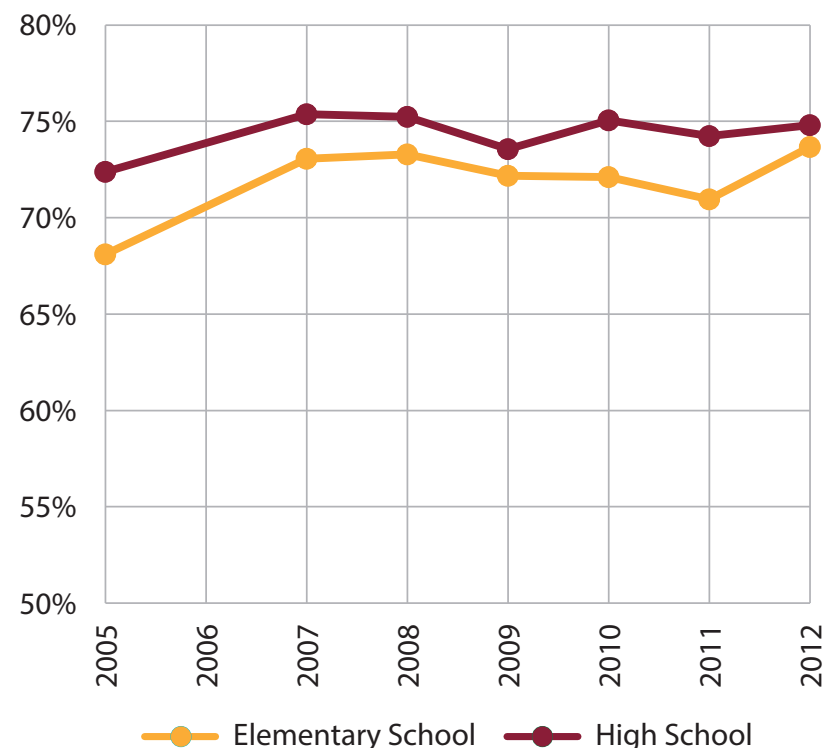

Source: DepEd (2015). DepEd Fact Sheet 2013. DepEd. Manila.

Note: The completion rate is the percentage of first year entrants who complete the full education cycle. 
Survey (APIS) show that high school net enrollment rates for those in the poorest quintile increased from 45 percent in 2002 to 53 percent in 2013, while rates remained relatively stable for the wealthier groups in the population. Differences in net enrollment rates across the income distribution have narrowed considerably at the kindergarten level and have been virtually eliminated at the elementary level. However, socioeconomic disparities in enrollment at the high school level remain high. In 2013, the high school net enrollment rate for children in the poorest 20 percent of households was only 53 percent compared to a rate of 81 percent for those in the wealthiest household quintile.

After some initial improvement, school completion rates have remained relatively stagnant since 2007 (Figure 8). It is important to note that completion rates reflect past investments in education. The 2012 data shown in Figure 7 relate to students who entered the system in 2006 before many of sector improvements outlined in the previous section came to fruition. The cohort survival rate is a more synthetic measure of school completion and reflects changes in the education system more quickly. ${ }^{21}$ However, cohort survival rates have also remained stable since 2005, with approximately three-quarters of all students starting elementary or high school being expected to complete the cycle. Recent studies have pointed to high repetition rates, particularly in Grade 1, as a major explanatory factor for why one in four children drop out of school before completing..22

\section{Education Quality}

The Philippines last participated in an international learning assessment in 2003. ${ }^{23}$ The results showed that only around one-third of elementary and secondary school students were able to reach the lowest international benchmark in mathematics. Differences among socioeconomic groups were also stark. In secondary school, only 23 percent of the poorest children achieved the lowest benchmark compared to 60 percent of the wealthiest children.

Since 2003, national examination scores have improved but it is unclear whether these improvements have changed the overall picture on learning significantly. Average scores on the national achievement test rose significantly between 2006 and 2008, reaching a high of 69 percent, but have remained stagnant since. ${ }^{24}$ However, it is not clear how comparable these achievement tests are from year to year which makes these increases difficult to interpret. High school achievement results have remained relatively stable over the last 10 years, although overall scores are only slightly above 50 percent. While issues of comparability make it difficult to make strong statements about trends, the national achievement scores do not suggest that there has been any significant improvement in overall learning achievement in recent times.

Differences among regions in elementary and high school student achievement are relatively small except in a limited number of regions (Figure 9). Students in Caraga tend to perform better than most students in the Philippines while students in ARMM score relatively poorly. Differences among regions tend to be similar across elementary and high schools with some exceptions. Most notably, elementary school students in NCR rank 16 out of the 17 regions, while high school students rank seventh. There is little correlation between levels of student achievement and per capita spending on basic education. In some cases (for example, (araga), basic education spending and learning achievement is high and in other cases achievement is low despite above average basic education spending (for example, in Region I).

\section{How Does the Public Financial Management System Affect the Link between Spending and Education Outcomes?}

Whether the public financial and resource management systems allocate resources effectively is a vital element in translating increases in public sector investment into improved education outcomes. These systems transform sector objectives and policies into budget allocations that are used to finance the inputs and programs necessary to deliver good quality education services. The overall level of funding, the level of administration or agency using resources, and the management and governance arrangements for these resources are key determinants of education outcomes. A number of recent studies have pointed to weaknesses in these systems in the Philippines that may limit the overall impact of the recent increases in sector spending. 
Figure 9: Differences in Learning Achievement across Regions Are Generally Small National Achievement Test Scores by Region (\%), 2011
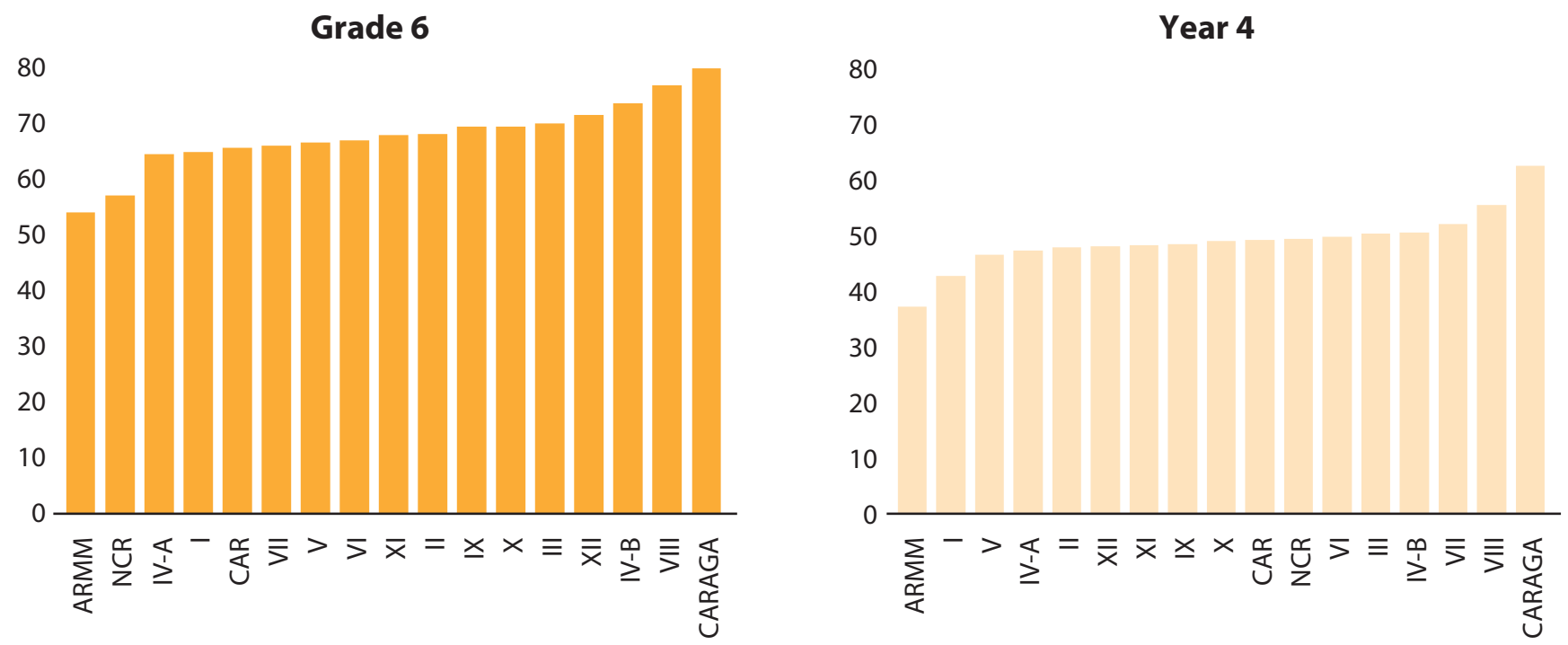

Source: DepEd

Not all of the increased government allocation to the education sector has been spent in recent years because of low budget execution rates. The overall execution rate for basic education has fluctuated over the last 10 years, but in 2013 it was lower than in 2004 (Figure 10). Execution rates vary among key education inputs. First, rates for maintenance and operating expenses have been falling since 2009. Less than three-quarters of the funds allocated to this category in 2013 were actually spent. Given that this budget category provides local education offices and schools with funding for important activities such as teacher training and the purchase of school supplies, this represents a missed opportunity to raise education outcomes further. Second, approximately onefifth of all capital outlay resources, including those for school

\section{Figure 10: Budget Execution Rates Are Low for Some Key Categories of Expenditure}

Budget Execution Rates for Basic Education Spending, 2006-2013

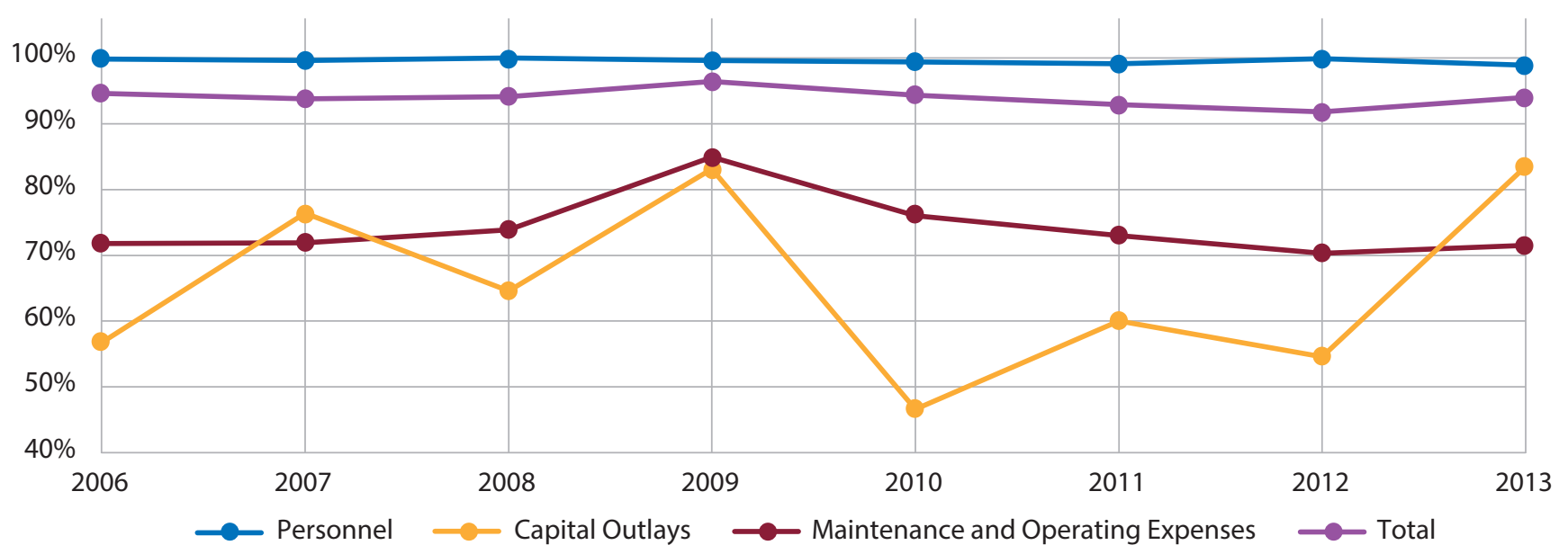

Source: DepEd Statement of Allotments, Obligations and Balances (SAOBs) for each year.

Note: Budget execution rates are defined as obligations as a percentage of allotments. 
construction and rehabilitation, go unspent annually. This is a real cause for concern given the high student-classroom ratios, particularly in high schools, and the general poor state of much of the existing infrastructure (see Figure 6). ${ }^{25}$

Several factors are likely to contribute to these low execution rates. A recent review by the World Bank and AusAID of existing studies both in the Philippines and in other countries has identified a number of factors that may lead to low budget execution rates: ${ }^{26}$

- Delays in fund releases and allocations. Delays in the release of allocations for some budget items mean that local education offices and schools often receive funds late or not at all. When allocations are received late, they have insufficient time to follow procurement rules and properly account for their use of funds before the end of the fiscal year. ${ }^{27}$

- Incomplete transfer of funds between levels. In other cases, there are delays in the transferring of funds from regional and division offices of DepEd to schools. For example, in 2011, a small-scale survey showed that approximately a quarter of schools did not receive any resources for maintenance and other operating expenses (MOOE) despite increases in overall school allocations. ${ }^{28}$

\section{- Difficulties at the school level in reporting on self-managed} funds. Schools frequently find it difficult to account for how they have used the monthly funds that they receive to cover their maintenance and operating expenses. This is particularly the case for schools in remote areas and with no dedicated accounting staff. When they are unable to produce these reports, the DepEd division office must withhold any subsequent funds, which are often left unspent.

\section{- Inadequate coordination between implementing units. A} significant part of the basic education budget for school construction and repair is implemented through the Department of Public Works and Highways (DPWH). This has significantly increased the workload of the agency and has emphasized the need for close collaboration with DepEd. In some cases, the absence of this necessary coordination has led to differences in budgeted and actual funding needs, which have in turn led to project delays and poor budget execution.

Inefficient and ineffective spending can compound low execution rates to further weaken the impact of increased education spending on outcomes. A recent public expenditure review by the World Bank and AusAID also highlighted some potential areas of inefficiency in government education spending that included: ${ }^{29}$

\section{- Complexity and lack of transparency in administrative} procedures for fund allocation. Fund flows in the education system are complex, and key staff are frequently unaware of the rules used to allocate resources. For example, school principals are typically unaware of the formula that determines how their maintenance and operating expenses are allocated. This limits accountability and prevents schools from being able to plan effectively.

- Rigid norms for the allocation, release, and use of resources. School principals frequently complain about the restrictions imposed on the use of their operating funds. The prohibition on using these funds for laptops, LCD projectors, and other instructional equipment because they are classified as capital goods unnecessarily restricts school autonomy. Rules for authorizing new classroom construction are inflexible and frequently do not adequately identify the needs of schools in remote and mountainous regions. These rules may be a significant factor in the regional inequalities in student-classroom ratios documented in Section 3.

- A lack of vertical coordination between national and local government education spending. There is relatively little coordination between central and local government funding of basic education. While relatively little is known about this, there is significant potential for duplication and wastage of resources due to this lack of effective coordination, which is likely to be another factor driving regional inequalities in spending and ultimately in education outcomes.

- School governance. How schools manage their financial and human resources has been shown to be a key determinant of the effectiveness of public spending. Schools that are managed and governed well tend to make better decisions and have better student outcomes. Evidence suggests that, while some elements of effective school-based management are in place in schools in the Philippines (such as school improvement planning), others are still lacking (such as community participation and autonomy). ${ }^{30}$ 


\section{Summary}

The Government of the Philippines has made significant efforts to increase public investment in education to expand access and raise education quality. This note has shown that recent increases have led to modest improvements in key education inputs and outcomes. However, it has also found that additional investment will be needed to build on these recent gains, particularly in schools and locations serving poor and disadvantaged communities. Moreover, recent studies have raised concerns about the effectiveness of existing systems to allocate and manage the increased resources. In particular, the World Bank's recent public education expenditure review concluded that merely increasing allocations to the sector is unlikely to produce significant improvements in outcomes.

These findings suggest that tackling spending inefficiencies has the potential to raise education outcomes both by using existing resources better and by ensuring that further funding increases are used effectively. While recent studies have highlighted many of the potential constraints to more efficient resource use, more detailed analytical work is needed to explore the main drivers of efficiency and inequality and to identify the changes that will be needed to increase the effectiveness of public education investments. 


\section{Endnotes}

1 Per student spending includes kindergarten.

2 Local governments support the delivery of basic education services by establishing and funding local school boards.

3 National guidelines require that SEF funds be used for school maintenance and operating expenditures, construction, and sports. Some local governments also use their general funds to provide additional financial support to local school boards.

4 Assistance from development partners is not generally included in the spending data used to construct regional aggregates.

5 The standard deviation of per capita regional spending increased from 783 to 1,833 between 2005 and 2013.

6 In 2012/2013, 91 percent of elementary school students attended government primary schools and 80 percent attended government high schools.

7 World Bank and AusAID (2010). "Philippines Basic Education Public Expenditure Review."World Bank and AusAID, Manila.

8 World Bank and AusAID (2013). "School-based Management in the Philippines: An Empirical Investigation."World Bank and AusAID, Manila.

9 GNP is significantly larger than GDP in the Philippines, but country rankings remain unchanged if spending as a proportion of GDP is used, with the exception of Cambodia, which then moves below the Philippines. It is preferable to use GNP because it allows the inclusion of the averages for country income groupings in Figure 3.

10 DepEd (2013)."Medium-term Expenditure Framework for Basic Education 2014-2020: Enrollment Projections and Cost Simulations under Alternative Scenarios." Department of Education, Manila.

11 World Bank and AusAID (2010). "Philippines Basic Education Public Expenditure Review."World Bank and AusAID, Manila.

12 These are appropriations and exclude an additional PHP 14 billion of school construction funds included in the Department of Public Works and Highways (DPWH) budget for 2013.

13 Approximately 3 percent of all public elementary schools organize their schedules around multiple shifts, and this has not changed much in recent years.

14 According to UNESCO statistics, the proportion of the total basic education budget in the Philippines devoted to salaries is similar to those in other neighboring countries.

15 Student-teacher ratios at the elementary level remained stable because increases in the number of teachers were offset by increases in student numbers during the same period.
16 While differences between regions in student-teacher and student-classroom ratios are wide, they have largely narrowed over the last 10 years. In particular, inequalities in student-teacher ratios at the high school level and student-classroom ratios at the elementary level have declined relatively rapidly since 2006.

17 Previous analysis conducted by the World Bank and AusAID in 2010 showed that adequate funding of teachers and classrooms is a key determinant of achievement in the Philippines context. See World Bank and AusAID (2010), "Philippines Basic Education Public Expenditure Review."World Bank and AusAID, Manila.

18 These are the author's calculations using household data from the Annual Poverty Indicators Survey (APIS) for both the "kindergarten" and "preparatory" categories. Calculations by the authors using DepEd kindergarten enrollment figures and UNESCO's population estimates show that the overall gross kindergarten enrollment rate increased from 52 percent in 2009 to 99 percent in 2013.

19 Net enrollment rates estimated by the authors using APIS household data suggest a more moderate increase in high school net enrollment from 66 percent in 2008 to 68 percent in 2013.

20 The cohort survival rate is the percentage of a cohort of students in the first grade in a given school year that is expected to survive to the last grade.

21 World Bank and AusAID (2010). "Philippines Basic Education Public Expenditure Review."World Bank and AusAID, Manila.

22 See, for example, Mullis, I., Martin, M., Gonzalez, E. and S. Chrostowski (2004). "TIMSS 2003 International Mathematics Report." International Study Center, Boston College, Lynch School of Education, Boston.

23 There have been some notable increases in achievement in some subjects. For example, average scores in grade 6 elementary science and English scores increased by 8 and 5 percentage points respectively between 2007 and 2012.

24 The execution rates in Figure 9 may be underestimated because capital allocations can be carried over from one year to the following year. However, they provide a good measure of what proportion of an appropriation tends to be used in a single year.

25 World Bank and AusAID (2010). "Philippines Basic Education Public Expenditure Review."World Bank and AusAID, Manila.

26 This appears to be a particular issue with centralized lump sum releases such as the School-based Management Grants.

27 World Bank and AusAID (2013). "School-based Management in the Philippines: An Empirical Investigation."World Bank and AusAID, Manila.

28 World Bank and AusAID (2010). "Philippines Basic Education Public Expenditure Review."World Bank and AusAID, Manila.

29 World Bank and AusAID (2013). "School-based Management in the Philippines: An Empirical Investigation."World Bank and AusAID, Manila. 


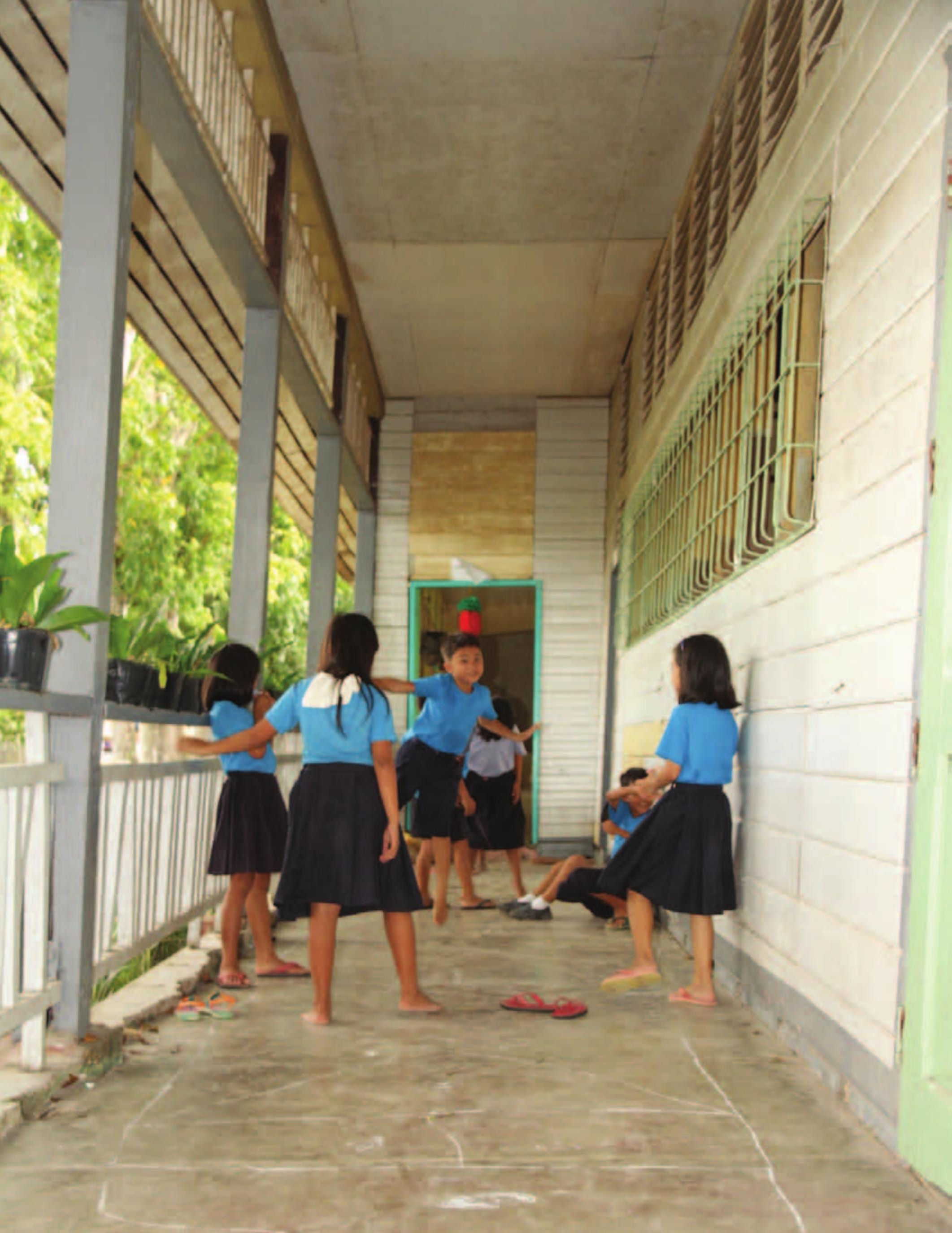




\section{Policy Note 1: Assessing Systems for Hiring and Deploying Teachers}

\section{Introduction}

Over the last decade, research from many different countries has demonstrated the important role played by teachers in improving students' learning and increasing their competencies.' Studies from countries as different as the US and Indonesia have shown the enormous benefits that follow from having adequate and effective teachers working in a country's schools. In Indonesia, a value-added analysis of student learning outcomes found that the more teachers know, the greater the improvements in the learning competencies of primary and junior secondary students. ${ }^{2}$ In the US, better teaching in elementary and secondary schools has been shown to increase students' college participation rates, raise their subsequent earnings, and improve other long-term outcomes. ${ }^{3}$

Ensuring that schools have enough teachers to provide education in classes that are small enough to foster a good learning environment is an important first step. While the optimal size of classes and the impact of reducing class sizes continue to be debated, it is clear that very large class sizes are detrimental to learning. Moreover, evidence from recent impact evaluations in developing countries shows that, on the whole, reducing class sizes in elementary schools improves learning. ${ }^{4}$ In the Philippines, the Department of Education (DepEd) has class size standards for each grade in elementary and high schools. Providing enough teachers to fulfill these standards in all schools can contribute to a good learning environment for basic education students throughout the country.

The distribution of public school teachers is also a key determinant of the efficiency of overall government spending. Public spending on teacher salaries has increased dramatically in recent years. Between 2010 and 2014, teacher salary spending increased from PHP 103 billion to PHP 172 billion (at 2014 constant prices). By 2014, teacher salaries represented about 9 percent of the national government budget of the Philippines. ${ }^{5}$ This puts into sharp focus how important an efficient distribution of teachers can be. Allocating teachers to schools

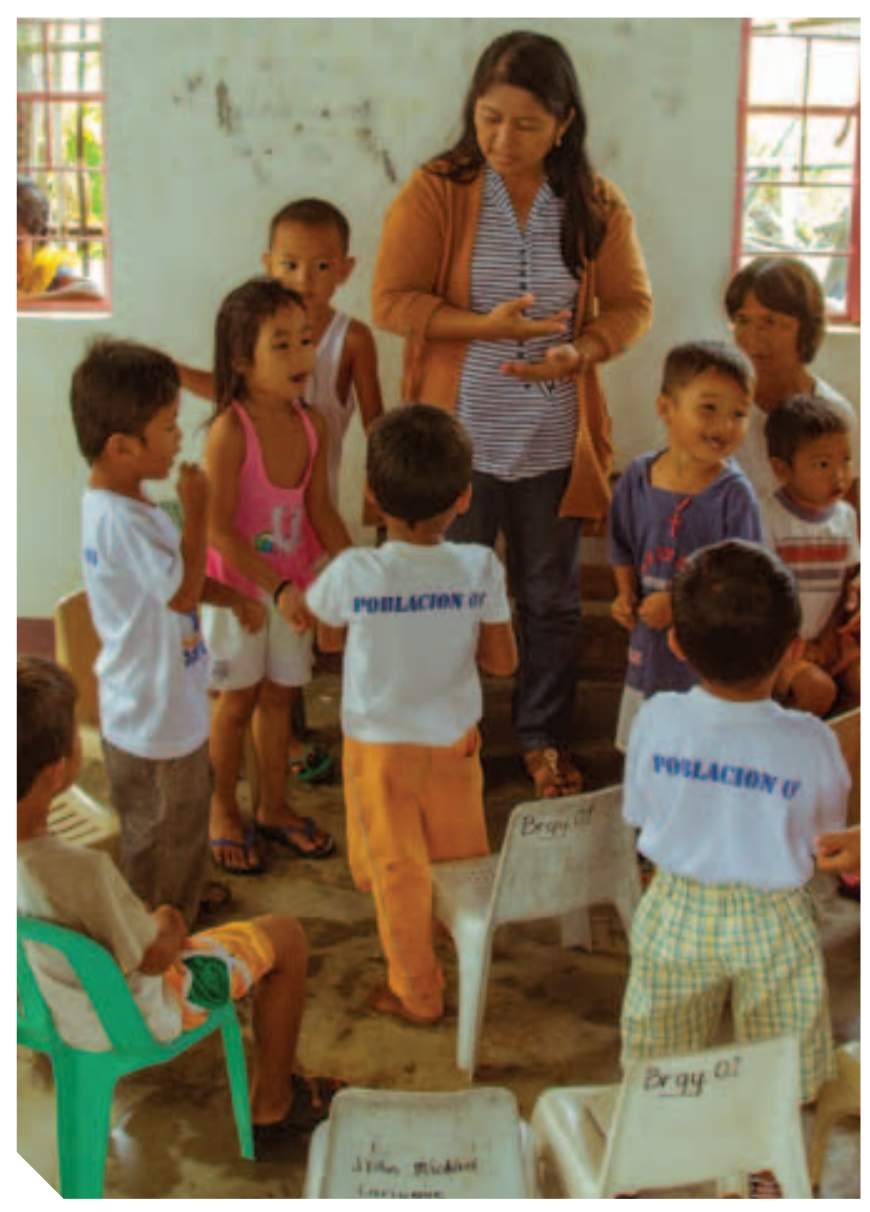

that already have a sufficient number while others continue to experience shortages is inefficient and potentially wasteful. Conversely, distributing the teacher workforce efficiently and equitably can both improve student learning and optimize the use of scarce public resources.

The purpose of this policy note is twofold. First, it aims to assess the adequacy, efficiency, and distribution of existing allocations of teacher positions across and within schools. Second, it evaluates current systems for hiring and deploying teachers and identifies areas in which they can be strengthened. ${ }^{6}$ The findings of this note are based on a comprehensive survey of the public education system in the Philippines that tracked public education expenditure and assessed the quality of education services. 
The note shows that substantial progress has been made in the Philippines in terms of reducing teacher shortages and improving the systems used to hire and deploy teachers. At the school level, class sizes have been reduced significantly, and teacher absenteeism rates are low compared with other countries. Despite these successes, some inefficiencies in the distribution of teachers and bottlenecks in the hiring process remain. In particular, the systems for hiring and deploying teachers need to be strengthened and need to be focused on those schools and regions with continuing teacher shortages. Also, there is a need to develop a system to govern the transfer of teachers between schools in order to reverse the growing number of schools with surplus teachers.

\section{The Availability of Teachers in Elementary and High Schools}

In order to operate effectively, schools require an adequate number of teachers that turn up regularly and on time to teach. Using the PETS-QSDS data, this section looks at trends in the overall level and distribution of teachers across basic education and patterns of teacher absenteeism across the Philippines.

\section{Level and Distribution of Teachers}

The Government of the Philippines has made enormous strides in recent years in providing schools with sufficient teachers. A key indicator of the adequacy of the number of teachers in the school system is the student-teacher ratio (STR). It measures the number of students per teacher and provides a very rough proxy of average class sizes. Over the last decade, STRs have been reduced considerably in basic education (Figure 1). For example, between 2011 and 2014, the number of students for every high school teacher fell from 37 to 27. This and other decreases in the numbers of students per teacher were the result of an aggressive hiring policy in those three years, during which an additional 123,000 elementary and high school teachers were hired, the equivalent of an increase of 24 percent in the total stock of teachers.

Despite achieving significant improvements in recent years, the Philippines still has some of the highest student-teacher ratios in East Asia and the Pacific and among countries at a similar stage of economic development. For example, in 2014 the high school STR in the Philippines was 27:1 compared to a region-wide average of 16:1. Even among the world's lowermiddle-income countries, the Philippines does not compare well, with an average STR in elementary schools of 36:1 compared with 31:1 for all lower-middle-income countries.

Figure 1: Student-teacher Ratios in Basic Education Have Fallen Significantly in Recent Years

Student-teacher ratios (STRs) and teacher numbers in basic education, 2006-2014

Elementary schools

50

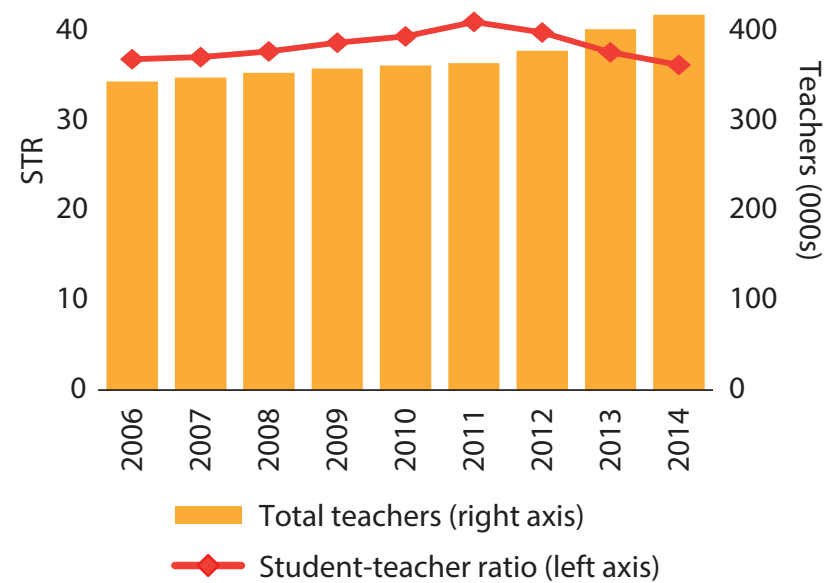

High schools

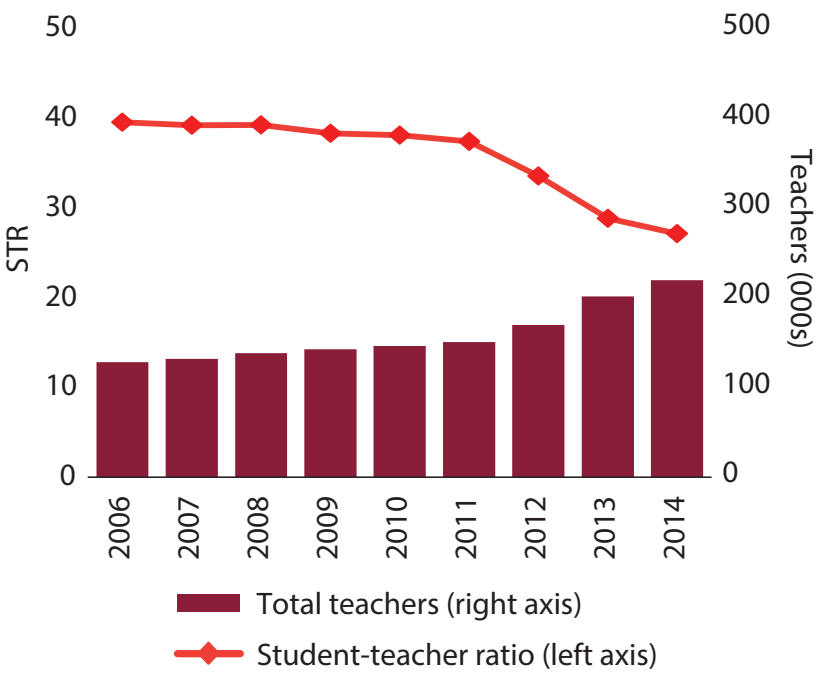

Source: BEIS data on enrolment and number of teachers from DepEd factsheet, various years.

Note: Data from the PETS-QSDS survey found similar student-teacher ratios for 2014. 
Figure 2: Student-teacher Ratios Reveal that Many Schools Have Teacher Shortages

Percentage of schools by student-teacher ratio, 2014

\section{Elementary schools}

$60 \%$

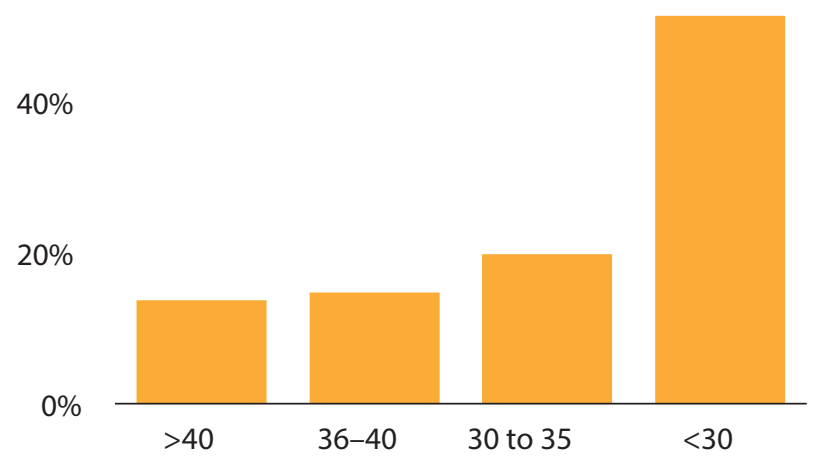

Source: PETS-QSDS national survey - school-level data.

Looking beyond national averages in the PETS-QSDS survey data, it can be seen that STRs tend to be worse in urban schools. For example, there is an average of 39 students for every teacher in elementary schools in highly urbanized cities compared to only 29 in schools located in municipalities. ${ }^{8}$ Differences in STRs in high schools are not as stark, but large urban schools have higher STRs than schools in rural areas. ${ }^{9}$

The distribution of teachers throughout the Philippines is uneven, and many schools do not have enough teachers according to DepEd's standards. While DepEd does not have fixed norms for school-level STRs, it does have guidelines on class size and on the ideal number of teachers per class for each grade. According to these guidelines, the average STR in elementary schools should be 35:1 while in high school the average STR should be 27:1.10 The distribution of STRS in the PETS-QSDS survey data reveals that approximately 29 percent of elementary schools and 37 percent of high schools do not have enough teachers (Figure 2). Perhaps unsurprisingly, the proportion of schools in urban areas with teacher shortages is much higher than schools in rural municipalities.

While a significant proportion of schools have teacher shortages, a large number of other schools, particularly at the elementary level, seem to have a surplus of teachers. About 52 percent of all elementary schools have STRs below existing standards (Figure 2). Lower STRs are frequently
High schools

$60 \%$

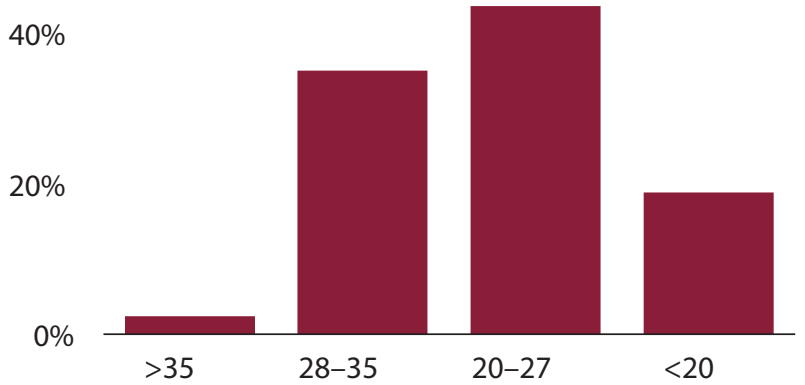

found in schools located in remote areas where there are not enough students in a school's catchment area to meet the STR guidelines. Indeed, a greater proportion of schools in rural municipalities tend to have STRs that are below existing guidelines compared to city schools. However, a significant number of schools in more densely populated areas also have low STRs. It is possible that transferring teachers from these schools to schools with teacher shortages would be a more efficient option than hiring additional teachers.

To get a better picture of the real learning environment faced by students in the Philippines, the study team observed around 7,000 classes and discovered that class sizes were much smaller than student-teacher ratios suggest. Only 9 percent of classes in elementary and high schools had more students than the relevant DepEd guideline (40-45 for elementary and 40 for high schools). The apparent contradiction between these findings and the proportion of schools experiencing teacher shortages is explained by shifting. Approximately 30 percent of all elementary and high schools in the study reported operating more than one shift in at least one grade. However, the use of multiple shifts raises concerns about the amount of learning time each student receives and for this reason DepEd is slowly phasing out shifting in all schools.

High school principals report significant teacher shortages in some subject areas even though DepEd currently has no specific norms." Approximately one-third of all high 


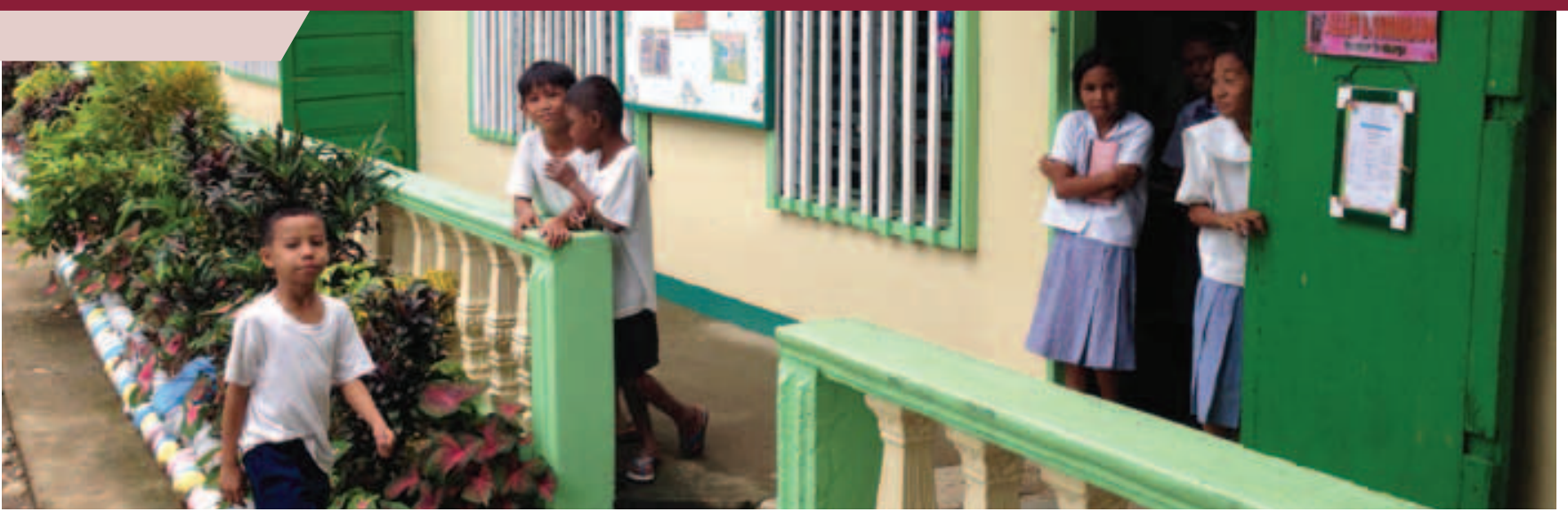

school principals interviewed during the PETS-QSDS survey reported having a shortage of subject specialist teachers (Figure 3). In the absence of any DepEd norms, it is difficult to assess how large these shortages are. However, the school principals who reported a shortage were asked to estimate their needs in each subject. Comparing these self-reported numbers with a school's existing stock of teachers showed that there were substantial shortages of Filipino teachers (Figure 3). Schools also reported that their shortages of mathematics, science, and English teachers were equivalent to about 30 percent of their existing workforce.

\section{Teacher Attendance}

Knowing how many teachers are allocated to each school is important for planning purposes, but whether they turn up to teach every day on time is more important for student outcomes. The PETS-QSDS survey carried out unannounced visits to the sampled elementary and high schools to record teacher attendance (Box 1). Survey enumerators observed teachers arriving at school and recorded the time when they arrived. Later on during the school visit, they recorded data on all of the teachers teaching in the school and their shift pattern in order to calculate absenteeism rates.

This exercise showed that overall levels of teacher absence in the Philippines are low. The percentage of teachers that were absent on the day of the direct observations by the survey teams was 7.6 percent for elementary school teachers and 5.9 percent for high school teachers. These rates are low compared with other countries that have similar measures of teacher absenteeism rates (Figure 4).

Figure 3: Many High School Principals Report Shortages of Subject Specialist Teachers

Percentage of high school principals reporting subject specialist teacher shortages and magnitude of need, 2014
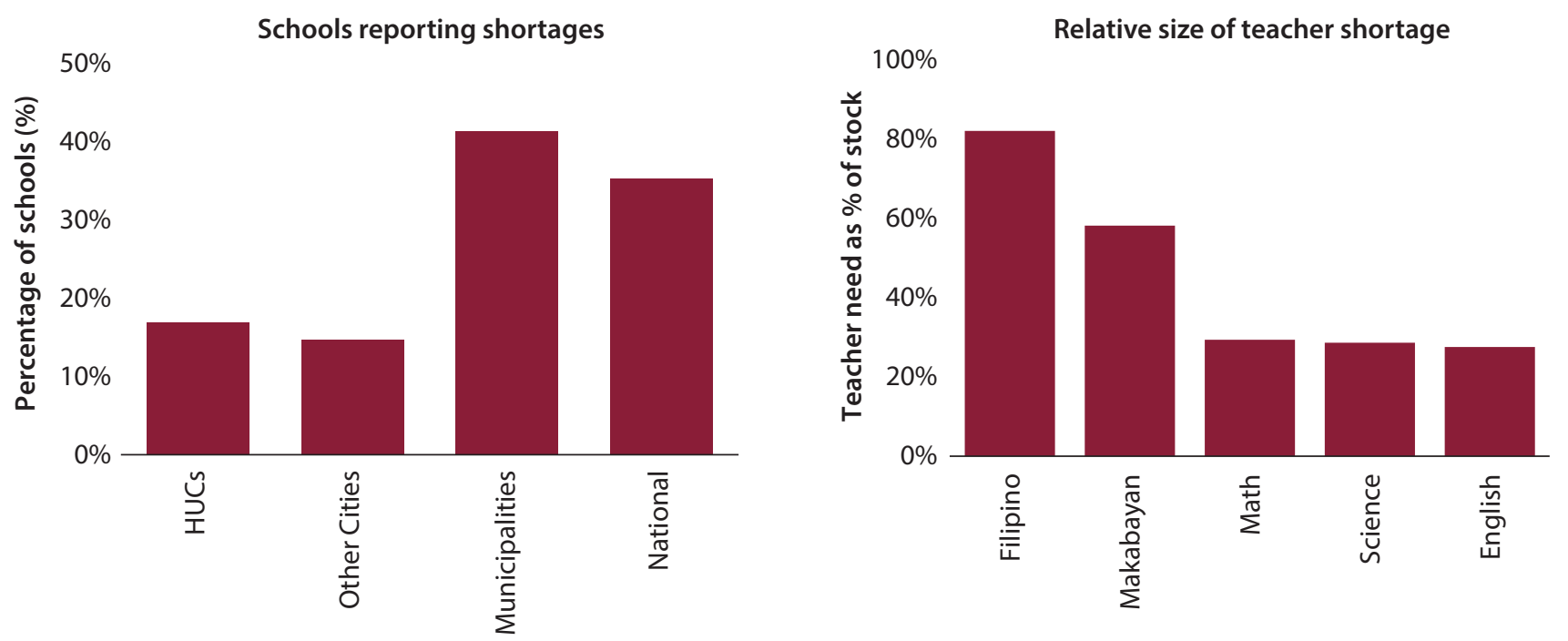

Source: PETS-QSDS national survey - school-level data.

Notes: Makabayan covers social studies, home economics, music, art, health and values. 


\section{Box 1: Procedures for Measuring Teacher Absenteeism through Observation}

The approach to directly observing teacher attendance that was adopted in the Philippines PETS-QSDS survey followed procedures and protocols used in a number of other well-known surveys of provider absence in health and education.

DepEd's regional and division offices were not informed in advance about which schools would be visited by the PETSQSDS survey teams. Where it was not possible to arrive unannounced on the first day of their school visit, survey teams would complete all other survey activities in the school and then come back to the school at a later date, usually after they had finished surveying the other sample schools in the city or municipality.

The survey teams would arrive at the sampled schools at least one hour before the start of the school day. An enumerator was posted at each school entrance and at the office where teachers officially recorded their arrival (on fingerprint readers or in manual records). As the teachers arrived, the team would record their full name and time of arrival.

After the teacher observation, field team supervisors transferred information from each enumerator's observation schedule to the teacher roster for the school. As part of the wider school survey, the team collected information on all school teachers and identified those who were scheduled to be at the school at the time when the teacher observation exercise was undertaken. This yielded information on the number of teachers who were supposed to be present at the time of the observation to compare with the number of teachers who actually arrived. Information on the punctuality of each teacher was also recorded.

The survey team did not monitor the activities of the teachers once they were in school. This made it impossible to discover how many teachers were actually present and teaching in the classrooms after they had arrived at the school as some other studies have done. Other studies have also checked for absenteeism at different times of the day to get a more thorough picture of teacher attendance throughout the day. However, given the size of many of the schools visited by the survey teams in the Philippines and the large amount of other school-level information that they collected, it was not feasible to do this as part of the PETS-QSDS study.

Source: Rogers, H. and M. Koziol (2012). "Provider Absence Surveys in Education and Health: A Guidance Note." World Bank, Washington D.C.

\section{Figure 4: Teacher Absenteeism Rates in the Philippines Are Low}

Primary/elementary teacher absenteeism rates in selected countries, various years

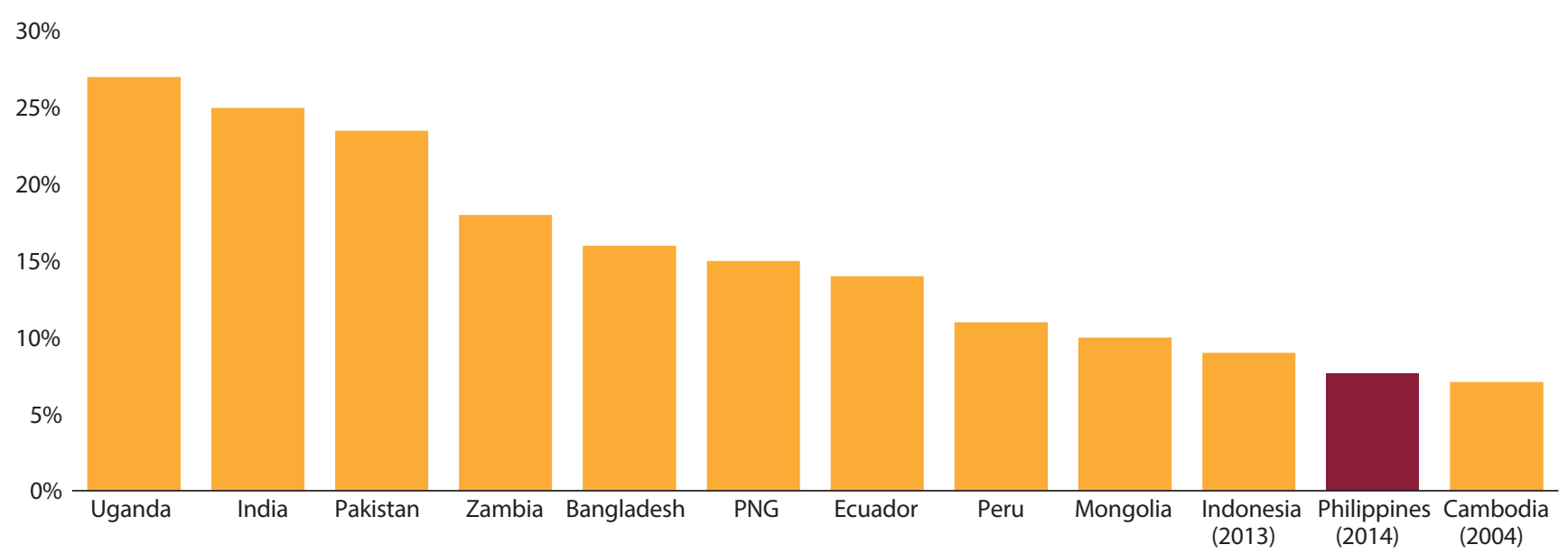

Sources: Philippines - PETS-QSDS national survey - school-level data. Data on Indonesia come from Analytical and Capacity Development Partnership (2014). "Teacher Absenteeism in Indonesia: Policy brief." Jakarta. Data for all other countries come from Rogers, F. H. and E. Vegas. (2009). "No More Cutting Class? Reducing Teacher Absence and Providing Incentives for Performance." Policy Research Working Paper. No. WPS 4847. World Bank, Washington D.C.

Notes: The Philippines study measured teacher absenteeism for teachers who were expected to be present at the beginning of the school day, whereas other studies checked teacher absenteeism at different times of the school day. All absenteeism rates are for 2002-2004 unless otherwise stated. 
While overall rates are low, teacher absenteeism appears to be higher in highly urbanized cities (Figure 5). In high schools located in highly urbanized cities (HUCs), almost 1 in 10 teachers were found to be absent in 2014. This absenteeism rate is 53 percent higher than the national average..$^{12}$ The factors that may contribute to these higher than average rates may be the larger size of schools in these areas, greater difficulties in terms of traffic congestion in getting to city schools, and greater demands on teachers' time.

On the whole, poorer children attend schools with lower rates of teacher absenteeism than wealthier children. The PETSQSDS survey included a nationally representative sample of public elementary and high school student households. Using the information on consumption and asset ownership collected from these survey households, it was possible to rank student households by their estimated levels of per capita household consumption. ${ }^{13}$ This ranking reveals that students in the bottom 20 percent of households in terms of consumption tend to attend schools with lower rates of teacher absenteeism than students from the wealthiest 20 percent of households. This reflects the greater proportion of wealthier students attending schools in highly urbanized cities where rates of teacher absenteeism are higher.

Levels of absenteeism varied according to a number of teacher and school characteristics.14 Absenteeism rates tended to be higher for more experienced teachers, although this was only statistically significant for elementary school teachers. ${ }^{15}$ Schools that appeared to be more supportive of teachers also appeared to have lower absenteeism. For example, elementary schools where principals routinely observed teachers in their classrooms tended to have lower rates of teacher absenteeism. Moreover, schools where teachers filled in their professional development plans more regularly tended to have better teacher attendance rates but the effects were only statistically significant for high schools. Regular visits from the DepEd division office also improves teacher attendance especially in high schools. On the whole, schools with better facilities (such as electricity) also had better teacher attendance, but this effect was only statistically significant for high schools.

The majority of teachers who were recorded as absent were out of school for permissible reasons (Figure 6). Relatively few elementary school teachers and only 16 percent of high

\section{Figure 5: Absenteeism Rates in Highly Urbanized Cities are Higher than the National Average}

Teacher absenteeism rates by school location, 2014

Elementary schools

$15 \%$

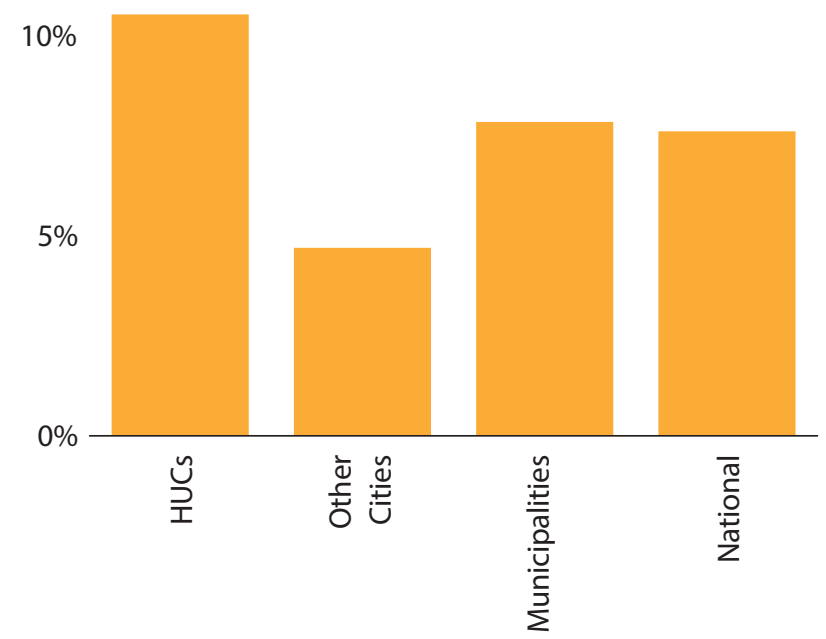

High schools

$15 \%$

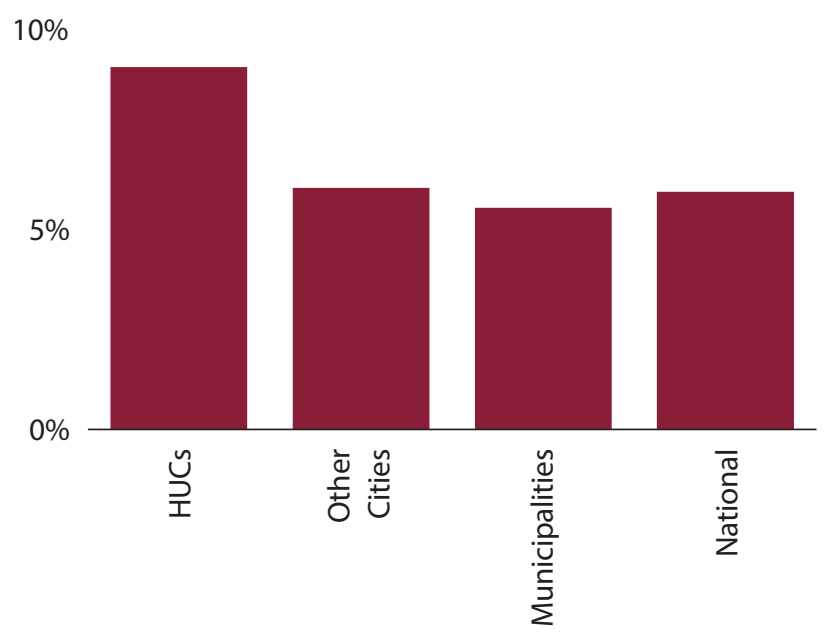

Source: PETS-QSDS national survey - school-level data. 
Figure 6: Most Teacher Absence was for Permitted Purposes

Percentage of absent teachers by reason of absence, 2014
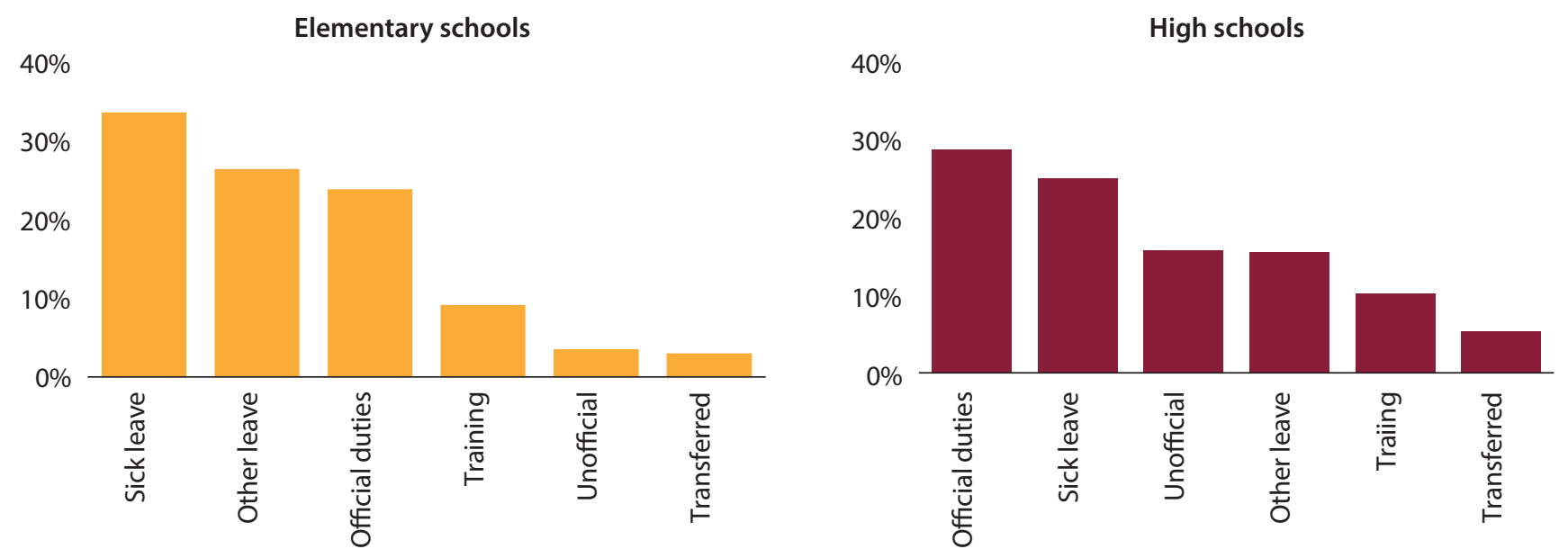

Source: PETS-QSDS national survey - school-level data.

school teachers were absent for unofficial reasons. More than one-third of elementary school teachers and a quarter of high school teachers who were absent on the day of the survey team's surprise visit were reported to be on sick leave. Another quarter of elementary school teachers and about 15 percent of high school teachers were away from school because they were taking official leave (casual, maternity, or earned leave). Teachers were also frequently absent from their schools while undertaking official duties elsewhere, including attending division-led training, managing school maintenance and other operating funding, and participating in meetings at the division office.

School principals appear to monitor teacher attendance closely. The survey collected information from official teacher attendance records in schools to assess their accuracy. These official records were similar to the PETS-QSDS direct observation data, which suggests that schools were keeping good records of teacher attendance. On the basis of these records, it appears that school principals take regular action to address teacher absenteeism and tardiness. Approximately 17 percent of all elementary and 49 percent of high school principals had taken action against teachers who were regularly absent or late. However, their disciplinary actions tended to be limited to verbal or written warnings.

\section{Teacher Hiring and Deployment}

Based on data from the PETS-QSDS survey, this section assesses the effectiveness of government systems at allocating teacher resources to the neediest schools and their ability to hire and place new teachers effectively.

\section{Allocation of New Teachers}

The allocation of new teachers in 2013 and 2014 was largely in line with need. In 2013 and 2014, approximately 90,000 new basic education teachers were hired through an allocation process managed by DepEd (Box 2). Schoollevel data from the PETS-QSDS survey show that, on the whole, new teachers were allocated to schools with high STRs (Figure 7). ${ }^{16}$ However, it is clear that there is still room for improvement in the targeting of new teacher allocations. For example, a large number of elementary schools with STRs higher than DepEd's guideline of 35 students per teacher were allocated no additional teachers in either 2013 or 2014. Moreover, a number of schools that already had relatively low STRs were allocated extra teachers. 


\section{Box 2: The Current Process for Allocating and Hiring Teachers}

The Department of Education's Central Office decides on the number of new teacher positions that will be allocated to each elementary school and high school. It then submits the list to the Department of Budget and Management (DBM) Central Office, which in turn informs all of its regional offices and provides them with copies of the NOSCA (notice of organization, staffing, and compensation action) for their region. The NOSCA specifies the number of new positions for each teacher classification and provides the authorization for making salary payments. The DepEd Central Office similarly informs all of its regional offices, which then inform the DepEd division offices who are responsible for hiring all elementary and high school teachers. Until 2014, the NOSCA for each division included new teacher positions for all elementary schools in the division. However, in 2015 this practice was changed. Now the DepEd Central Office allocates specific positions to each elementary school in an addendum to its main memo and this is also reflected in the NOSCA.

The hiring process begins when the DepEd division offices advertise the vacancies. Once applications are received, the division office checks that candidates are included on the Registry of Qualified Applicants (RQA), a list of teachers who are qualified to fill these positions. The division offices then interview candidates and select individuals to fill the new positions. They then submit the names of the teachers whom they have selected to the regional offices of the DBM.

There are special procedures for the DBM to release funds to DepEd division offices to pay newly hired teachers in their first few weeks on the job. These procedures were initiated in 2012 to enable newly hired teachers to start being paid as soon as they were hired because there were often delays in establishing them on the official payroll.

\section{Figure 7: Allocations of New Teachers Have Favored Schools with High Student-teacher Ratios}

Proportionate increase in stock of school teachers in 2013 and 2014 compared to 2012 school-level student-teacher ratios
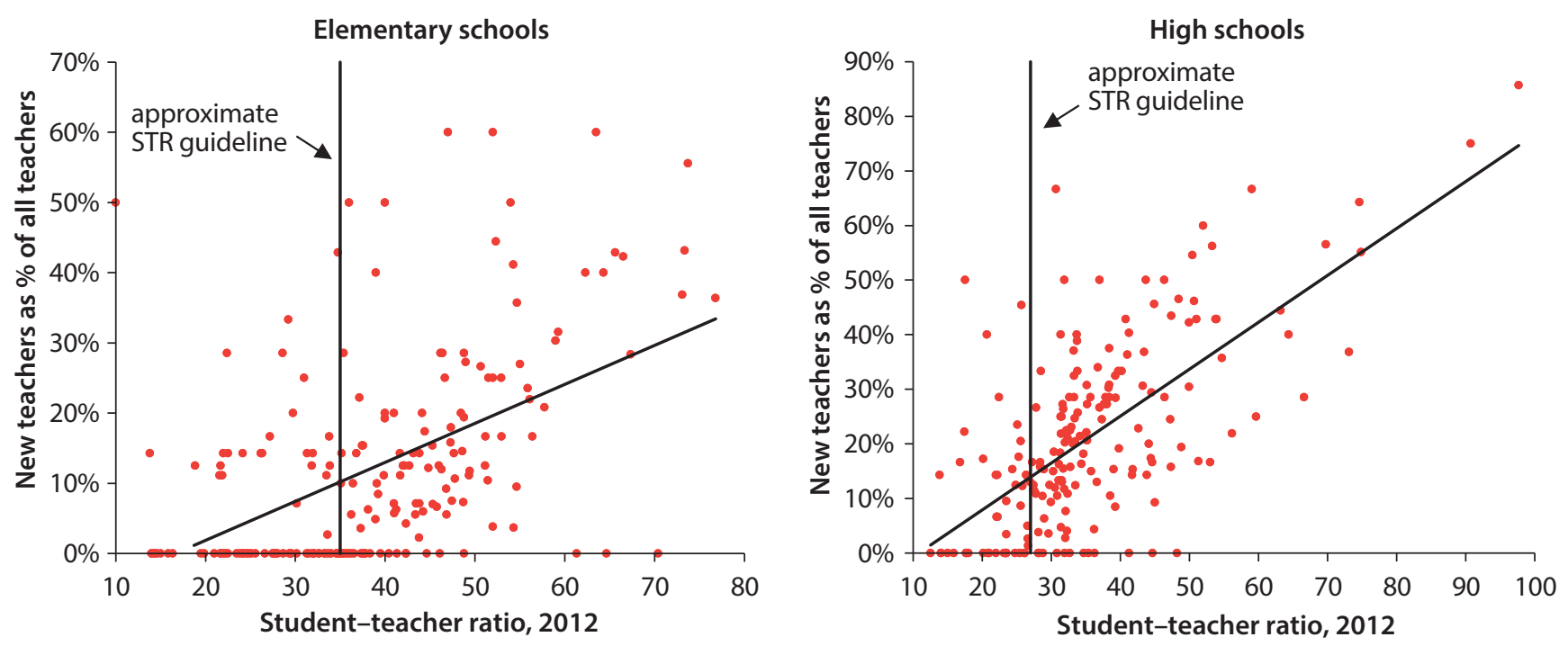

Source: PETS-QSDS national survey - school-level data. 


\section{Figure 8: Hiring New Teachers Has Reduced Teacher Shortages but Has Also Increased the Number of Schools with Surplus Teachers}

Percentage of schools by student-teacher ratio, 2012 and 2014 school years

\section{Elementary schools}

$60 \%$

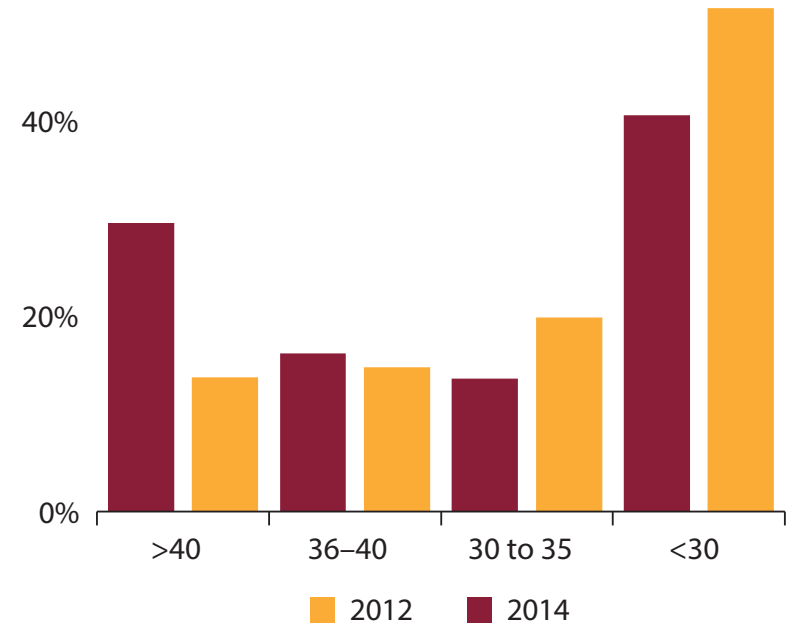

$60 \%$

High schools

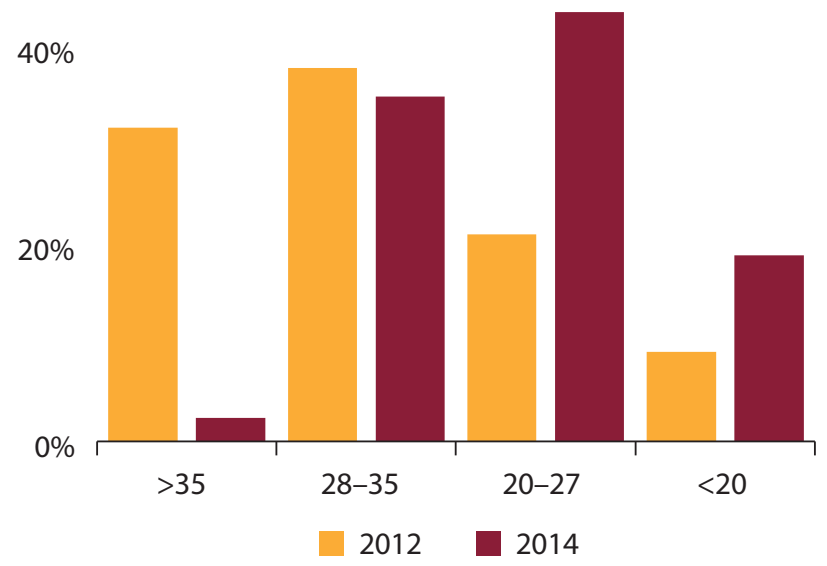

Source: PETS-QSDS national survey - school-level data.

While the recent hiring and allocating of a large number of new teachers has significantly reduced the number of schools with a teacher shortage, it has also increased the number of schools with teacher surpluses (Figure 8). ${ }^{17}$ The proportion of elementary schools with teacher shortages dropped from 46 percent to 29 percent between 2012 and 2014. The proportion of high schools with teacher shortages also dropped, from 70 percent to 38 percent over a similar period. However, the percentage of schools with teacher surpluses has also increased. At the elementary level, the proportion of schools with STRs below 30 increased from 41 percent to 52 percent between 2012 and 2014. On closer inspection, it is likely that some of these schools may be unable to achieve the STRs outlined in the DepEd guidelines, but in most cases, while the surplus teachers are easing the burden in their particular schools, they are not the most efficient use of public education spending.

Until recently, DepEd's process for allocating teacher positions among schools was based on a color coding system according to which schools with high STRs were prioritized..$^{18}$ However, a recent assessment of this system revealed that the allocations did not always follow the color coding system. ${ }^{19}$ The current system now uses DepEd guidelines on class sizes and teacher-class ratios to identify each school's need for teaching staff. However, there is no official DepEd order or memo to guide division offices in how to make new teacher hiring decisions. This makes it difficult to monitor DepEd's allocation decisions.

More than one-third of high school principals and almost a quarter of elementary school principals interviewed for the PETS-QSDS survey felt that DepEd's current methods of allocating new teachers was unfair and suboptimal. The high school principals felt that the lack of a mechanism to account for geographical differences and the need for subject-specific teachers were significant weaknesses. Similar opinions were expressed at the division level by school division superintendents (SDSs), about half of whom reported that they had not received an adequate number of new teacher positions in the previous two years. Moreover, one-fifth of SDSs said that they had not been consulted by their regional office on their teacher needs for 2014.

\section{Teacher Hiring Process}

The PETS-QSDS survey tracked the timeliness of the teacher hiring process in 2013 and 2014. There are four key steps in 
Table 1: Benchmarks and Actual Timing of Key Steps in the Teacher Hiring Process, 2013

\begin{tabular}{|c|c|c|c|c|}
\hline & $\begin{array}{l}\text { Receipt of } \\
\text { NOSCA }\end{array}$ & $\begin{array}{c}\text { Posting of registry } \\
\text { of qualified } \\
\text { applicants }\end{array}$ & $\begin{array}{l}\text { Submission } \\
\text { of list of filled } \\
\text { positions }\end{array}$ & Receipt of SARO \\
\hline & $(1)$ & $(2)$ & (3) & $(4)$ \\
\hline Benchmark date for completing each step & March 2013 & April 2013 & June 2013 & July 2013 \\
\hline \multicolumn{5}{|l|}{$\begin{array}{l}\text { Date on which the key steps were completed in } \\
\text { the sample DepEd divisions: }\end{array}$} \\
\hline - Earliest date & December 2012 & January 2013 & January 2013 & January 2013 \\
\hline - Average date & January 2013 & May 2013 & May 2013 & July 2013 \\
\hline - Latest date & May 2014 & May 2014 & August 2014 & - \\
\hline $\begin{array}{l}\text { Percentage of divisions that completed the } \\
\text { process on or before benchmark date }\end{array}$ & $56 \%$ & $61 \%$ & $75 \%$ & $67 \%$ \\
\hline
\end{tabular}

Source: PETS-QSDS national survey - DepEd division office data.

Notes: Numbers in parenthesis refer to the steps outlined in the text.

the teacher hiring process that determine whether teachers are hired according to the DepEd guidelines, are ready to start teaching at the beginning of the school year, and are paid on time:

1. The DBM provides the list of teacher positions to DepEd's division offices and/or DepEd's regional offices. The DBM regional offices release to DepEd division offices the NOSCA (notice of organization, staffing, and compensation action), which contains information on the number and type of all teacher posts in each division.

2. The DepEd division offices post a list of qualified applicants. DepEd division offices verify and post the Registry of Qualified Applicants (RQA) in the division office. The list consists of all individuals with the required qualifications to be a public school teacher in the division.

3. The DepEd division offices interview and appoint new teachers. Each division office holds interviews for all new positions within its jurisdiction and then submits a list of new hires to the DepEd and/or DBM regional office.

4. The DBM releases the allotment to pay new teachers. Once the DBM regional office receives the list of new hires from each division, it releases a special payment in the form of a special allotment release order (SARO), which division offices then use to pay their newly hired teachers until they are put on the regular payroll, usually in the following financial year.
The PETS-QSDS survey collected data from the DepEd division offices on the timing of these critical steps in the hiring process during the 2013 school year. ${ }^{20}$

A significant proportion of DepEd division offices continue to experience delays in completing the key steps of the hiring process. Table 1 compares the benchmarks that the DepEd Central Office issued for the completion of key steps with the actual completion dates achieved by the 51 DepEd division offices sampled in the PETS-QSDS study. It shows that nearly half of all division offices receive the notification of their allocation of new teacher posts late. The late receipt of the NOSCA leads to further delays in the hiring process. Around 40 percent of DepEd division offices are late posting the registry of qualified applicants but are able to catch up a little by hiring teachers more quickly (Table 1). Only around two-thirds of division offices received their allotment to pay teachers on time, with most schools receiving it on or after the beginning of the school year.

However, there is evidence that there have been some improvements in the overall timeliness of the teacher hiring process in the DepEd division offices. The PETS-QSDS analysis of the 2013 hiring process shows that it took on average five months from the time when the division offices receive the NOSCA to their submission of the list of filled positions to DepEd and the DBM. In 2007, a similar analysis found that this process had taken as long as 18 months to complete. ${ }^{21}$ 
Despite these improvements, divisions reported that about one-third of the new teacher positions for the 2013-14 school year remained unfilled even by the end of the 2014 calendar year (Figure 9). The large number of new teachers unable to report for work at their new schools was partly the result of delays in the hiring process outlined in Table 1. For example, 65 percent of the divisions where teachers were not in post at the start of the school year reported receiving the NOSCA late, while 22 percent reported posting the RQA late, and 19 percent reported submitting the list of filled positions late. However, the majority of divisions where teachers were not in post at the start of the school year had completed all processes on time. It is likely that delays in the submission by teachers and verification by division offices of teacher documentation partly explains these delays in the final step of getting new teachers into the classroom. However, further research is needed to fully understand why these delays occur and to identify ways to address them.

It was not the aim of the PETS-QSDS study to evaluate the hiring process at the division level, but SDSs and school principals did feel that these processes were on the whole fair. About 90 percent of SDSs agreed that the process for hiring new teachers results in the best teachers being hired, while 86 percent of elementary school principals and 80 percent

\section{Figure 9: A Significant Number of Newly Hired Teachers Were Not in Post at the Beginning of the School Year}

Percentage of teacher posts allotted for the 2013 school year where newly hired teachers were in post by the final quarter of the 2014 calendar year

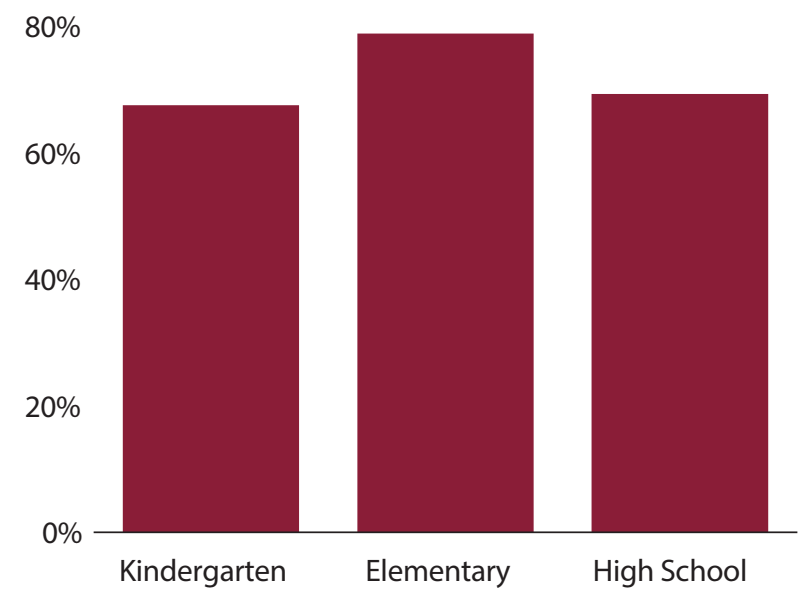

Source: PETS-QSDS national survey - DepEd division office data. of high school principals agreed with this statement. The school principals who disagreed raised a number of reasons, including the overly selective nature of the recruitment process, the lack of weight given to demonstration teaching, and the lack of focus on subject specialization.

\section{Tracking of Funds for Newly Hired Teachers}

The study team's tracking of fund flows for newly hired teachers revealed inconsistencies in the data and poor record keeping. Information on the budget allocation for newly hired teachers was not available from either the DepEd division offices or the DBM's regional offices. ${ }^{22}$ This meant that the team was largely unable to track the flow of funds between these two sets of offices. In the rare cases where it was possible to do so, only one-third of the divisions reported receiving the same amount as the amount reported by the DBM regional office. About half of the remaining divisions reported receiving substantially more in SAROs than the DBM had reported releasing. This may be because the SAROs received by these division offices contained funds for additional payments. Fewer than a quarter of divisions reported receiving substantially less than the amount reported by the DBM regional office. This lack of consistency between the DBM and DepEd division offices is concerning and highlights the need to strengthen monitoring and reporting mechanisms.

\section{Teacher Transfers}

Transferring teachers from one school to another is a useful way to redress imbalances in the distribution of teachers and increase the efficiency of public spending. Decisions about teacher transfers within each division are made by the SDS, and a transfer can be requested by the school principal, a teacher, or the SDS based on needs of the schools in the division. However, it is more complicated to transfer a teaching post across divisions or regions as this requires the approval of the central offices of both DepEd and the DBM. DepEd's recent medium-term expenditure plan (2014 to 2020) estimated that, in 2012, there were about 23,000 excess elementary school teachers and about 5,000 excess high school teachers. Even if only 25 percent of the surplus teachers (a conservative estimate) were transferred to schools with shortages, this would enable DepEd to save about PHP 3.8 billion annually. ${ }^{23}$ 
However teacher transfers are rarely used to address the uneven distribution of teachers and the growing proportion of schools with teacher surpluses. The PETS-QSDS interviews with a nationally representative sample of Grade 6 and 10 teachers showed that fewer than 2 percent of teachers were transferred in 2013. It is also likely that the majority of these teacher transfers were made for personal family reasons rather than to redress imbalances in the distribution of teachers.

Any efforts to use teacher transfers to redistribute the allocation of teachers across the country are currently constrained both by the 1968 Magna Carta for Public School Teachers and by the localization law. The Magna Carta gives teachers the right to refuse a transfer without being disciplined or fired. However, the latest DepEd order on teacher transfers in 2013 indicates that teachers can be transferred without the teacher's consent in certain cases. These include situations where a teacher's existing school has an STR lower than the DepEd guidelines of 35:1 for elementary schools and 27:1 for high schools. The new clause is a clear attempt to give SDSs greater authority to use transfers to manage teacher distribution. ${ }^{24}$ Nevertheless, the Magna Carta states that teachers can contest transfers even in such cases by appealing to the Director of Public Schools. The localization law gives priority to appointing and assigning teachers to residents of the barangay, city, or municipality in which the school is located. While this has the potential to increase the diversity of the teaching force, support mother tongue policies, and ensure that schools in remote areas have teachers in place, it does constrain teacher management.

\section{Policies for Strengthening Teacher Hiring and Deployment}

Over the last five years, the strong focus on improving school learning environments has led to a substantial increase in the availability of teachers in basic education schools across the Philippines. Moreover, teacher absenteeism rates are low and compare favorably with other countries. Systems to allocate and hire teachers have also improved, and the time taken to complete key steps in the process has been shortened considerably. However, this policy note has shown that many schools still do not have enough teachers or enough of the right mix of teachers, and the over-supply of teachers in some schools is emerging as a key issue. The note has also shown that, despite recent improvements in the formal processes governing the hiring of teachers, there are still frequent and significant delays in getting teachers into the classroom.

Having a clear set of guidelines that outline the size, allocation, and hiring of the required teaching force in the Philippines based on expected class sizes and curriculum load would be a useful tool to support the more equitable allocation of both new and existing teachers. The last DepEd memorandum on teacher allocation processes was issued in 2010, and its guidance is now outdated. Specific guidelines for specialist subject positions will also be necessary to ensure that schools have enough specialist teachers and can plan effectively. Ensuring that these guidelines are widely disseminated throughout all levels of DepEd and to the wider public would enable better decision-making within DepEd and increase the transparency of all decisions made about teacher deployment.

DepEd Central Office needs to monitor the hiring process more closely, ensuring that regional and divisional offices are adhering to the hiring timetable and providing them with additional support where necessary. However, further research is needed to understand why so many newly hired teachers are unable to take up their posts before the start of the school year, even when all of the administrative formalities appear to have been completed.

Making more information available on the existing teaching force would improve initial teacher allocations and facilitate future planning. It is currently difficult for DepEd division offices to obtain anything more than basic information on teacher allocations in their division without having to go through large numbers of paper files. Given the large number of schools and teachers in most divisions, this is a barrier to the efficient planning of division-level teacher workforces. Plans are underway within DepEd to develop a Human Resource Information System (HRIS), which will provide planners at all levels of the department with the necessary information and capacity to make well-informed decisions about teacher allocations.

If DepEd were to adopt a more flexible and effective deployment and transfer policy (taking into account special circumstances such as remote schools), this would have the potential to greatly improve the distribution of 


\section{Table 2: Strengthening Systems to Hire and Deploy Teachers}

\begin{tabular}{|c|c|}
\hline Findings & Policy suggestions \\
\hline \multirow[t]{3}{*}{$\begin{array}{l}\text { Further improvements in teacher } \\
\text { distribution are needed }\end{array}$} & $\begin{array}{l}\text { - Further develop guidelines/norms for school-level teaching needs, } \\
\text { particularly for subject-specific teachers in high schools }\end{array}$ \\
\hline & $\begin{array}{l}\text { - Monitor the distribution of teachers more closely to ensure efficiency and } \\
\text { develop and implement the Human Resource Information System (HRIS) }\end{array}$ \\
\hline & $\begin{array}{l}\text { - Revise teacher transfer policy to make it a more effective tool to improve } \\
\text { teacher distribution }\end{array}$ \\
\hline \multirow[t]{3}{*}{$\begin{array}{l}\text { Hiring and deployment systems need to } \\
\text { be strengthened }\end{array}$} & $\begin{array}{l}\text { - Strengthen the accountability of regional and divisional offices for } \\
\text { carrying out processes in a timely way }\end{array}$ \\
\hline & $\begin{array}{l}\text { - Improve monitoring to ensure hiring timelines are met and that teachers } \\
\text { are in post at the beginning of the school year }\end{array}$ \\
\hline & - Improve coordination between the DBM and DepEd regional offices \\
\hline \multirow[t]{3}{*}{$\begin{array}{l}\text { High teacher absenteeism in highly } \\
\text { urbanized cities }\end{array}$} & $\begin{array}{l}\text { - Increase the authority of DepEd division offices and schools to deal with } \\
\text { absenteeism }\end{array}$ \\
\hline & $\begin{array}{l}\text { - Link teachers' attendance to their career development and performance } \\
\text { bonuses }\end{array}$ \\
\hline & $\begin{array}{l}\text { - Explore the potential for increasing community involvement in } \\
\text { monitoring teacher attendance }\end{array}$ \\
\hline
\end{tabular}

teachers and ultimately increase the learning opportunities available to all children. The 2013 DepEd order on teacher transfers and its alignment with school staffing guidelines was an important development, but further efforts will be needed to reconcile this policy with existing regulations and agreements on teacher employment conditions if it is to be effective. Introducing additional incentives such as cost-ofliving adjustments within teacher salaries and reevaluating hardship allowances in supporting transfers of teachers to remote schools would help to make transfers more attractive. However, incentives of this kind need to be introduced carefully and evaluated quickly to ensure that they are delivering the desired outcomes.

Systems at the school level for monitoring teacher attendance appear to work well, but sanctions for absenteeism and lateness are weak. On the whole, teacher absenteeism rates are low in the Philippines, but in highly urbanized cities as many as one in ten teachers were absent during the study team's unannounced visits. The findings of the study suggest that school principals and division supervisors need to have a wider range of sanctions and incentives to address attendance issues. For example, attendance rates could be a key results indicator in teachers' performance plans and ultimately be linked to their career development and to performance-based bonuses. Research from other countries has shown that school governing councils and parents can help to reduce teacher absenteeism. A systematic global review concluded that "a combination of close monitoring (community/parents level) and attractive incentives (teacher level) showed the highest potential to reduce teacher absenteeism." ${ }^{25}$

Over the last five years, the Philippines government has greatly increased the size of the basic education teacher workforce. Ensuring that the teacher workforce is serving the neediest schools and redressing imbalances in the existing distribution of teachers will ensure that these increases will translate into better student learning outcomes. 


\section{Endnotes}

1 See, for example, Bruns, B. and J. Luque (2014). "Great Teachers: How to Raise Student Learning in Latin America and the Caribbean." World Bank, Washington, D.C.

2 De Ree, J. (2016). "How Much Teachers Know and How Much It Matters in Class: Analyzing Three Rounds of Subject-specific Test Score Data of Indonesian Students and Teachers." Policy Research Working Paper No. WPS 7556. World Bank, Washington, D.C.

3 Chetty, R., J. Friedman, and J. Rockoff. (2011). "The Longterm Impacts of Teachers: Teacher Value-added and Student Outcomes in Adulthood." National Bureau of Economic Research, Cambridge MA.

4 See, for example, McEwan, P. (2013). "Improving Learning in Primary Schools of Developing Countries: A Meta-Analysis of Randomized Experiments."Wellesley College, Wellesley, MA.

5 This includes salaries for technical positions.

6 A second note in this series focuses on teacher quality and assesses the systems used to strengthen the competencies of teachers in the existing workforce.

7 In this section, years refer to school years. For example, 2014 refers to the 2014/15 school year.

8 Highly urbanized cities are cities with a population of more than 200,000 and with average revenues of at least PHP 50 million in 1991 prices. Other cities are defined as cities that do not meet the criteria to be classified as highly urbanized. Municipalities are administrative units for all other areas in the Philippines.

9 While STRs for each grade are not discussed in detail in this note, they show, on the whole, that STRs tend to be higher in the earlier grades.

10 These estimates were calculated by combining the ideal class size and the ideal number of teachers per class as recommended in the DepEd service standards.

11 Elementary school teachers are expected to be generalists.

12 Differences between absenteeism rates in HUCs and other cities and municipalities are not statistically different from the national average.

13 The household questionnaire included a short module on consumption and a set of questions on assets that have been used by the Department of Social Welfare and Development (DSWD) to undertake a proxy means testing (PMT) approach to estimating household consumption per capita. The results reported here are based on information gathered using the PMT approach, and a full description is included in a separate note.
14 The full results of the regression analysis reported here is included in additional annexes and tables accompanying the main PETSQSDS report.

15 Years of experience were also positively related to absenteeism, but the results were not statistically significant.

16 A similar analysis was also carried out at the division level, which confirmed that there was a positive relationship between high STRs and new teacher allocations.

17 The figures for shortages and surplus teachers are based on the approximate student-teacher ratios estimated from the DepEd guidelines.

18 DepEd order number 77 (2010). "Guidelines on the Allocation/ Deployment of New Teaching, Teaching-related, and Nonteaching Positions for FY 2010." Department of Education, Manila.

19 Albert, J. R. (2012). "Improving Teacher Deployment Practices in the Philippines." Policy Note 2012-02, Philippines Institute of Development Studies, Manila.

20 Similar data were collected for 2014, but, since the survey was conducted in the last quarter of 2014, this information does not cover all steps.

21 World Bank and AusAID (2010). "Philippines Basic Education Public Expenditure Review." World Bank and AusAID, Manila.

22 Unfortunately, it was not possible to track payments for newly hired teachers from the DepEd or DBM central offices down to the regional offices because these funds are comingled with funds for all newly created positions, including non-teaching positions, at all levels.

23 DepEd (2013). "Medium-term Expenditure Framework for Basic Education 2014-2020: Enrollment Projections and Cost Simulations under Alternative Scenarios." Department of Education, Manila.

24 In 2013, DepEd issued an order that granted transferring teachers a one-off redeployment allowance of PHP 18,000. However, this was discontinued after a year.

25 Guerrero. G., J. Leon, M. Zapata, and S. Cueto (2013). "Getting teachers back to the classroom. A systematic review on what works to improve teacher attendance in developing countries." Journal of Development Effectiveness 5(4): 466-488. 


\section{Policy Note 2: Developing a Proficient and Motivated Teacher Workforce}

\section{Introduction}

Over the last decade, research from many different countries has demonstrated the important role played by teachers in increasing students' learning and improving their academic performance.' Studies from countries as different as the US and Indonesia have shown the enormous benefits that follow from having adequate and effective teachers working in a country's schools. In Indonesia, a value-added analysis of student learning outcomes found that the more teachers know, the greater the improvements in the learning competencies of primary and junior secondary students. ${ }^{2}$ In the US, better teaching in elementary and secondary schools has been shown to increase students' college participation rates, raise their subsequent earnings, and improve other long-term outcomes. ${ }^{3}$

Providing teachers with good quality professional development opportunities has been shown to be an effective way of increasing their competencies and improving student learning outcomes in many different settings. A series of systematic reviews have been undertaken recently to assess the impact of different interventions on student learning outcomes in developing countries. ${ }^{4}$ One of the most consistent findings from these reviews has been the positive and significant impact that interventions to strengthen teaching practice, introduce innovative instructional methods, and strengthen teachers' subject knowledge can have on student learning. However, in many countries, such professional development opportunities frequently fail to meet even minimum levels of quality and fall short of what teachers want and need.

These reviews also highlight the importance of teachers' motivation in determining their effectiveness and ultimately in improving the learning outcomes of their students. They found some evidence that introducing financial incentives for teachers based on individual teacher or school performance can increase the amount that students learn.

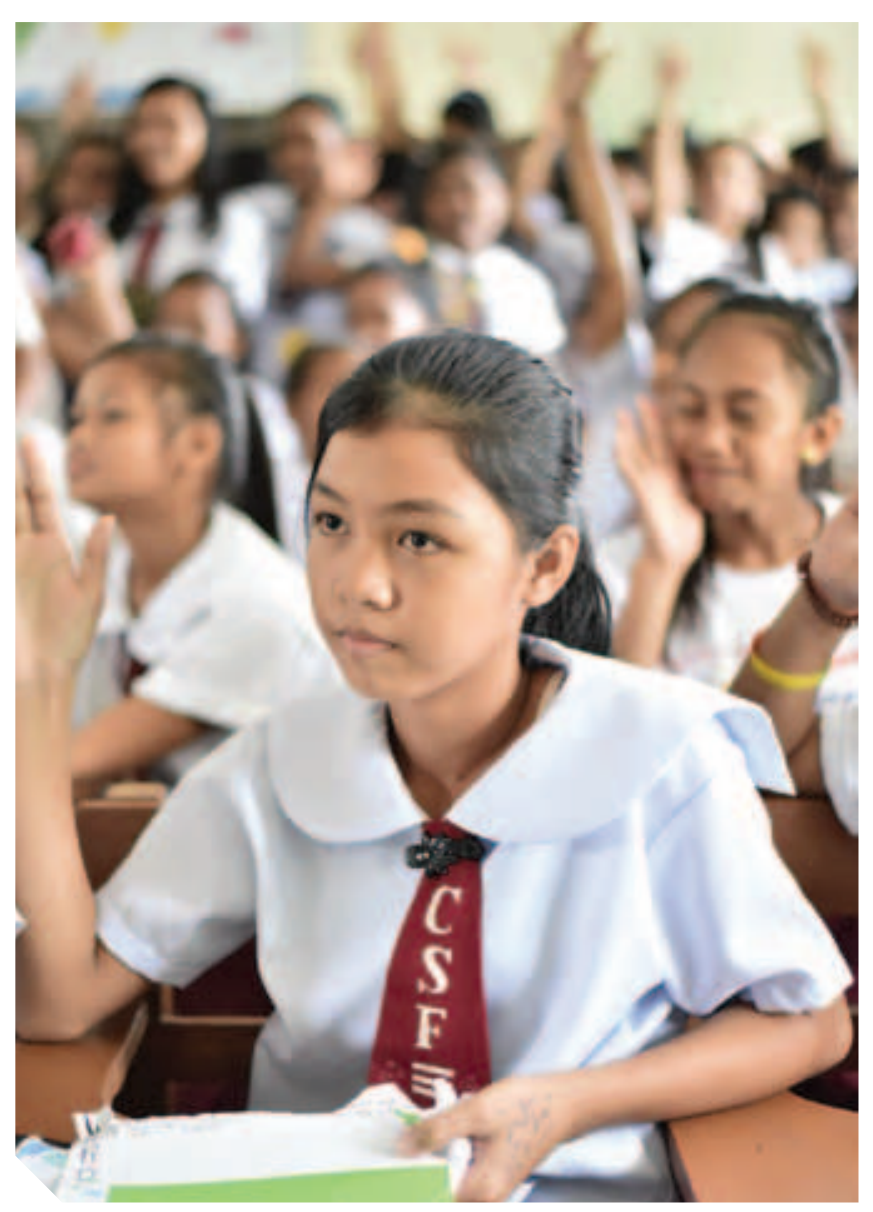

The purpose of this policy note is to provide an overall picture of teacher competencies in the Philippines and to assess whether the country's professional development systems deliver the training opportunities that teachers need to be effective. ${ }^{5}$ The findings reported in the note are based on a comprehensive survey of the public education system that tracked public education expenditures and assessed the quality of education services.

The note shows that elementary and high school teachers' subject knowledge is weak and a major constraint to improving student performance. While public spending on 
professional development activities has been increasing, these findings highlight the need to significantly expand in-service training opportunities and tailor them more closely to teachers' needs. Moreover, systems for professional development, teacher performance monitoring and incentives need to be aligned to improve teacher competencies and motivation.

\section{The Quality of Elementary and High School Teachers}

The competency of teachers both in terms of their subject matter knowledge and instructional methods has been shown to be an important determinant of student learning outcomes in the Philippines. ${ }^{6}$ However, getting an accurate measurement of the competencies of teachers is challenging. The Department of Education (DepEd) along with experts at the Philippines Normal University (PNU) and their partner university in Australia have developed a set of teacher competency assessments for the new $\mathrm{K}$ to 12 curriculum (Box 1). All the assessments have gone through a rigorous design and validation process to ensure that they accurately measure a teacher's knowledge of the subjects required to teach in elementary and high schools. In addition to subject content tests, the PNU also designed a shorter version of DepEd's Teacher Strengths and Needs
Assessment (TSNA). This self-assessment tool gives a picture of a teacher's pedagogical competence according to DepEd's own National Competency Based Teacher Standards (NCBTS). These assessments have been used by the PETS-QSDS study to provide evidence on levels of teacher competency in public elementary and high schools.

According to the results of the PETS-QSDS exercise outlined in Box 1, knowledge of subject matter among elementary and high school teachers is low in most subjects. With the exception of English at the elementary school level, the average elementary or high school teacher could answer fewer than half of the questions on the subject content tests correctly (Figure 1). For example, the median mathematics teacher in high school was able to answer only 31 percent of the questions completely correctly. Since these tests are closely aligned with the curriculum, the results suggest that teachers face significant challenges in teaching a considerable portion of the current $\mathrm{K}$ to 12 curriculum. In other words, the findings point to the need for significant improvements in teachers' skills and subject knowledge if they are to have a full command of the curriculum and to provide effective instruction in the classroom.

To explore why so many teachers were unable to answer the assessment questions correctly, the PETS-QSDS study used a partial credit model to look more closely into the

Figure 1: Teachers' Performance on Content Knowledge Assessments Was Poor

Percentage of questions answered correctly by the median teacher (binary scoring method), 2014

\section{Grade 6 elementary school teachers}

$80 \%$

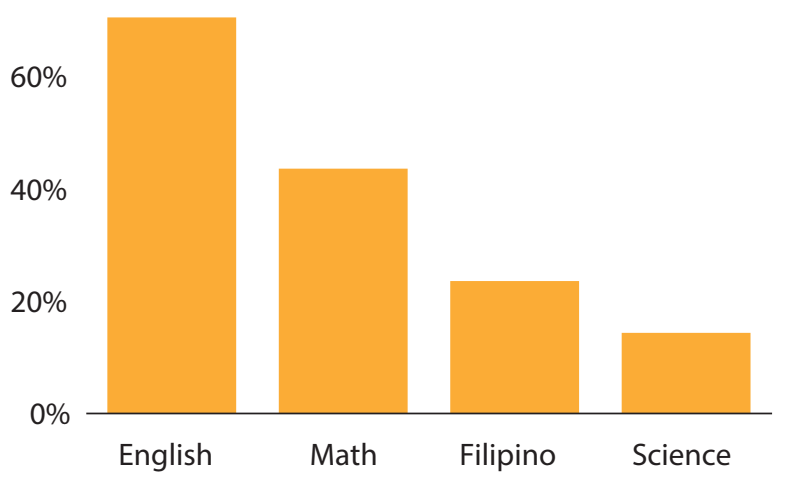

Grade 10 high school teachers

$80 \%$

$60 \%$

$40 \%$

$20 \%$

$0 \%$
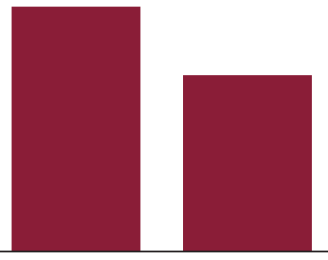

English

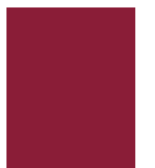

Filipino

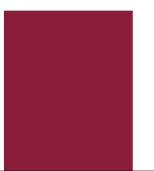

Science

Source: PETS-QSDS teacher content knowledge assessments. 
incorrect answers that teachers gave. For example, teachers were given a choice of four possible answers to each multiple choice question, and the three incorrect choices reflected different levels of understanding on the part of the respondents (Box 1).
The results of the partial credit scoring model showed that many teachers had some understanding of the subject area but lacked the higher order problem-solving skills necessary to teach the curriculum effectively. The model showed that, in most cases, teachers do have some understanding, skill,

\section{Box 1: PETS-QSDS Approach to Assessing Teachers}

As part of the PETS-QSDS study, a nationally representative sample of 377 Grade 6 (elementary) teachers and 946 Grade 10 (high school) teachers took two assessments:

1. A subject-based content assessment for measuring teachers' knowledge of the content of the K to 12 curriculum in English, Filipino, Mathematics, and Science. The assessments consisted of multiple choice and open-ended questions. Grade 6 teachers were randomly assigned to complete one subject assessment, whereas Grade 10 teachers completed the test in the subject that they taught.

2. A short form of the Philippine government's Teacher Strengths and Needs Assessment (TSNA) based on the National Competency Based Teacher Standards (NCBTS). The TSNA assesses a teachers' own perceptions of their pedagogical competence in the seven NCBTS domains: (i) social regard for learning; (ii) learning environment; (iii) diversity of learners; (iv) curriculum; (v) planning, assessing, and reporting; (vi) community links; and (vii) personal growth and development. Teachers were asked to rate their own level on a four-point scale from low to high on a set of statements related to the seven domains.

The content tests were drawn from larger assessments used by the Research Center for Teacher Quality (RCTQ) at the Philippines Normal University. The results of the PETS-QSDS tests are consistent with findings from a larger regionally representative study conducted by the RCTQ.

Two scoring rubrics were used for the content tests:

1. Binary credit - questions were marked either correct or incorrect.

2. Partial credit - each question was scored on a four-category scale, with 1 being "incorrect," 2 being "displays some understanding, skill, and knowledge," 3 being "displays a higher level of understanding, skill, and knowledge," and 4 being "completely correct."

Responses coded 1, 2 or 3 on the partial credit scale were recorded as 0 on the binary scale and those coded as 4 on the partial credit scale were recoded to 1 on the binary credit scale. In the case of the multiple choice items, the choices provided represented different levels of the teacher's understanding of the competency being tested. For open-ended questions, the graders marking the tests interpreted written responses according to the four-point scale.

The binary credit scores provided a clear picture of whether teachers displayed a thorough understanding of the competencies included in the curriculum. The partial credit scale, on the other hand, provided a more detailed assessment of how far teachers were from a complete understanding of the underlying competencies and from having the necessary knowledge to teach effectively.

Given the assessment categories used by teachers to assess their own competencies, the TSNA was scored using a rubric similar to the partial credit scale. To account for differences in the difficulty of test items, a one-parameter Rasch model was used for both the subject content tests and the TSNA to transform the raw test scores into scores (logits) that ranked teachers according to their underlying ability.

Full details of the instruments used and the methods for analyzing the data are available in RCTQ and SiMERR, (2015) "PETS-QSDS final report". 
and knowledge in all curriculum areas but not necessarily enough to answer all of the question correctly. For example, the scoring for a relatively difficult test question showed that, while only 20 percent of high school science teachers got the question completely correct, another 64 percent chose an answer that demonstrated some useful knowledge in the curriculum area covered by the question (Figure 2). These more detailed results can inform efforts by DepEd to develop professional development activities that are more closely aligned with the existing knowledge and abilities of the country's teachers.

The study team performed a simple regression analysis to explore associations between teachers' scores on the subject knowledge assessment and their characteristics. ' Overall, they found that teachers' performance was not associated with their levels of education or experience. For example, the scores of teachers who had obtained a postgraduate qualification did not differ from those of teachers with only a bachelors' degree in a statistically significant way. Although newly hired teachers tended to do less well than existing teachers in most of the subject-specific tests, these differences were not statistically significant either.

The better-performing high school teachers tended to teach in schools that serve better-off students. The PETS-
QSDS survey included a nationally representative sample of public elementary and high school student households. Using information on consumption and asset ownership that was collected in the survey, it was possible to rank student households by estimated levels of per capita household consumption. ${ }^{8}$ Using this indicator, it was possible to look at differences in the performance of teachers who were teaching different kinds of students. The key finding was that, in high school, poorer students tended to be taught by less competent teachers except in English. ${ }^{9}$ At the elementary level, no clear pattern emerged although poorer students tended to be taught by teachers that performed better on the Filipino test.

Teachers themselves generally assess their levels of skills as satisfactory. A shorter version of the TSNA self-assessment was given to the same teachers who completed the subject matter tests. These teachers were asked to rate their own skill level in seven domains that included social regard for learning (including punctuality and the use of information from a variety of sources for learning), the learning environment (maintaining a safe and conducive learning environment and setting high expectations for learners), and the curriculum (demonstrating a mastery of the subject and communicating learning goals). ${ }^{10}$ The teachers were given a set of statements related to each domain and were

\section{Figure 2: Despite their Overall Poor Performance, Teachers Have Some Relevant Skills and Knowledge Upon Which to Build}

Percentage of Grade 10 science teachers by their responses to easy and hard test questions, 2014

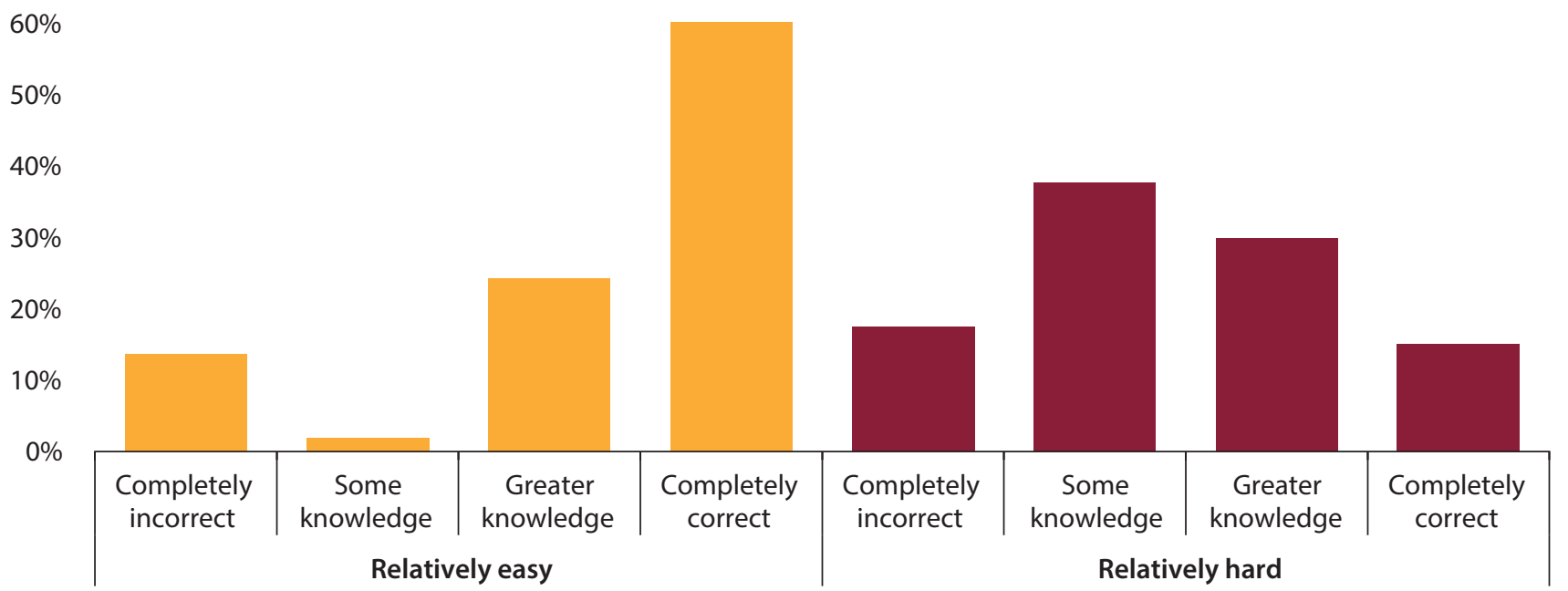

Source: Results of the PETS-QSDS Grade 10 teacher content knowledge assessment.

Note: The easy question is in the lowest quartile of Rasch model scores while the hard question is in the highest quartile of difficulty. 
asked to rate themselves on a scale of 0 (low) to 3 (high). On average, teachers rated themselves above 2 (satisfactory) on all domains. Moreover, there were no significant differences in the self-reported levels of strengths and weaknesses between teachers in elementary schools and those in high schools.

The teachers generally felt that they were weakest in the planning and the learning environment domains. The study team developed a common scale that accounted for the difficulties involved in obtaining the various competencies measured by the statements in the assessment. This made it possible to compare the relative strengths and weaknesses of teachers (Figure 3) and revealed that both elementary and high school teachers tended to rate their competencies in planning as the weakest. This domain includes competencies associated with instructional planning, the use of different assessment strategies to evaluate students' learning, and providing feedback to learners. The teachers also felt that they were weak in the competencies associated with the learning environment such as communicating high learning expectations and the ability to deal with students' behavioral issues.
Despite having had relatively low scores in the subject matter tests, teachers rated their competencies in the curriculum domain, including subject-matter knowledge, very highly (Figure 3). Competencies in this area include demonstrated mastery of the subject area and the appropriateness of the teaching methods used for different learning activities. Teachers rated their competency in this area higher than on any of the other competencies in the national standards. These results are in stark contrast with the same teachers' results on the objective subject matter tests (Figure 1). This mistaken perception of their own skills on the part of teachers highlights the difficulty they are likely to have in assessing their students' performance as well.

The results of the PETS-QSDS assessments suggest that selfassessments of teachers' strengths and weaknesses may not be a good basis on which to plan professional development activities. Simple correlation coefficients among the elementary school teachers who took these tests showed a weak relationship between the teachers' self-assessment ratings and the subject-matter test scores. In most cases, these correlations were not statistically significant. There was more variation in the picture for high school teachers. The self-assessment ratings for Filipino and Mathematics teachers

\section{Figure 3: Teachers Assess Their Weakest Skills as Those Associated with the Learning Environment and Planning and Assessment}

Average self-assessment scores on national competency-based standards, 2014

4
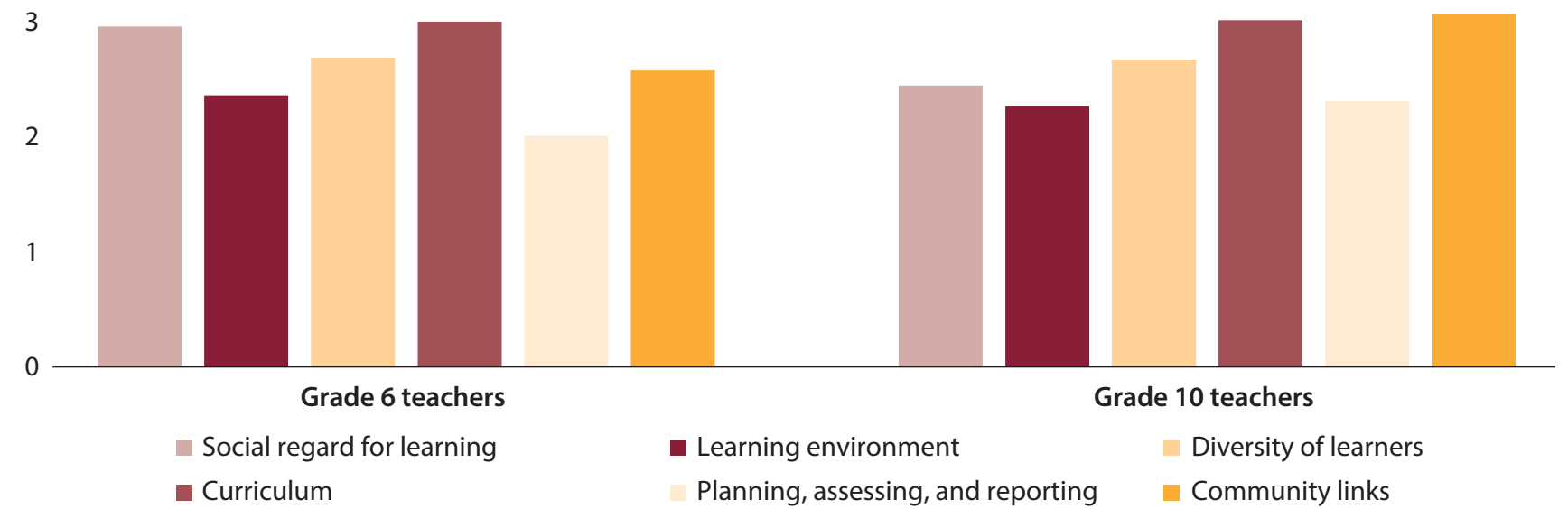

Grade 10 teachers

Curriculum

- Learning environment

Planning, assessing, and reporting
Diversity of learners

- Community links

Source: Results of the PETS-QSDS Grade 6 and 10 teacher strengths and needs assessment.

Note: The mean of the Rasch scores has been shifted by five units to report positive averages to aid interpretation. Higher scores are related to higher selfassessed skill levels in the particular domain. 
were generally positively correlated with their subject matter test scores, and these associations were statistically significant. However, similar correlations for English and Science teachers were generally not statistically significant. In all cases, the strength of the association was relatively weak, which casts doubt on the usefulness of existing selfassessment tools to plan teachers' in-service training.

\section{Supporting Teachers in School through Professional Development}

High quality and regular professional development opportunities are needed to address the weaknesses in the competencies of the existing teacher workforce. Studies from both developing and developed countries have shown that, when well-designed, in-service teacher training can increase teacher's content knowledge, improve their methods of instruction, and ultimately improve student learning outcomes." This section looks at in-service teacher training in the Philippines and assesses the systems that plan and finance these opportunities.

\section{Incidence and Intensity of Training}

The percentage of teachers in the Philippines who receive some annual in-service training is high even when compared to levels in high-income developed economies. The PETSQSDS survey collected detailed data on the in-service training received by sampled teachers in 2013 and 2014. The data revealed that more than three-quarters of all basic education teachers had received some in-service training (Figure 4). More high school teachers had received in-service training than elementary or kindergarten teachers. The team compared these rates with the rates of professional development activities for teachers in 34 OECD countries collected in the Teaching and Learning International Survey (TALIS). ${ }^{2}$ On average, 89 percent of public school lower secondary teachers in these countries participated in professional development activities in 2013. Participation rates in the Philippines were comparable although they were higher in Malaysia, an East Asian country with similar levels of student learning as the Philippines.

While the majority of teachers in the Philippines received some professional development training, it was less than in most other countries. In 2013, the average Grade 10 high school teacher received approximately five days of in-service

\section{Figure 4: Most Teachers Receive Some In-service Training but Only for Short Periods}

Percentage of teachers receiving in-service training and duration of all training received, 2013

\section{Participation, \% teachers}

$90 \%$

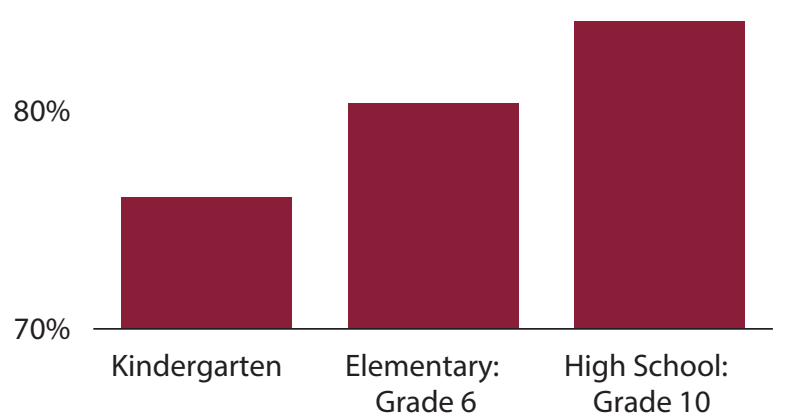

8

6

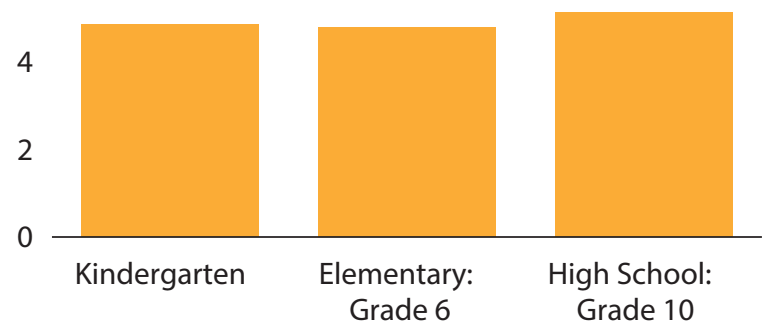

Source: PETS-QSDS national survey - teacher-level data. 
Figure 5: A Large Proportion of Teachers Felt They Needed More In-service Training Opportunities

Percentage of Grade 10 high school teachers by the type of additional support that they most need to improve their classroom teaching, 2014

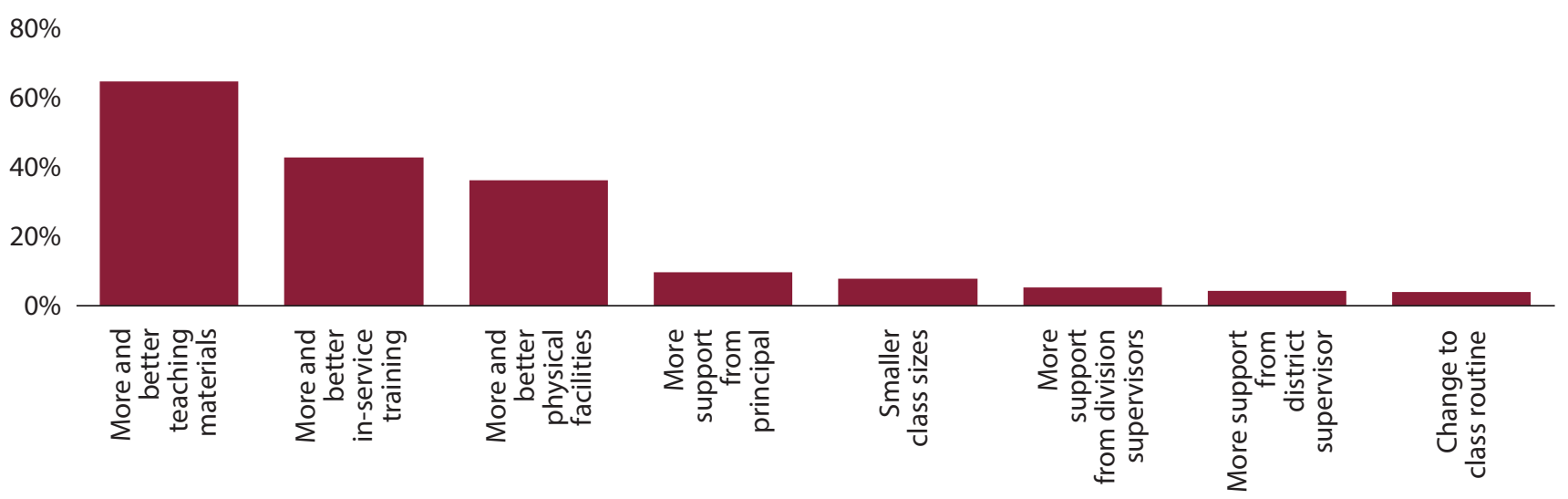

training. The PETS-QSDS survey was conducted at the end of 2014, which was approximately two-thirds of the way through the school year, and there were signs that the length of in-service training had increased over the 2013 level. For example, Grade 10 high school teachers had already received seven days of in-service training by the time of the survey. However, even this level is relatively low. The average lower secondary teacher in the OECD TALIS study received approximately eight days of professional development a year. ${ }^{13}$ Given the higher levels of teacher competency in OECD countries, it might be expected that the duration of in-service training in the Philippines should be longer.

The most common kind of training received by elementary and high school teachers in the Philippines was in subject content. Approximately, 40 percent of elementary and 30 percent of high school teachers reported attending some subject-based training during the 2013 school year. Training in methods of instruction and teaching was also relatively common with around 12 percent of elementary and high school teachers attending this kind of training in 2013.

The training usually took place in schools and was frequently conducted by school principals. About a half of all elementary teacher training and two-thirds of high school teacher training conducted in 2013/14 took place in schools. DepEd division offices were also commonly used to conduct training, while DepEd district-level offices were frequently used for training for elementary school teachers. Just over half of all training sessions for elementary school teachers and 39 percent of sessions for high school teachers were conducted by DepEd division, region, or central-level staff. School principals were also involved, conducting 32 percent of all training for elementary school teachers and 44 percent of training for high school teachers. Outside experts were used sparingly, accounting for less than 15 percent of training sessions.

Teachers were generally positive about the training that they had received, but a significant proportion felt that they needed more. Elementary and high school teachers ranked over 80 percent of the training that they received in 2013 as extremely useful. ${ }^{14}$ However, approximately 40 percent of teachers interviewed said that they needed more and better quality in-service training to improve their classroom teaching (Figure 5).

Systems at the school level to support teachers and identify their professional development needs do not seem to be working well. Each teacher is expected to complete an Individual Plan for Professional Development (IPPD) to outline their professional development needs. In preparing these plans, teachers are expected to use a toolkit prepared by DepEd which utilizes a teacher's own strengths and needs assessment using the TSNA. School principals are then expected to aggregate the needs of individual teachers into a School Plan for Professional Development (SPPD) and to submit it to the DepEd division office, which prepares a division-level master plan for professional development. 
In the PETS-QSDS team's interviews with teachers, it became clear that a significant proportion of teachers and schools had not developed professional development plans. For example, a quarter of high school teachers had never prepared an individual professional development plan (Figure 6). Even the plans that had been prepared were over a year old on average for both elementary and high school teachers.$^{15}$ School plans were even less common, with a quarter of elementary school principals and nearly one-third of all high school principals reporting that they had never prepared one. While the teachers and school principals that had completed plans agreed that their training was related to the goals set out in their plans, the PETS-QSDS training data show that the type and duration of training was more or less the same for those teachers who had filled out an IPPD and those who had not.

Other mechanisms to link teacher training to need also did not appear to differentiate training between teachers with different needs. The length and type of training that teachers received did not vary significantly by their characteristics such as levels of experience or qualifications. Moreover, the number of days of training received by teachers did not differ in line with their performance in the assessments administered as part of the PETS-QSDS survey. This concurs with other findings that have shown that most teacher training in the Philippines is based on a mass training model that provides all teachers with very similar training. Only 17 percent of school division superintendents (SDSs) said that division offices based their decisions about teacher training on the actual needs of teachers within the division. The majority of SDSs said that most division-level teacher decisions about training were based on the SDS's own assessment of needs or on directives from DepEd's central office.

Support from school principals for teachers' professional development also tended to vary considerably among elementary and high schools. Only two-thirds of Grade 10 teachers in high schools reported that the school principal had spent a full period in their classroom over the course of the whole 2013 school year. (The equivalent figure for Grade 6 elementary teachers was much higher at 82 percent.) When principals did observe classroom teaching, most of them gave written comments to the teacher, mostly focused on the teaching method used. Only around a quarter of comments concerned the teacher's knowledge of the subject content even though the PETS-QSDS assessments indicated that teachers have major weaknesses in this area. ${ }^{16}$

\section{Figure 6: The Implementation of Systems to Identify Professional Development Needs is Weak} Percentage of school staff completing professional development plans and the time since one was completed
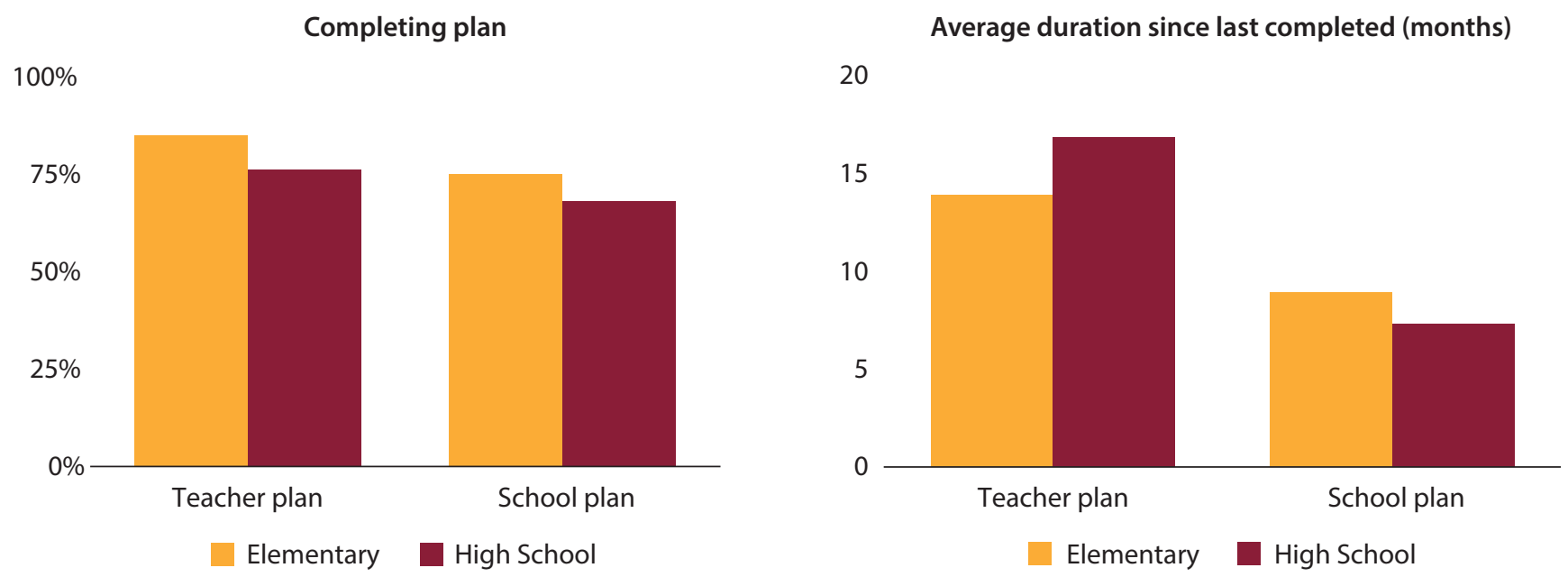

Source: PETS-QSDS national survey - teacher-level and school/principal data.

Notes: Information on teacher plans taken from interviews with Grade 6 (elementary) and Grade 10 (high school) teachers. 
Figure 7: The Budget for In-service Training Has Increased Recently but Utilization Rates Are Frequently Low Appropriations, allotments, obligations, and utilization rates for HRTD funds (PHP billions in 2014 constant prices), 2005-2014
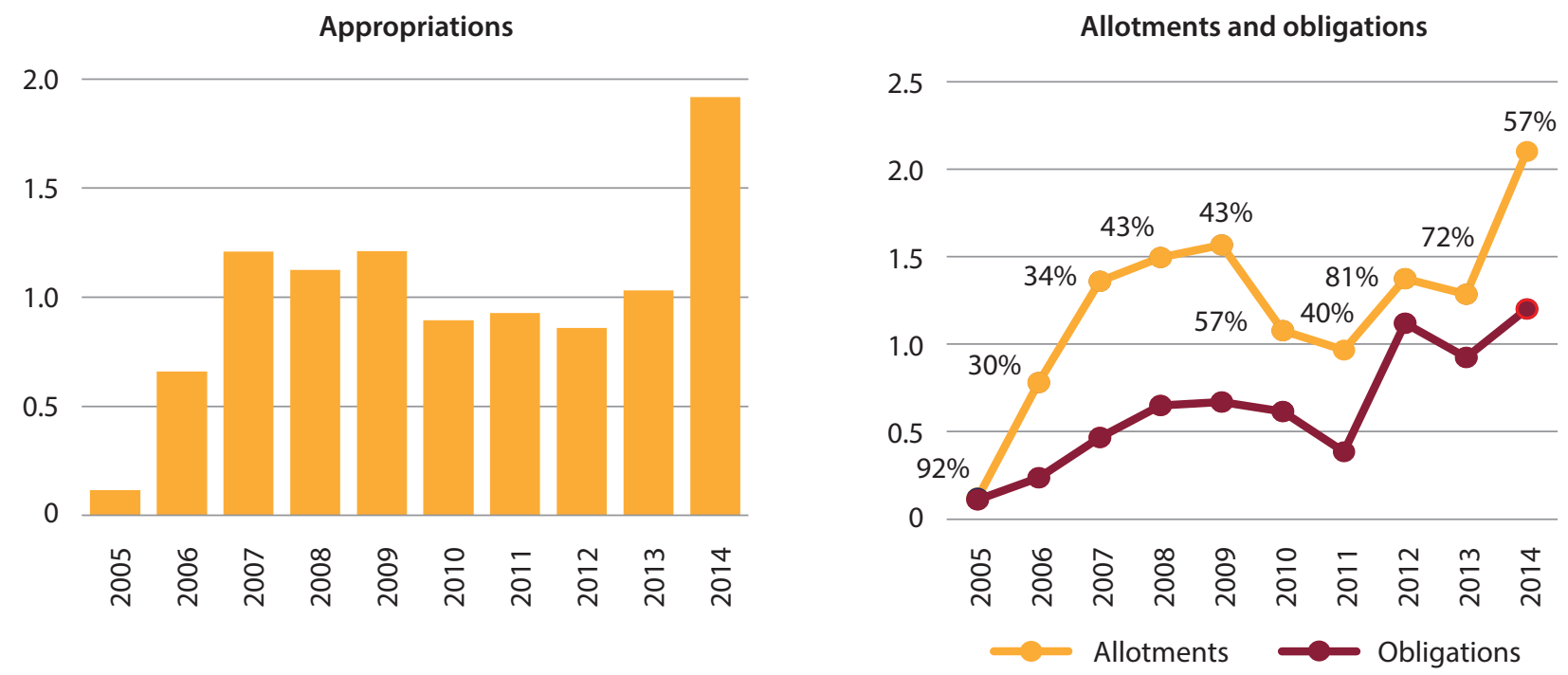

Source: Appropriations - Department of Budget and Management. All other data - DepEd Statement of Appropriations and Obligations, various years. Note: Allotments/obligations for a given year include current, continuing, and extended allotments/obligations. The utilization rate is indicated by the percentage figures in the graph and show the proportion of allotments obligated in a given year.

\section{Funding In-service Teacher Training}

In an effort to provide more and better in-service teacher training, DepEd has begun to increase the budget allocation for human resource training and development (Figure 7). Human resource training and development (HRTD) funds are the main professional development resources provided by DepEd. Most HRTD funds are spent on in-service training for teachers, but they are also used to provide training for non-teaching personnel. After having risen gradually since 2005, the budget for all in-service training nearly doubled to PHP 1.9 billion in 2014 to allow for more in-service training related to the new $\mathrm{K}$ to 12 curriculum. While all these funds are not solely for the use of in-service teacher training they represent approximately PHP 3,000 (US\$70) for every public basic education teacher.

However, the utilization of these funds fluctuates considerably. HRTD funds are managed by DepED's central office, and a portion are downloaded or transferred to DepEd's regional offices and onward to division offices for training activities. ${ }^{17}$ This process of downloading has often been delayed, which has resulted in relatively low utilization rates. For example, between 2005 and 2014, the average utilization rate for HRTD funds was only 55 percent (Figure 7). Even in 2014 after the significant increase in the HRTD appropriation, only 57 percent of the budget was used because of delays in downloading these funds.

The PETS-QSDS data revealed that DepEd's allocations of HRTD funds to each region are positively correlated with the number of public school teachers in each region. Regions with a larger number of teachers received a larger HRTD allocation. However, it was not possible to assess whether HRTD funds were also allocated according to the different professional development needs of teachers in each region.

The PETS-QSDS survey also tracked the flow of HRTD funds and found that a relatively small share is downloaded to DepEd division offices. In 2014, about half of all HRTD funds were allocated for training activities provided at DepEd's central office. The remainder of the HRTD funds was split 
relatively equally between DepEd's regional offices and division offices. Given that division offices and their staff have the most contact with schools and are thus most likely to know their in-service training needs, it is surprising that a larger share of HRTD funds is not downloaded to divisions.

On the whole, the tracking exercise also found that all HRTD funds that DepEd central office downloaded to regional offices were received in full. The specific amounts released by DepEd central office closely matched the amounts that the regional offices reported receiving. However, two regional offices did not report having received any funds even though records in the central office showed that funds had been transferred to them. This is more likely to be due to poor record keeping in DepEd regional offices than to be a leakage of funds.

The share of HRTD funds downloaded from DepEd's regional offices to division offices varies enormously (Figure 8). In total, around 58 percent of the regional HRTD funds that are received by DepEd regional offices are downloaded to DepEd division offices. However, the proportion of funds that regional offices retain varies enormously. Some regions retain all of their
HRTD funding and do not download any funding for division offices, while other regions download all of their HRTD funds and the responsibility for their use to division offices.

Little information is available on how DepEd's regional offices used their retained HRTD funds. The regional offices retained approximately 42 percent of all of the HRTD funds that they received from DepEd central office rather than downloading them to division offices. DepEd expects regional offices to use these funds to organize mass teacher training on, for example, the introduction of the new K to 12 curriculum. DepEd's guidelines governing the use of these funds require regional offices to keep detailed records on who has been trained and the kind of training provided. However, when the PETS-QSDS study team visited all regional offices to collect this information, no such information was available. This lack of records greatly reduces the transparency of the use of these funds.

Significant delays in the allotment process account for the relatively low utilization rate of HRTD funds. Fewer than 15 percent of regional offices had received their HRTD allotment from DepEd's central office by the end of the first quarter of

Figure 8: The Share of Regional HRTD Funds Transferred to Division Offices Varies Enormously Amounts of HRTD funds received by DepEd regional offices and transferred to DepEd division offices, 2013

Received by DepEd regional offices (PHP millions)

80

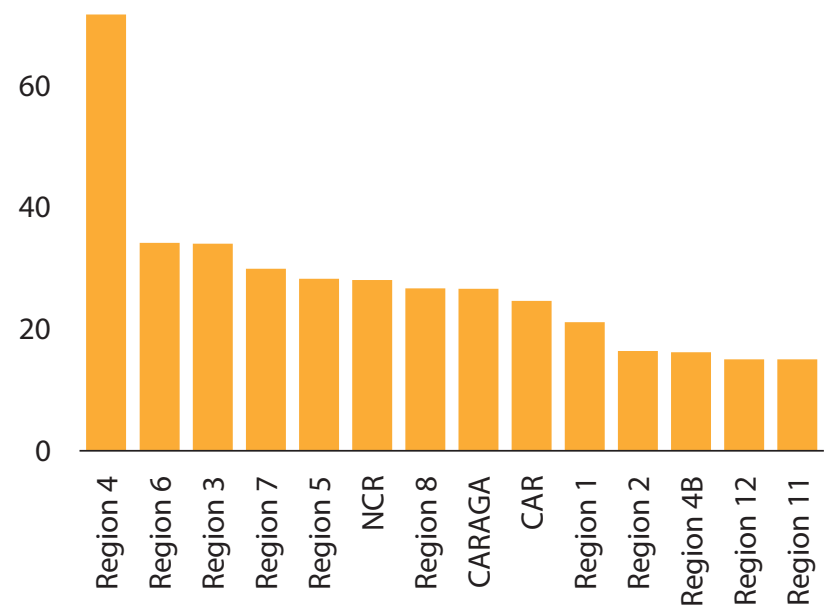

Share downloaded to division offices

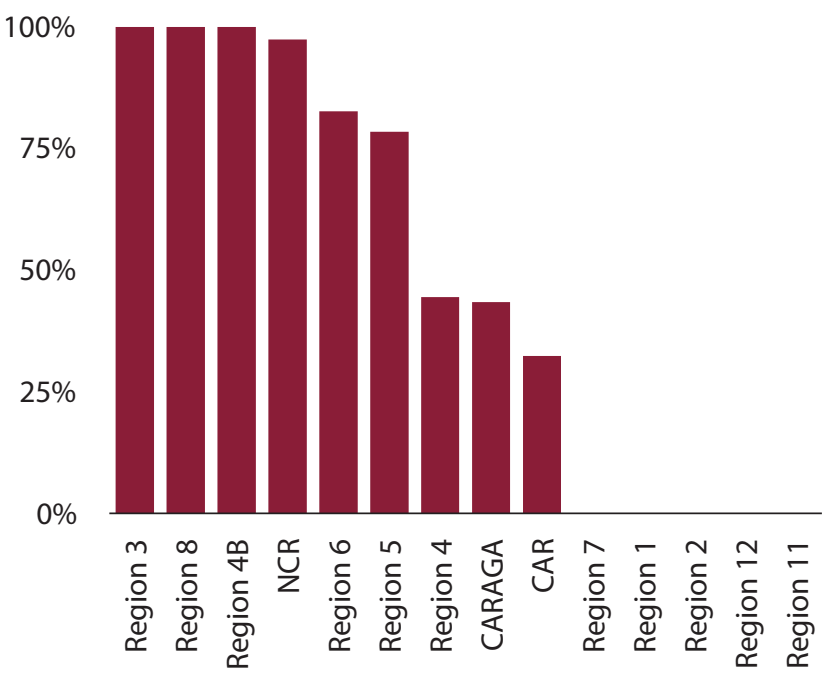

Source: PETS-QSDS national survey - DepEd regional office level.

Note: The information on the HRTD funds received by Region 7 from the central office is taken from the central office database because some information was missing from the regional questionnaire. Only regions reporting receipt of HRTD funds are included. 
Figure 9: A Significant Number of Division Offices Receive HRTD Funds Very Late in the Financial Year Percentage of division offices receiving 2013 HRTD funds by the quarter during which it was received

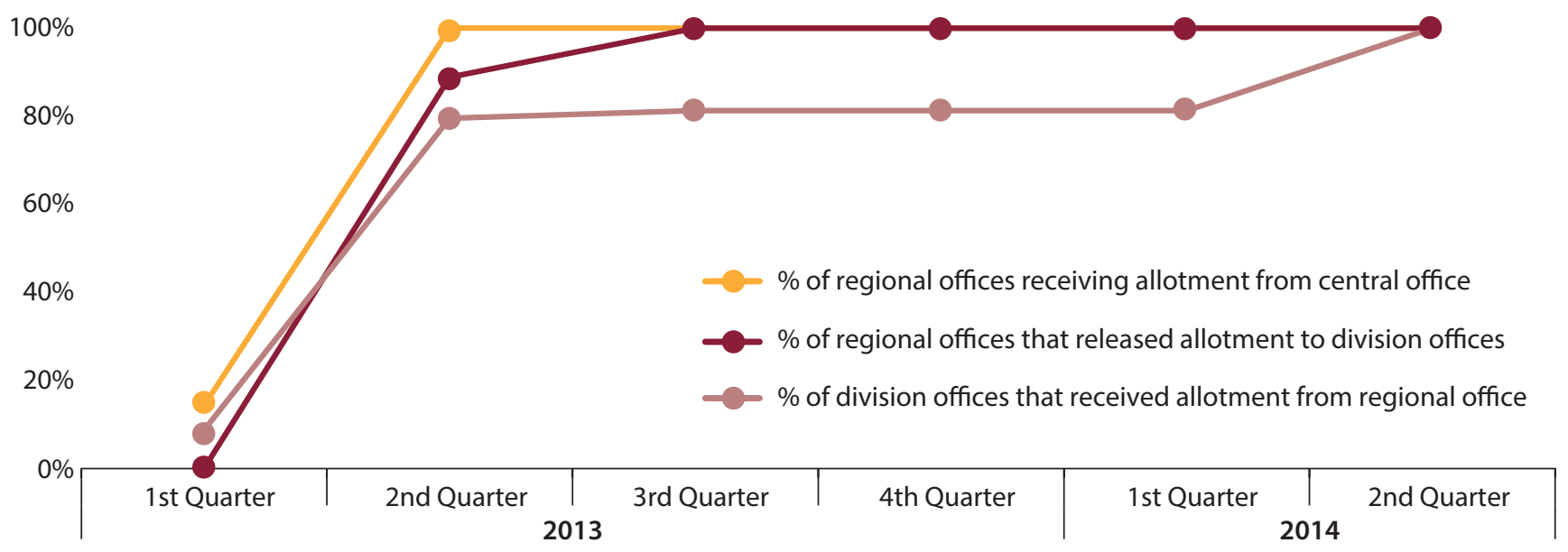

Source: PETS-QSDS national survey - DepEd region and division office levels. Note: Only those sampled divisions that reported receiving HRTD funds are included.

2013 (Figure 9). However, by the end of the second quarter, all regional offices had already received their allotments and most had downloaded funds to at least some of their division offices. However, 19 percent of the divisions that received HRTD funds received their allotment a year after the regional office first received its transfer of funds from DepEd's central office.

These delays can happen because the regional offices of the Department of Budget Management (DBM) are required to carefully check the funds requested by DepEd's central and regional offices on the Sub-Allotment Release Orders (SARO). Further delays occur because of the late release of cash allocations. One-fifth of the DepEd division offices that had received their HRTD allotments for 2013 at the time of the PETS-QSDS survey had not received the associated release of funds (notice of cash allocations) needed to use or obligate the funds. The difficulties in using the allotted funds are particularly concerning given the clear need for in-service training that was highlighted by the PETS-QSDS teacher content knowledge assessments.

\section{Teacher Remuneration}

The level and timeliness of salary payments can be an important factor in motivating teachers, which in turn can affect levels of student learning. The PETS-QSDS study did not formally track teachers' salaries but did ask a nationally representative sample of teachers some questions about the adequacy of their salary payments and whether they received their salaries on time and in full.

Cross-country comparisons indicate that teachers in the Philippines are relatively well paid but their salary scale is more compressed. Comparable information on other East Asian countries shows that the starting salary of teachers in the Philippines is relatively high. For example, the average earnings of a newly hired elementary school teacher in the Philippines is equivalent to 150 percent of per capita GDP compared with only around 50 percent in Indonesia, Malaysia, and Thailand (Figure 10). However, earnings do not increase very quickly after teachers are hired. After 15 years, salaries increase by only 15 percent in the Philippines, which 
Figure 10: Teacher Salaries Tend to be Higher in the Philippines than in Other Countries in the Region Elementary school teacher salaries as a percentage of per capita GDP, 2010

$300 \%$

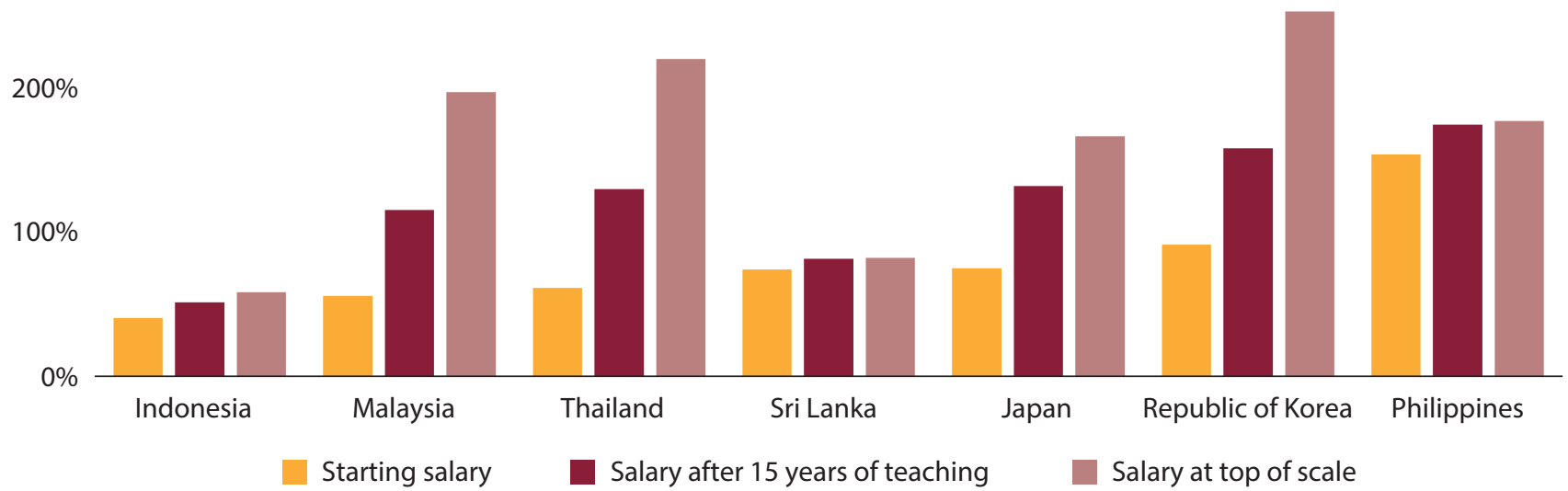

Source: UNESCO (2012). "Global Education Digest," UNESCO Institute for Statistics, Montreal.

is low compared to other countries. These relatively small salary increases over the course of a teacher's career are unlikely to motivate them significantly. The PETS-QSDS study found that high school teachers with a post-graduate degree felt that their remuneration was not adequate. Moreover, about one-fifth of teachers reported that they had to have other jobs or sources of income to supplement their earnings from teaching.

However, teachers also receive a bonus based on their school's ranking on a set of performance-based indicators including how well the school's students score on the National Achievement Test. Teachers' performance-based bonuses in 2015 ranged from PHP 5,000 to PHP 35,000, which was equivalent to between 1 and 9 percent of a teacher's average annual salary. ${ }^{18}$

Teachers' motivation can also be affected by the timeliness of their salary payments. The PETS-QSDS study found that, while the majority of teachers were paid on time, 40 to 50 percent of newly hired kindergarten and elementary school teachers received their salaries late (Figure 11).

Most teachers also reported that they had been paid correctly and were not owed any salary payments. Only around 11 percent of elementary and high school teachers reported that they were owed salary payments from the government. However, the length of the delay was much longer for elementary school teachers than for high school teachers. Elementary school teachers had to wait an average of six months for their salary payments compared with a four-month wait for high school teachers.

\section{Figure 11: Some Teachers Experienced Delays in Receiving their Salaries and Others Were Still Owed Back Payments} Percentage of teachers whose salary payments were late, 2014

$60 \%$

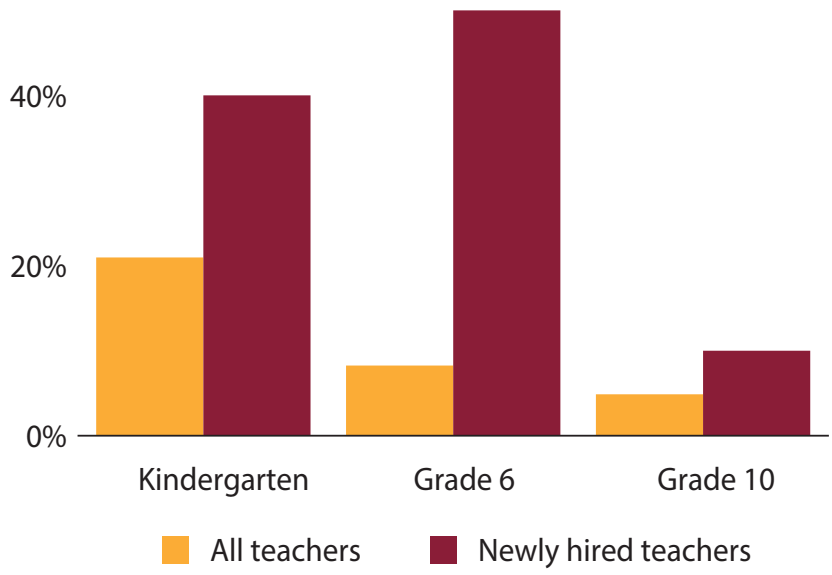

Source: PETS-QSDS data from DepEd teacher questionnaires for sampled teachers, 2014. 


\section{Policy Directions for Strengthening Systems to Support Teacher Development}

This note has shown that teacher competencies are weak and that systems to support teacher development are inadequate. While some of the gaps in teacher competencies are partly due to weaknesses in pre-service teacher training and induction, more efforts need to be made to increase the support available to teachers who are already teaching in schools.

A first step would be to raise levels of funding to increase both the duration and quality of in-service training for basic education teachers. As this note has shown, a significant proportion of HRTD funds are used for training that is organized at the regional level and above. Previous studies have found that the most successful professional development models are provided within schools or at the local level. They also provide opportunities for teachers to collaborate and support each other in implementing new knowledge and techniques at the school level. ${ }^{19}$

Providing divisions and schools with a larger share of professional development funding would make training more relevant and thus result in more substantial improvements in teachers' competencies. DepEd could revise its guidelines on the use of HRTD funds to require DepEd's regional offices to download a larger proportion of these funds to divisions and schools. Currently the DepEd guidelines encourage the provision of mass training at the regional level, which makes the training too remote from the actual needs of teachers at the school level. If more funds are provided to DepEd's division offices and schools, it will also be vital to improve the timeliness of fund release to give the recipients time to properly plan and implement their professional development activities.

DepEd is currently establishing "school learning action cells" in elementary schools to strengthen early grade learning outcomes. These cells, or groups, of kindergarten to grade 3 teachers meet regularly and provide opportunities for members to learn from each other and to collaborate on strategies to improve teaching and learning. These school learning action cells have the potential to increase the quantity and improve the quality of in-service training opportunities for teachers. However, it is vital that these cells are monitored and evaluated closely by DepEd to ensure that their potential is fully realized.

This note has also shown that the monitoring of the use of HRTD funds has been weak and needs to improve if these resources are to be used more effectively. Information on who is being trained and the type of training being provided is often unavailable. This makes it impossible to monitor how the funds are being used and whether teachers' professional development needs are being met. Developing simple reporting formats for DepEd's regional and division offices to record how they use HRTD funds would greatly facilitate the monitoring and evaluation of in-service training provision by DepEd.

The existing system for identifying and planning professional development activities needs to be strengthened. This note has shown that the TSNA may not be adequate for identifying teachers' professional development needs. Developing a diagnostic teacher competency assessment to better identify teachers' in-service training needs could support improvements in this area. Moreover, neither teachers nor schools seem to be routinely preparing their professional development plans, and these plans do not seem closely related to the in-service training opportunities currently being provided. Greater efforts need to be made to ensure that teachers and schools use these plans to help division offices to plan in-service training opportunities better.

Stronger links between teacher performance appraisals, professional development opportunities and career development for teachers may create stronger incentives for teachers, school principals and administrators to utilize these systems and strengthen professional development opportunities. For example, individual and school plans for professional development and their implementation could 
be used more specifically in decisions over promotion or in determining performance bonuses (see Box 2).

Increasing the number and effectiveness of teachers has been a central component of efforts in the Philippines to raise the quality of basic education. While significant improvements have been made in terms of the number and distribution of teachers, there is an urgent need to provide greater support to teachers to improve their competencies and effectiveness in the classroom. Only then will efforts to provide adequate teachers to all schools translate into better quality and improved learning outcomes.

\section{Box 2: Indonesia's Integrated Framework for Teacher Accountability}

The Ministry of Education in Indonesia is starting to implement its integrated Teacher Professional Management System (TPMS). The system consists of three main elements:

- Competency Testing. Teachers are expected to undergo a competency assessment to identify their strengths and weaknesses. The competency test is focused on teachers' subject knowledge, which has been shown to be strongly related to student learning outcomes. Performance on the competency test is expected to be used as one of the key criteria for teachers' career advancement.

- Performance Appraisal. A school-based scheme has been piloted that links the outcomes of teachers' annual performance appraisal to increments in the salary scale in order to give them an incentive to improve their performance.

- Continuous Professional Development. This component covers a number of different aspects of in-service teacher training including the induction of teachers into schools, mentoring, and the activities of local teacher working groups.

The aim of the TPMS is to link these three components together and make teachers more accountable for both their work performance through the annual appraisal and for taking advantage of in-service training opportunities. By scoring well on their appraisals and by participating in training, teachers can earn credit points that are ultimately linked to salary increases and promotion. While the TPMS is not yet being fully implemented, it represents a major development in terms of the provision of incentives and is expected to increase the motivation of teachers to improve how they teach. Integrating continuous professional development into the TPMS framework has also provided the government with the information necessary to target teachers' professional development activities better.

It is expected that the TPMS will sustain the momentum towards improving the quality of teachers in Indonesia and will establish a quality assurance mechanism that will ensure higher education standards well into the future.

Sources: Ragatz, A. (2015). "Teacher Quality and Management. Background Study for the Preparation of the Education Chapter of the National Development Plan, 2015-2019." Jakarta, Ministry of Planning, Republic of Indonesia., and Chang, M.C., S. Shaeffer, S. Al-Samarrai, A. Ragatz, J. de Ree, and R. Stevenson (2013). "Teacher Reform in Indonesia: The Role of Politics and Evidence in Policy Making." Directions in Development. World Bank, Washington, D.C. 
Table 1: Strengthening Teacher Support Systems

\begin{tabular}{|c|c|}
\hline Findings & Policy suggestions \\
\hline $\begin{array}{l}\text { Teacher subject knowledge is } \\
\text { generally low }\end{array}$ & - Strengthen pre-service and in-service training opportunities for all teachers (see below) \\
\hline $\begin{array}{l}\text { Professional development } \\
\text { opportunities are limited } \\
\text { and delivery mechanisms are } \\
\text { weak }\end{array}$ & $\begin{array}{l}\text { - Increase funding and opportunities for effective professional development for teachers } \\
\text { - Provide a greater share of this funding to division offices and schools to enable them } \\
\text { to organize professional development activities } \\
\text { - Transfer HRTD funds in a more timely manner } \\
\text { - Increase the transparency of HRTD funds through improved reporting by DepEd region } \\
\text { and division offices and increase central office monitoring of fund use }\end{array}$ \\
\hline $\begin{array}{l}\text { Systems to identify teachers' } \\
\text { professional development } \\
\text { needs are weak }\end{array}$ & $\begin{array}{l}\text { - Revaluate existing teacher strength and needs assessments and teacher professional } \\
\text { development planning } \\
\text { - Develop diagnostic teacher competency tests to identify teachers' in-service training } \\
\text { needs } \\
\text { - Develop content for professional development activities that will address existing } \\
\text { weaknesses } \\
\text { - Evaluate and scale up the use of school learning action cells as the main venue for } \\
\text { in-service training }\end{array}$ \\
\hline $\begin{array}{l}\text { A greater need to align } \\
\text { teacher accountability } \\
\text { systems to raise teacher } \\
\text { motivation and competencies }\end{array}$ & $\begin{array}{l}\text { - Support a stronger alignment between professional development planning, career } \\
\text { development and performance incentives }\end{array}$ \\
\hline
\end{tabular}




\section{Endnotes}

1 See for example, Bruns, B. and J. Luque (2014). "Great Teachers: How to Raise Student Learning in Latin America and the Caribbean."World Bank, Washington D.C.

2 De Ree, J. (2016). "How Much Teachers Know and How Much It Matters in Class: Analyzing Three Rounds of Subject-specific Test Score Data of Indonesian Students and Teachers." Policy Research Working Paper No. WPS 7556. World Bank, Washington D.C.

3 Chetty, R., J. Friedman, and J. Rockoff. (2011). "The Long-Term Impacts of teachers: Teacher Value-added, and Student Outcomes in Adulthood," National Bureau of Economic Research, Cambridge MA.

4 See, for example, McEwan, P. (2013). "Improving Learning in Primary Schools of Developing Countries: A Meta-Analysis of Randomized Experiments."Wellesley College, Wellesley MA. Glewwe, P.W., E. A. Hanushek, S.D. Humpage, and R. Ravina. (2011). "School Resources and Educational Outcomes in Developing Countries: A Review of the Literature from 1990 to 2010." National Bureau of Economic Research, Cambridge MA.

5 Another note in this series assesses the systems used to hire and deploy teachers in the Philippines.

6 See for example, Yamauchi, F. and Y. Liu (2013). "Impacts of an Early Stage Education Intervention on Students'Learning Achievement: Evidence from the Philippines." Journal of Development Studies 49(2) and Tan, J. P., J. Lane, and P. Coustere. (1997). "Putting Inputs to Work in Elementary Schools: What Can Be Done in the Philippines?" Economic Development and Cultural Change 45(4): 857-879.

7 The full results of the analysis reported here is included in a set of additional annexes and tables accompanying the main PETSQSDS report.

8 The household questionnaire included a short module on consumption and a set of questions on assets that have been used by the Department of Social Welfare and Development (DSWD) to undertake a proxy means testing (PMT) approach to estimating household consumption per capita. The results reported here are based on information gathered using the PMT approach, and a full description is included in a separate note.

9 These results are statistically significant for Filipino and Mathematics but not for Science.

10 Box 2 describes all seven domains contained in the teacher competency standards. All teachers rated their skills in the professional development and growth domain highly. These results are not discussed in this note.
11 See, for example, McEwan, P. (2013) "Improving Learning in Primary Schools of Developing Countries: A Meta-Analysis of Randomized Experiments"Wellesley College, Wellesley, MA; Glewwe, P.W., E. A. Hanushek, S.D. Humpage, and R. Ravina (2011) "School Resources and Educational Outcomes in Developing Countries: A Review of the Literature from 1990 to 2010"National Bureau of Economic Research, Cambridge MA; and the Council of Chief State School Officers (2009) "A Meta-Analysis Study of the Effects of Teacher Professional Development with a Math or Science Content Focus on Improving Teaching and Learning." Washington D.C.

12 OECD (2014). TALIS 2013 Results: An International Perspective on Teaching and Learning, OECD Publishing, Paris.

13 OECD (2014). "TALIS 2013 Results: An International Perspective on Teaching and Learning." OECD Publishing, Paris.

14 The sampled teachers were asked to rank each training they attended from 1 (least useful) to 7 (most useful). Grade 6 teachers rated 88 percent of all training as a 6 or 7 with 84 percent of Grade 10 teachers doing the same.

15 Just under 90 percent of school principals reported that teachers were expected to complete an IPPD annually.

16 Similar results were found when school principals were asked the same questions.

17 Downloading refers to the issuance of a sub-allotment release order from DepEd central office to DepEd region and division offices. Sub-allotments are authorizations issued by the central office of DepEd transferring a portion of an available allotment to DepEd region or division offices. See DepEd order No. 25 (2014) "Guidelines for the Utilization of HRTD Funds," Department of Education, Manila and DepEd order No. 66 (2010) "Policies and Guidelines on Planning and Administration/Management of the Human Resource Training and Development Program," Department of Education, Manila.

18 Based on the average annual basic salary of a Teacher 1 position on Grade 18 Step 8.

19 Blank, R. and N. Alas (2009). "Effects of Teacher Professional Development on Gains in Student Achievement." Report prepared for the Council of Chief State School Officers (CCSSO), Washington D.C. 


\section{Policy Note 3: Building Better Learning Environments}

\section{Introduction}

Evidence from around the world has shown that improving school infrastructure leads to better learning outcomes. For example, a 2011 review of the economics literature over the last 20 years showed that the availability of basic school infrastructure (such as classrooms, desks, and chairs) and facilities (such as electricity, libraries, and blackboards) is frequently associated with better student learning achievement. ${ }^{2}$ These findings have been backed up by a systematic review of recent impact evaluations, which showed that infrastructure investments have a positive impact on school enrollment rates, attendance rates, and learning achievement. ${ }^{3}$ Also, research in the Philippines has shown that reducing the number of students per classroom is associated with better student learning outcomes, particularly in rural schools. ${ }^{4}$

Ensuring that schools have adequate infrastructure of good quality is a central pillar of government efforts to improve education outcomes in the Philippines. Over the last five years, the government has been conducting a renewed reform effort to increase access to good quality basic education. It has supported these reform efforts with significant increases in public spending on education. In real terms, school infrastructure spending in 2015 was five times higher than in 2010 and has been used to reduce classroom congestion and the proportion of schools operating multiple shifts.

The purpose of this policy note is to provide a snapshot of the state of existing school infrastructure in the Philippines and to assess the government systems that build and repair school buildings and facilities. The findings come from a comprehensive survey of the public education system carried out for the Philippines Public Education Expenditure Tracking and Quantitative Service Delivery Study (PETS-QSDS) that tracked public education expenditure and assessed the quality of education services.

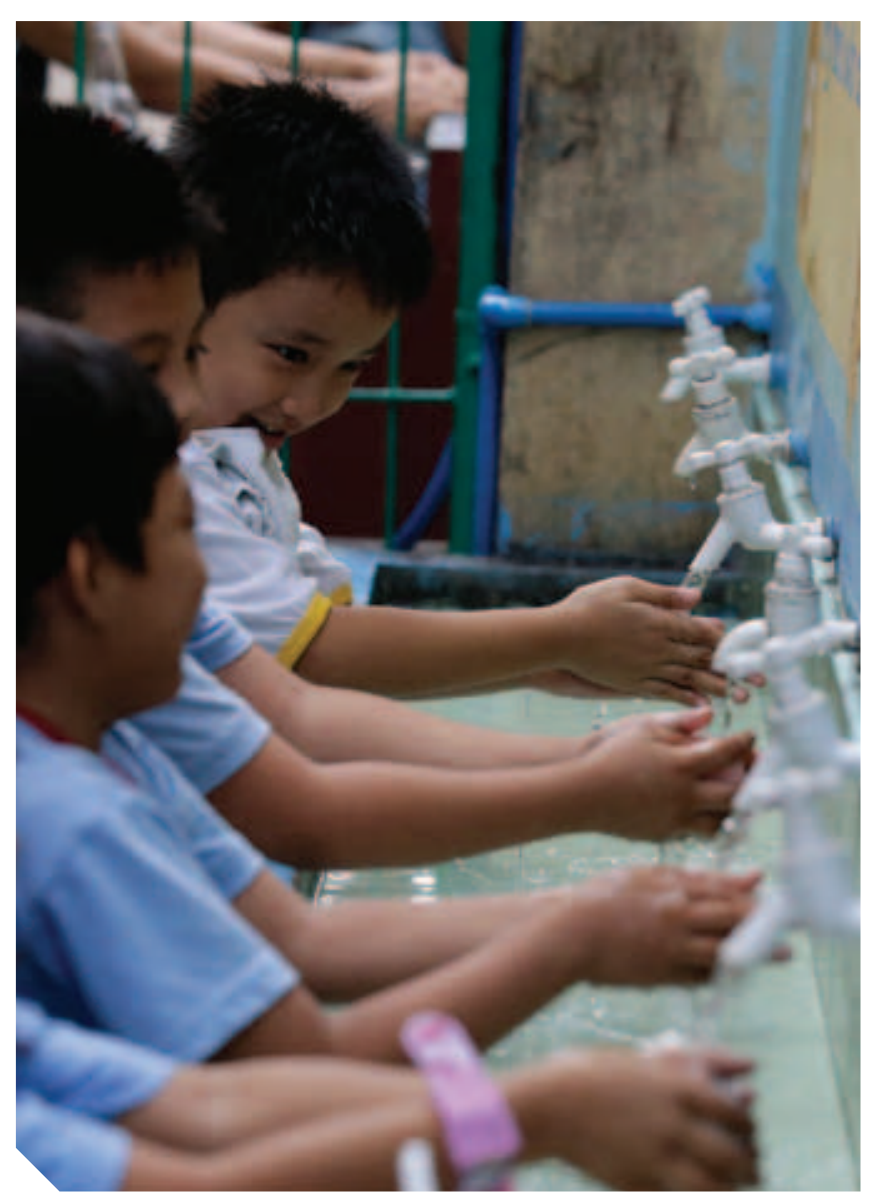

In assessing government systems, it primarily focused on projects managed by the Department of Public Works and Highways (DPWH), which is responsible for the bulk of school infrastructure projects.

The note finds that, while there is a continuing need to invest in school infrastructure, any increases need to be combined with efforts to improve allocation mechanisms and project implementation. The note also finds that existing monitoring, coordination, and accountability mechanisms are weak. The note argues that increasing the involvement of schools in the planning, implementation, and monitoring process is a promising route to ensuring that all students are provided with good quality schools and learning environments. 


\section{The Current State of School Infrastructure}

The bulk of public school infrastructure in the Philippines was built using funds from national and local governments, with only a limited proportion built using funds from private sector sources. For example, in 2014 approximately threequarters of all instructional rooms in elementary and around two-thirds of rooms in high schools were built by the central government. Local governments were responsible for building around 10 percent of instructional rooms across the whole country, although wealthier city governments have played a much more significant role than their counterparts elsewhere with approximately one-quarter of all instructional buildings being built with local government funds in highly urbanized cities. ${ }^{5}$

While high schools tend to be better equipped than elementary schools, around one-third have no safe source of drinking water (Figure 1). This is partly because more high schools than elementary schools are located in urban areas where they rely on piped water and do not have access to alternative sources such as drinking wells. When schools do not have access to safe drinking water, this can be detrimental to attendance and learning, particularly when students and teachers have to leave the school premises to collect water.

Schools in municipalities tend to have more limited facilities than those in cities. Municipalities include almost all rural areas in the Philippines, and rural schools tend to be less well equipped than their urban - and generally wealthier - counterparts. For example, elementary schools in highly urbanized cities are almost twice as likely as schools in municipalities to have a health clinic (Figure 1).

However, schools in more densely populated areas tend to be larger and have more congested learning environments. Schools, particularly high schools, tend to be much larger in city and urban areas. For example, in 2014 the average high school in a highly urbanized city had approximately 1,700 students compared to about 1,000 students and 570 students in city and municipality schools respectively. These large numbers translate into more students in each classroom in highly urban areas (Figure 2). On average, 51 high school students share each classroom in highly urbanized cities compared with only 39 students per classroom in municipal schools. Moreover, around 30 percent of high schools in these highly urbanized cities have student/

Figure 1: High Schools Tend to Have Better Facilities than Elementary Schools

Availability of key facilities in elementary and high schools, 2014
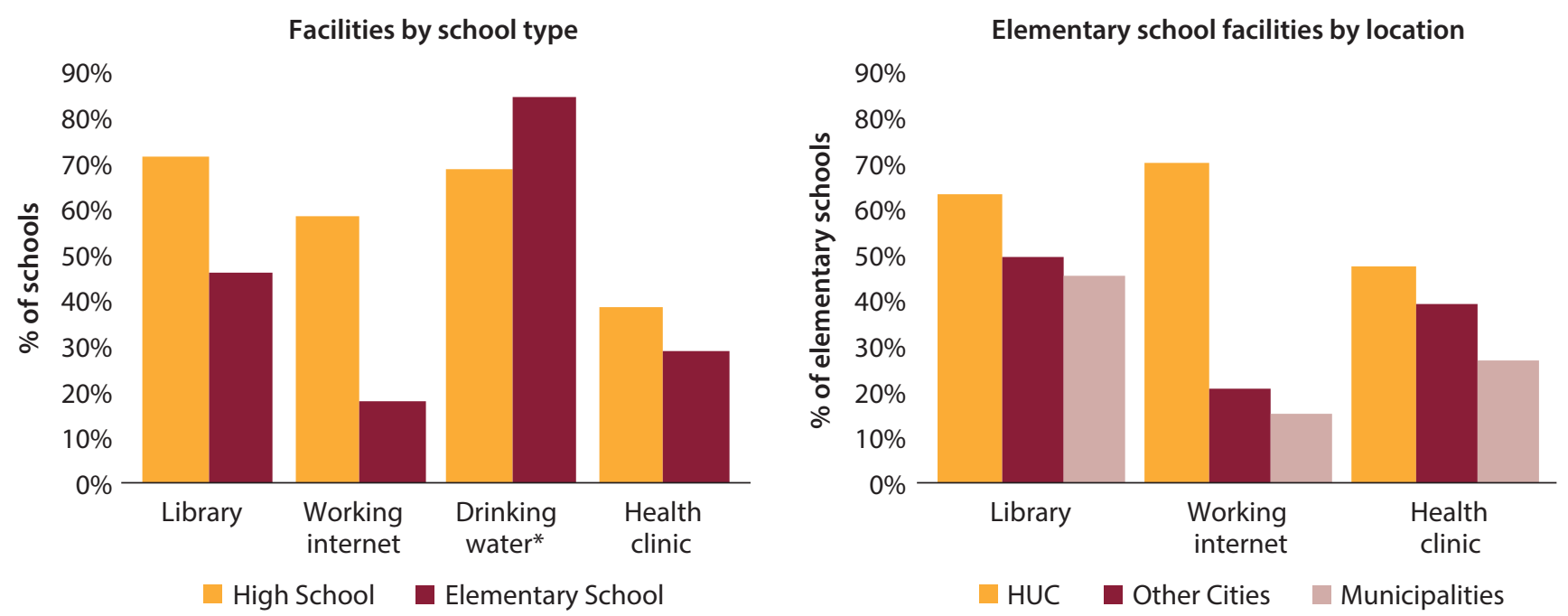

Source: PETS-QSDS national survey - school level data.

Note: * Drinking water only includes piped, well, and natural sources. 
Figure 2: School Facilities Tend to be Used by More Students in Urban Areas

Intensity of use and quality of classrooms, 2014
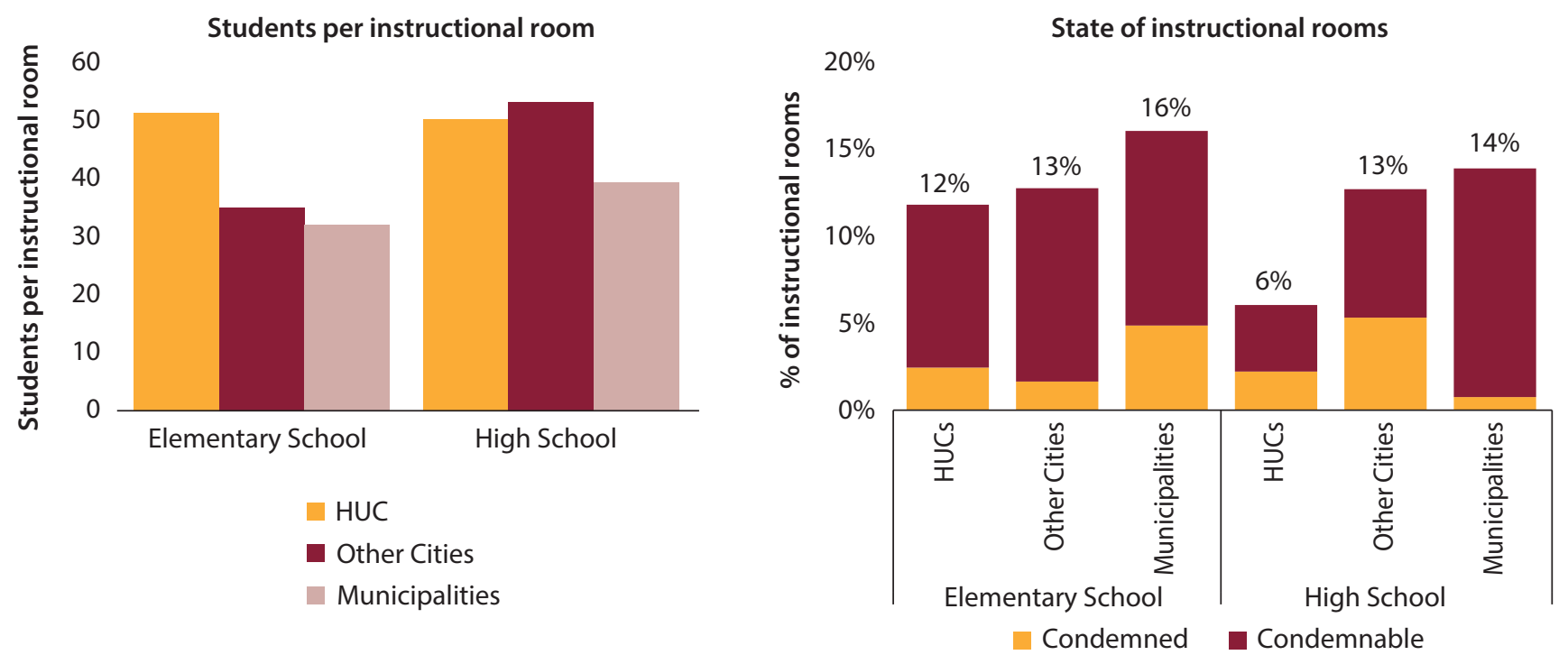

Source: PETS-QSDS national survey - school-level data.

Note: DepEd's definitions of condemned and condemnable instructional rooms are used.

instructional room ratios in excess of 55 . While this is not a measure of class size because double shifting is more commonplace in cities, it does point to the greater intensity of use of school facilities in urban areas. This is likely to result in the need for larger upkeep and maintenance resources for schools in these areas.

In 2014, the study found that approximately one in seven of all elementary and high school instructional rooms in the Philippines to be unsuitable for teaching and learning. On the whole, a larger share of elementary school infrastructure than high school infrastructure was of poor quality (Figure 2). Given the much larger numbers of elementary schools in the Philippines, these findings suggest that a larger share of resources would be needed at this level to address shortcomings in the existing stock of classrooms. Fewer classrooms in cities tend to be classified as condemned or condemnable than in municipalities despite their greater intensity of use. This may reflect their greater ability to maintain their facilities because city schools tend to receive more resources from local governments and their communities that can be used for this purpose.
Aggregate statistics on the availability and quality of school infrastructure often do not adequately represent the true learning environment in schools. Most statistics use studentclassroom ratios as a proxy for the average number of students taught together. However, many schools operate more than one shift during the school day, and student groupings and timetables often mean that class sizes are very different to the simple averages recorded in official statistics at the school level. For example, approximately 23 percent of both elementary and high schools in the study reported operating more than one shift in at least one grade. To get a better picture of the real learning environment faced by students, around 7,000 classes and classrooms were observed as part of the Philippines Public Education Expenditure Tracking and Quantitative Service Delivery Study (PETS-QSDS).

These classroom observations revealed that class sizes were much smaller than official statistics on student-classroom ratios suggest. The average class size observed by the study in 2014 was 34 in high schools and 27 in elementary schools. This is below DepEd's guidelines on ideal class sizes, which range 
Figure 3: A Significant Proportion of Classrooms Were Observed to Be of Poor Quality Indicators of classroom quality from direct classroom observation

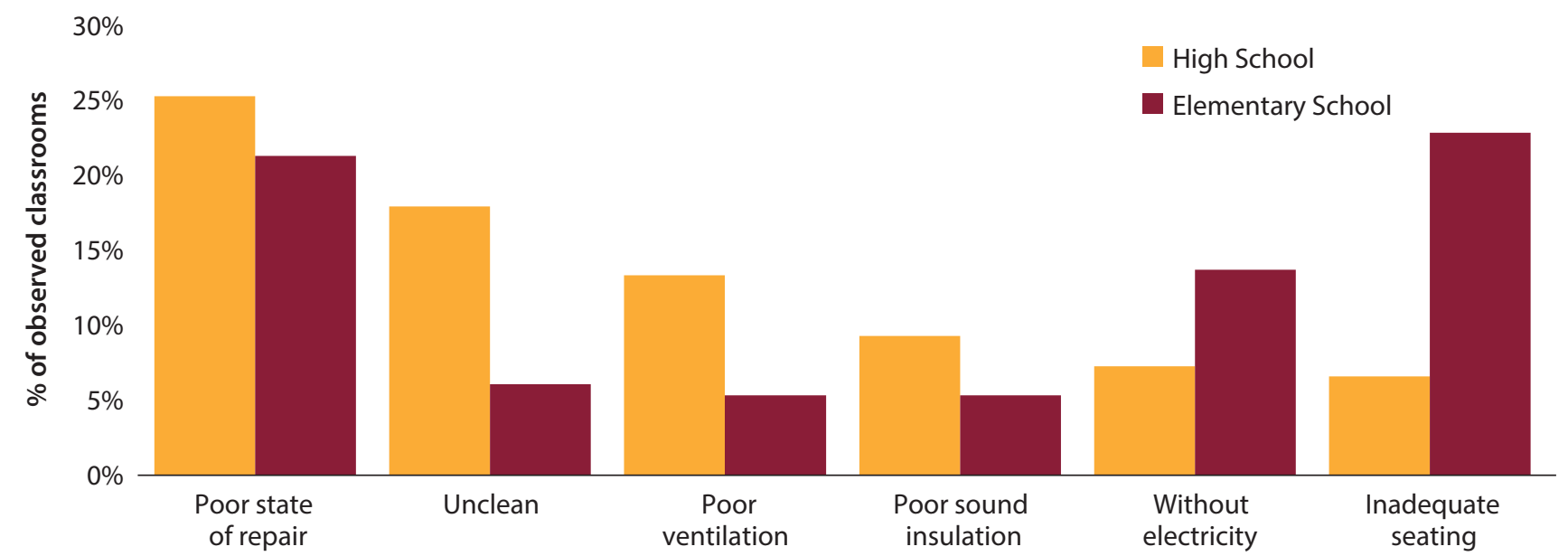

Source: PETS-QSDS national survey - classroom observations at the school level.

from 40 to 55 students. According to the study, only 5 percent of classrooms in elementary schools and 12 percent in high school had more than 45 students being taught at the same time.

A significant number of classrooms used by schools for teaching were judged by the enumerators of the PETSQSDS survey to be in a relatively poor state of repair in 2014 (Figure 3). The survey enumerators found that over 20 percent of classrooms in both elementary and high schools were in a poor state of repair. While the enumerators were not specifically trained to assess the quality of infrastructure, these findings do raise concerns about the impact that this may have on student learning.

The more intensive use of high school infrastructure also affects the learning environment negatively. In most cases, high schools have poorer indicators of the overall learning environment than smaller and less crowded elementary schools. For example, as of 2014, a greater proportion of high school classrooms tended to suffer from poor ventilation and insulation and to be less clean than elementary classrooms (Figure 3). In contrast, far fewer elementary classrooms than high school classrooms appeared to have adequate seating for all students.
While most schools meet DepEd's service standards, a significant proportion do not, particularly in highly urbanized cities. The government's medium-term expenditure framework highlights a number of key service standards that DepEd is seeking to achieve. ${ }^{6}$ In particular, DepEd aims to eliminate multiple shifts in all schools and has set a target for student-classroom ratios of between 45 and 55 in most elementary and high school grades.? Over 94 percent of elementary schools and 83 percent of high schools have studentclassroom ratios that fall within or below that range (Table 1). However, 24 percent of elementary and 30 percent of high schools in highly urbanized cities have student-classroom ratios well above the maximum set out in DepEd standards.

A large proportion of schools also fail to meet DepEd standards regarding sanitation facilities (Table 1). In particular, around one-third of high schools fail to meet the 50 students per toilet standard. The proportion of schools failing to meet sanitation standards is much higher in city schools than in municipal schools. For example, 70 percent of high schools in highly urbanized cities have ratios of female students to toilets in excess of 50. 
Table 1: Percentage of Schools that Failed to Meet DepEd Service Standards, 2014

\begin{tabular}{|c|c|c|c|c|c|c|c|c|}
\hline & \multicolumn{4}{|c|}{ Elementary Schools } & \multicolumn{4}{|c|}{ High Schools } \\
\hline & HUCs & $\begin{array}{l}\text { Other } \\
\text { Cities }\end{array}$ & Municipalities & $\begin{array}{c}\text { All } \\
\text { schools }\end{array}$ & HUCs & $\begin{array}{l}\text { Other } \\
\text { Cities }\end{array}$ & Municipalities & $\begin{array}{c}\text { All } \\
\text { schools }\end{array}$ \\
\hline \multicolumn{9}{|c|}{ Students per instructional room } \\
\hline Fewer than 45 & 46 & 74 & 87 & 84 & 61 & 40 & 70 & 66 \\
\hline Between 45 and 55 & 30 & 19 & 9 & 10 & 9 & 16 & 19 & 17 \\
\hline More than 55 & 24 & 7 & 4 & 6 & 30 & 44 & 11 & 17 \\
\hline \multicolumn{9}{|l|}{ Students per toilet } \\
\hline More than 50: Girls & 41 & 22 & 21 & 22 & 70 & 56 & 32 & 38 \\
\hline More than 50: Boys & 35 & 14 & 19 & 19 & 65 & 49 & 33 & 37 \\
\hline \multicolumn{9}{|l|}{ Students per seat } \\
\hline More than 1 & 21 & 24 & 23 & 23 & 7 & 6 & 7 & 7 \\
\hline
\end{tabular}

Source: PETS-QSDS national survey - classroom data at the school level.

Notes: Assumes that a trough urinal can be used by two boys. Unisex toilets are counted in both boys'and girls'totals. All students, including kindergarten and special education students, are included in the calculations. Numbers of students per seat are taken from classroom observations and relate to the percentage of classrooms rather than schools.

\section{An Assessment of Existing Government Efforts to Improve School Infrastructure}

In 2013, approximately two-thirds of all infrastructure projects taking place in basic education schools were funded by the Department of Education. Local governments provided 13 percent of project funding, while the rest of the projects were largely financed from congressional funds, by the private sector, or by non-governmental organizations.

The government budget devoted to improving and expanding school infrastructure has risen rapidly in recent years (Figure 4). Recognizing the backlog in school infrastructure needs, the government has devoted an ever-increasing share of the budget to construction and rehabilitation. In 2005 only around 2 percent of the budget was used for infrastructure, but this had increased to 18 percent by 2015. Given the increasing size of the overall education budget, this has meant that infrastructure spending has increased nineteen-fold in real terms since 2005.

The increased priority afforded to school infrastructure in the national budget has resulted in a large increase in the number of classrooms built, which has eased congestion, particularly in high schools. National statistics show that between 2005 and 2013 an additional 122,000 elementary and high school classrooms were built, increasing the overall stock to 477,000 . These increases have also reduced studentclassroom ratios particularly in high schools. Between 2005 and 2013 , the average number of students per classroom fell from 70 to 47 in high schools.

While the Department of Education maintains overall control over the selection of projects, most projects have recently been managed and implemented by the Department of Public Works and Highways (Box 1). Since 2013 the Basic Education Facilities Fund (BEFF) and the School Building Program (SBP) have been the two main budget lines for school infrastructure, with the BEFF accounting for over 95 percent of the total funds. The DPWH manages approximately three-quarters of these funds, most of 
Figure 4: Government Spending on School Infrastructure Has Been Rising Rapidly

Trends in government school infrastructure spending, 2005-2015

60

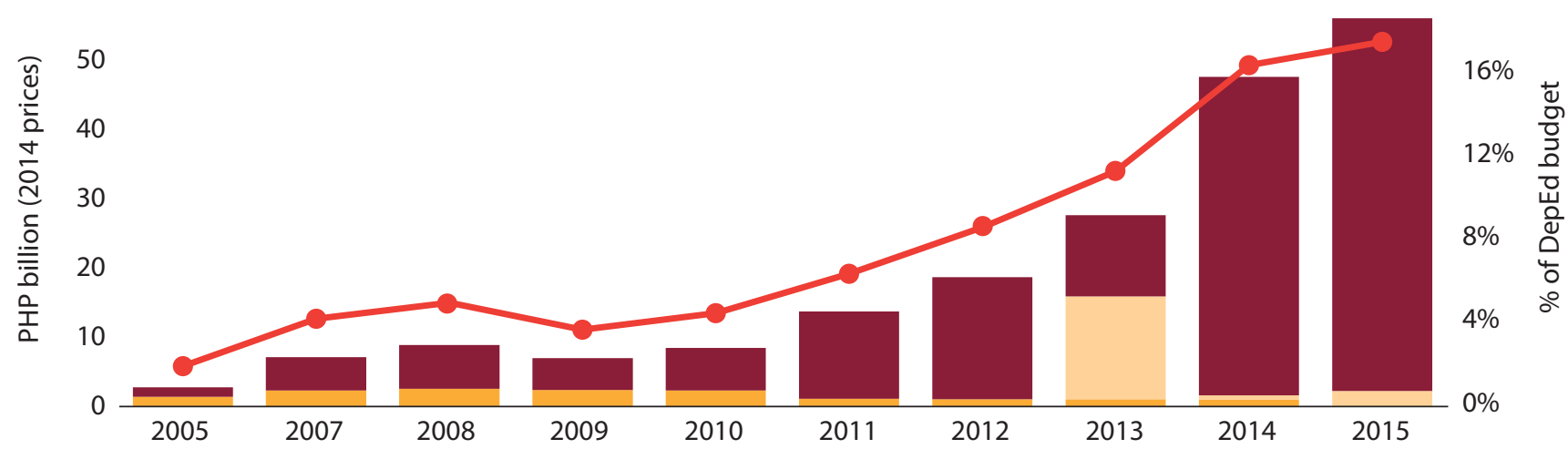

DepEd Infrastructure Funds

DepEd School Building Program — \% of total DepEd budget (right axis)

DPWH local infrastructure support for schools and basic education facilities

Source: Department of Budget and Management.

Note: All figures are appropriations. DepEd school infrastructure funds include all DepEd infrastructure spending including funds under construction of elementary and high schools in areas experiencing acute classroom shortages prior to 2011 and the Basic Education Facilities Fund (BEFF) from 2011 onwards. In 2013, the Department of Public Works and Highways (DPWH) received an appropriation for the BEFF directly. The 2014 and 2015 figures also include separate DPWH programs for local infrastructure support to schools.

\section{Box 1: Responsibilities for Joint DPWH-DepEd Projects}

Each year, DepEd identifies the extent of school infrastructure needs using the Basic Education Information System (BEIS) and develops a list of school-level projects to be carried out by the DPWH using the infrastructure budget appropriations for the year. Once the DepEd central office has selected the projects, it informs the regional and divisional offices who in turn notify the selected schools.

The Schools Division Superintendent (SDS) and the Schools Division Engineer (SDE) within DepEd Division offices are responsible for coordinating with their DPWH counterparts on the procurement and implementation of projects. The main stages where coordination occurs are:

- The DPWH prepares the program of works, undertakes procurement, and implements the works in accordance with DepEd's standard designs and specifications.

- The SDS approves the program of works prepared by the DPWH.

- The staff of DepEd's Physical Facilities and Schools Engineering Division (PFSED) and the Division Physical Facilities Coordinator (DPFC) supervise the DPWH's procurement, monitor the implementation of the projects, and conduct joint inspections of the completed works.

- The DPWH, DepEd's Physical Facilities staff, and the school principals are expected to carry out a joint inspection of the completed works.

- The DepEd SDS and the DPWH District Engineer both approve the Certificate of Completion for each completed project.

Sources: DepEd Memo No. 87 (2015) and DepEd/DPWH joint circular No. 2013-1 (2013). 
which are allocated to new construction of classrooms and water and sanitation facilities. The remaining funds are managed by DepEd and used for repair and rehabilitation, additional water and sanitation projects, and the provision of school furniture. Funds managed by DepEd are also devoted to infrastructure projects carried out through the Public Private Partnership scheme. ${ }^{8}$ In the 2013 budget, national government funding was allocated to support the construction of 16,000 classrooms and the repair of 8,000 classrooms and a large number of toilets and washroom facilities (Table 2).

The central office of DepEd identifies priorities and allocates funds for infrastructure projects using information collected annually in the Basic Education Information System (BEIS). First, the office identifies schools with high studentclassroom ratios and a lack of water and sanitation facilities.
In the second step through site visits, the office verifies the actual condition of facilities and the feasibility of the needed work and finally prepares a list of potential projects that are aligned with the available budget. Once the national budget is approved by Congress, the Department of Budget and Management releases budget allocations to the DPWH and DepEd central offices, which in turn allocate these funds to their local offices in charge of the implementation of the various projects. Projects managed by the DPWH are governed by a set of guidelines that outlines the roles and responsibilities of DepEd and the DPWH during their planning and implementation (see Box 1).

\section{Allocations}

The allocation of government infrastructure resources tends to be broadly in line with need. The study has found that new classroom construction as a proportion of the total existing

Table 2: Characteristics of School Infrastructure Projects, 2013

\begin{tabular}{|c|c|c|c|c|}
\hline & \multicolumn{3}{|c|}{ Basic Education Facilities Fund } & \multirow{2}{*}{$\begin{array}{l}\text { School Building } \\
\text { Program }\end{array}$} \\
\hline & Construction & $\begin{array}{l}\text { Water and } \\
\text { Sanitation }\end{array}$ & Repair & \\
\hline \multicolumn{5}{|l|}{ Projects } \\
\hline Elementary Schools & 3,597 & 8,794 & 1,656 & 505 \\
\hline High Schools & 1,765 & 3,768 & 367 & 189 \\
\hline \multicolumn{5}{|c|}{ Classrooms built/repaired } \\
\hline Elementary Schools & 8,204 & & 5,696 & 1,081 \\
\hline High Schools & 6,524 & & 1,749 & 496 \\
\hline \multicolumn{5}{|c|}{ Toilets (urinals and bowls) } \\
\hline Elementary Schools & 3,012 & 32,607 & - & - \\
\hline High Schools & 4,795 & 18,355 & - & - \\
\hline \multicolumn{5}{|c|}{ Hand washroom counters } \\
\hline Elementary Schools & - & 34,224 & - & - \\
\hline High Schools & - & 19,878 & - & - \\
\hline \multicolumn{5}{|c|}{ Allocation (PHP billions) } \\
\hline Elementary Schools & 7.1 & 3.5 & 0.9 & 0.6 \\
\hline High Schools & 6.9 & 1.9 & 0.3 & 0.3 \\
\hline Other & - & 1.3 & 0.1 & 0.1 \\
\hline \multicolumn{5}{|l|}{ Allocation (\%) } \\
\hline Elementary Schools & 51 & 52 & 69 & 60 \\
\hline High Schools & 49 & 28 & 23 & 30 \\
\hline
\end{tabular}

Source: DepEd central office construction project list, 2013

Note: Estimates drawn from school project lists for each funding source. Of the 1,081 elementary and 496 high school classrooms, 674 elementary and 325 high school classrooms were newly constructed while 325 and 171 respectively were repaired. 
stock of classrooms was generally higher in those regions with more congested classrooms (Figure 5). For example, in the 2013 budget, funds were allocated to build an additional 800 classrooms (equivalent to 5 percent of the current stock) in the National Capital Region (NCR) where student-classroom ratios were far higher than any other region. Classroom construction in the Autonomous Region in Muslim Mindanao (ARMM) in 2013 was much higher than in other regions, which partly reflects the region's need for additional school places to accommodate out-of-school children.

A closer look reveals that on the whole schools with poorer quality facilities are more likely to be selected for a school improvement project (Figure 5). For example, a higher proportion of the schools that were awarded an infrastructure project in 2013 had no access to drinking water and had fewer classrooms and toilets relative to the size of their student populations compared to schools that did not receive a project.

However, there is still significant room to strengthen the link between allocation and need. Approximately half of the elementary schools that had student-classroom ratios in excess of DepEd standards (in other words higher than 55) were selected for a project, while 30 percent of schools with student-classroom ratios well below 45 received school improvement funding. A similar picture emerges regarding sanitation facilities, with 28 percent of elementary schools with a female student to toilet ratio below 50 being selected for a project while only 55 percent of elementary schools with ratios in excess of 60 received support.

\section{Implementation}

Utilization rates for school infrastructure funds have been relatively low over the last 10 years (Figure 6). Between 2005 and 2014, only 54 percent of allotments were obligated in the same year they were allocated. With the exception of 2013, DepEd has experienced significant difficulties in utilizing the growing budget for school infrastructure development. For example, in 2014, the utilization rate was only around two-thirds, suggesting that one-third of allocations were not obligated.

Utilization rates mask large differences in budgeted funds and the amounts actually released in any given year. In the

\section{Figure 5: New Classroom Construction is Broadly in Line with Need at the Regional Level}

Infrastructure needs and project allocations, 2013

New elementary school classroom construction under BEFF and student-classroom ratio by region

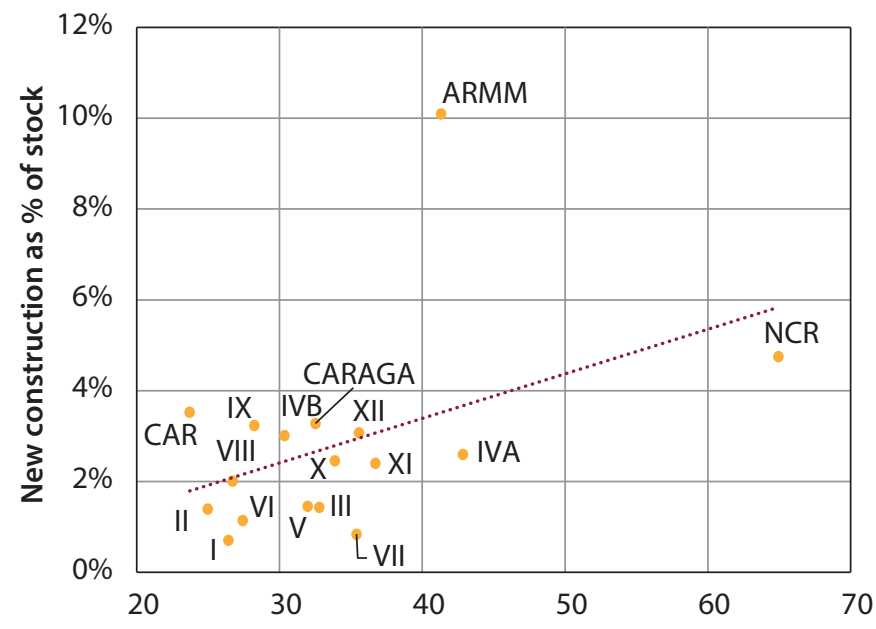

Student classroom ratio $2013 / 14$
Differences in facility quality between elementary schools with infrastructure projects and those without, 2013

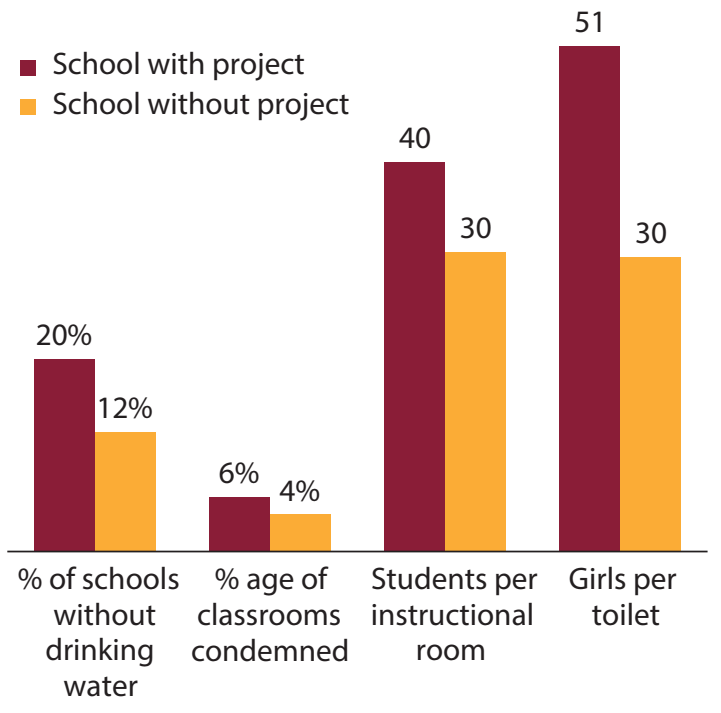

Source: Left panel = DepEd central office construction project list (2013) and DepEd EBEIS. Right panel = PETS-QSDS DPWH and DepEd records of school construction projects and school-level information on school facilities.

Note: School Building Program construction is not included. 
Figure 6: Utilization Rates for School Infrastructure Have Been Relatively Low

School infrastructure fund allotments, obligations, and utilization rates, 2005-2014

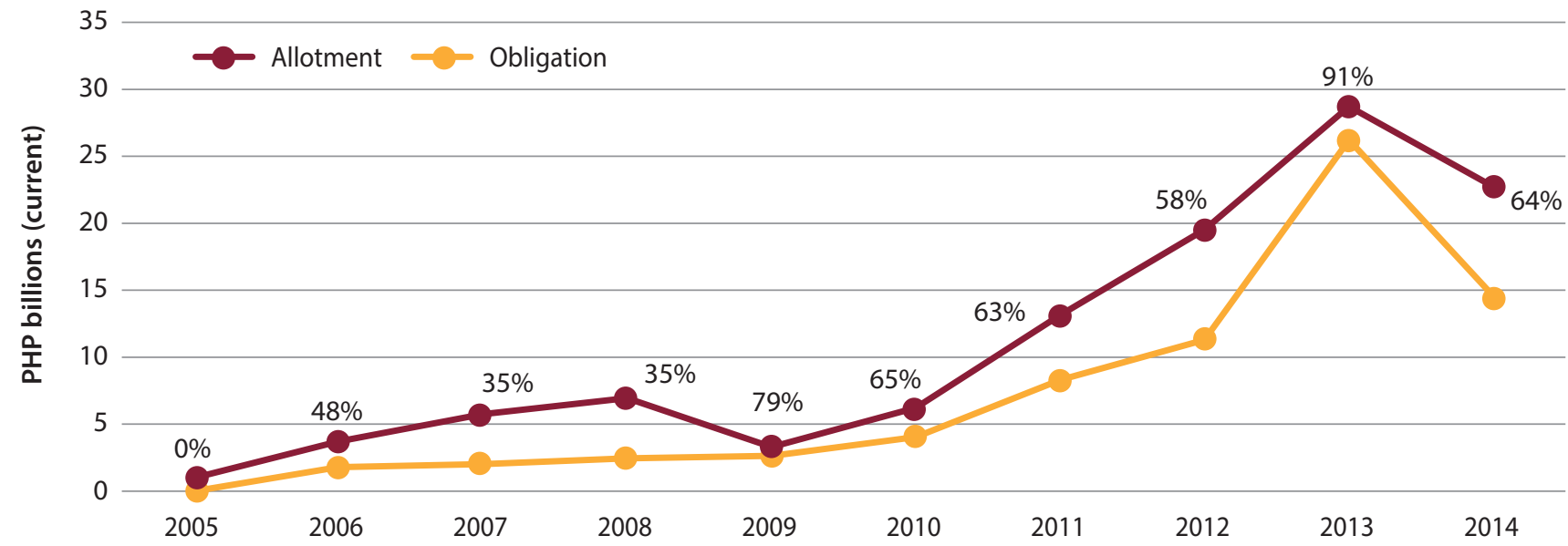

Source: DepEd and DPWH Statement of Appropriations and Obligations, various years

Note: Allotments/obligations for a given year include current, continuing, and extended allotments/obligations. The utilization rate is indicated by the percentage figures in the graph and show the proportion of allotments obligated in a given year.

2013 budget, Congress appropriated approximately PHP 27 billion for school infrastructure improvements, but only around 70 percent of this appropriation was released in 2013. Even taking into account the releases from this appropriation in the following year (2014), only 74 percent of the 2013 appropriation was finally released. This is a particular concern given the infrastructure shortages outlined in the previous section and the large increases planned for infrastructure investment in the coming years. ${ }^{9}$

Even when national government projects have been identified and funds have been released, a significant proportion of projects are not completed, which results in low levels of satisfaction at the school level. School staff reported to enumerators of the PETS-QSDS survey that one in five DepEd projects that began in 2013 remained incomplete by the final quarter of 2014 (Figure 7). They cited insufficient funds, other demands on contractors' time, and design issues as the main reasons why projects were not completed. Moreover, completion rates were much higher for local government and school-managed projects than projects managed by DepEd and the DPWH. The high completion rates of school-managed projects is likely to reflect the greater control that schools have over contracts and contractors when they are managing their own resources.

\section{Figure 7: Schools Report Low Levels of Satisfaction with Government-funded Infrastructure Projects}

Completion and satisfaction rates for 2013 school infrastructure projects, 2014

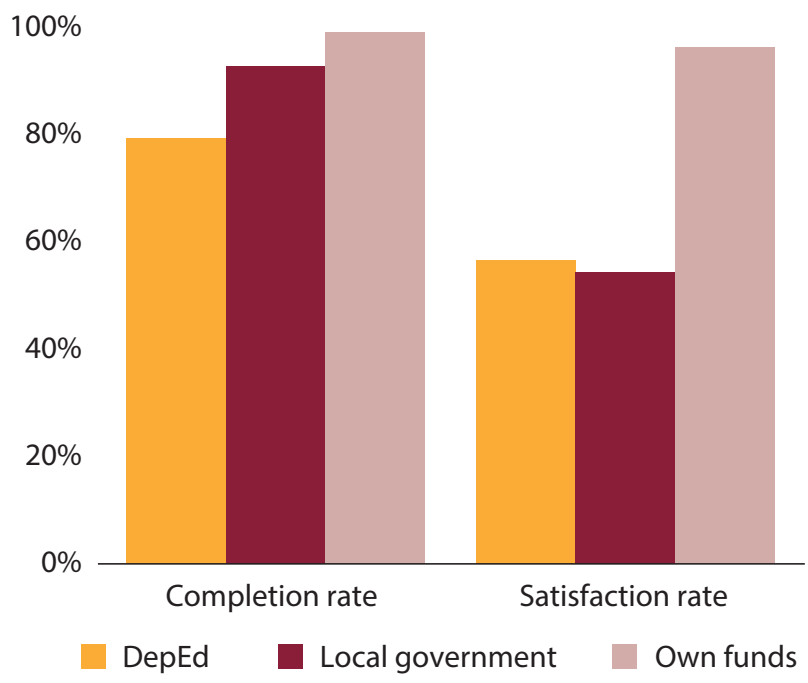

Source: PETS-QSDS national survey - infrastructure project information at the school level

Note: Data relates to all school infrastructure projects in 2013. Completion rates are the proportion of 2013 projects that were completed by the last quarter of 2014. DepEd projects include those managed by the DPWH as well as major school repair and water and sanitation projects managed by DepEd Division offices. 


\section{Figure 8: The Timeliness of the Downloading of Infrastructure Allotments from} Central Offices Varies by Budget Source

Receipt of project list and first sub-allotment at DPWH district engineering offices ${ }^{11}$
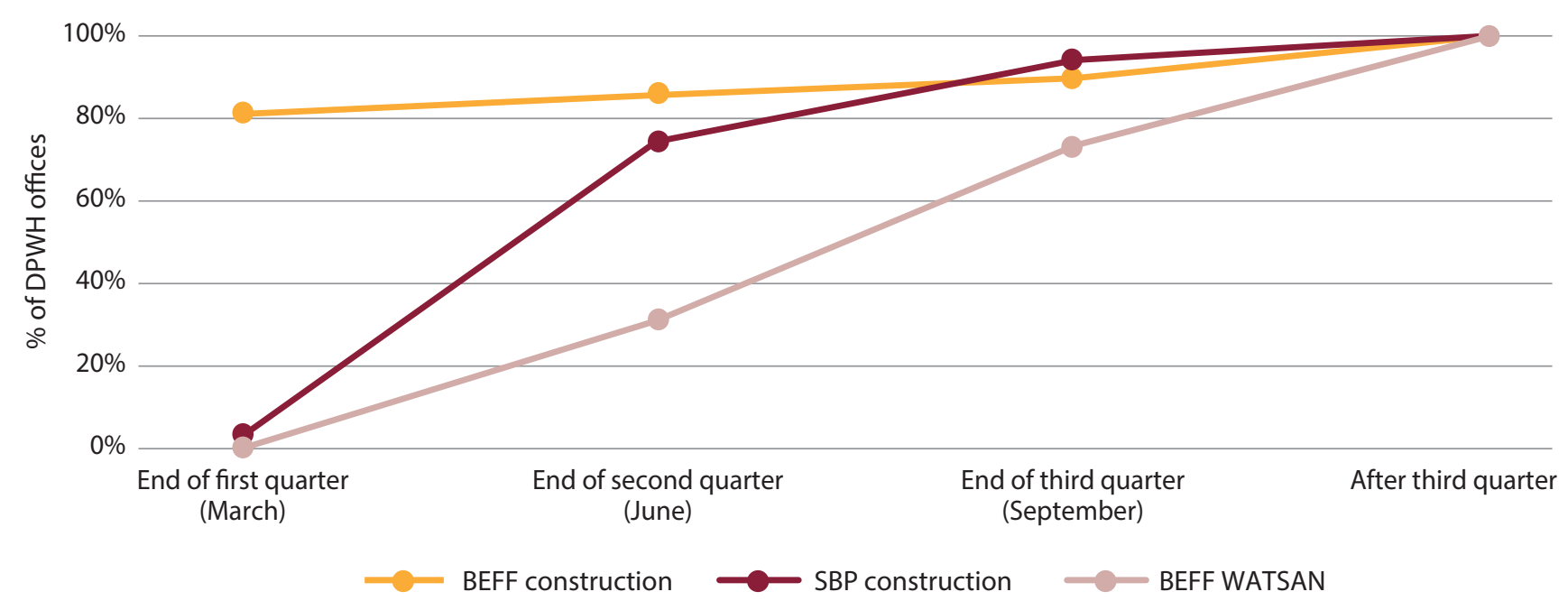

Source: PETS-QSDS national survey - DPWH district engineering offices.

Approximately 40 percent of national and local government infrastructure projects undertaken in 2013 were rated as unsatisfactory by schools (Figure 7). The schools reported being much more satisfied with the projects that they managed and financed themselves. A major factor in this dissatisfaction, particularly with projects financed by the national government, is the large number of projects that are left incomplete by contractors. Moreover, approximately three-quarters of schools also mentioned the poor quality of the repairs and new construction as a reason for their dissatisfaction.

Delays in transferring project lists and financial allocations from DepEd to the local offices responsible for implementing them are the reason for many project implementation delays. Figure 8 shows the proportion of DPWH district engineering offices that had received their infrastructure allocation by the end of each quarter in 2013. It shows that over 80 percent of DPWH district offices had received their 2013 allocation to carry out work on the BEFF construction component by the end of the first quarter. The prompt release of these funds gives district engineering offices time to plan out their infrastructure projects over the course of the financial year. Given that BEFF construction funding represented the bulk of national government infrastructure spending, this is a positive finding. However, around 15 percent of engineering offices did not receive these funds until the end of the second quarter of the year.

Also, the majority of DPWH offices received other infrastructure funds (such as the BEFF water and sanitation and school building program funds) much later in the year. For example, regarding funds from the School Building Program, only around three-quarters of the offices had received their allocations for BEFF water and sanitation projects and fewer than one-third of them had received their allocations for school construction by June. Receiving funds so late in the year limits the time available to implement projects and means that they are still being implemented when the school year starts in June, thus inconveniencing school staff and students. ${ }^{10}$

A majority of district engineering offices reported that, even after they have received their resources, they have to overcome many difficulties to implement their projects successfully. Two-thirds of DPWH district engineering offices and all offices in urban areas reported finding it difficult to implement school infrastructure projects, particularly due to a lack of flexibility in the funding of school projects. For example, 62 percent of offices reported that they did not 
receive sufficient funds to cover hauling away debris and 33 percent complained of the impractical costing of school projects (Figure 9). A further issue raised by over 60 percent of the offices was a lack of space within the schools to locate the new infrastructure.

The PETS-QSDS survey asked staff of the DPWH and DepEd divisional offices about the infrastructure projects that they undertook within the surveyed schools. The study team then compared this information with similar information collected within the schools themselves to check whether the projects were actually carried out and to assess the accuracy of systems used to monitor the use of infrastructure funds.

There were large discrepancies between implementing offices and schools in their accounts of infrastructure projects. The analysis was carried out only on elementary schools since the number of projects documented in high schools was not sufficient for the team to be able to draw any reliable conclusions. First, the elementary schools reported that fewer DepEd-funded projects had been implemented than was reported by DepEd and the DPWH. Second, only around one-half of the projects that the DepEd and DPWH offices claimed to have implemented could be verified by information provided by the schools. However, one-quarter of projects reported by schools as DepEdfinanced projects could not be matched with information from the relevant DepEd divisional or DPWH district office. Third, among those projects that appeared in both sets of data, about 40 percent had different descriptions. For example, schools reported the project as being a water and sanitation project while DepEd or the DPWH reported it as a construction project. The project costs also frequently differed.

It is hard to draw firm conclusions about whether all infrastructure funds are reaching their intended destinations. On the one hand, a significant number of projects recorded at the district or division level were not implemented in schools. On the other hand, schools reported projects funded by DepEd that were not recorded in the DepEd or DPWH offices. However, it does seem clear that existing information and monitoring systems are not able to accurately record the use of infrastructure funds.

Weaknesses in monitoring and feedback systems are also highlighted by other findings from the survey. Managers of projects in the DepEd and DPWH offices reported that almost all infrastructure projects in 2013 had already been completed even though the schools reported a completion

\section{Figure 9: Many DPWH Offices Reported Facing Difficulties in Implementing and Supervising School Infrastructure Projects}

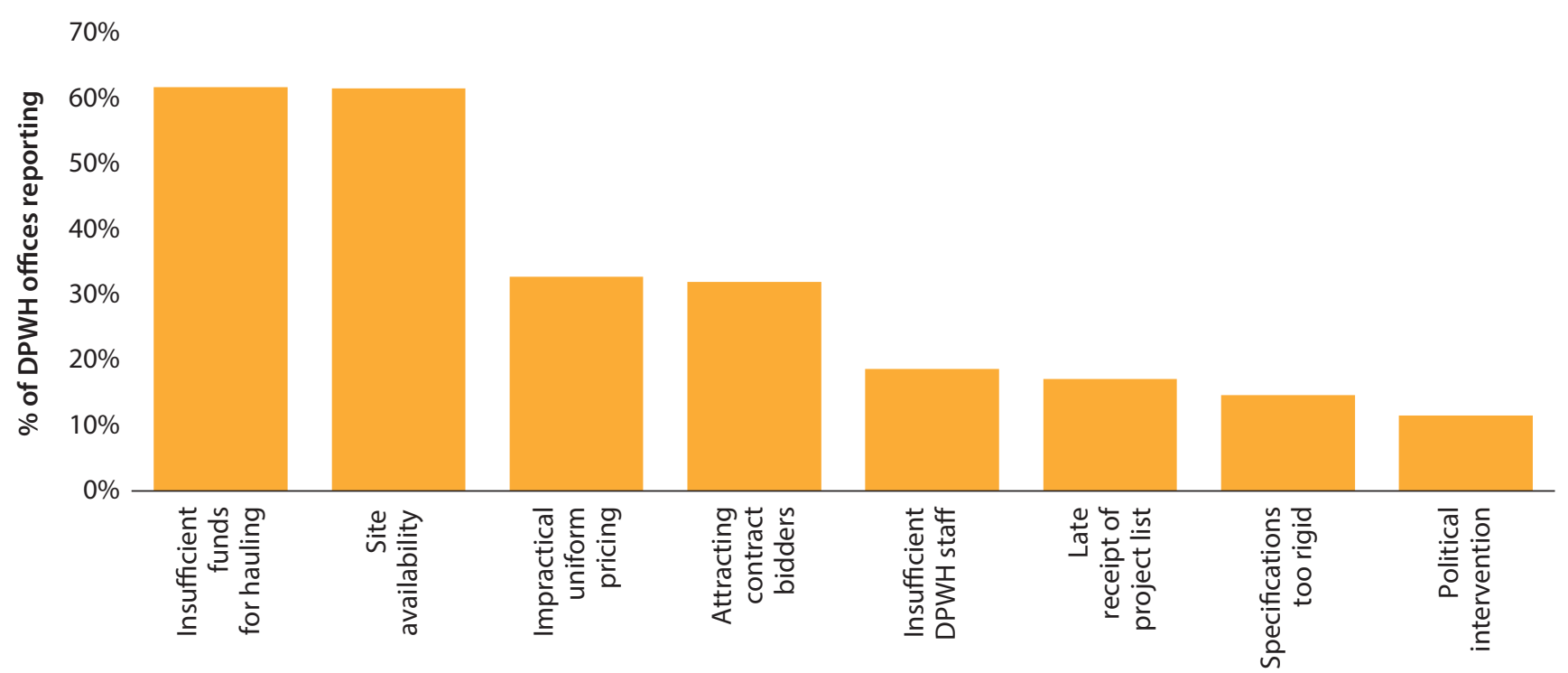

Source: PETS-QSDS national survey - DPWH district engineering offices. 
rate of only 80 percent (see Figure 7). The widespread dissatisfaction with projects at the school level also does not appear to be reflected at higher levels of the administration. Nearly all respondents in DepEd and DPWH offices reported that they were satisfied with the projects undertaken in the surveyed schools, whereas only 57 percent of school heads were satisfied.

Social accountability initiatives aimed at soliciting feedback and providing oversight on the state of school infrastructure also do not appear to be widespread. There are many civil society initiatives in the Philippines that aim to ensure that education funds reach their intended beneficiaries. For example, the Check My School initiative aims to promote citizen participation in the monitoring of public school performance..$^{2}$ It mobilizes communities to validate schoolrelated information from DepEd on many issues including school infrastructure. Any discrepancies with this information or issues with the relevant school infrastructure that citizens raise are publicized and fed back to DepEd to be resolved. While such initiatives have the potential to improve DepEd's projects and strengthen accountability for the delivery and quality of infrastructure improvements, they operate on a limited scale. Only around 20 percent of elementary and high school principals had heard of the program and only around 10 percent of schools had any interaction with the initiative in 2013 or 2014.

\section{Policy Directions for Improving School Learning Environments}

Notwithstanding the significant investments made in school infrastructure over the last five years, further investment is needed. Funds are needed to address the remaining deficiencies in existing school facilities and to keep pace with the ever-growing student population. Between 2010 and 2013, an additional 1 million children entered the basic education system, an average of around 350,000 students annually, and the introduction of the senior high school program in 2016 will put an additional burden on existing high schools.
The findings from the PETS-QSDS study also show that government systems for delivering infrastructure improvements need to be strengthened and made more accountable if any increased funding is to be used effectively. First, the methods used to identify and target school improvement projects need to be strengthened to ensure that the neediest schools are prioritized. Second, implementation capacity needs to be increased to ensure that government systems are fit for purpose and are able to absorb the funds needed to fill infrastructure gaps. Finally, monitoring and evaluation efforts need to be stepped up and mechanisms to feed the findings back to implementers are needed to improve the quality of repairs and construction.

\section{Improving the Allocation of Public Infrastructure Funds}

At the end of 2014, DepEd embarked on a school inventory exercise, the results of which will help to improve the allocation of infrastructure funds. The exercise provided division-level and school staff with guidance on how to classify schools in terms of the state of their facilities with the aim of improving the quality of data collected annually through the Enhanced Basic Education Information System (EBEIS). This information can then be used to identify schools that do not meet existing DepEd standards. Combined with a realistic assessment of the potential to improve or expand school facilities (for example, the amount of buildable space), policymakers can use the information to develop and establish a clear and transparent set of criteria to prioritize infrastructure spending among schools whose facilities do not meet existing standards.

Allocation decisions could also be greatly improved by the creation of a validation and finalization process at the division level. The present centralized mechanism for allocating funding according to need requires validation at the local level to ensure that the central-level data reflect the real situation in the selected schools. This would make sure that the extensive knowledge that divisional staff have of schools and communities is reflected in the final allocation decisions and would ensure that infrastructure funds are put to the best use. 
To ensure that allocation decisions are transparent, information on the criteria and data used to select schools for infrastructure improvements could be widely disseminated. Feedback mechanisms could also be established to provide a channel for schools and their communities to voice any grievances that they may have about either the data used or the selection process (see below).

\section{Strengthening Implementation Capacity}

Building strong partnerships between government systems and non-government partners would increase the capacity for infrastructure improvement. While infrastructure budgets have been growing rapidly, the study's findings have raised concerns about whether government systems have enough capacity to absorb these increases. There is a long tradition of NGO and private sector support for school infrastructure in the Philippines. Many of these non-government initiatives have demonstrated that they can effectively deliver good quality classrooms at a comparable or lower cost than government systems and frequently in areas where government systems are particularly stretched (such as remote and hard-to-reach areas). ${ }^{13}$ Establishing or expanding partnerships between the government and these institutions is likely to reduce the stress on government systems and speed up the process of improving and expanding school facilities.

Developing a medium-term planning framework for school infrastructure investment would have the potential to increase the timeliness and improve the quality of projects. The findings of this study demonstrate that in many instances both project lists and funds are received well after the start of the financial year. This shortens the period for implementation and compromises the ability of DepEd and DPWH offices to monitor projects adequately. Developing a two- or three-year plan that would list all school improvement projects in each DepEd division would reduce the work involved in putting together the annual project list and accelerate the transmission of funds to the responsible implementing offices. It would also give implementing offices time to do some advance planning and thus avoid some of the difficulties associated with inadequate funding and site availability so commonly cited as reasons for implementation delays.
Coordination has improved between DepEd and the DPWH in recent years, but increasing the role played by schools in project planning and implementation could also yield significant benefits. In 2015, DepEd and the DPWH reissued a 2013 joint circular outlining their respective roles and responsibilities in project management (see Box 1). However, the guidelines specify only a weak role to be played by schools and their principals in project management. For example, the guidelines state that school principals should accompany DepEd and DPWH officials on inspection visits but they are not empowered to approve the completed works. Giving school principals authority alongside DepEd and DPWH officials for certifying that projects have been satisfactorily completed might reduce the differences in rates of reported completion between DPWH/DepEd managers and schools that were highlighted in the PETS-QSDS survey findings. School principals in the Philippines have taken on roles of this kind in the past and with appropriate training could become a major driving force in improving the quality of school infrastructure projects. Other countries in the region (such as Indonesia and Laos) and beyond (for example, Mexico) have engaged local communities in project implementation with significant success (see Box 2).

\section{Developing Better Monitoring, Evaluation, and Feedback}

The findings outlined in this policy note have shown that the monitoring and evaluation of school improvement projects in the Philippines is weak. Users reported that the overall quality of projects is low, and project managers do not seem to be informed about the progress and completion of projects on the ground.

In order to address these weaknesses, it seems clear that the capacity of DepEd divisional and DPWH offices to monitor projects effectively requires strengthening. Trained engineers need to make frequent visits to project sites and make detailed reports to DepEd and DPWH in order to address the project quality issues highlighted in the PETS-QSDS survey. Allocating projects to specific DepEd divisional or DPWH staff and requiring them to visit these project sites on a regular basis (for example, twice a month) has the potential to improve the quality of projects for a relatively small investment. Given the significant increase in the number of 


\section{Box 2: Mexico's Better Schools Program}

The Better Schools Program (BSP) in Mexico was a key component of a broader education reform program aimed at improving the quality of basic education. Between 2008 and 2012 the program carried out school infrastructure improvement projects in 19,400 of the neediest basic education schools in Mexico.

The involvement and participation of each school community through its parent association was a major thrust of the BSP. A central government body was in charge of making payments to contractors and of overseeing the overall implementation of the program, but the schools' parents associations acted as the legal client and was responsible for:

- Commenting on, making decisions, and supervising the school project

- Contributing to the transparency and presentation of financial accounts

- Verifying that the building materials and improvements were of good quality

- Approving all stages of the planning and implementation of the project.

After the Ministry of Education made an initial selection of schools in need of urgent repair, technical facilitators worked with each school to complete a technical assessment of its requirements that formed the basis of the project. Prospective contractors aiming to implement BSP projects were required to go through a rigorous pre-screening exercise, after which an approved list of contractors was drawn up and these companies were randomly selected to implement packages of projects.

A recent assessment of the program noted:

- The process of identifying priority schools and working with the schools' parents associations to undertake the necessary work was efficient and flexible enough to adapt to each school's circumstances

- The procedure of awarding contracts was relatively quick, and the payments process was transparent. It also ensured that contractors had incentives to deliver good quality projects

- Overall, the project was cost-effective in that it reached more schools than was initially intended and used resources effectively and in line with the relevant regulations and guidelines.

The necessary components for the effective participation of local communities in school infrastructure improvement were summarized in the assessment report:

"The BSP has demonstrated how partnerships between the community and government can result in substantial benefits to the community and foster trust in the government's capacity to deliver quality education services. A clear decision-making framework, clarity of roles and expectations, and well-defined lines of responsibility have contributed to the successful engagement of parents and others in the BSP."

Source: Blyth, A., Almeida, R., Forrester, D., Gorey, A. and J. Zepeda (2012). "Upgrading School Buildings in Mexico with Social Participation: The Better Schools Program," OECD, Paris.

projects that have been undertaken in recent times, it is likely that current numbers of physical facilities staff in DepEd and DPWH offices will need to be reassessed to ensure that they are adequate.

Monitoring and evaluation systems also need to make much better use of schools and local communities. School principals, teachers, and local communities have a strong interest in ensuring that projects are implemented well. Giving school principals and governing councils a stronger role in project monitoring could improve the quality of projects and also yield better information on the effectiveness of contractors. While school principals are already nominally involved in inspection visits, their role could be expanded. For example, they could produce regular on-site reports about project progress to share with DepEd and DPWH engineers as well as contractors. If they were also involved in approving inspection reports and completion certificates, this would signal to contractors that the schools are the final clients for their projects. 
In order to increase transparency, information on ongoing school projects could also be made more widely available. Allowing public access to divisional lists of school projects would enable schools and local communities to check selections and ensure that criteria have been applied correctly for allocating projects. In a similar way to the school maintenance and operating funds provided by DepEd, school staff could also report on the project and its progress on the school's transparency board to inform parents and other stakeholders about progress and to give them greater oversight over infrastructure improvements. ${ }^{14}$

Increasing transparency is only one of the steps needed to increase accountability for project funds. Across the whole process for allocating and implementing infrastructure spending, mechanisms are needed to enable schools and other stakeholders to seek redress for unfair allocations or poor project implementation. Exploring the feasibility of introducing a formal grievance system for schools to utilize for all school funding, including school infrastructure projects, would be a useful step that policymakers could take towards making government education spending more effective and improving education services. Encouraging social accountability initiatives such as Check My School could also help schools to use grievance systems as well as providing further external pressure on government to implement improvements.

The government of the Philippines has made rapid progress in improving school learning environments. It has introduced a process to identify the infrastructure needs of thousands of elementary and high schools and developed systems to fund and implement a huge school building program every year. While these achievements are impressive, more funding will be needed to meet the remaining infrastructure challenge. However, increased funding will not be enough. A stronger focus on the governance and management of these resources will be required if schools and students across the Philippines are to get the good quality facilities that they need to improve the teaching and learning environment and raise learning achievement levels.

\section{Table 3: Strengthening Government Systems for School Infrastructure Improvements}

\begin{tabular}{|c|c|}
\hline Findings & Policy suggestions \\
\hline $\begin{array}{l}\text { Allocation mechanisms for } \\
\text { school infrastructure systems } \\
\text { need strengthening }\end{array}$ & $\begin{array}{l}\text { - Establish transparent criteria for prioritizing schools based on existing facility standards } \\
\text { - Validate project priority list at the division level } \\
\text { - Increase transparency and accountability by disseminating project selection criteria } \\
\text { and by establishing feedback/grievance mechanisms }\end{array}$ \\
\hline $\begin{array}{l}\text { Large increases in } \\
\text { infrastructure spending are } \\
\text { required but implementation } \\
\text { capacity also needs to be } \\
\text { strengthened significantly }\end{array}$ & $\begin{array}{l}\text { - Expand and establish partnerships to build and improve infrastructure } \\
\text { - Introduce multi-year planning for school improvement projects } \\
\text { - Strengthen coordination between implementing institutions } \\
\text { - Strengthen the role of schools and school governing councils in implementation }\end{array}$ \\
\hline $\begin{array}{l}\text { Weaknesses in the } \\
\text { monitoring and evaluation of } \\
\text { infrastructure spending need } \\
\text { to be addressed }\end{array}$ & $\begin{array}{l}\text { - Increase the capacity of DepEd and DPWH to monitor projects regularly } \\
\text { - Increase the transparency of school infrastructure improvement activities at the } \\
\text { division and school levels } \\
\text { - Empower schools to monitor projects more closely and provide effective feedback } \\
\text { channels for all stakeholders to use }\end{array}$ \\
\hline
\end{tabular}




\section{Endnotes}

1 Woolner, P. Hall, E. Higgins, S. McCaughey, C. and K. Wall (2007). "A Sound Foundation? What We Know about the Impact of Environments on Learning and the Implications for Building Schools for the Future." Oxford Review of Education 33(1): 47-70

2 Glewwe, P. Hanushek, E. Humpage, S. and R. Ravina. (2011). "School Resources and Educational Outcomes in Developing Countries: A Review of the Literature from 1990 to 2010," National Bureau of Economic Research, Cambridge, MA.

3 Krishnaratne, S. White, H. and E. Carpenter. (2013). "Quality Education for All Children? What Works in Education in Developing Countries?"Working Paper 20. New Delhi: International Initiative for Impact Evaluation (3ie).

4 Yamauchi, F. and S. Parandekar (2014). "School Resource and Performance Inequality: Evidence from the Philippines."World Bank Policy Research Working Paper No. 6748, World Bank, Washington D.C.

5 Highly urbanized cities are cities with populations of over 200,000 and with average revenues of at least PHP 50 million in 1991 prices. Other cities are defined as cities that do not meet the criteria to be classified as highly urbanized. Municipalities are administrative units for all other areas in the Philippines.

6 DepEd (2013)."Medium-term Expenditure Framework for Basic Education 2014-2020: Enrollment Projections and Cost Simulations under Alternative Scenarios." Department of Education, Manila.
7 In kindergarten and Grades 1 and 2, DepEd aims for classes to consist of fewer than 45 students.

8 In 2013, 62 percent (PHP 4 billion) of the BEFF releases managed by DepEd were allocated to the PPP program.

9 Appropriations for school infrastructure are set to grow from PHP 27 billion in 2013 to PHP 81 billion in 2016.

10 A similar pattern can be seen in the infrastructure funds that flow through DepEd divisional offices.

11 Downloading refers to the issuance of a sub-allotment release order from DPWH central office to the DPWH district engineering office. Sub-allotments are authorizations issued by the central office of DPWH or DepEd transferring a portion of an available allotment to the district office.

12 World Bank (2012). "Check My School: A Case Study on Citizens' Monitoring of the Education Sector in the Philippines." Washington D.C.

13 Philippines-Australia Classroom Construction Initiative (2013). "Partnership Scoping Study - A Discussion Paper." Manila.

14 The transparency board is a publicly accessible notice board where schools post information on the receipt of government operating funds and school canteen funds. 


\section{Policy Note 4: Assessing School-based Management}

\section{Introduction}

In recent times, many countries around the world have begun to devolve more authority and resources to schools in an effort to improve teaching and learning conditions. Schoolbased management (SBM) reforms of this kind are seen as a strategy to improve education quality by bringing decisionmaking closer to local communities and by strengthening accountability between schools and the parents and children that they serve.

Recent studies from many different countries have shown that school-based management can have a positive impact in terms of increasing access to education and improving learning outcomes.' However, these reviews have also shown that the type of SBM reforms being implemented varies enormously from country to country and that the reforms can take some time to yield results. Moreover, their success depends critically on parental participation, political support, and effective implementation.

In the early 2000s, the Government of the Philippines began to introduce school-based management reforms, which have had a positive impact on student learning outcomes. ${ }^{2}$ A key aspect of the success of these reforms has been the provision of ever-increasing levels of operational funding to the school level coupled with the devolution of greater school autonomy over the use of these funds. ${ }^{3}$ By 2014, schools were managing significant amounts of resources and using these funds to implement their own school improvement plans. Also, in 2015, the Department of Education (DepEd) issued new guidelines drawing on past experience that aimed to strengthen school improvement planning and make it more transparent.

The purpose of this policy note is to assess the current status of school-based management in elementary and high schools in the Philippines. The findings reported in the note are based on a comprehensive survey of the public education system that tracked public education expenditure and assessed the quality of education services.

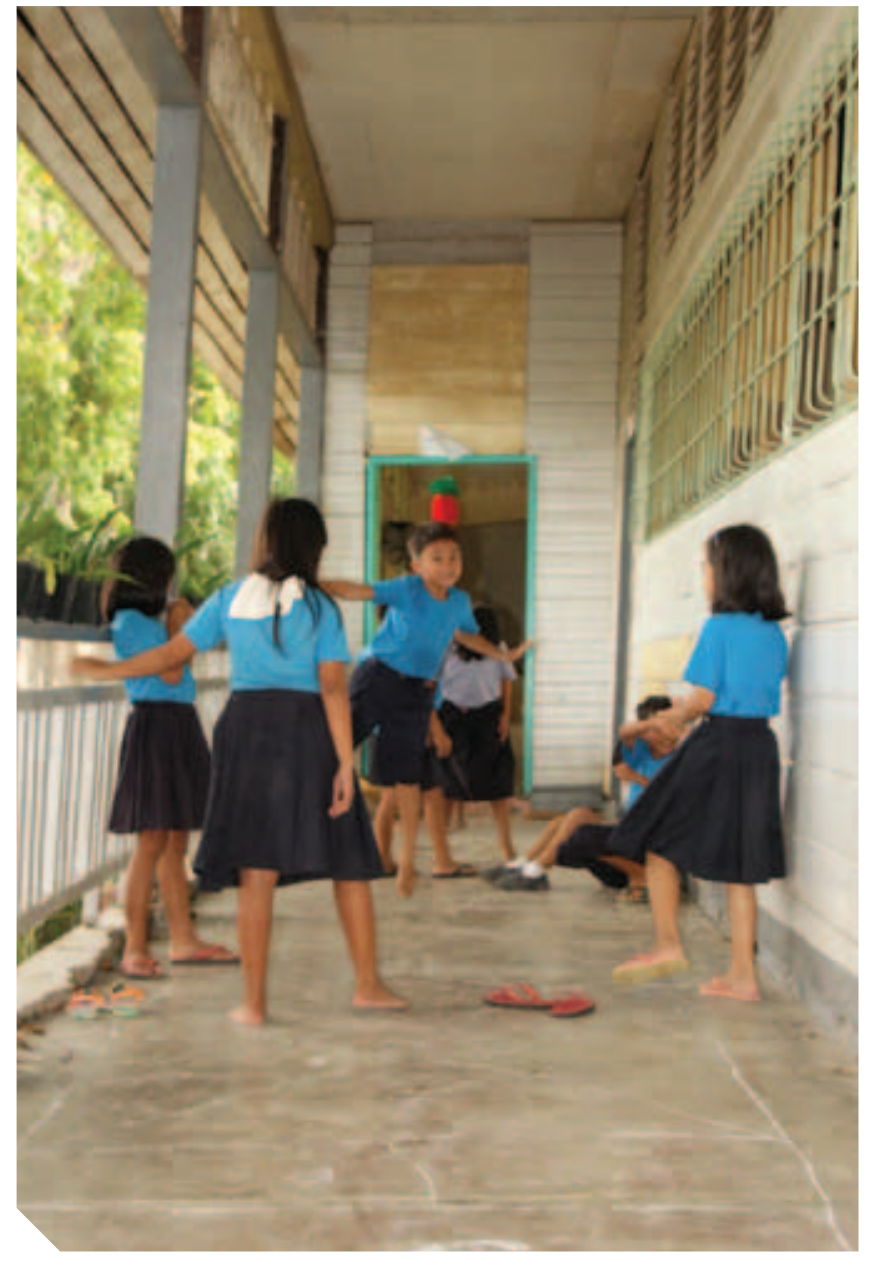

The note shows that the key elements of an effective school-based management system are in place. However, schools report that they are not yet implementing many of the key aspects of this system. Moreover, parents and local communities still play a very limited role in decisionmaking and in holding schools accountable. Given the ever increasing amounts of resources that schools now control and the need to give them more flexibility over how to use those funds, this note argues that the role of representative school governing councils could be expanded and efforts made by DepEd to increase awareness among parents and education stakeholders of the useful role they could play in supporting school-based management. 


\section{Implementation of School- based Management in the Philippines}

Studies that have assessed the implementation of schoolbased management have generally focused on three key dimensions:

- Autonomy. The degree of autonomy that schools have to make their own decisions determines their ability to affect the educational outcomes of their students.

- Participation in decision-making. A central component of SBM reforms has been to encourage greater participation by parents and other members of the community in supporting schools, usually by establishing or strengthening school governing bodies.

- Accountability and transparency. The extent to which a school is accountable to its local community is an important aspect of its management practices, including the transparency of the school decisionmaking process and the quality of information that the school provides to its stakeholders.

Most schools in the Philippines have as yet not gone very far in implementing school-based management. In 2009, DepEd introduced a tool for schools to carry out their own assessment of their progress in implementing SBM (Box 1). In 2014 the PETS-QSDS study collected information on the results of these self-assessments and found that the majority of elementary and high schools reported having put in place only the lowest level of SBM (Figure 1). This means that they had only a minimum number of arrangements in place for community participation and for taking action to improve learning outcomes. Fewer than 10 percent of schools reported being at the highest level of SBM implementation and, thus, meeting all standards of community participation and school-based management.

Poorer students were more likely than wealthier students to attend schools with lower self-assessed SBM ratings. The PETS-QSDS survey included a nationally representative sample of public elementary and high school student households. Using information collected on consumption and asset ownership in the survey, it was possible to rank student households by estimated levels of per capita household consumption. ${ }^{4}$ Using this indicator, it was possible to disaggregate the SBM ratings by schools serving different socioeconomic groups. The study found that students from

\section{Figure 1: Most Schools Rated Themselves as Being at the Lowest Level of SBM Implementation Percentage of schools by latest self-assessed SBM implementation level, 2014}
$100 \%$
$\square$ Level 1-developing
Level 2-maturing
- Level 3-advanced
$80 \%$

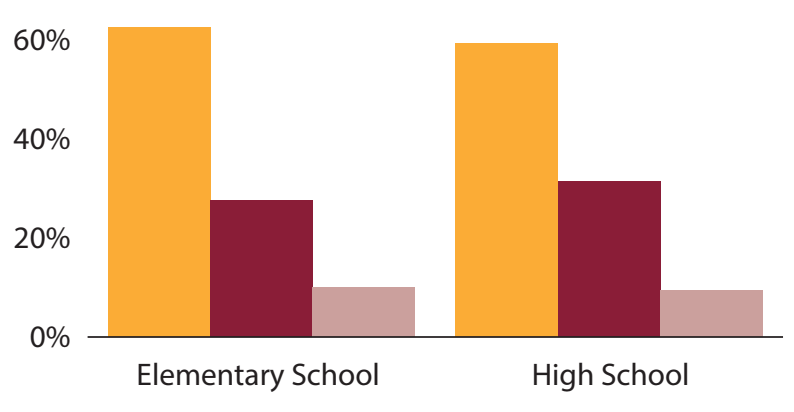

Source: PETS-QSDS national survey - school-level data.

the poorest 20 percent of households were more likely to attend elementary and high schools that had the lowest level of self-assessed SBM implementation than students from the wealthiest 20 percent of households. ${ }^{5}$ Other research has shown that SBM reforms have had only a limited impact in schools that serve poorer communities. ${ }^{6}$ The findings from the PETS-QSDS study suggest that this may be due at least in part to the fact that schools in poorer areas are finding it difficult to put SBM into practice.

The main weaknesses identified by school principals were related to school autonomy. On the whole, more elementary school principals than high school principals highlighted weaknesses in their implementation of SBM. However, more high school principals mentioned their inability to raise sufficient resources as a major impediment to putting SBM into practice (Figure 2). It is likely that this also limits the ability of schools to carry out the activities included in their school improvement plans. Approximately 20 percent of elementary and high school principals also cited weaknesses in school improvement planning as an issue preventing the implementation of SBM.

Most principals did not regard the participation of teachers and other internal stakeholders in decision-making at the school level as a weakness. However, 40 percent of elementary school principals felt that the engagement of external stakeholders, including parents, local government, and other community representatives, was relatively weak. 


\section{Box 1: Measuring the Implementation of School-based Management in the Philippines}

DepEd first introduced a self-assessment tool in 2009 to help schools to improve their school-based management practices. In 2013, it introduced a new self-assessment tool that asked schools to rate the extent to which they had implemented SBM based on 22 indicators that could be converted into an aggregate three-point scale as follows:

1. Level 1 - developing: Schools have developed structures and mechanisms that have increased community participation and improved learning outcomes to an acceptable level.

2. Level 2 - maturing: Schools have introduced and sustained continuous improvements that have led to community participation and have significantly improved student learning outcomes.

3. Level 3 - advanced: Schools have fully implemented a school-based management system that fully involves the local community and is self-renewing and self-sustaining.

In the PETS-QSDS study, schools were also asked to identify any weaknesses they might have in six aspects of schoolbased management defined in the original 2009 assessment. These six aspects are related to the three dimensions of school-based management assessed in this policy note, which are:

1. Autonomy. School principals were asked about strengths and weaknesses in their school leadership, their ability to raise resources, and their school improvement planning process.

2. Participation. School principals were asked to identify strengths and weaknesses in their schools'links with internal and external stakeholders.

3. Transparency and accountability. School principals were asked about strengths and weaknesses in the institutions that hold the school accountable for performance.

Sources: Parandekar, S. (2014). "Benchmarking Public Policy: Methodological Insights from Measurement of School-based Management."World Bank Policy Research Working Paper No. 6938, World Bank, Washington D.C.; DepEd Order No. 83 (2012) "Implementing Guidelines on the Revised SBM

Framework, Assessment, and Tool," Department of Education, Manila; and DepEd (2009). "A Manual on the Assessment of SBM Management Practices," Department of Education, Manila.

\section{Figure 2: School Principals Cited Issues Related to School Autonomy as a Major Weakness in the Implementation of SBM}

Percentage of schools reporting weaknesses in key SBM dimensions, 2014

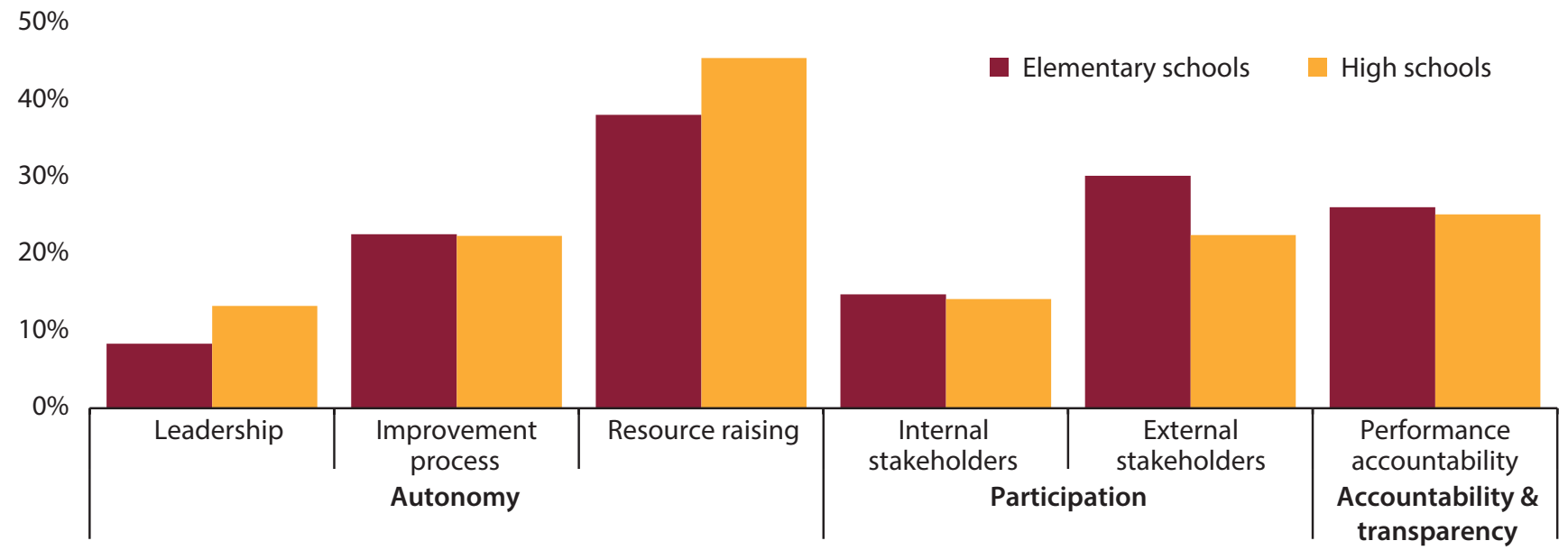

Source: PETS-QSDS national survey - school-level data. 


\section{Autonomy}

While schools have only a limited amount of autonomy to make decisions about their own affairs, most schools develop their own improvement plans and implement them to the extent that their authority and resources allow. In each school, the school improvement plan (SIP) is developed by the principal with help and input from teachers and the local community. It reviews the school's performance (for example, in terms of student scores on the National Achievement Test) and identifies areas where improvements are needed. Each SIP covers a three-year period, and the school produces a more detailed implementation plan every year. However, schools have very limited authority over such important areas as the hiring and deployment of teachers and school infrastructure improvements.? In 2014, almost all schools had current school improvement plans in place, and only 5 percent of elementary schools and 10 percent of high schools did not have an up-todate annual implementation plan.

Schools have discretion over only a very small amount of their total revenues. The PETS-QSDS study collected detailed information on all sources of school revenue and expenditure from a nationally representative sample of elementary and high schools. ${ }^{8}$ The findings showed that the average annual revenue of an elementary school was approximately PHP 3 million and for high schools it was PHP 8.1 million (Figure 3). Over 80 percent of school funding is devoted to teacher and staff salaries, and most of these salary payments are for centrally hired government teachers and staff. While school principals have some control over the day-to-day supervision of their staff, the hiring and resources used for school staffing fall outside the school's control. Only around PHP 188,000 or 7 percent of total funds are available to each elementary school to use at its own discretion. High schools have a little more flexibility in the use of their funds but only around PHP 987,000 or 12 percent of each school's total funds are discretionary.

The bulk of these discretionary funds are provided by DepEd and come with some conditions over their use. DepEd provides 70 percent of discretionary funds for elementary schools and 83 percent for high schools. The bulk of cash funds provided by DepEd is allocated on the basis of student numbers and is provided to cover maintenance and other operating expenses (MOOE). ${ }^{9}$ Schools are allowed to use these funds on many recurrent items (such as utility payments and small repairs) but are prohibited from spending them on other important items such as learning materials and any capital assets (for example, IT equipment). ${ }^{10}$

\section{Figure 3: Discretionary Resources at the School Level are Low}

Annual school revenue by type and source, 2013/14 school year

\section{Composition of all school funding (PHP 000s)}

10,000

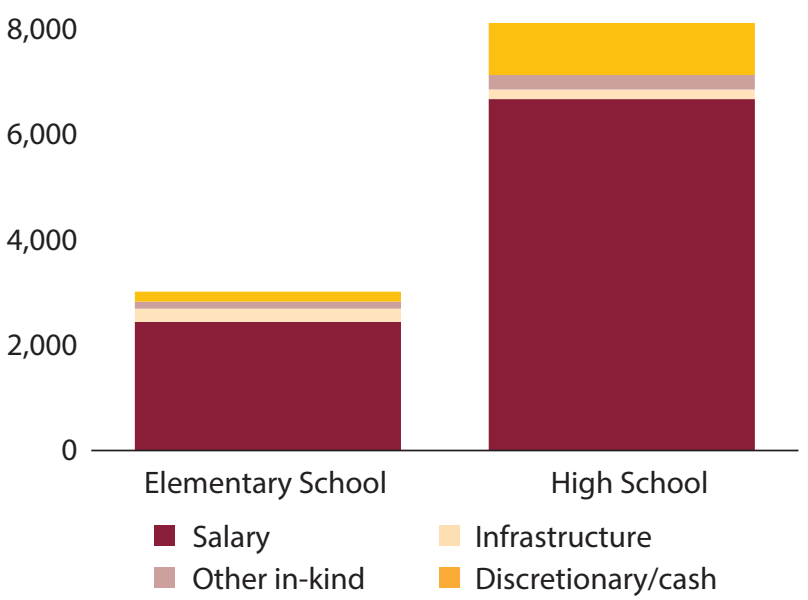

\section{Percentage of discretionary funds by source}

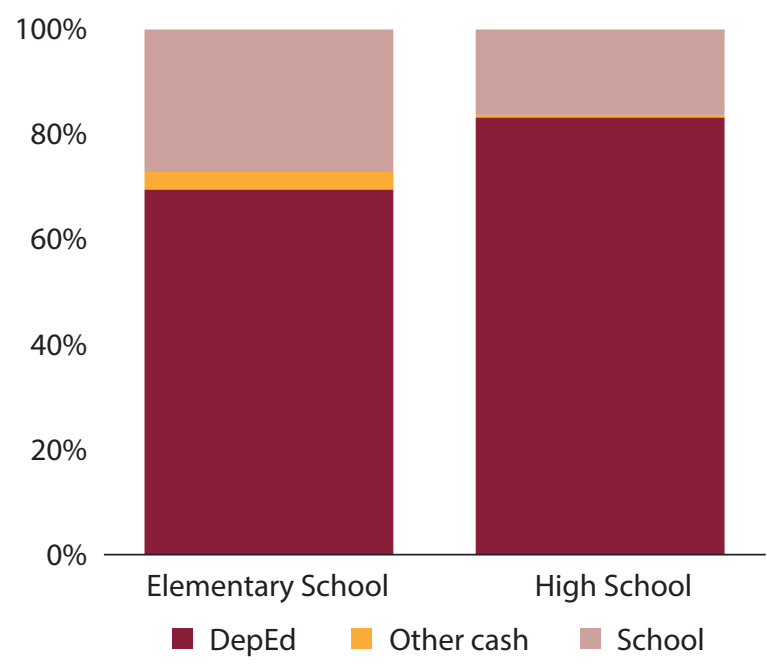

Source: PETS-QSDS national survey - school level.

Note: The averages reported in the table are for all schools even if they received zero revenue under a particular category. Other cash revenue includes cash provided to schools by parent-teacher associations, local governments, and barangays and from private sector or NGO contributions. 
Schools also generate their own funds, but their ability to do so is dependent on the socioeconomic composition of their student populations. Schools collect student contributions to cover specific activities (such as school projects, Red Cross, uniforms, and school feeding programs) as well as running the school canteen and other income-generating projects. About 27 percent of discretionary revenue comes from these sources in elementary schools compared with 16 percent in high schools." However, schools that serve a large proportion of children from poorer households are restricted in terms of how much of this kind of revenue they can raise. For example, in 2014 students in the poorest quintile attended high schools that collected approximately PHP 60 per student in canteen funds, while students in the wealthiest quintile attended schools that collected PHP 116 per student in canteen funds. ${ }^{12}$ While some of this difference may have been due to the quantity and quality of food provided, it may also have reflected the greater capacity of wealthier schools to collect revenues to support their own school improvement planning.

A lot of school discretionary resources are devoted to routine expenditures, which leaves only a limited amount available to fund additional activities. The most detailed information available on the use of school discretionary resources comes from official school records on school-level spending on MOOE. In 2013, schools used approximately three-quarters of their MOOE funding to pay for supplies and printing, to undertake routine maintenance, and to pay their utility bills..$^{3}$ While these are clearly important, it does not leave much room for schools to invest in other activities that might support better learning. For example, less than 5 percent of MOOE funding was used to finance teacher training. A recent detailed costing study found that existing levels of MOOE were insufficient to provide education services up to the standard of existing DepEd norms. ${ }^{14}$ The limited amount of funding that schools have available to spend at their own discretion in effect curtails the autonomy that they have to make their own decisions on how best to improve their operations.

\section{Participation}

Effective school-based management requires parents and local community members to play a strong supporting role in school decision-making and oversight. The School Governing Council (SGC) for each school is a forum for parents, students, teachers, and community stakeholders to participate in making school improvement decisions. It takes an active role in developing the school improvement plan (SIP) and, together with the school principal, is responsible for endorsing it to the schools division superintendent (SDS) for approval. It is also expected to participate in the monitoring of the implementation of the SIP..$^{15}$ The number and type of the SGC's members and the frequency of its meetings are initially decided through an establishment meeting attended by parents and other stakeholders. In this meeting the constitution and by-laws of the SGC and the election process for selecting council members are agreed.

Most schools have established school governing councils, and their composition tends to be representative of stakeholders within the school and in the local community (Figure 4). The PETS-QSDS survey found that approximately 90 percent of elementary schools and 80 percent of high schools had SGCs. The PETS-QSDS survey was administered in the last quarter of 2014, and its results showed that, on average, SGCs had met

\section{Figure 4: School Governing Councils Are Representative of Most Key Stakeholders}

Percentage of SGCs by type of membership, 2014

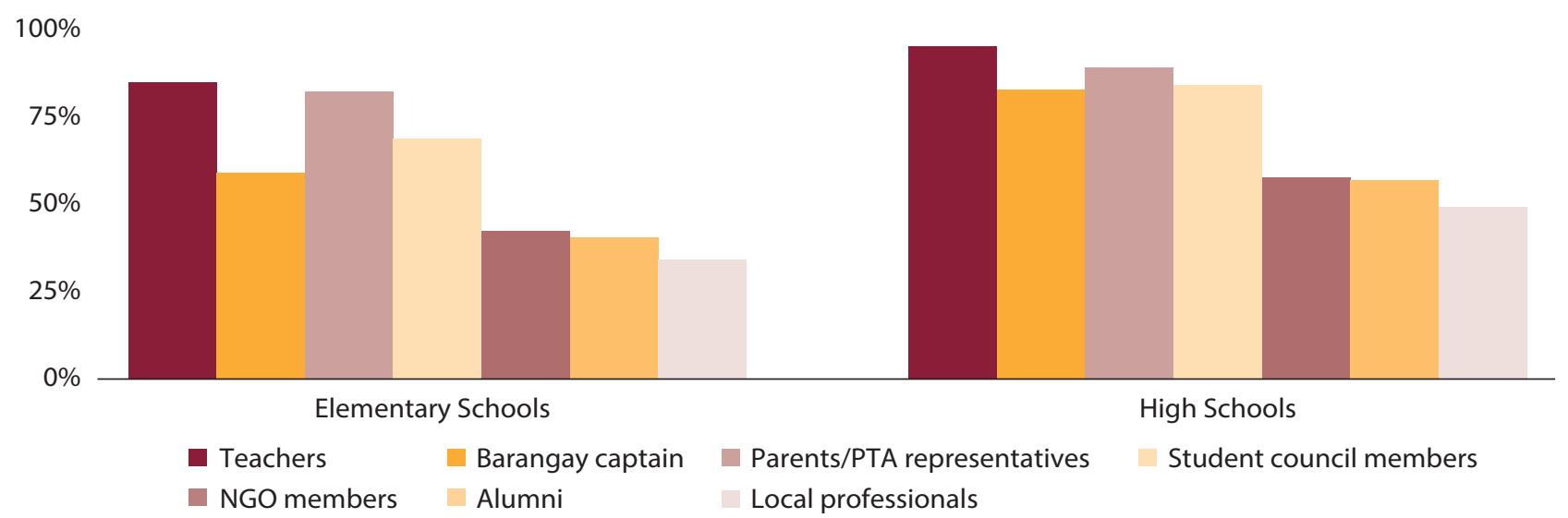

Source: PETS-QSDS national survey - school level. 
twice since the beginning of the 2014/15 school year. This implies that SGC meetings are usually held every quarter. The survey found that SGCs generally include representatives of most of the major stakeholders including parents, teachers, and students. In terms of overall numbers, parents and students tend to be most heavily represented on elementary school SGCs, whereas in high schools, teachers are more heavily represented.

School principals reported that the most common types of support provided by SGCs is the time and labor that they devote to school activities. Two-thirds of elementary school principals and nearly half of all high school principals reported receiving this kind of support from SGCs. About half of all principals also cited financial support for school planning as another type of support received from the SGC. When SGCs meet, the most common topics of discussion are student discipline, school improvement planning, school finances, and student academic performance.

Very few parents of students were aware that their child's school had an SGC. The PETS-QSDS study interviewed a random sample of student households from the schools that were sampled. Nearly three-quarters of the household heads that were interviewed were unaware that their child's school had an SGC (Figure 5). These findings raise questions about how effectively the SGCs are fulfilling their role as forums for

\section{Figure 5: Few Parents Know about the SGC or Are Aware of the School Improvement Plan} Percentage of parents of elementary and high school students who know about the SGC and the SIP, 2014

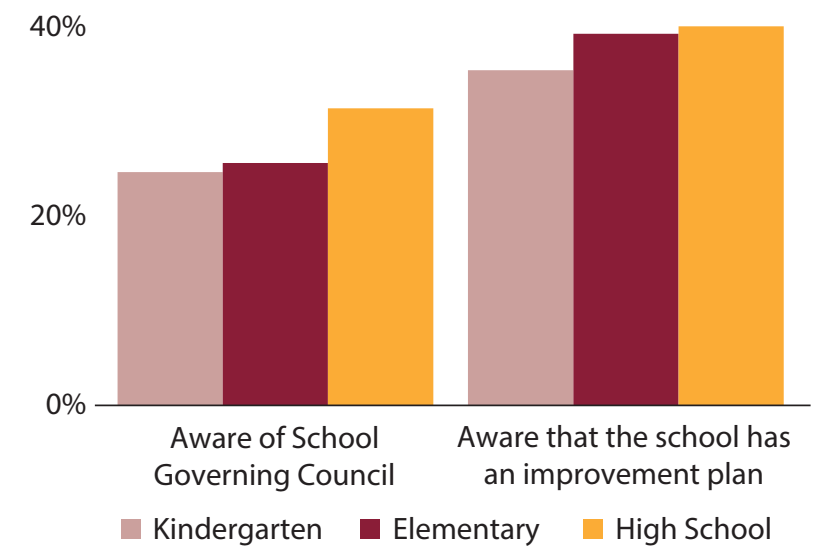

Source: PETS-QSDS national survey - household level.

Note: The bars relate to the level of education attended by the student from the interviewed household. school and community collaboration in improving learning outcomes.

Given that parents tend not to know about the existence of the SGC, it is perhaps not surprising that fewer than half of all parents interviewed were aware that their school had an improvement plan. Most of the parents who knew about the SIP seem to have been invited to participate directly in its preparation, but any awareness beyond this group of parents was rare.

Parent-teacher associations (PTA) are another mechanism through which parents can support school improvement. All schools sampled as part of the PETS-QSDS study reported that they had a functioning PTA. The role of PTAs in school decision-making and in the development of the school improvement plan in particular is less clearly articulated than the role of the SGC. The DepEd guidelines governing PTAs focus almost exclusively on procedures for collecting funds and reporting on their use. ${ }^{16}$ However, PTAs are an important way in which parents can raise any concerns about school issues and provide support for school operations. As with SGCs, many PTAs include representatives of other local stakeholders including barangay captains and other local government officials.

Parents are moderately more aware of and active in PTAs than in school governing councils. All schools and almost all parents reported that their child's school had a PTA. Interviews with the Presidents of the PTAs indicated that most PTAs met on a monthly or quarterly basis (Figure 6). Only 10 percent of PTAs in elementary and high schools met less than twice a year. Almost a half of all parents participated in PTA meetings and on average attended four meetings during the school year (Figure 6). On the whole, over 90 percent of parents were satisfied with the functioning of their local PTA.

Even though PTAs play only a limited formal role in school affairs, PTA Presidents reported that they had had some involvement in both the formulation and monitoring of school plans. Approximately 85 percent of elementary and high school PTAs participated in the development of the school improvement plan as well as in monitoring its implementation. The small proportion of PTAs that were not involved in the SIP process mentioned either that they were not asked to help or that the PTA did not have the time to devote to it. 
Figure 6: PTAs Meet Regularly and Parents Play an Active Role

Frequency of PTA meetings and percentage of parents reporting that they attended regularly in 2013/14 school year

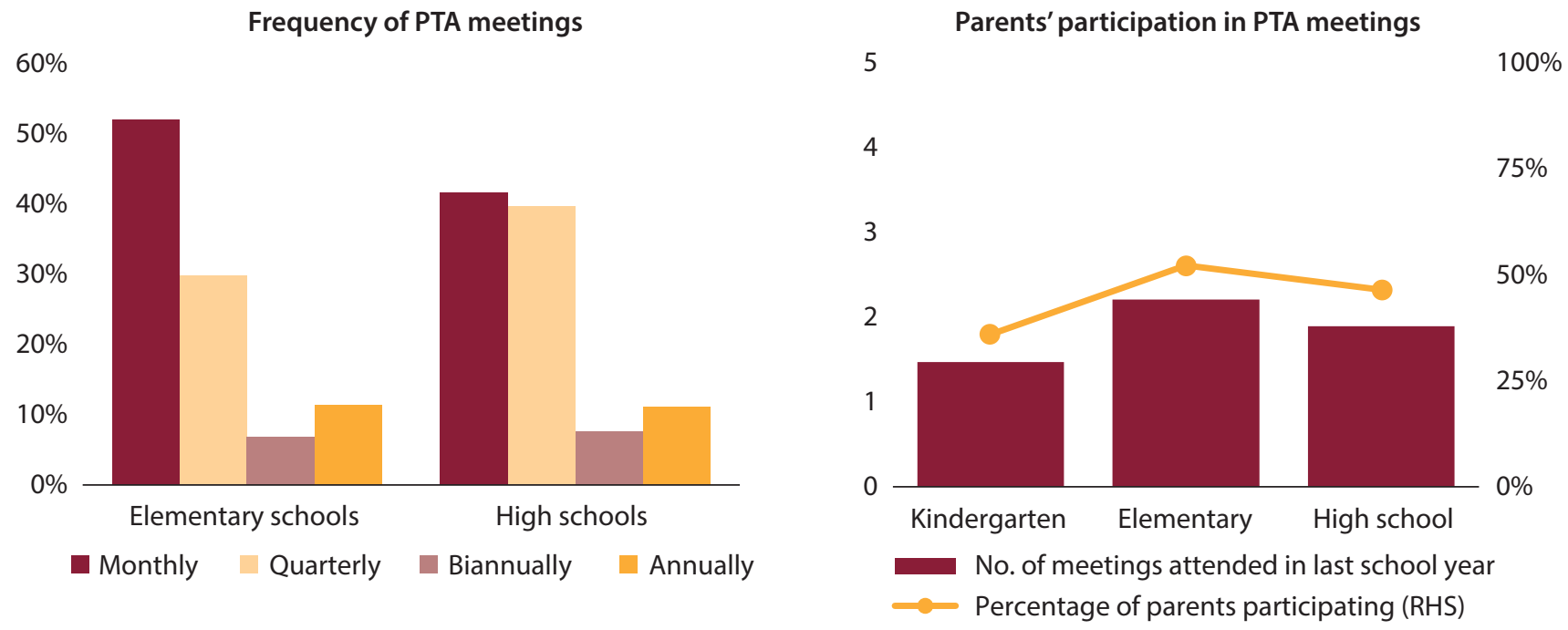

Source: PETS-QSDS national survey. Left hand panel from student household interviews and right hand panel from PTA interviews.

The main kind of support that PTAs provide to schools is in the form of additional financial and human resources. PTA Presidents mentioned that providing their labor and skills for school projects was one of their most common activities in support of schools (Figure 7). Two of the most commonly cited kinds of support given to schools by their PTAs were physical labor and participation in school maintenance week (Brigada Eskwela). PTAs were also active in providing additional funding to schools through their own PTA fees as well as organizing fund-raising activities for the school. Only 32 percent of elementary school PTAs and 41 percent of high school PTAs mentioned planning as one of their main areas of support.

These findings suggest that PTAs are generally more active in school affairs than SGCS and are the main mechanism through which parents and other stakeholders participate.

Figure 7: PTAs Commonly Provide Schools with Labor, Finances, and Assistance during the Brigada Eskwela Percentage of PTAs providing support by type, 2014

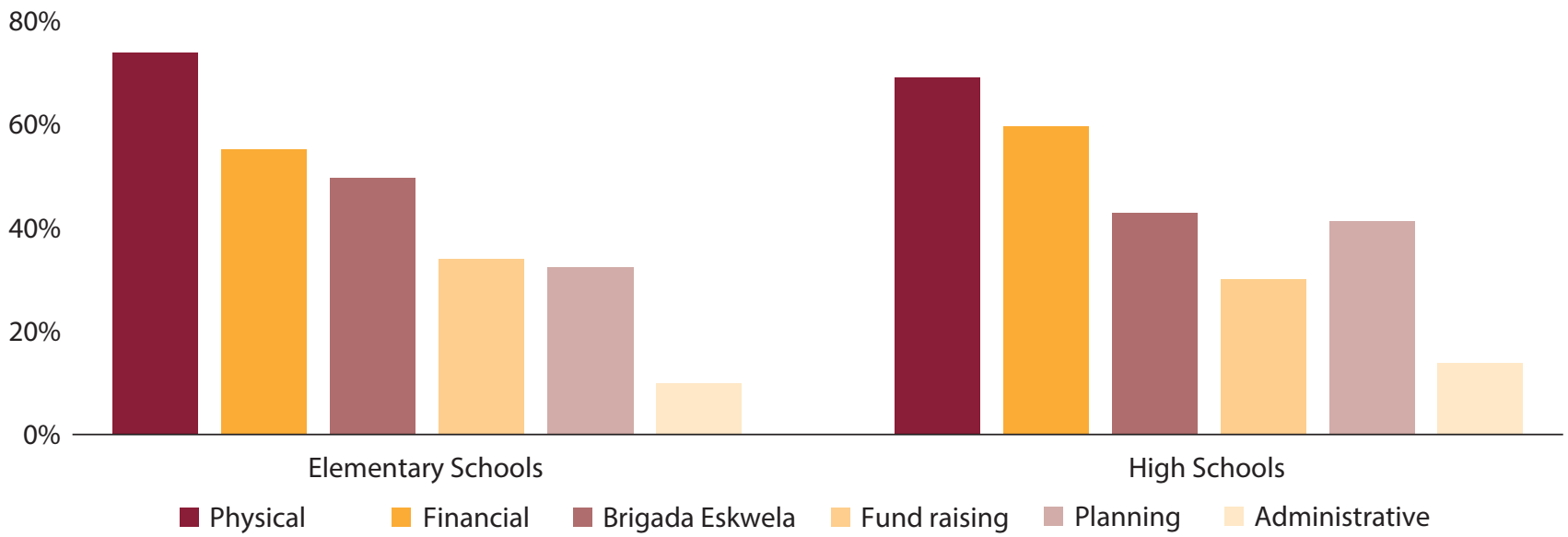

Source: PETS-QSDS national survey - PTA interviews.

Note: Brigada Eskwela, or school maintenance week, happens at the start of the school year and the local community provides labor and resources to repair and tidy up school facilities. 
These findings are confirmed by school principals who stated that one of the most common ways in which they receive feedback and complaints from parents and other stakeholders is through the PTA. Approximately 60 percent of elementary and high school principals reported receiving comments and complaints from the PTA, and, with the exception of direct discussions with parents and students, this was their most common feedback mechanism.

\section{Accountability and Transparency}

This note has already provided an assessment of the kinds of institutions that are available at the school level to hold schools accountable for the resources they receive and ultimately for the education outcomes they deliver. This section focuses on the information that parents, PTAs, and SGCs can use to hold schools to account and ways in which parents and other stakeholders are able to provide feedback to schools.

While the PETS-QSDS enumerators were visiting schools, they noted that approximately 70 percent of elementary and high schools had some kind of notice board or transparency board where information was posted (Figure 8). However, many of these transparency boards were not publicly accessible. For example, around 40 percent of the transparency boards in elementary schools were located inside the principal's office or in the staff room.

Most schools do not display or publish up-to-date information on how they spend their discretionary resources. The proportion of schools, particularly high schools, that reported such information was low (Figure 8). The most common information posted in schools was reports on how they had spent their MOOE funds. However, in one-third of the cases where this information was included on the transparency board, it was over three months old. Information on how revenues from sources such as school canteen funds were reported in slightly over half of all elementary schools but in fewer than one-third of high schools.

Information on school performance was also rarely provided on publicly accessible notice boards. Only 41 percent of elementary schools and 12 percent of high schools placed information such as the results achieved by their students on the National Achievement Test and school dropout rates on

\section{Figure 8: About a Half of Schools Have an Accessible Transparency Board but the Information Provided Is Frequently Limited}

Percentage of schools with a transparency board and types of information posted on the boards, 2014

\section{Elementary Schools}

$80 \%$

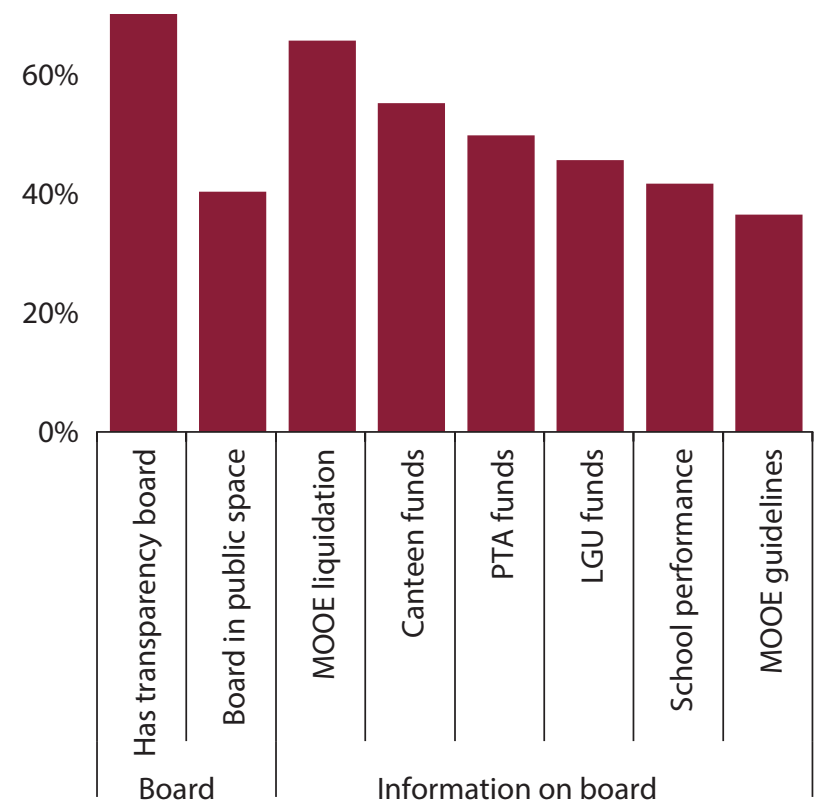

High Schools

$80 \%$

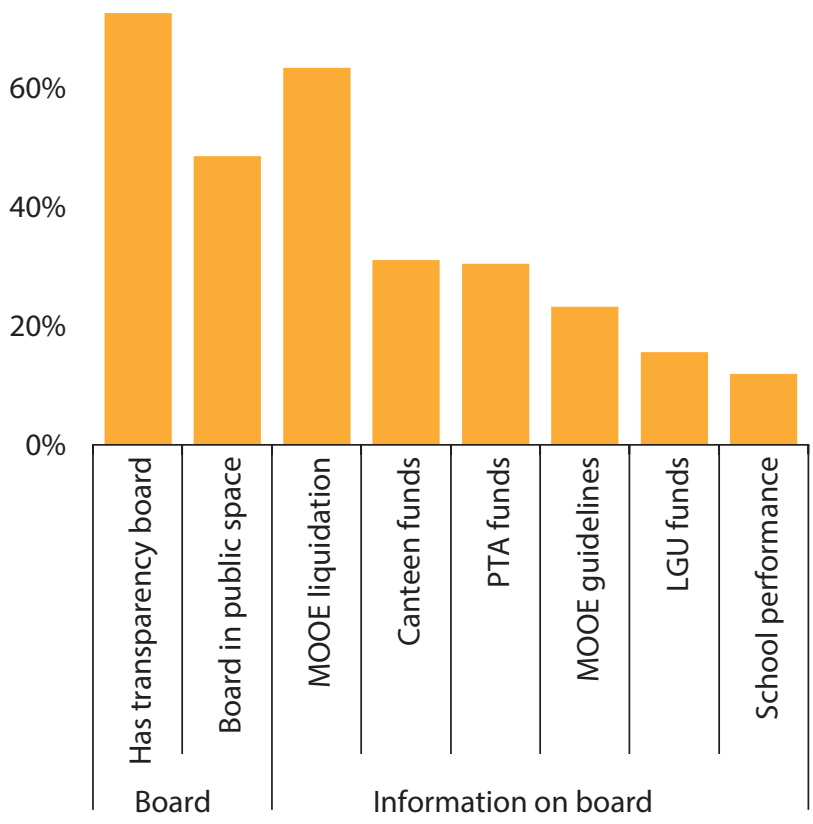

Source: PETS-QSDS national survey - school level. 
transparency boards (Figure 8). While many schools do display this information, they usually do so within the principal's office, which is inaccessible to parents and other community stakeholders.

The limited availability of information provided by schools is perhaps a key reason why parents appear to be unaware of the kinds of financial resources that schools receive to fund improvements. Interviews with the parents of students in PETS-QSDS schools revealed that they had little knowledge of what resources the schools received. For example, only 40 percent of parents of elementary and high school students were aware that schools received MOOE funding from the national government. Even among the parents who were aware of this, fewer than half had received any information on how the funds had been allocated in their school over the previous year. School meetings and PTA meetings were the most common places where information on MOOE was disseminated. Fewer than 5 percent of elementary and high school parents reported obtaining this information from the transparency board at the school.

There are few other ways by which parents and other stakeholders can access information on school performance. As part of the school improvement planning process, schools are supposed to prepare an annual school report card that includes information on key school performance indicators such as the National Achievement Test (NAT) results and student progression indicators. Yet only around a half of parents of elementary and high school students said that they had been given such a card or even any information in the previous two school years. A similar proportion of parents reported that they had not even received a report card on their own child's progress.

Despite the limited provision of information by schools, parents on the whole felt that schools were fairly responsive and that there were a number of mechanisms in place for parents to provide feedback. Over 85 percent of parents either agreed or strongly agreed that schools provided opportunities for parents to file complaints on school-related issues. A similar proportion of parents of elementary and high school students felt that their school worked well with other stakeholders to respond to the needs of learners.

Beyond school-level institutions, social accountability initiatives like Check My School do not appear to have had a significant impact. Check My School (CMS) is a project that uses mobile and internet technology to enable communities to monitor the quality of basic education services. The initiative involves local facilitators who mobilize communities to verify information on the status of their school. Any discrepancies between official government data and the data collected by the CMS are then brought to the attention of DepEd. Although the initiative began in 2011, its coverage appears to be quite small. Only 15 percent of elementary school principals and 20 percent of high school principals were aware of CMS, and only a small proportion of these schools had had any direct dealings with the initiative (Figure 9). For example, fewer than 5 percent of high schools had ever provided feedback through CMS. ${ }^{17}$

\section{Figure 9: Social Accountability Initiatives like Check My School Do Not Work in Many Schools}

Percentage of school principals reporting any involvement with Check My School (CMS) in 2013 or 2014

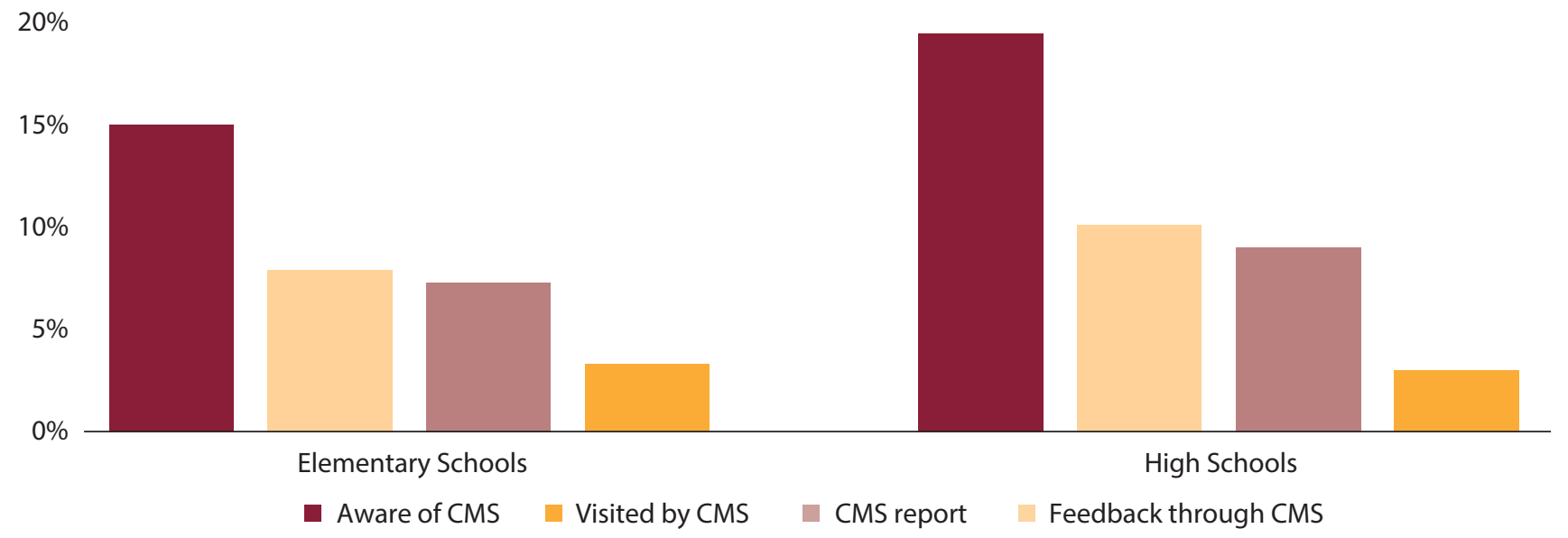

Source: PETS-QSDS national survey - school level. 
Figure 10: Division and District Supervisors Carry Out School Monitoring Visits Regularly Average number of visits to schools in first half of 2014/15 school year and issues covered

Number of visits

3

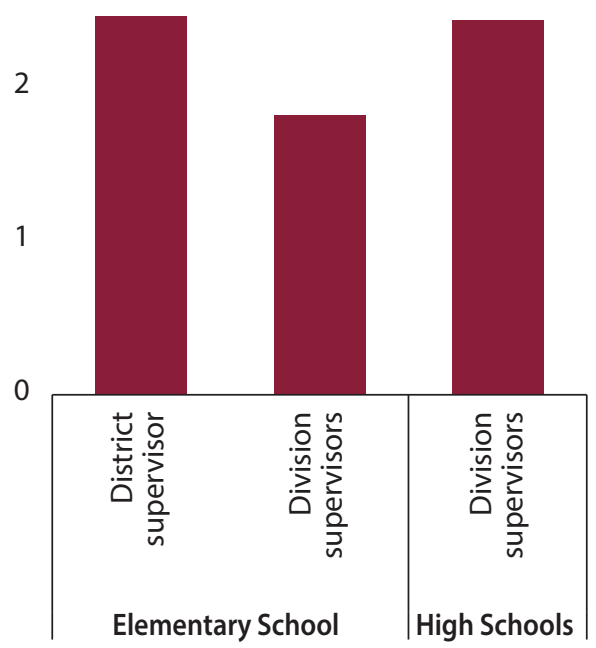

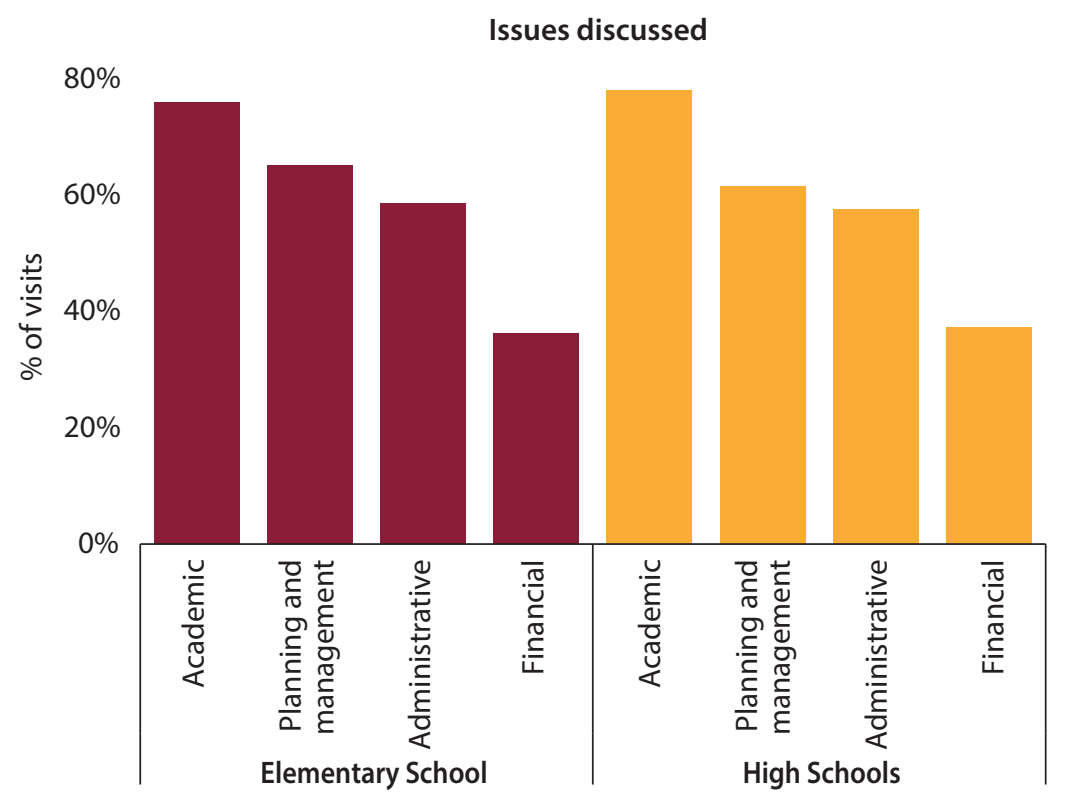

Source: PETS-QSDS national survey - school level.

Note: Only issues that were discussed with the public schools district supervisor are reported for elementary schools.

Division and district supervisors from DepEd regularly visit schools to monitor their operations and to provide them with administrative and academic support. Elementary school principals reported that, since the start of the 2014/15 school year, they had received two visits on average from the public schools district supervisor (PSDS) and one visit from division office supervisors (Figure 10). Given that the PETSQSDS survey was administered in the last quarter of 2014, this means that the PSDS was visiting an average of once every two months and the division supervisors were visiting every quarter. Similarly, high schools were being visited by division supervisors every two months. ${ }^{18}$ These visits usually included academic supervision of classroom teaching and discussions with school principals on planning, management, and administration.

\section{Policy Directions to Strengthen School-based Management}

The relatively low level of SBM implementation reported by schools in their own self-assessments highlights the need for DepEd to provide more support to schools. Providing school-level staff and SGC and PTA members with training on their roles and responsibilities has the potential to enable them to support schools in implementing all of the aspects of SBM. However, it is also likely that schools will need support from district and division-level supervisors to help them to develop and implement better school improvement plans and to increase the effectiveness of PTAs and SGCS. 
This support could be provided during the existing visits that district and division supervisors make routinely to schools.

A recent evaluation of training in Indonesia highlighted the importance of supervisors playing this kind of mentoring role in supporting school improvements (see Box 2).

Providing schools with more discretionary funding could support the implementation of SBM and increase the effectiveness of public spending. The small share of discretionary funding that schools currently receive limits their autonomy and ability to implement their school improvement plans. Less than 15 percent of school funding is controlled directly by schools, and much of this funding is spent on utility bills and routine supplies instead of on actions aimed at improving the learning outcomes of their students. DepEd has already embarked on a strategy to increase the level of school MOOE funds significantly, and this will go some way towards providing schools with the resources that they need.

The government should consider increasing the authority that schools have over the use of other school-level funding. For example, DepEd is currently engaged in a massive school infrastructure improvement program, but analysis of the PETS-QSDS survey has shown that the quality of classrooms and water and sanitation facilities built or rehabilitated under this program has generally been poor. Giving schools and the SGC a greater role during the planning and

\section{Box 2: An Evaluation of School-based Management Training Activities in Indonesia}

In 2011, Indonesia embarked on a massive program to train school principals and school committee members on the core elements of school-based management, including planning, budgeting, and financial management. Approximately 650,000 people attended a three-day training event held in different locations across Indonesia. An evaluation of the program came to a number of important conclusions:

- A follow-up survey of participants found that the materials covered under the training program were relevant to the needs of schools in terms of school-based management.

- The training program contributed to a number of changes at the school level particularly in terms of school governance. These positive findings were confirmed by interviews with parents and community members, which revealed that schools were using discretionary funds in a transparent and accountable way.

- Schools reported that they were better able to follow the central government's guidelines for reporting on their use of discretionary funds, which increased transparency and accountability.

- The follow-up survey highlighted overall improvements in the management of school operational funding, particularly by school committee members.

- The quality of training varied greatly across regions. There was a lack of supervision of the training events at the district level, which resulted in differences in the length of the training, class sizes, the capacity of trainers, and the quality of training facilities.

The majority of trainees interviewed in the follow-up survey felt that more guidance and assistance was needed to help them to implement the training elements in their own schools.

Source: Shaeffer, S. (2013). “BOS Training: Its Implementation, Impact, and Implications for the Development of Indonesia's Education System. An Independent Review" Report prepared for AusAID Indonesia, Jakarta. 
implementation of these improvement projects and giving schools the authority to certify project completion could improve the quality of these facilities in the future. ${ }^{19}$

This note has also highlighted the need for DepEd to provide greater support to schools that serve poorer communities. It has shown that poorer children generally attend schools where SBM implementation is less advanced and where fewer discretionary funds are available. The introduction of an equity component in the school MOOE funding formula would be one way to address these funding inequalities. For example, schools in remote areas and/or that serve disadvantaged groups could be given additional funding to account not only for differences in their own revenueraising abilities but also for the higher costs they incur to purchase school equipment and supplies and to attend training sessions. While more training and support for SBM implementation is needed throughout the Philippines, it is likely that additional help will be needed by the most disadvantaged schools.

Greater efforts are required to revitalize the role played by school governing councils in the school improvement planning process in schools across the Philippines. As DepEd considers devolving more of the public education budget to schools, it is vital that accountability structures and resource planning processes are strengthened. In particular, SGCS could be given greater responsibility for monitoring how schools use their MOOE funds as a supplement to DepEd's oversight mechanisms. For example, SGCs could become jointly responsible with the DepEd divisions office for signing off on schools' MOOE liquidation reports. If the SGCs are to take on an expanded role, then more training and support will need to be provided by DepEd to their members.

This note has shown that most parents of students are unaware of the existence of SGCs or their school's improvement plan. It seems clear that a campaign is urgently needed to increase the awareness of parents and other education stakeholders of the role of SGCs and school improvement plans. Recent evaluations in Indonesia and
Pakistan have shown that it is possible to use old and new technologies to increase awareness. In Indonesia, an impact evaluation study showed that well-designed information campaigns using simple SMS text messages or school meetings can significantly increase public knowledge about schools' funding levels and responsibilities. ${ }^{20}$ It also found that this increased knowledge led to higher levels of parental participation in school affairs. In Pakistan, a similar strategy was used in a successful pilot program to disseminate information about school councils. ${ }^{21}$ The pilot set up a call center and used inbound and outbound calls, robot calls, and SMS text messages to transmit important information on the role played by school councils and their members. An assessment of the pilot showed that the knowledge that school council members had of their roles and responsibilities had increased, while school principals reported an increase in the participation of the councils in school affairs.

This note has found that PTAs seemed to function well, with high participation rates by stakeholders and good relations with school principals. These findings suggest that parents and other stakeholders could participate to a greater extent in school improvement planning and in the management and oversight of school funds. However, it is also vital that the roles and responsibilities of SGCS and PTAs should be clarified by DepEd to ensure that there are no duplications in functions and that each institution fulfils its particular role.

Schools also need to make more information available to their stakeholders on how they use their funds and on the school's overall performance. This note has shown that many schools do not routinely share this kind of information with parents even though there are regulations obligating them to do so. Keeping parents informed can encourage them to expand their role in supporting schools and in holding schools to account. Schools in the Philippines are required to produce report cards on the performance of the school and of individual students, but this note has shown that this often does not happen. There is evidence from other countries that these report cards can have significant benefits in terms 
of, for example, higher student test scores and reduced absenteeism by teachers (Box 3). Therefore, DepEd needs to ensure that its regulations requiring schools to produce report cards are enforced and to make parents aware that they are entitled to expect to be given more information on their children's schools.

The evidence from the Philippines clearly shows that the introduction of school-based management can have enormous benefits in terms of better education outcomes. Schools around the country have already embarked on many of the reforms needed to realize these benefits. However, there is a need to revitalize school-level institutions and to increase the amount of information that schools provide to parents and other stakeholders on the services that the schools are providing. Only then will the full potential of school-based management to improve education outcomes be realized.

\section{Box 3: An Evaluation of School-based Management Training Activities in Uganda}

A randomized controlled trial in Uganda explored the impact of different interventions that used school report cards as a way for school managing committees to monitor performance. The two interventions that were tested were as follows:

- A standard scorecard. School committee members were trained on how to use a school-level report card developed by education officials and NGOs.

- A participatory scorecard. School committee members were trained and helped to produce a school-level report card that they themselves had developed and that included indicators of school progress agreed upon with the school.

Interventions like these can be expected to improve education outcomes by providing local communities with the information needed to hold their schools accountable. They can also encourage schools to improve their performance either through social pressure or through a closer collaboration between the school and community.

The experiment found that the participatory scorecard approach had a statistically significant impact on education outcomes. In terms of student learning, schools where the participatory scorecard was introduced had a statistically significant advantage in primary school test scores of approximately 0.2 standard deviations over control schools. Teacher attendance also improved, with teachers working in participatory scorecard schools being 13 percentage points more likely to be present than teachers in control schools.

The results for the standard scorecard approach were less promising. The experiment found no statistically significant effects on student learning although it did appear to have a positive effect on the attendance of some teachers.

The authors argue that the better outcomes for the participatory scorecard were primarily the result of increased cooperation between the school and the local community rather than because of differences in the information contained in the different scorecards. These findings suggest that using participatory methods to develop school report cards may improve education outcomes and strengthen the supporting role played by school committees.

Source: Barr, A., F. Mugisha, P. Serneels and A. Zeitlin. (2012). "Information and Collective Action in Community-based Monitoring of Schools: Field and Lab Experimental Evidence from Uganda." Unpublished paper. 
Table 1: Strengthening School-based Management

\begin{tabular}{|c|c|}
\hline Findings & Policy suggestions \\
\hline $\begin{array}{l}\text { Schools assess their level of SBM } \\
\text { implementation as low }\end{array}$ & $\begin{array}{l}\text { - Provide further training to school principals, school governing councils, and } \\
\text { parent-teacher associations on school-based management } \\
\text { - Build the capacity of district and division supervisors to mentor schools in } \\
\text { the implementation of school-based management }\end{array}$ \\
\hline $\begin{array}{l}\text { Only a small share of school funding is } \\
\text { discretionary }\end{array}$ & $\begin{array}{l}\text { - Increase central government MOOE funds to a level that will enable schools } \\
\text { to meet existing education service standards } \\
\text { - Increase the authority of schools over other funds (such as school } \\
\text { construction funding) }\end{array}$ \\
\hline $\begin{array}{l}\text { SBM implementation is less advanced } \\
\text { and fewer discretionary funds are } \\
\text { available in schools that serve poorer } \\
\text { communities }\end{array}$ & $\begin{array}{l}\text { - Introduce an equity component into the MOOE funding formula } \\
\text { - Provide additional supervisory support on school-based management to } \\
\text { schools serving disadvantaged groups }\end{array}$ \\
\hline $\begin{array}{l}\text { SGCs are not functioning as they were } \\
\text { designed to do }\end{array}$ & $\begin{array}{l}\text { - Clarify the roles and responsibilities of SGCs and PTAs } \\
\text { - Establish a role for the SGC in overseeing the use of school discretionary } \\
\text { - Increase the knowledge of SGC members on their roles and responsibilities } \\
\text { through school-level training initiatives } \\
\text { - Conduct an information campaign to increase public awareness of the role } \\
\text { of SGCs and PTAs, the SIP, and the use of and the reporting requirements } \\
\text { associated with discretionary school funds (such as MOOE funds and } \\
\text { canteen revenues) }\end{array}$ \\
\hline $\begin{array}{l}\text { Transparency at the school level needs } \\
\text { to be increased }\end{array}$ & $\begin{array}{l}\text { - Strengthen monitoring by DepEd district and division offices of the } \\
\text { production of key information (such as school report cards and student } \\
\text { report cards) by schools } \\
\text { - Enforce regulations on making information publicly available on school } \\
\text { performance and use of funds }\end{array}$ \\
\hline
\end{tabular}




\section{Endnotes}

1 AusAID ERF (2011). "Current Issues in Education: School Grants and School-based Management." Canberra; Bruns, B., D. Filmer, and H. Patrinos (2011) "Making Schools Work: New Evidence on Accountability Reforms"World Bank, Washington, D.C.; and CarrHill, R., C. Rolleston, T. Pherali, and R. Schendel (2014). "The Effects of School-based Decision-making on Educational Outcomes in Low- and Middle-income contexts: A Systematic Review"Institute of Education, London.

2 Khattri, N., C. Ling, and S. Jha (2010). "The Effects of School-based Management in the Philippines: An Initial Assessment Using Administrative Data" Policy Research Working Paper Series. No. 5248, World Bank, Washington, D.C. and Yamauchi, F. (2014) “An Alternative Estimate of School-based Management Impacts on Students' Achievements: Evidence from the Philippines." Journal of Development Effectiveness. 6, no. 2: 97-110.

3 World Bank and AusAID (2013). "School-based Management in the Philippines: An Empirical Investigation."World Bank and AusAID, Manila.

4 The household questionnaire included a short module on consumption and a set of questions on assets that have been used by the Department of Social Welfare and Development (DSWD) to undertake a proxy means testing (PMT) approach to estimating household consumption per capita. The results reported here are based on information gathered using the PMT approach, and a full description is included in a separate note.

5 The full results are provided in a set of additional annexes and tables accompanying the main PETS-QSDS report.

6 Carr-Hill, R., C. Rolleston, T. Pherali, and R. Schendel (2014). "The Effects of School-based Decision-making on Educational Outcomes in Low- and Middle-income Contexts: A Systematic Review"Institute of Education, London.

7 Systems governing the use of school infrastructure improvement funds is discussed in detail in a separate note - Building Better Learning Environments in the Philippines.

8 A full description of the information collected in the PETS-QSDS study and the approach used to calculate total school revenue and expenditure is included in a set of additional annexes and tables accompanying the main PETS-QSDS report.

9 In 2013/14, DepEd also provided school-based management grants of between PHP 100,000 - 200,000 to 7 percent of elementary and 17 percent of high schools in low income class municipalities. The revenue from these funds is included under revenue from DepEd in Figure 3.
10 A more detailed assessment of the systems governing the use of MOOE funding for schools is provided in a separate noteProviding Schools with Adequate Operating Expenses to Deliver Quality Education in the Philippines.

11 Despite these sources representing a lower proportion of total discretionary funds in high schools than in elementary schools, high schools collected higher absolute amounts from these sources in 2014.

12 The pattern is similar in elementary schools and for other school-level revenues (for example, charges for school utilities). Full details are available in a set of additional annexes and tables accompanying the main PETS-QSDS report.

13 A more detailed assessment of school MOOE funding is provided in a separate note- Providing Schools with Adequate Operating Expenses to Deliver Quality Education in the Philippines.

14 World Bank (2016). "The Development and Implementation of a Normative School MOOE Formula in the Department of Education in the Philippines."Washington D.C.

15 SGCS also play a role in making policies regarding student welfare and in managing council resources. See DepEd (2009). "A Manual on School Governing Councils." Department of Education, Manila.

16 DepEd Order No. 54 (2009). "Revised Guidelines Governing Parents-Teachers Associations at the School Level." Department of Education, Manila.

17 Similar results were also found for Government Watch initiatives in the education sector like textbook count and textbook walk.

18 High schools are not monitored by public schools district supervisors.

19 A fuller discussion of the strengths and weaknesses of existing school infrastructure improvement systems is provided in a separate note in this series - Building Better Learning Environments in the Philippines.

20 Cerdan-Infantes, P. and D. Filmer (2015). "Information, Knowledge, and Behavior: Evaluating Alternative Methods of Delivering School Information to Parents."World Bank Policy Research Working Paper No.7233, World Bank, Washington D.C.

21 Cambridge Education (2014). "Review of Implementation of School Council Policy 2013." Cambridge, UK. 


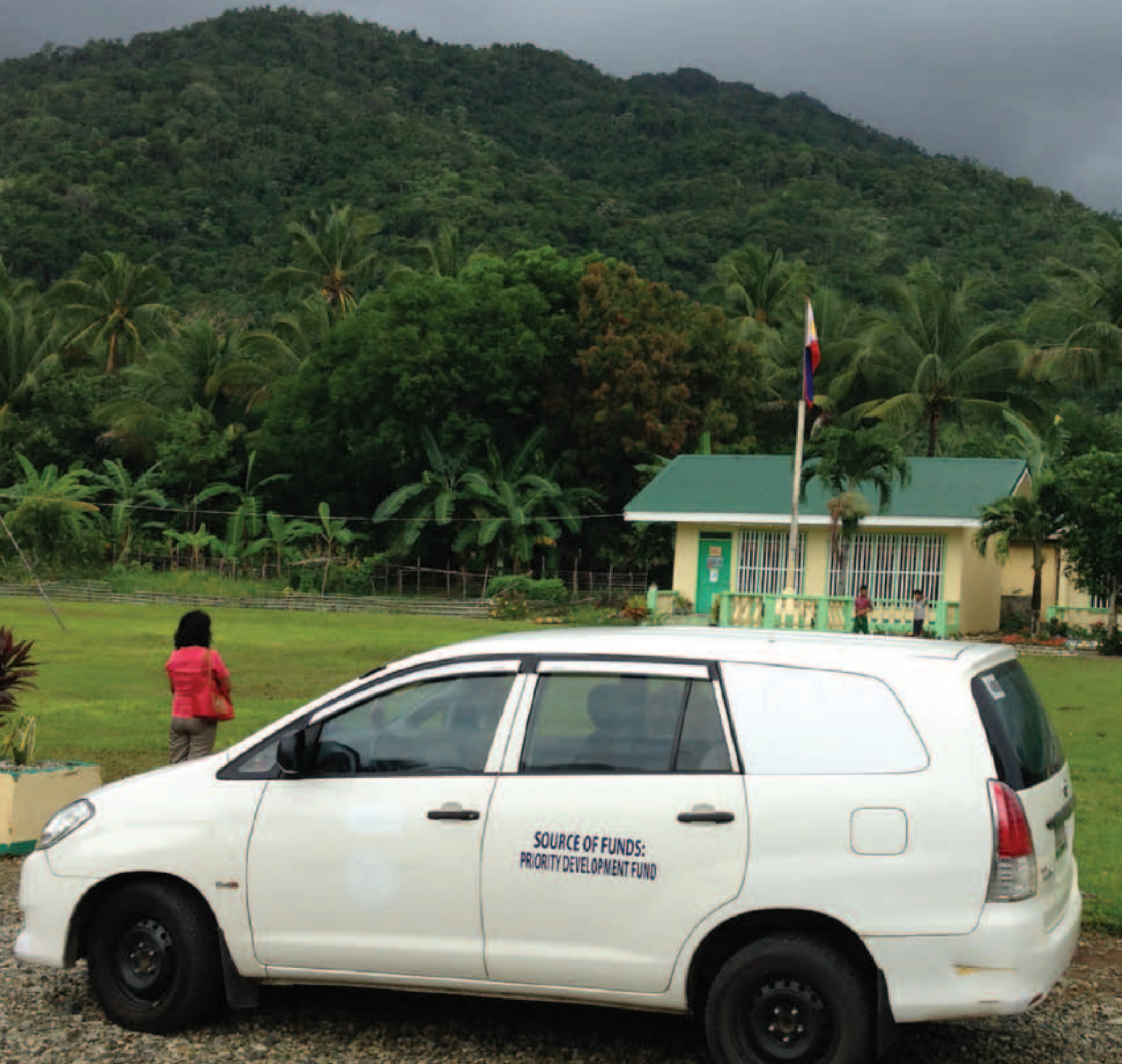

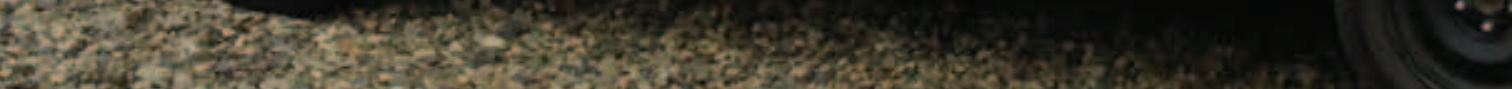

E.

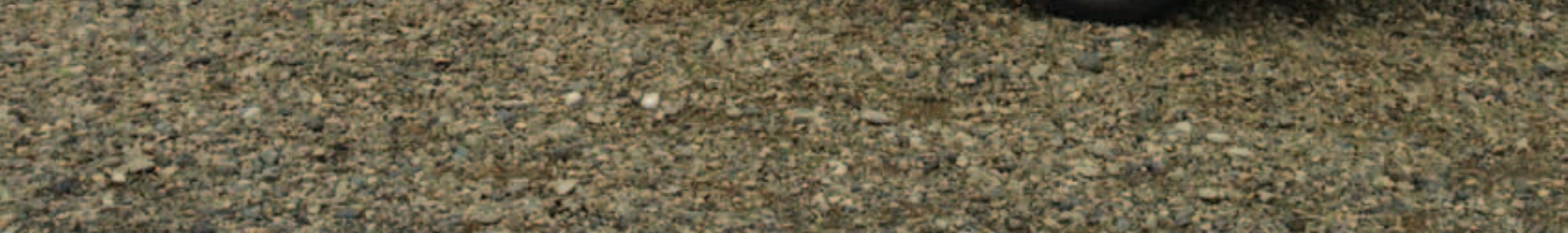




\section{Policy Note 5: Providing Schools with Enough Resources to Deliver Quality Education}

\section{Introduction}

Providing schools with direct funding to meet their operational needs is the cornerstone of the government's efforts to strengthen school-based management in the Philippines. Over the past five years, funds that the government has provided directly to schools to support their maintenance and other operating expenses (MOOE) have increased by 45 percent in real terms, demonstrating the government's commitment both to increasing operational funding and to providing schools with the funding that they need to implement their own improvement plans.'

Evidence from the Philippines and elsewhere shows that increased school funding and effective school-based management (SBM) can lead to more efficient use of resources and, ultimately, to better education outcomes. Evaluations of a school-based management program in the Philippines have shown that this program coupled with the provision of school grants led to significant improvements in school performance. ${ }^{2}$ Over a threeyear period, the introduction of SBM and the provision of grants improved the scores of Philippines students on the National Achievement Tests (NAT) by 4 to 5 percentage points (approximately 0.25 standard deviations). ${ }^{3}$ These findings echo similar results from other countries that, on the whole, show that school-based management reform, if implemented effectively, can improve education outcomes over time. ${ }^{4}$

The aim of this policy note is to assess the current systems that govern the allocation, transfer, and use of MOOE funds for schools. It uses data collected as part of the PETS-QSDS study from a nationally representative sample of public elementary and high schools. ${ }^{5}$ It shows that a significant proportion of MOOE funds do not reach schools and that schools serving better-off students tend to receive a larger share of their intended allocation than other schools. While funding for school MOOE has and will continue to increase,

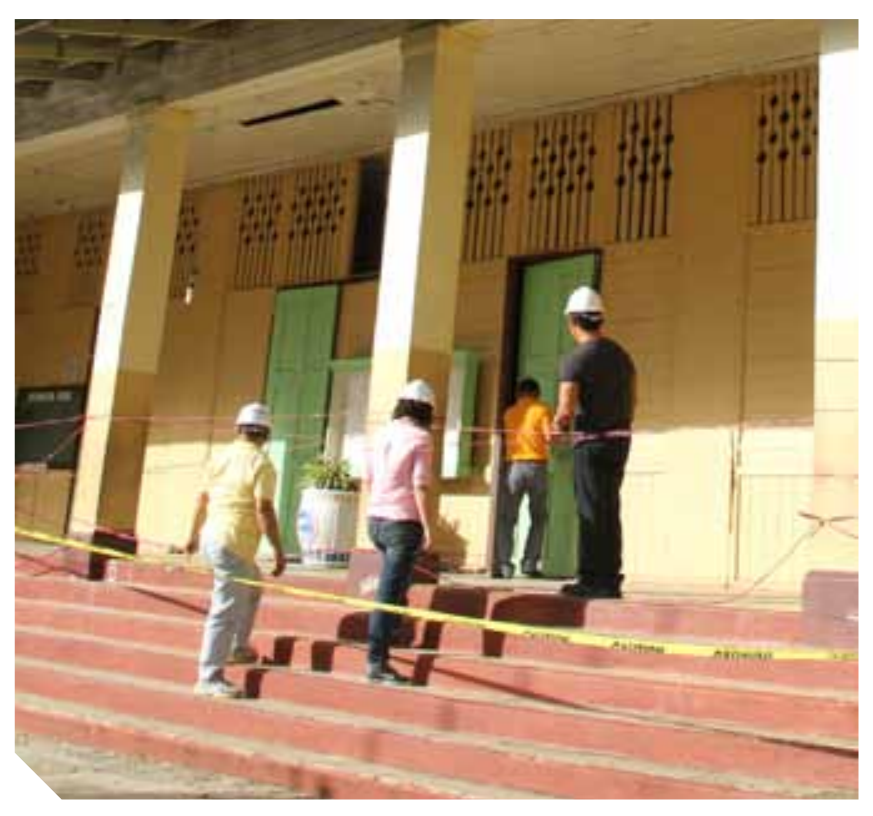

these and similar findings demonstrate the need to improve the systems that manage MOOE funds in division offices and in schools. The findings also highlight the need to strengthen the accountability mechanisms associated with the use of MOOE funds, particularly at the school and community levels. Addressing these weaknesses is likely to significantly improve education outcomes and to support recent schoolbased management reforms in the Philippines.

\section{Levels of and Trends in School Operational Funding}

Over recent years, school MOOE funding has increased significantly in real terms even though its share in the overall basic education budget has remained relatively stable. The total school MOOE budget increased in real terms by over 50 percent between 2011 and 2015 (Figure 1). ${ }^{6}$ The biggest increase during this period was associated with the introduction in 2013 of a new formula for allocating school MOOE funding. These large overall increases in the school MOOE budget have translated into even larger increases 
in per-student funding levels. For example, between 2011 and 2014, per student appropriations for elementary school MOOE increased from PHP 317 (US\$7) to PHP 566 (US\$13).

Public schools rely heavily on the school operating funds provided by the national government. The PETS-QSDS study collected detailed information on all types of school revenues. In 2013, MOOE allocations accounted for 68 percent of all discretionary funding received by elementary schools and 82 percent received by high schools. In the case of over 10 percent of schools, their MOOE allocations were the only source of operational funding that they received?

Despite the importance of MOOE allocations to schools and despite recent increases, a detailed costing study has revealed that existing levels of school MOOE do not cover the full operating costs of public elementary and high schools. ${ }^{8}$ The study reviewed existing DepEd service standards and norms for elementary and high schools and collected data and information on the funds needed to meet each of these standards. After verifying its findings with DepEd staff and school principals throughout the Philippines, the study concluded that overall levels of elementary and high school MOOE funding will need to more than double if existing service standards are to be met.

\section{Assessing the Systems that Govern the Allocation and Use of School MOOE Funds}

\section{Allocation}

As in other countries, MOOE allocations in the Philippines are based on school and student characteristics. DepEd introduced a funding formula for school MOOE allocations for the first time in 2013 (Table 1). According to the new formula, in 2013 the average elementary school was allocated approximately PHP 170,297 (US\$3,720) and the average high school was allocated PHP 744,358 (US\$16,180). ${ }^{9}$

However, the amount of MOOE funds that is actually allocated to each school is frequently different to the amount prescribed by the formula. For example, in 2013 the allocations of MOOE funds to elementary schools differed from the expected amount based on the formula by PHP 7,000 or approximately 4 percent of the average allocation for each school. In the case of a small number of schools, the allocation differed from the formula by as much as PHP 50,000.10 Possible reasons for these discrepancies include confusion over which types of classrooms are included in the formula and DepEd's "no diminution policy," which prevents a school's MOOE funds in

Figure 1: National MOOE Funding for Schools Has Increased Significantly in Recent Years

Total and per student appropriations for school MOOE, 2005-2015 (in 2014 constant prices)

Total appropriations

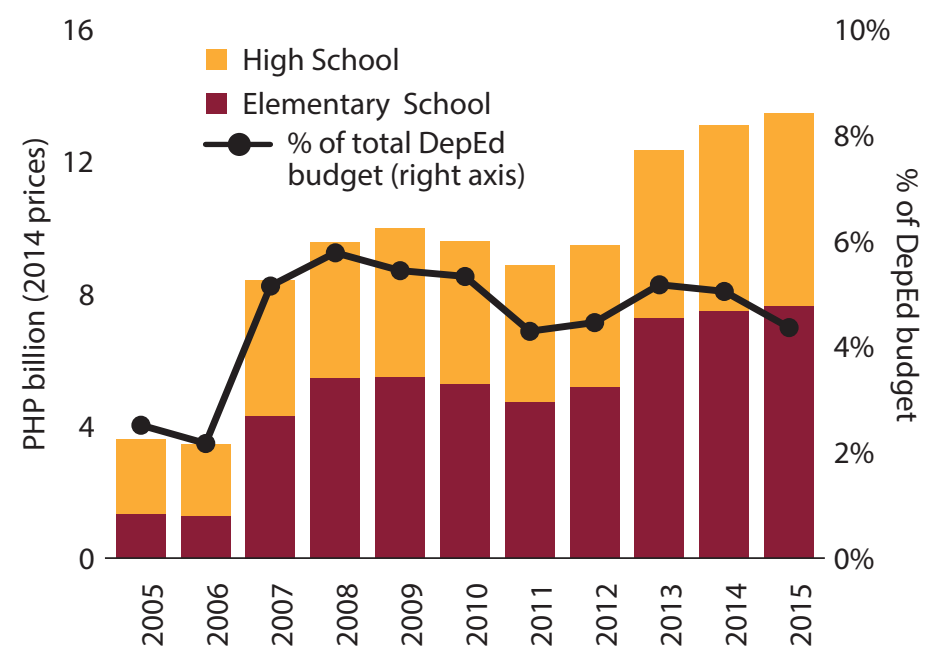

Appropriations per-student

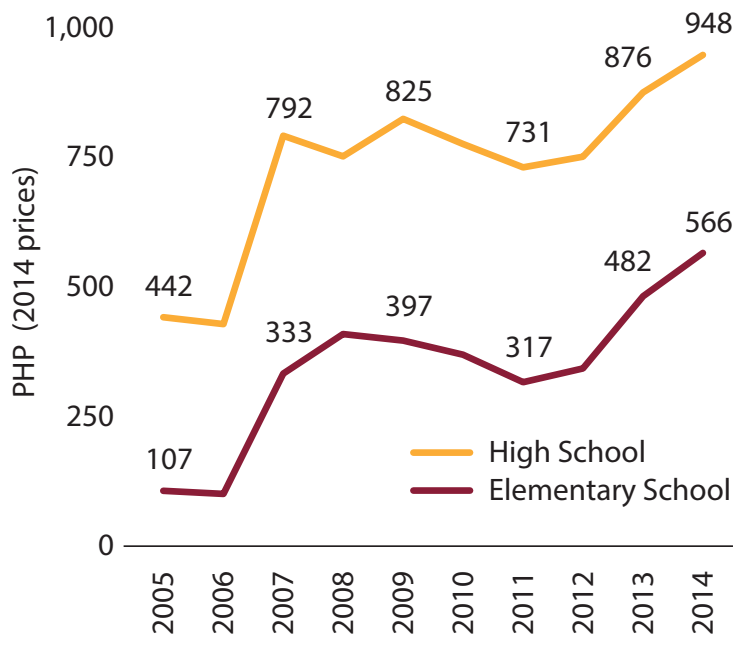

Sources: National government appropriations from General Appropriations Act, various years. Enrollment data come from DepEd Fact Sheets, various years. 
Table 1: Components of the MOOE Allocation Formula

\begin{tabular}{|c|c|c|c|c|}
\hline \multirow[b]{2}{*}{ Allocation component } & \multicolumn{2}{|c|}{2013 to 2015} & \multicolumn{2}{|c|}{2016} \\
\hline & $\begin{array}{c}\text { Elementary } \\
\text { (PHP) }\end{array}$ & $\begin{array}{l}\text { High Schools } \\
\text { (PHP) }\end{array}$ & $\begin{array}{c}\text { Elementary } \\
\text { (PHP) }\end{array}$ & $\begin{array}{l}\text { High Schools } \\
\text { (PHP) }\end{array}$ \\
\hline 1. Fixed & 40,000 & 80,000 & 50,000 & 96,000 \\
\hline 2. Per Student & 200 & 400 & 250 & 480 \\
\hline 3. Per DepEd Teacher & 4,000 & 8,000 & 5,000 & 9,600 \\
\hline 4. Per classroom & 3,000 & 6,000 & 3,750 & 7,200 \\
\hline 5. Per graduating student & 250 & 250 & 313 & 300 \\
\hline
\end{tabular}

Notes: Prior to 2016, the fixed component for technical and vocational high schools was PHP 160,000. DepEd follows a no diminution policy that, in any given year, prevents a school's MOOE from being less than its level in the previous year.

any given year from being less than the previous year's level. However, it is difficult to identify the main causes for each school because school-level data on the formula components (for example, on the number of students in each school) is not published on DepEd's website alongside the data on schoollevel MOOE allocations. This prevents school officials from being able to understand any discrepancies in their MOOE allocations and reduces the benefits, in terms of increased transparency, that a funding formula can provide.
The limited knowledge that education stakeholders have of the funding formula reduces accountability for MOOE allocations. While over half of all school principals claim to be aware of the MOOE formula, fewer than one in ten know the formula's components and hardly any know the funding associated with each component (Figure 2). Knowledge of the allocation formula is also limited among DepEd's division officials. The study team's interviews with student households also revealed a lack of awareness among parents.

\section{Figure 2: Knowledge of the MOOE Formula among Education Stakeholders is Limited}

Percentage of stakeholders who are aware of MOOE funding and its components
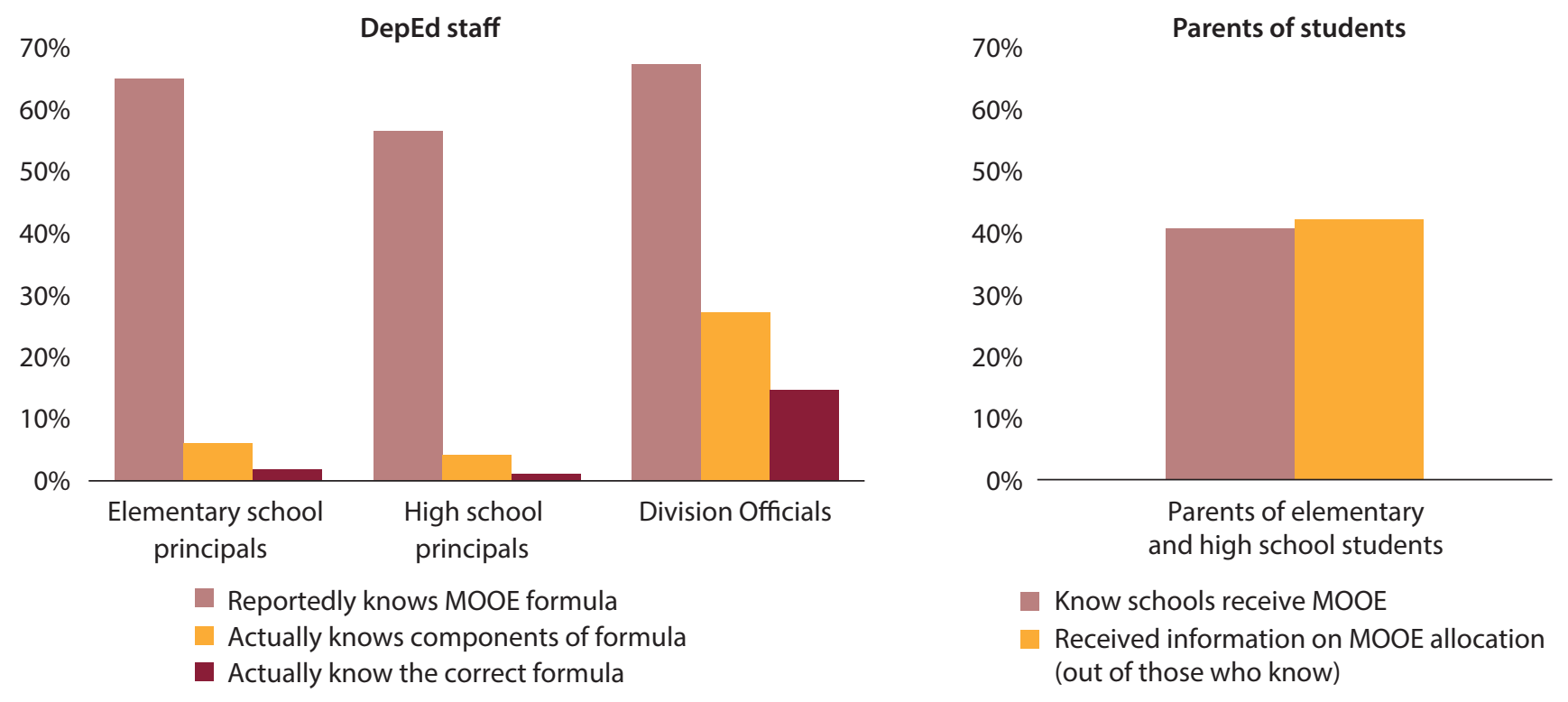

Source: PETS-QSDS national survey - division, school, and household levels. 


\section{Box 1: Approach to Tracking}

In order to track the flow and use of MOOE funds, the study team obtained from official records maintained by Division offices the amount they received for school MOOE, and on the amount they reported downloading to each PETS-QSDS sample school and for each MOOE advance. The records also included details on the check number, the date of check, the date on which the check was collected by schools, and the date on which the corresponding liquidation report was submitted. The same set of information was collected from records maintained by schools. In addition, the team collected information on the types of expenditures for which the schools used their MOOE funds from school liquidation reports corresponding to each MOOE advance downloaded to the school from the division office.

Only 40 percent of parents were aware that schools receive MOOE funds, and the majority did not know how MOOE funds were allocated. With no knowledge of the formula, schools, division offices, and parents cannot confirm whether the schools are receiving the correct allocation and are unable to seek redress in cases where their funding falls below expectations.

\section{Transfer of MOOE Funds to Schools}

The PETS-QSDS study tracked MOOE funds from their initial allocation in the DepEd central office all the way down to their receipt by a nationally representative sample of schools. Implementing unit (IU) high schools were excluded from the analysis since they follow a different system for receiving and reporting on funds. The survey used official records (such as notices of cash advancements, checks, and liquidation reports) to record the receipt and downloading of funds from each administrative level and to schools (Box 1).

The main finding of this tracking exercise is that only 77 percent of the total allocations for elementary and non-IU high schools ultimately reached those schools in 2013 (Figure 3)." In other words, elementary and high schools received only PHP 448 of the PHP 581 allocated for each student. Given that the guidelines stipulate that all school MOOE funds should be downloaded to schools, this finding is a concern. It implies that about PHP 1.8 billion out of the PHP 8 billion MOOE budget intended to be used by schools in 2013 were not downloaded. ${ }^{12}$

\section{Figure 3: A Significant Portion of the MOOE Allocations Do Not Reach Schools}

Share of MOOE allocation downloaded and received by schools, 2013

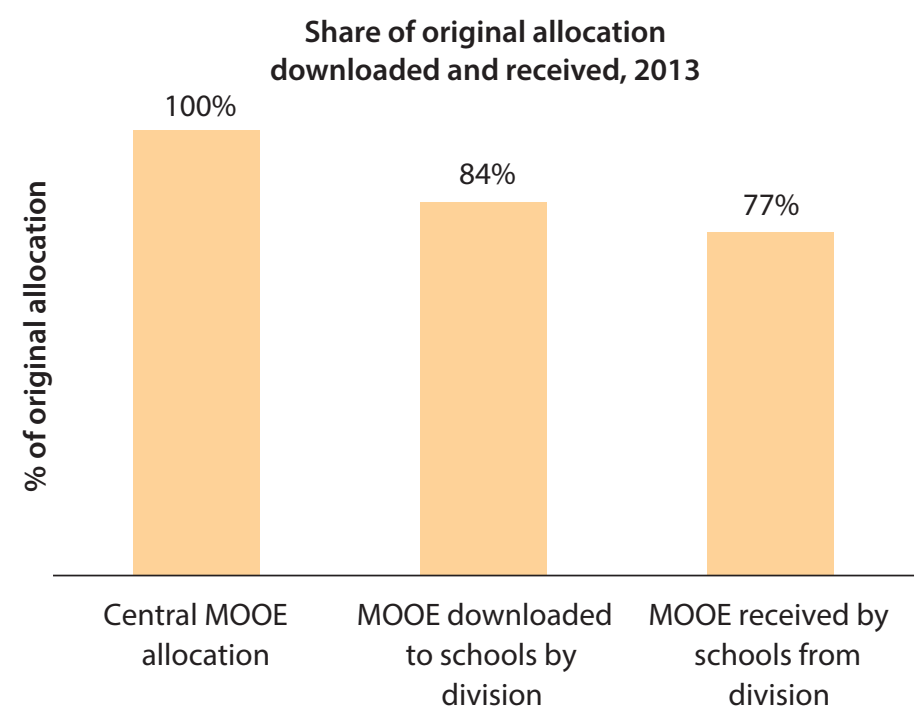

\section{Proportion of schools}

$100 \%$

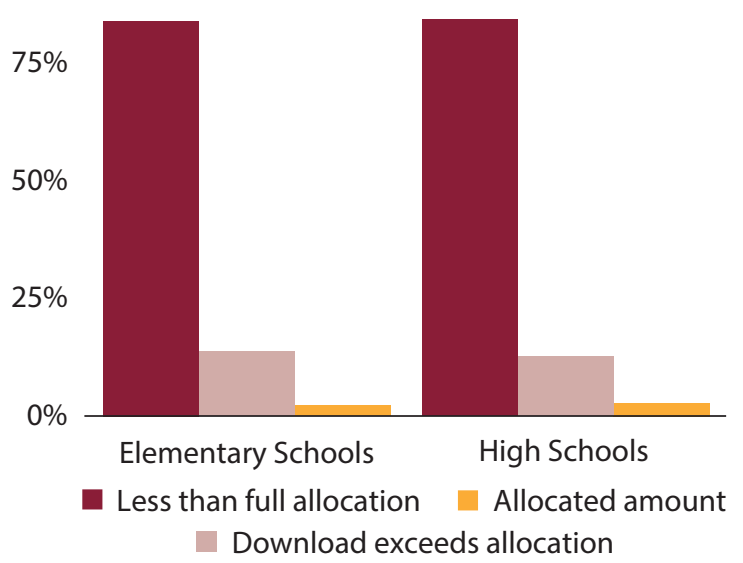


These aggregate findings can be explored further to identify the key stages where school MOOE funds are diverted. The first stage relates to differences between DepEd central office allocations and how much DepEd division offices actually report downloading to schools. The second stage relates to differences in the amount that DepEd division offices report downloading to schools and the amount that schools, through their records (for example, liquidation reports), report receiving.

Differences between DepEd central office allocations and the amount of MOOE funding that the division offices downloaded to schools account for the largest share of funds that fail to reach schools. These differences account for 16 percent of the 23 percent of school MOOE funds that do not reach schools. The records show that DepEd division offices failed to download the full allocation to over 80 percent of elementary and non-IU high schools in 2013 (Figure 3). In many schools, these differences were large; in around 20 percent of elementary schools and 15 percent of high schools, the amount downloaded by division offices was less than half of the schools' original allocation. These underallocations were partly offset by over-allocations to some other schools; approximately 13 percent of schools were given amounts that exceeded their allocation. ${ }^{13}$

The retention of school MOOE by Division offices is the main factor behind differences between initial allocations and the funds downloaded to schools. While a 5 percent deduction by the Department of Budget and Management (DBM) for tax purposes explains part of the gap between the MOOE funds allocated and received, the bulk of the gap at this level is explained by division offices withholding funds.

Although division offices are required to download funds to schools in full, the tracking exercise indicates that over 60 percent of divisions held onto some MOOE funds in 2013.14 They did so to procure items for schools, to pay their utility bills, or to fund other services for schools (Figure 4). This is the case even though DepEd explicitly prohibits divisions from procuring items using school MOOE funds except in extreme cases where there is a demonstrated need for the division to do the procurement. This practice reduces the amount of discretion that schools have over the use of their own MOOE funds and has the potential to limit the effectiveness of ongoing school-based management reforms. Procurement

\section{Figure 4: Divisions Retain MOOE Funds to Spend on Behalf of Schools}

Reasons why DepEd division offices retain MOOE funds (\% of divisions), 2013

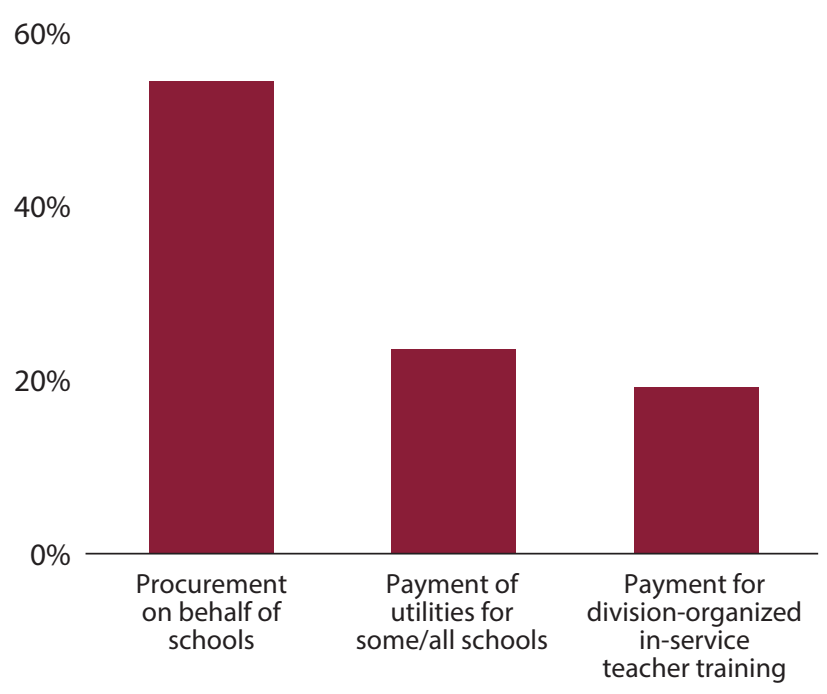

Source: PETS-QSDS national survey - division and school levels. Note: Only divisions that reported retaining funds are included.

by divisions also makes it difficult to monitor whether school MOOE funds are being used for their intended purpose as schools have no way of verifying how the divisions used the retained funds.

Smaller discrepancies are also evident in the second stage of the flow of MOOE funds to schools. Of the 23 percent of school MOOE funds that do not reach schools, 7 percent can be accounted for at this stage (Figure 3). ${ }^{15}$ However, the poor quality of records at the school level makes it difficult to make a full accounting of the extent of the funds diverted at this stage. While it is possible to compare the aggregate annual amount of MOOE funds downloaded by divisions to schools with the amounts that the schools received, gaps in the records kept at the school level stymie efforts to identify the sources of the discrepancies. For example, at the school level, one-third of the entries recording the schools' receipt of the MOOE transfers do not include a check number, which makes it impossible to compare them with each individual check sent by the division. Such gaps in documentation emphasize the need to strengthen MOOE reporting processes at every level. 


\section{Figure 5: Schools Often Do Not Receive their Full Allocation of MOOE Funds Because of Delayed and} Unpredictable Transfers by Division Offices

Timing of first MOOE advance and share of overall allocation received, 2013
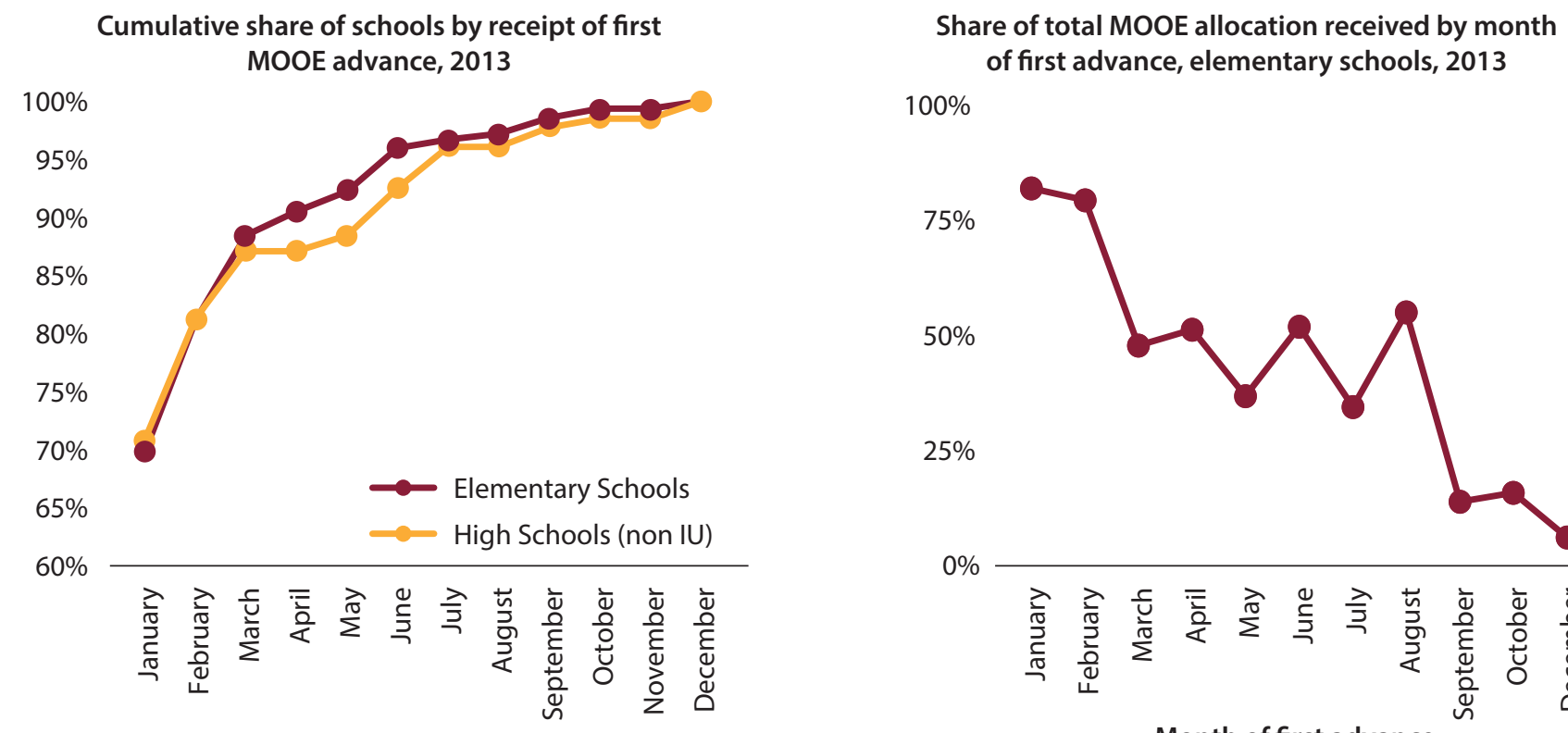
$100 \%$

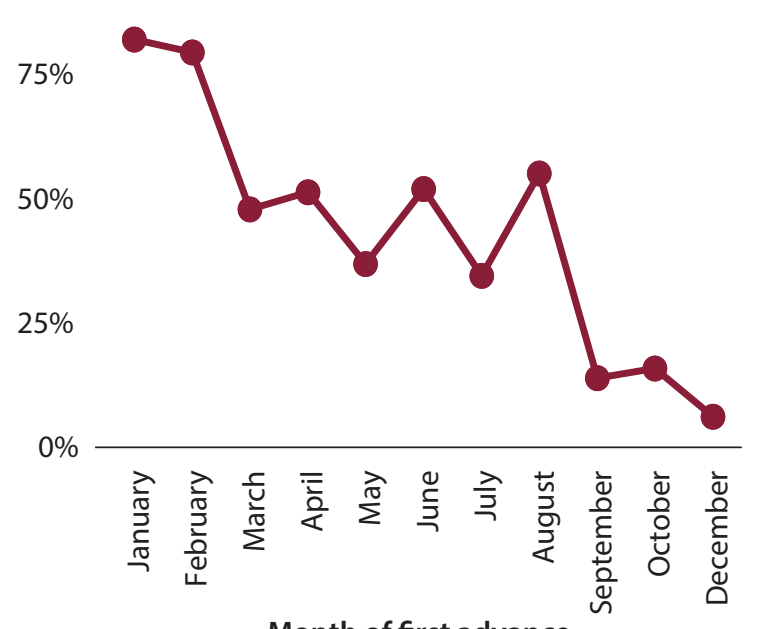

Source: PETS-QSDS national survey - school level.

Any delays by DepEd division offices in downloading MOOE funds to schools not only prevent schools from receiving those funds in a timely manner but also reduces the total amounts that they receive. For example, in 2013, while most division offices downloaded the first advances to schools at the beginning of the calendar year, around 10 percent of schools did not receive their first advance of MOOE funds until the start of the school year in June (see Figure 5). Schools that receive their first advance late also tend to receive a smaller share of their total allocation. For example, elementary schools that received their first advance in February 2013 received approximately 80 percent of their full allocation whereas schools that received their first advance after August received less than a quarter of their full allocation. ${ }^{16}$

Any irregularity in the downloading of MOOE funds makes school planning more difficult and potentially less efficient. In 2013, 20 percent of elementary schools and 25 percent of high schools received MOOE funds from division offices every month, but 34 percent of elementary schools and 30 percent of high schools received only five advances in the whole financial year. In the remaining schools, downloading did not follow any regular pattern.17

\section{School Management of MOOE Funds}

The late downloading of MOOE funds by divisions is compounded by delays on the part of schools in collecting their MOOE checks. A comparison of the issuing and collection dates of MOOE checks shows that only 40 percent of elementary school checks and 20 percent of high school checks were collected from the division offices on the day on which they are released. These collection delays can be quite long. Over one-third of MOOE checks were collected more than two weeks after they were issued. In some cases, when transfers are delayed or unpredictable, school principals use their personal funds or raise money from teachers to cover the school's operating expenses. School liquidation reports show that in 2013 over 60 percent of elementary school and 45 percent of high school principals paid for approximately 5 percent of their operating expenses from their own funds while they waited for their MOOE funds.

School liquidation reports reveal that some schools find it difficult to use all of the MOOE funds that they receive. Although schools are required by law to spend all of the MOOE funds that they receive, around 70 percent of schools 
were unable to do so in 2013. On average, a quarter of MOOE funds received by these schools went unspent. The underspending of available MOOE funds is especially concerning because other studies have revealed the inadequacy of current levels of MOOE to meet schools' needs. ${ }^{18}$ However, any efforts to persuade the government to raise the MOOE budget will meet with only limited success unless these school liquidation difficulties are overcome.

The main reason why so many schools find it difficult to spend their entire MOOE allocation is because they have insufficient capacity and time to meet their reporting and procurement requirements. Over a third of elementary schools and a quarter of high schools reported encountering such problems in 2013, and the lack of capacity to meet reporting requirements was one of the most commonly cited challenges (Figure 6). Other salient problems included difficulties locating suppliers and canvassing. ${ }^{19}$ School principals also reported having insufficient time to spend MOOE funds in general. Although fewer schools reported facing such issues in 2014, their primary challenges remained the same - a lack of time and insufficient capacity.
Smaller elementary schools and those in rural areas are more likely to struggle to spend their MOOE resources. For example, the elementary schools that reported facing such issues had an average allocation of PHP 132,500 each compared with the average of PHP 191,600 for elementary schools that reported experiencing no difficulties in spending their allocations. The lower allocation reflects the smaller number of students in schools facing liquidation difficulties. Small high schools were also more likely to find it difficult to spend their MOOE funds, but the differences between small and larger high schools were not statistically significant. ${ }^{20}$

The management of MOOE funds is particularly demanding on school principals. In the 2014 school year, principals reported spending six to eight hours a week on administrating MOOE funds, including procuring goods and services and preparing liquidation reports (Figure 7). It is possible that a key factor that determines the time needed to process MOOE funds is related to the location of the school. For example, for schools far away from division offices and markets, it takes more time to collect their MOOE checks and to find suppliers. However, the study team's analysis shows that this is not the case nor is it related to whether schools are located in rural or

\section{Figure 6: Schools Do Not Have Enough Time or Capacity to Spend All of Their MOOE Funds}

Challenges experienced by schools in spending MOOE funds, 2013/14 school year

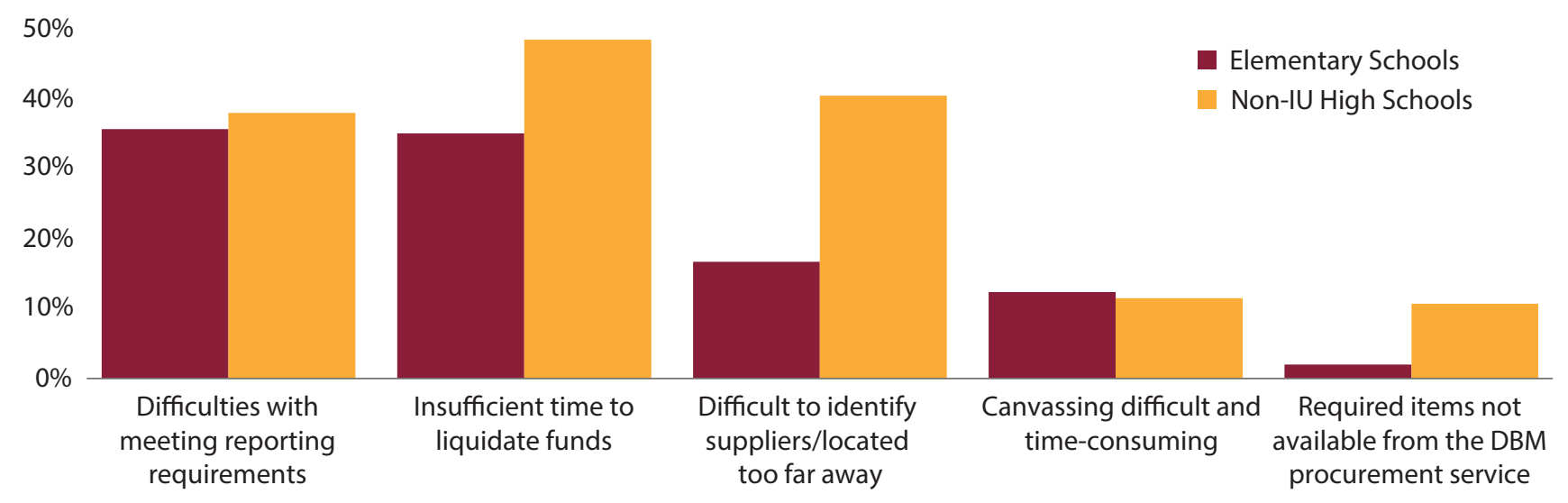

Source: PETS-QSDS national survey - school level.

Notes: Only schools that reported experiencing difficulties in spending their MOOE allocations are included. 
Figure 7: Managing MOOE Funds at the School Level is Time-consuming

Average hours spent on MOOE administration per week by schools' distance to division office, 2014 school year
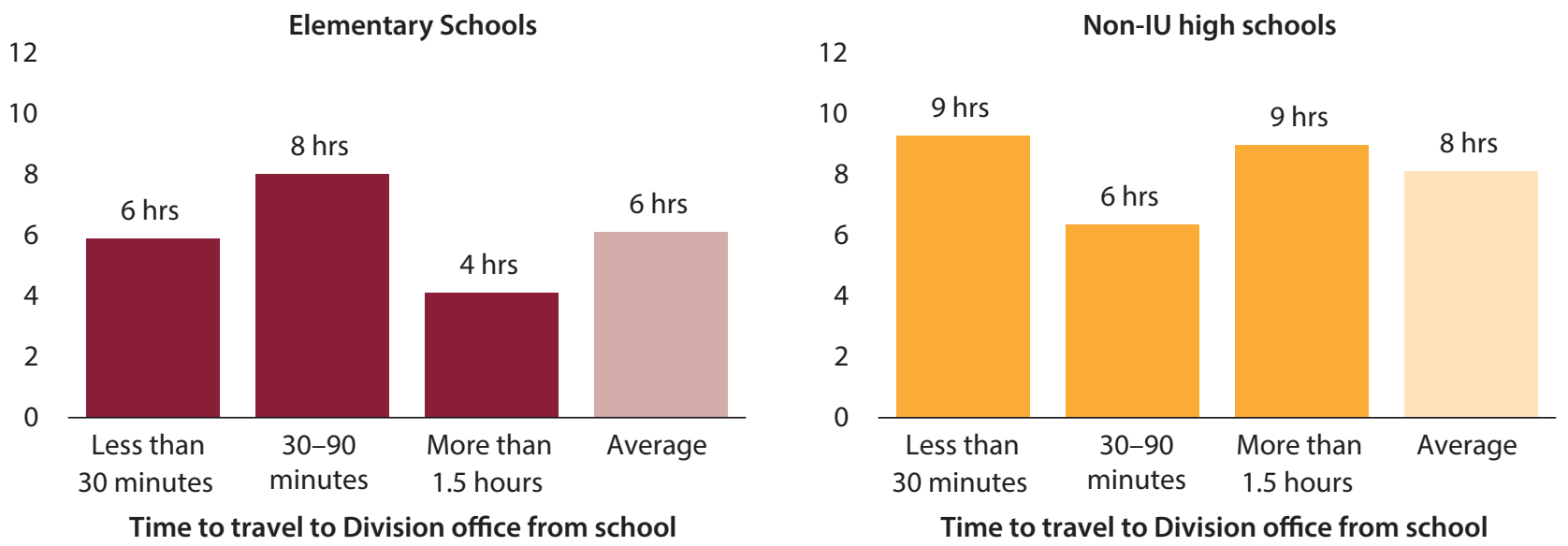

Time to travel to Division office from school

Source: PETS-QSDS national survey - school level.

Note: The label above the bars shows the average number of hours taken to administer MOOE funds by schools located at different distances from their division office.

urban areas (Figure 7). The team's findings suggest that the bulk of the time that school principals spend on managing MOOE funds goes on activities that are common to all schools such as reporting and canvassing.

The difficulties that school principals experience in managing MOOE funds can result in significant delays in their submission of liquidation reports as well as some misreporting of data. Although schools are usually required to submit liquidation reports within 35 days of receiving an MOOE advance only about half of all elementary school advances and one-third of high school advances were submitted within this period. ${ }^{21}$ Some schools submit reports as long as three months after the initial advance was made.

Moreover, division officials report that these delays are a leading cause of their own delays in downloading MOOE funds to schools. This is the case because schools are not allowed to receive their next MOOE transfer unless they submit a complete and correct liquidation report on how they spent the previous transfer. Of the 37 percent of division officials who reported delays in downloading MOOE funds to elementary schools in 2014 and the 31 percent who reported delays in transferring MOOE funds to non-IU high schools, over half of them cited late liquidation reports as the reason, while more than a third (for elementary schools) and a quarter (for high schools) mentioned problems with previous liquidation reports.

\section{Equity of School MOOE Funding}

Schools serving poorer and more marginalized groups are provided with higher levels of MOOE funding for each student. The PETS-QSDS survey included a nationally representative sample of the households of public elementary and high school students. Using information collected on consumption and asset ownership collected in the survey, it is possible to rank student households by estimated levels of per capita household consumption.22 This indicator of household welfare reveals that elementary students from poorer households are more likely than students from wealthier households to attend schools that have higher per capita allocations of MOOE funds (Figure 8). This is not because the MOOE funding formula provides additional funding to schools serving poorer groups. Instead, this is partly a reflection of the fact that wealthier students are more likely to attend schools in urban areas where student-classroom and studentteacher ratios are higher, thus leading to lower per-student MOOE funding (Table 1). High schools serving the poorest students also have higher per-student allocations than those serving the wealthiest students, but the difference is not statistically significant. 
Figure 8: The MOOE Funds that Schools Receive Do Not Reduce Inequalities in Overall School Funding Elementary school per-student funding by source, 2013 and 2013/14 school year
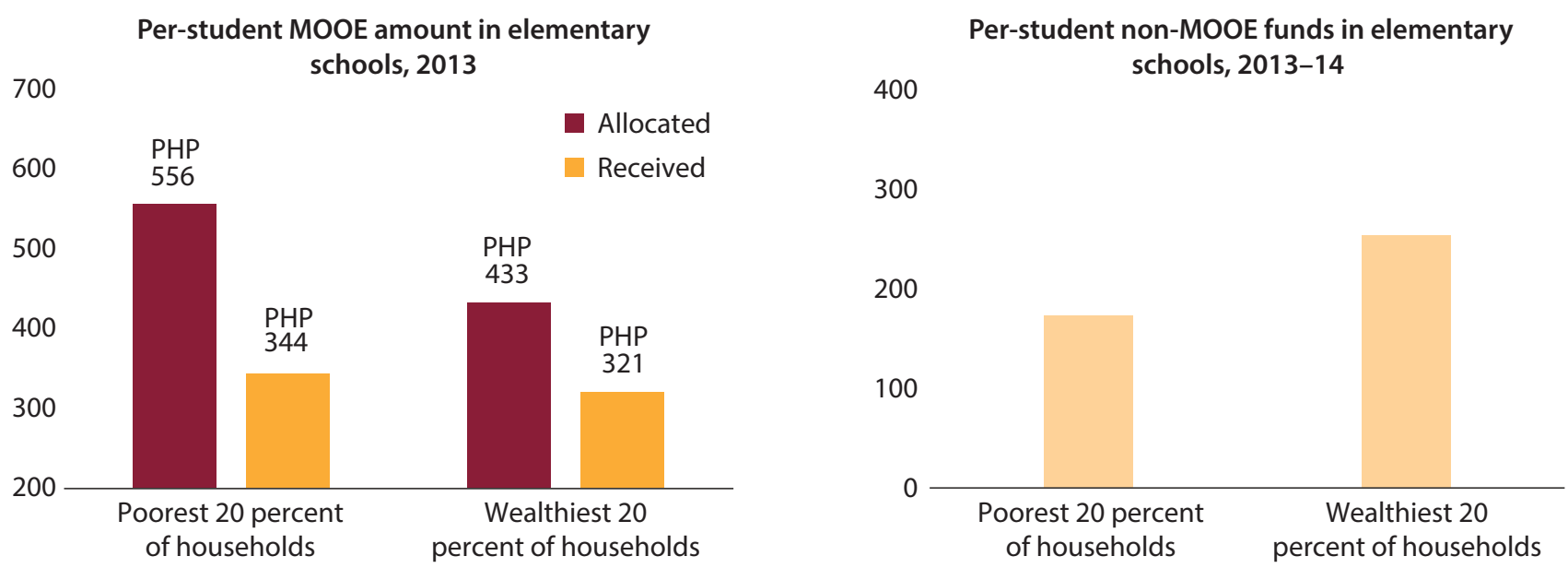

Source: PETS-QSDS national survey - school and student household levels.

Notes: Non-MOOE sources are all other cash contributions received by schools directly (e.g. local government, Parent Teacher Associations, fees) and school based management grants. A full description of the funding sources included and the approach to estimating overall school revenue is contained in additional tables to the full PETS-QSDS report.

However, in elementary schools, the pro-poor allocation virtually disappears in terms of the amount of MOOE funding that the schools actually spend. The result is that, in practice, students from different socioeconomic groups attend schools that receive similar levels of per-student MOOE despite the large differences in their original allocations. This is a missed opportunity to use school MOOE as a way to narrow the very large differences in school revenue among schools serving different socioeconomic groups (Figure 8).

The PETS-QSDS findings also suggest that, among elementary schools, a larger share of the MOOE allocations for schools in poorer areas is not reaching the schools. It might be expected that division offices are managing a larger share of the resources of poorer schools given that they are likely to lack the capacity to manage the funds themselves (Figure 4). Since there is little information on how the division offices spend school MOOE funds, it is not possible to establish whether poorer schools receive their full allocation after any procurement by the division offices is factored in. This significantly reduces the transparency of and accountability for MOOE funds and may be fueling unintended inequalities in levels of school funding.

\section{Oversight and Monitoring of the Use of MOOE Funds}

Schools' liquidation reports show that they spend only a small proportion of their MOOE funds on prohibited items. Over 80 percent of school MOOE expenditures are spent on allowable items (Table 2 and Figure 9). However, in 2013, elementary schools used 5 percent of their MOOE funding to purchase equipment and instructional materials prohibited under current guidelines, while high schools used 2 percent of their funding on prohibited items.

Table 2: Allowed and Prohibited Spending Categories for MOOE Funds

\begin{tabular}{ll}
\hline Allowable expenses & Ineligible expenses \\
\hline $\begin{array}{l}\text { Supplies for teaching, utility payments, minor repairs, travel, } \\
\text { wages for janitorial services, teacher training, graduation }\end{array}$ & $\begin{array}{l}\text { Textbooks and instructional materials (such as publications, } \\
\text { periodicals, or review materials), furniture and equipment, } \\
\text { ceremonies, and other activities identified in the School } \\
\text { Improvement Plan (SIP). }\end{array}$ \\
\hline
\end{tabular}


Figure 9: Most MOOE Funds Are Spent in Accordance with Existing Guidelines

Percentage of total MOOE expenses by item of expenditure, 2013
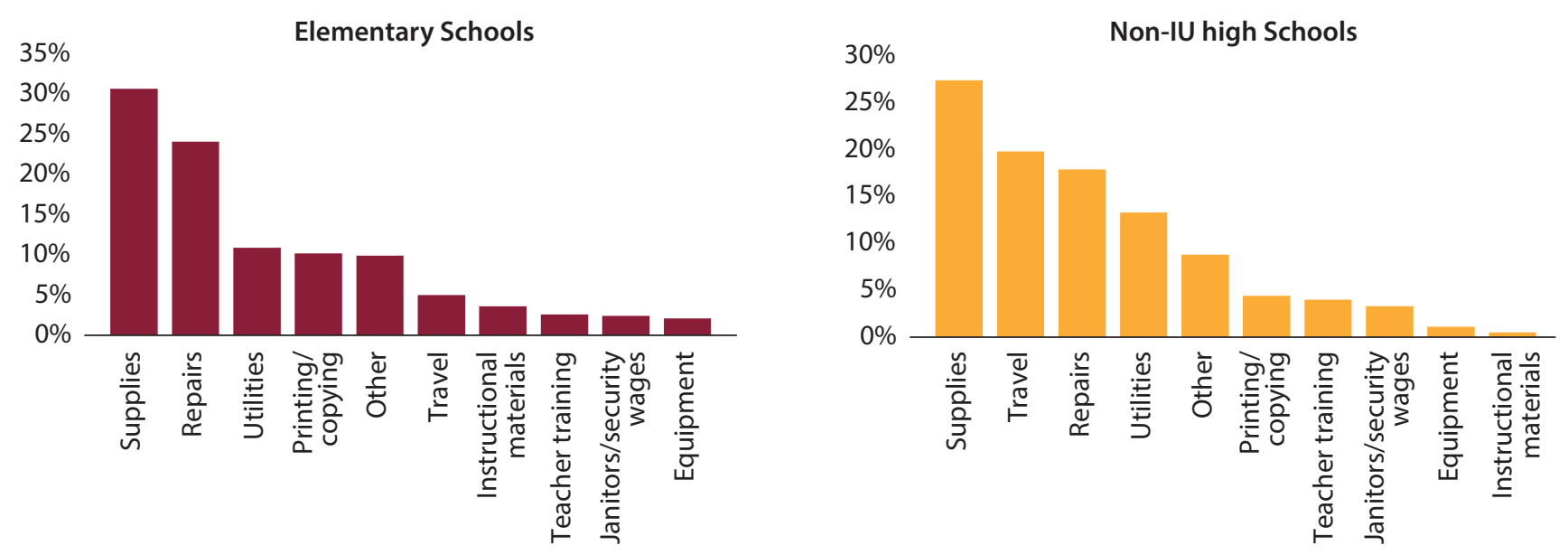

Source: PETS-QSDS national survey - school level.

Approximately 10 percent of total school MOOE expenditures were not reported on liquidation reports so it was not possible to assess whether those expenses were eligible.

The schools' records also reveal that the proportion of funds that they used to purchase items directly related to learning was relatively low. For example, elementary schools spent only 3 to 4 percent of their total MOOE expenditures on teacher training and only 4 percent on purchasing instructional materials such as periodicals or review materials.
While there are regulations in place that aim to strengthen the transparency over MOOE use, compliance with these regulations is low. The Anti-Red Tape Act (2007) mandates public schools to maintain a transparency board or bulletin board detailing how they are using their MOOE funds. However, as of 2014, fewer than two-thirds of schools had a transparency board containing information on MOOE expenditures (see Figure 10). Moreover, the information posted on about a third of transparency boards was more than three months old.

Figure 10: Schools' Compliance with the Transparency Board Requirement is Low

Percentage of schools that had transparency board displaying MOOE information in 2014
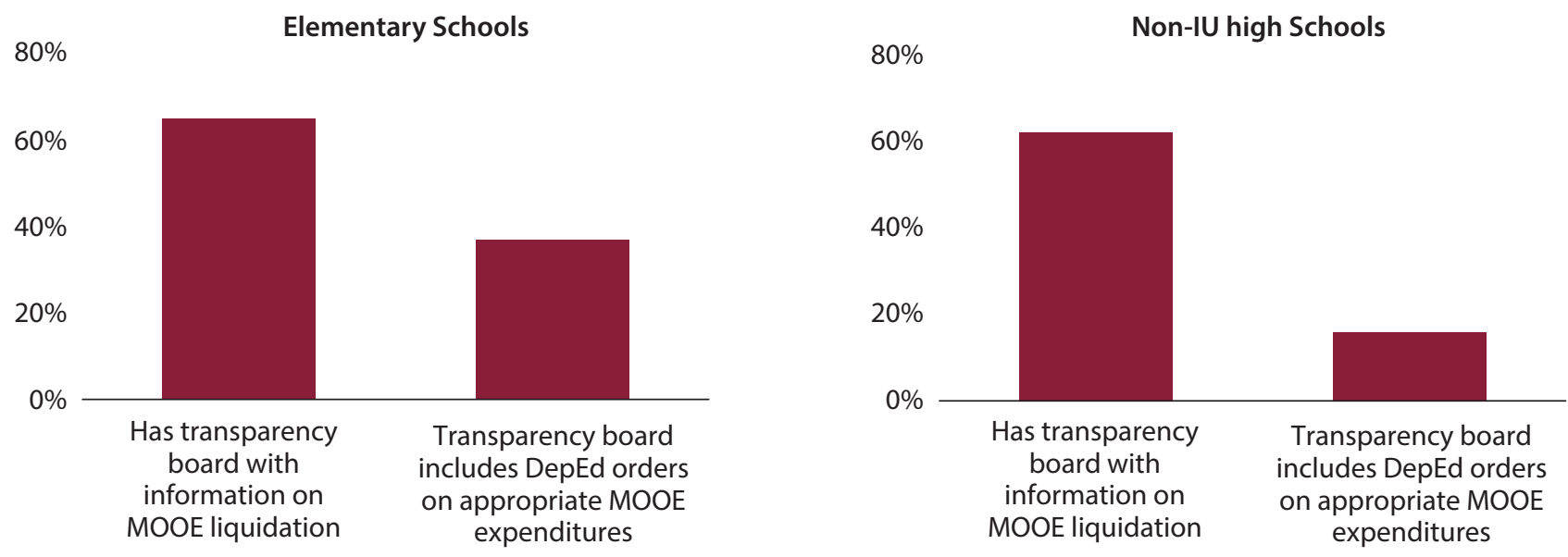
Figure 11: There Is Little Participation by Local Stakeholders in Decisions about How MOOE Funds Are Used Percentage of schools that received input from stakeholders about MOOE funds, 2014 SY
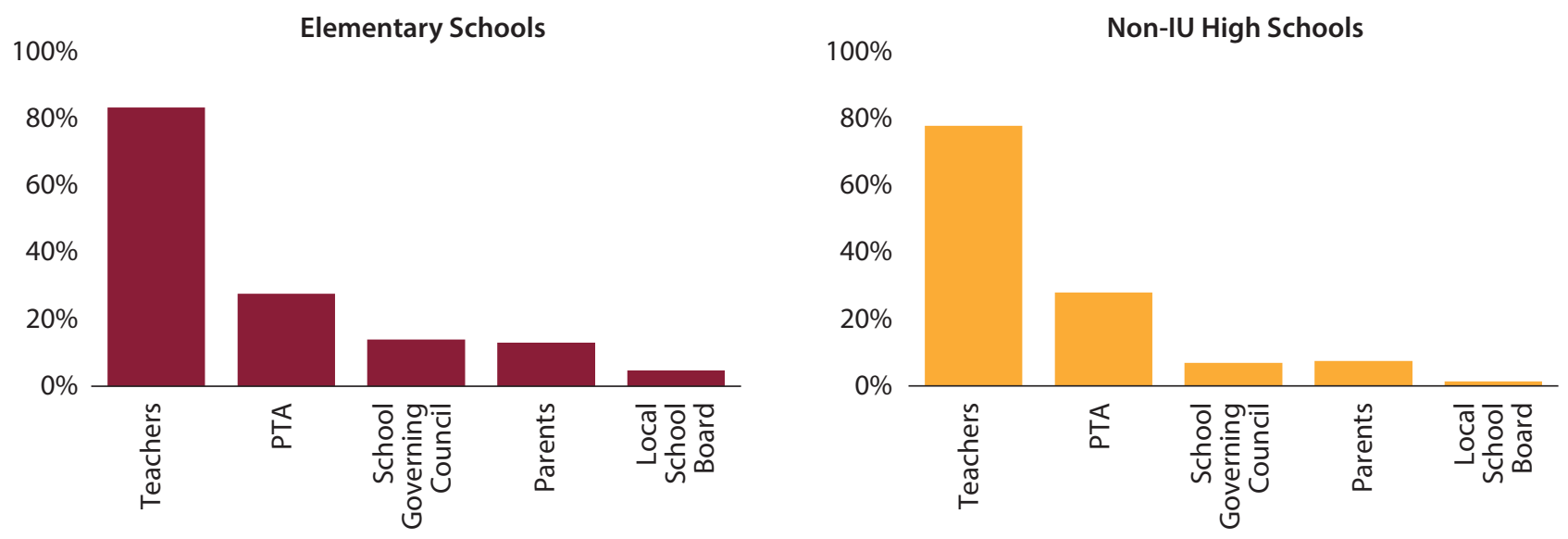

Source: PETS-QSDS national survey - school level.

Another factor that contributes to weak monitoring is the lack of knowledge among stakeholders of the rules governing MOOE funds. Although schools are legally required to publicly disclose how they use their funds, there is no specific law requiring them to post information on their expenditures on allowable and prohibited items. Not surprisingly, only about half of the elementary schools and a quarter of the non-IU high schools that have transparency boards post DepEd's orders on the appropriate use of MOOE funds (Figure 10). This lack of information makes it difficult for parents and other local stakeholders to judge whether the funds are being used appropriately.

Decisions on the use of MOOE funds are largely confined to the school principal and other teachers. In 2014, over 80 percent of schools reported that teachers had been consulted about how to use the schools' MOOE funds (Figure 11). PTAs have an input into how MOOE funds are used in fewer than 30 percent of schools. This is not surprising since DepEd's current guidelines explicitly prohibit PTAs from "interfering in schools' administrative management."23

Only 13 percent of elementary schools receive input from school governing councils (SGCs) even though SGCs are responsible for developing and implementing the school improvement plan (SIP), which includes activities financed by MOOE funds. ${ }^{24}$ This number is even lower among non-IU high schools, with SGCs, parents, and local school boards participating in MOOE decisions in fewer than 10 percent of schools. The study's interviews with parents revealed a similar picture. Only about one-third of parents reported participating in discussions about the school's use of financial resources in general and fewer than a quarter reported participating in decisions about how to use the school's MOOE funds.

\section{Policies to Strengthen the Allocation, Implementation, and Accountability of MOOE Funds}

This note has shown that the bulk of MOOE funds are transferred to schools and that schools use these funds for the purposes for which they were intended. However, in light of the government's plans to significantly increase school operational funding, it will be necessary to tackle the remaining weaknesses to ensure that these funds are used in the most effective way to improve education outcomes. It is crucial that the system for allocating and managing MOOE funds is strengthened to ensure that schools receive their allocations in full and in a timely manner. The current problems that some schools face in spending these funds fully and in an effective way also need to be solved. 
Increasing the transparency and oversight of fund use by involving school governing councils and parents could be an effective way of improving school management of MOOE funds. The note also found significant funding inequalities between schools serving disadvantaged groups and those serving children from better-off households. Adjusting the MOOE allocation formula to include an equity component would narrow these funding differences and thus improve education outcomes.

\section{Improving the Flow of MOOE Funds to Schools}

Ensuring that division offices download all allocated MOOE funds to schools would be an important first step in improving the use of MOOE funds. Tightening and enforcing the rules governing division offices procuring material on behalf of schools would reduce the extent to which division offices retain MOOE funds rather than transfer them directly to the schools. Even in cases where centralized procurement may be more efficient, the division offices could still download the funds to schools, who could then pay the division offices for any goods and services procured on their behalf. This would also ensure that these funds are properly accounted for in school liquidation reports and make it easier for all MOOE funds to be monitored. Setting division office targets for the full and timely downloading of school MOOE funds and tying these to performance-based bonuses (PBB) would also facilitate the flow of funds.

Stepping up monitoring efforts will also be essential to improve the flow of funds to schools. The current reporting requirements hinder the effective monitoring of MOOE downloading to schools. While division offices are required to submit monthly reports on the status of downloading and utilization to the Office of the Secretary, there is no mechanism to verify whether each school in the division has received their full allocated amount. Establishing a system to provide this information as well as a feedback mechanism for schools to inform DedEd about the fund transfers that they have received would go a long way towards strengthening monitoring.

In order to strengthen accountability, it is vital that schools and other stakeholders know the details of the funding formula and the correct MOOE allocation for each school. A first step would be to enforce the existing requirement for division offices to inform schools about their allocation at the beginning of the fiscal year. Moreover, posting the criteria used to determine the allocated amount for each school (such as the number of teachers and classrooms) online as well as on the division office transparency board at the beginning of the year would strengthen accountability.

\section{Simplifying the Liquidation Process and Supporting the Management of MOOE Funds}

Simplifying the existing requirements for schools to prepare liquidation reports on how they used their MOOE funds would reduce the significant burden that this currently puts on schools. It would also give school principals more time to focus on providing academic leadership in their schools. One approach that has been adopted in other countries would be to treat MOOE funds as grants. For example, this is the case in Indonesia, where these funds now have much less onerous reporting requirements than required by the usual government budget and implementation systems. ${ }^{25}$ Schools use simplified reporting templates to report on their use of the funds and submit these reports to district (division) offices every quarter. The Indonesian system also encourages much more involvement by school committees (school governing councils) in overseeing the use of school MOOE funds, a role that used to be played by the district office, and this has strengthened monitoring. Developing a similar system, adjusted for the specific context of the Philippines, could reduce the burden on schools and at the same time strengthen oversight of the use of funds.

Reducing the frequency of transfers from once a month to once a quarter would make procurement processes more efficient and would reduce the time that school principals would need to spend preparing liquidation reports. Releasing larger sums on a less frequent basis would make it easier for schools to procure items in bulk for both immediate and future activities instead of having to procure small quantities frequently. It would also reduce the time needed to undertake canvassing and the time spent travelling to make purchases. Less frequent transfers would also reduce the number of liquidation reports that schools would need to submit, which again would reduce the burden on schools. 
Extending the current deadline for schools to submit liquidation reports on their MOOE expenditures would further ease their management burden. Giving schools more than the current 35 day limit would give them more time to spend MOOE funds and to do so efficiently. For example, they would have more time to identify the best available suppliers in terms of both cost and quality.

Schools will need more support and training from the DepEd district level offices to build their capacity to manage MOOE funds. It is not financially feasible to provide a dedicated bookkeeper to each school to manage the administrative requirements associated with MOOE funding. Instead, the role played by district offices in assisting and supporting schools needs to be expanded. In particular, district offices could encourage schools to spend their MOOE funds in accordance with the priorities in their school improvement plans and could help them with the administration of MOOE funds. Providing stakeholders such as teachers, parents, and members of SGCs and PTAs with training on how to spend MOOE funds effectively could also help schools to manage their funds better.

Allowing schools, at least those with bigger allocations, to deposit their MOOE funds in bank accounts would also help them to manage their funds safely. Many schools have to maintain large sums of MOOE funds in cash, which is clearly a security risk. For example, rough calculations suggest that about 22 percent of non-IU high schools with a thousand or more students would have to hold onto more than PHP 100,000 in cash at any given time if the division offices were to transfer allocations to schools on a quarterly rather than a monthly basis. Allowing schools to deposit these funds in bank accounts would overcome this security issue.

\section{Strengthen Oversight over the Use of MOOE Funds by Schools}

Strengthening the role played by school governing councils (SGCS) in overseeing MOOE funds has the potential to lead to more effective use of MOOE funds. While SGCs are already expected to play a role in school improvement planning, their role could be expanded, for example, by requiring them to sign off on liquidation reports and to ensure that the reports are posted on school transparency boards. It will be vital to disseminate information about the current and future responsibilities of the SGCs in order to reinvigorate this important school-level institution and to hold schools more accountable for their use of MOOE and other funds.

Ensuring that MOOE and other funds that schools receive from both DepEd and other sources are added together and treated as a single school budget in the SIP can also increase oversight over use of MOOE funds. Having a single budget in each school can help stakeholders such as teachers and SGCs to identify any potential duplication of expenses and enable effective monitoring of MOOE and other school funds.

\section{Reduce Funding Inequalities by Including an Equity Component in the MOOE Funding Formula}

Introducing an equity component into the MOOE funding formula would be one way to reduce the large school-level funding inequalities highlighted in this note. In order to compensate those schools that receive lower funding from non-DepEd sources such as local governments, an equity component could be introduced in the allocation formula. This could go some way to equalizing school funding and provide schools in poorer areas with the additional resources that they need to support the learning needs of marginalized students. Many other countries, like the United Kingdom, have introduced funding components of this kind (Box 2). MOOE allocations should also be adjusted to take into account price differences between regions so that schools operating in high-cost areas such as remote locations where travel and transportation costs are high are able to purchase similar amounts of goods and services as those in lower-cost locations.

Over the last five years, the Philippines government has provided schools with ever greater amounts of operational funding. While this trend is set to continue, it is imperative that the systems used to allocate and manage MOOE funds are strengthened. Only then will the full potential of funds of this kind to improve education outcomes be realized. 


\section{Box 2: The Pupil Premium in England}

In 2011, the United Kingdom government introduced a "pupil premium."This initiative provides government-funded schools within England with additional per-student funding to raise the attainment of disadvantaged pupils and to narrow the gap between them and other students. In 2014/15, each school received an additional $£ 1,300$ (US\$2,031) for primary-aged students and $£ 935$ (US\$1,461) for secondary-aged students. Rough calculations suggest that an average sized secondary school would receive approximately $£ 200,000$ (US\$312,500) in additional funding through the pupil premium, which is the equivalent of five full-time teachers.

The main criteria used to calculate schools' eligibility for this extra funding is the number of students in the school that have received free school meals over the last six years. Head teachers and school governing bodies are accountable for the use of these funds in two ways. First, performance tables that outline the performance of disadvantaged students compared to their peers are made available to the public. Second, schools are required to publish details online each year of how they have used the premium and what impact it has had.

Schools typically use the additional resources to hire more teachers and teaching assistants in order to introduce special programs for disadvantaged students. In addition, the resources are frequently used to allow eligible students to participate fully in after-school activities.

A recent study of the implementation of the pupil premium found that:

- Schools are using the funding effectively to improve learning outcomes of disadvantaged students and narrowing learning disparities.

- The best schools combine targeted interventions with robust tracking to evaluate their effectiveness.

- School governing bodies take strategic responsibility for student targeting and hold school leaders accountable.

- Challenges remain in schools with weak leadership, including weak governing bodies.

Sources: OFSTED (2014) and www.gov.uk/pupil-premium-information-for-schools-and-alternative-provision-settings.

\section{Table 3: Strengthening Systems to Provide Operational Funding to Schools}

\section{Findings Policy suggestions}

Not all schools receive their full MOOE allocation and the transfers are often not made on a predictable schedule
- Enforce existing regulations on the transfer of funds

- Introduce transfer targets for DepEd division offices tied to performance bonuses

- Make MOOE allocations and formula components for each school publicly available

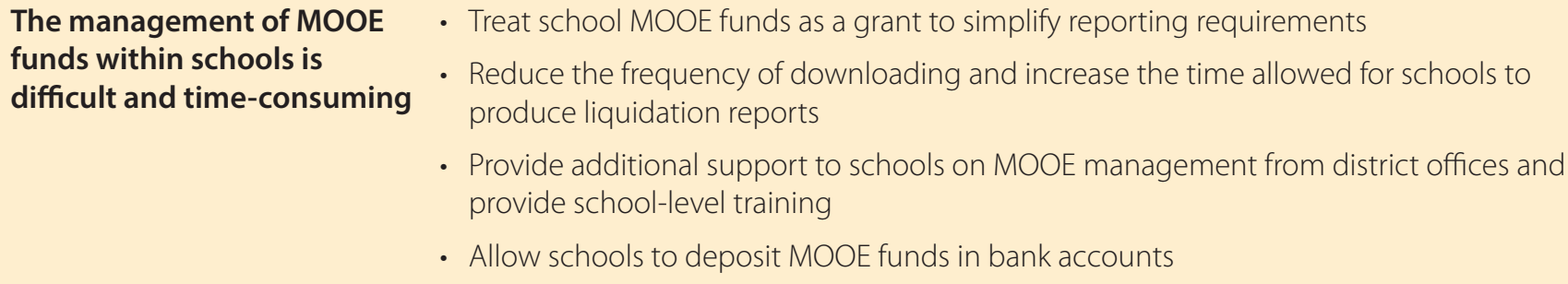
produce liquidation reports

- Provide additional support to schools on MOOE management from district offices and provide school-level training

- Allow schools to deposit MOOE funds in bank accounts

School-level institutions like the school governing council are relatively weak

- Review and strengthen the role of SGCs in the planning and monitoring of MOOE funds

- Disseminate information on the roles and responsibilities of SGCs to parents and the local community

- Ensure that MOOE and other school-level funds are incorporated into school improvement plans

\section{Funding inequalities at the school level are large}

- Introduce an equity component into the MOOE allocation formula. 


\section{Endnotes}

$1 \mathrm{MOOE}$ is different to school grant funding because schools are required to use and account for the use of these funds in the same way as any other recipient of budget funds would be.

2 Khattri, N., C. Ling, and S. Jha (2010). "The Effects of School-based Management in the Philippines: An Initial Assessment Using Administrative Data." Policy Research Working Paper Series. No. 5248, World Bank, Washington, D.C.

3 World Bank and AusAID (2013). "School-based Management in the Philippines: An Empirical Investigation."World Bank and AusAID, Manila.

4 AusAID ERF (2011). "Current Issues in Education: School Grants and School-based Management." Canberra.

5 The findings reported in this note are discussed in more detail in additional annexes and tables accompanying the main PETSQSDS report.

6 Years refer to financial years (January to December) unless otherwise stated.

7 Discretionary funding refers to the funds that schools receive in cash, over which they have discretion to use as they please.

8 World Bank (2016). "The Development and Implementation of a Normative School MOOE Formula in the Department of Education in the Philippines."World Bank, Washington D.C.

9 These averages are based on statistics on the 2013 MOOE allocations from DepEd for the elementary schools in the PETSQSDS sample and from the DBM for high schools.

10 Author's calculations using eBEIS data on enrollment and on the numbers of teachers, classrooms, and graduating pupils for all public elementary schools.

11 The word "allocation" here refers to the cash allocation released by the DBM to DepEd divisions based on authorized allotments and released to cover spending obligations.

12 The study team determined this amount by scaling up the sum of the amounts allocated for public elementary and non-IU high schools in the PETS-QSDS survey to represent nationwide MOOE funding. In addition, they estimated national-level funding for non-IU high schools as about one-quarter of the total funding for high schools (PHP 5.06 billion) as suggested by the data from the DBM on per-school funding for the schools in the PETS-QSDS sample.
13 Occasional congressional insertions (additions to the originally approved budget) or additional MOOE funding for Special Education programs may partly explain why some schools received more than their allocated amount.

14 Interestingly, only a quarter of the divisions admitted to retaining funds when asked.

15 Schools reported receiving only 77 percent of the funds that the division offices reported downloading in the first three-quarters of 2014.

16 The pattern is similar for high schools.

17 The available data for 2014 show a similar pattern.

18 World Bank (2016). “The Development and Implementation of a Normative School MOOE Formula in the Department of Education in the Philippines."Washington D.C.

19 Canvassing relates to the requirement that schools obtain at least three quotes for purchases that they make with MOOE funds.

20 There were no differences in the proportion of rural and urban high schools that reported finding it difficult to spend their MOOE allocations.

21 More specifically, schools are required to submit a completed liquidation report to the division offices by the fifth day of the month after they have received an MOOE advance in order to receive their next MOOE advance.

22 The household questionnaire included a short module on consumption and a set of questions on assets that have been used by the Department of Social Welfare and Development (DSWD) to undertake a proxy means testing (PMT) approach to estimating household consumption per capita. The results reported here are based on information gathered using the PMT approach, and a full description is included in a separate note.

23 DepEd Order 54, s. (2009). "Revised Guidelines Governing ParentsTeachers Associations (PTAs) at the School Level." Department of Education, Manila.

24 DepEd (2009). "A Manual on School Governing Councils." Department of Education, Manila.

25 Al-Samarrai, Samer; Fasih, Tazeen; Hasan, Amer; Syukriyah, Daim. 2014. "Assessing the Role of the School Operational Grant Program (BOS) in Improving Education Outcomes in Indonesia." World Bank, Jakarta, Indonesia. 


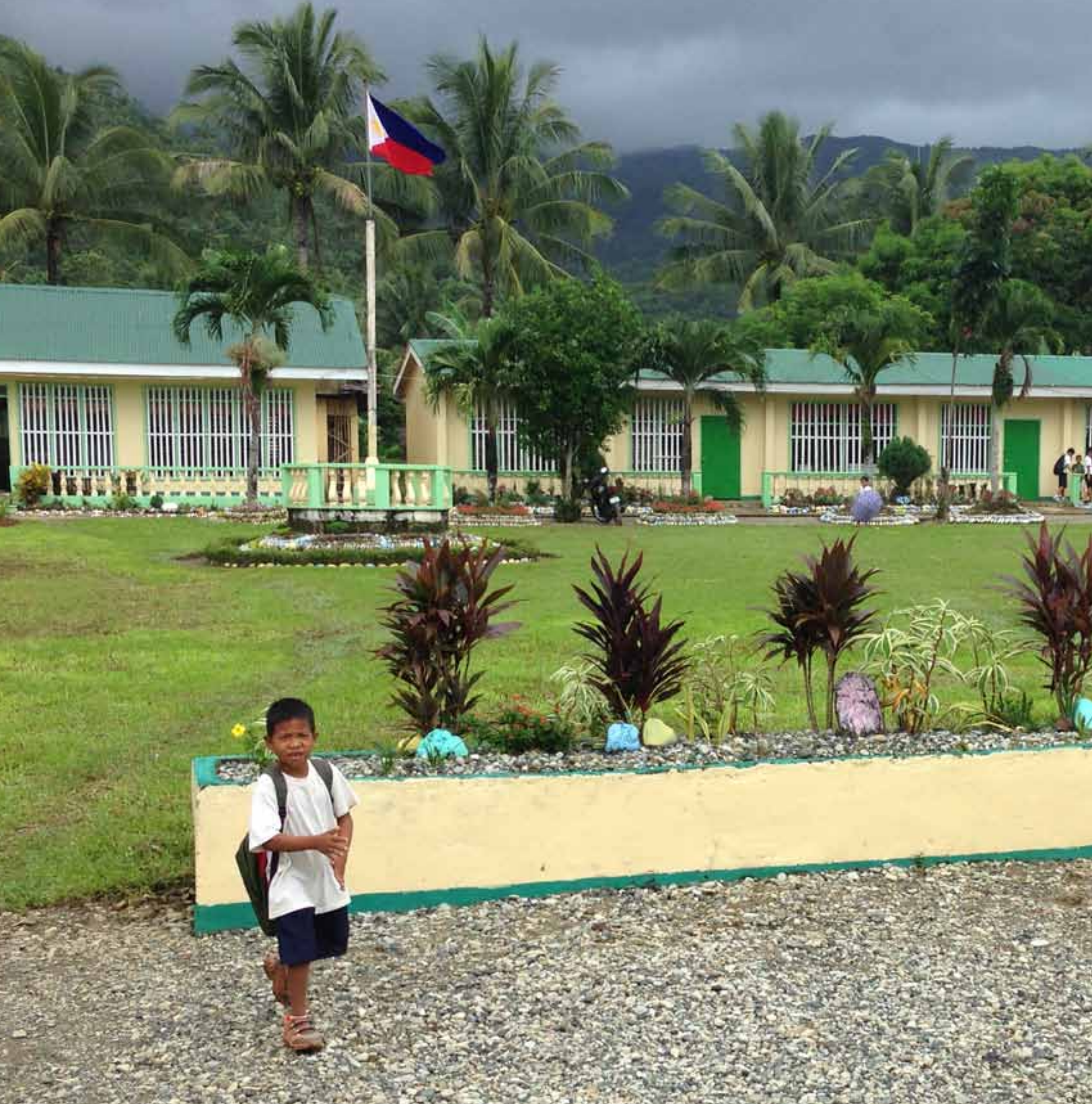

1.

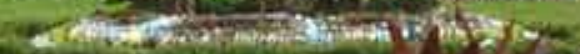

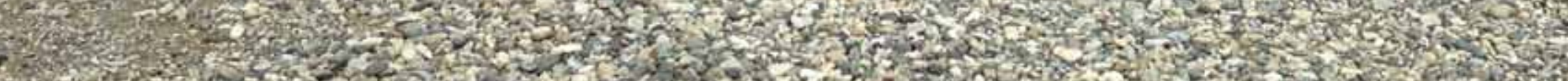

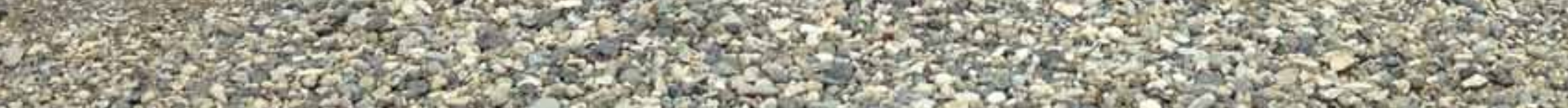

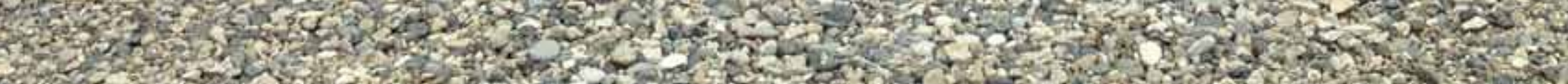

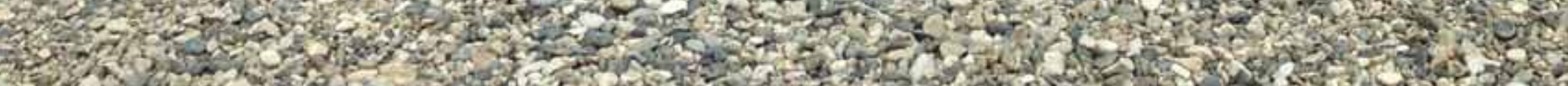

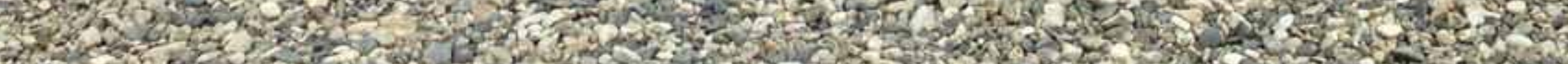
7. 


\section{Policy Note 6: Assessing the Role Played by Local Government in Supporting Basic Education}

\section{Introduction}

Many developing countries have devolved the responsibility for education services to local governments in an effort to improve educational quality and make public spending more efficient. Advocates of decentralization have argued that bringing decision-making closer to schools makes public policy more responsive to local needs, strengthens accountability, and fosters innovation. In some countries, decentralization has gone further in that schools have been given responsibility for developing their own improvement plans and a degree of autonomy over the use of their resources.

While the Philippines decentralized some public services to local governments in the early 1990s, basic education remains largely under the control of the national government. The 1991 local government code devolved responsibility for many basic services to local government units (provinces, cities, municipalities, and barangays') including primary health care, hospital care, social welfare services, and a range of environmental and agricultural services. Local governments' responsibilities in the field of education were largely limited to maintaining basic education infrastructure and funding sports activities. The funding that each local government uses to fulfill its basic education responsibilities comes primarily from a surcharge on local property taxes that goes into a Special Education Fund (SEF) managed by a local school board (LSB). Over time, LSBs have used SEF funding for a growing range of purposes including, for example, employing additional school-level staff and paying school utility bills. However, responsibility for education policy, standards, curriculum, and the hiring of teachers and the bulk of education financing remains with the national government.

The purpose of this policy note is to assess the financing of basic education services by local governments in the

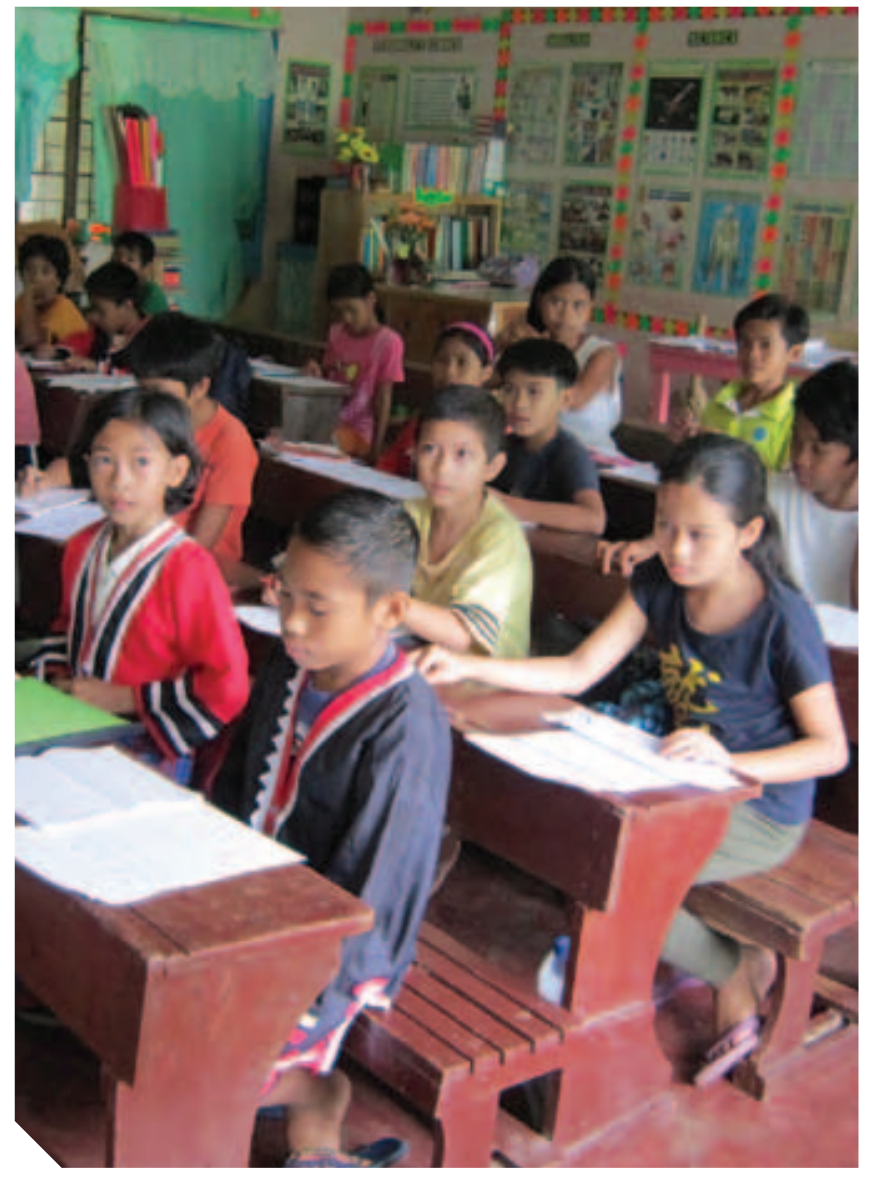

Philippines. Using data that the PETS-QSDS team has carefully collected from a nationally representative sample of elementary and high schools, it explores the magnitude of the funding that local governments are giving to schools and assesses the systems that govern the use of local government funds in the education sector. The policy note shows that local governments' contribution to overall public education funding is small and highly inequitable. It also shows that the systems used to allocate and manage these funds are weak and that greater transparency and accountability over these resources is urgently needed. 


\section{Trends in Local Government Financing of Basic Education}

Education makes up only a small share of local government spending and has not changed much over the last decade (Figure 1). The composition of local government spending is aligned with their devolved responsibilities, with the bulk of funds being allocated to the provision of general public and economic services as well as health, nutrition, and population services. In 2014, only PHP 13.3 billion or 5 percent of local government spending was devoted to education.

Local government funding also represents a very small and declining share of overall public funding for basic education. While spending on basic education by local government units (LGUs) has fluctuated considerably over the last 10 years, in real terms, it appears to have been on a declining trend since 2007 (Figure 1). Combined with ever-increasing levels of national spending, the share of public basic education funding accounted for by local government spending declined from 11 percent in 2006 to only 6 percent in 2013.
Local government trends in education spending have translated into declining levels of funding for each basic education student (Figure 1). Between 2003 and 2013, LGU spending per student declined from PHP 951 to PHP 744, a fall of over 20 percent in real terms. This is in stark contrast to national government funding, which rose by 35 percent from PHP 9,500 to PHP 12,800 over the same period.

Local government support for education has declined even though local revenue for education has increased considerably. Each province, city, and municipality in the Philippines has a Special Education Fund (SEF), which is the source of the majority of its spending on basic education. These SEFs are funded by a 1 percent surcharge on property taxes raised by the local government. ${ }^{2}$ Between 2007 and 2014 and partly as a result of increasing property prices, SEF income has risen in real terms by approximately 40 percent from PHP 17 billion to PHP 24 billion (in constant 2014 prices). However, over the same period, SEF spending actually declined, from PHP 15 billion to PHP 12 billion. The accumulated surplus of unspent SEF funds since 2007 amounts to over PHP 63 billion. While the reasons for this under-spending are likely to differ between local governments, earlier studies have pointed to problems with cash management and poor budgeting. ${ }^{3}$

\section{Figure 1: Spending on Basic Education by Local Governments is Low and Has Been Declining}

Total and per-student public basic education spending, 2003-2013

\section{Total public spending}

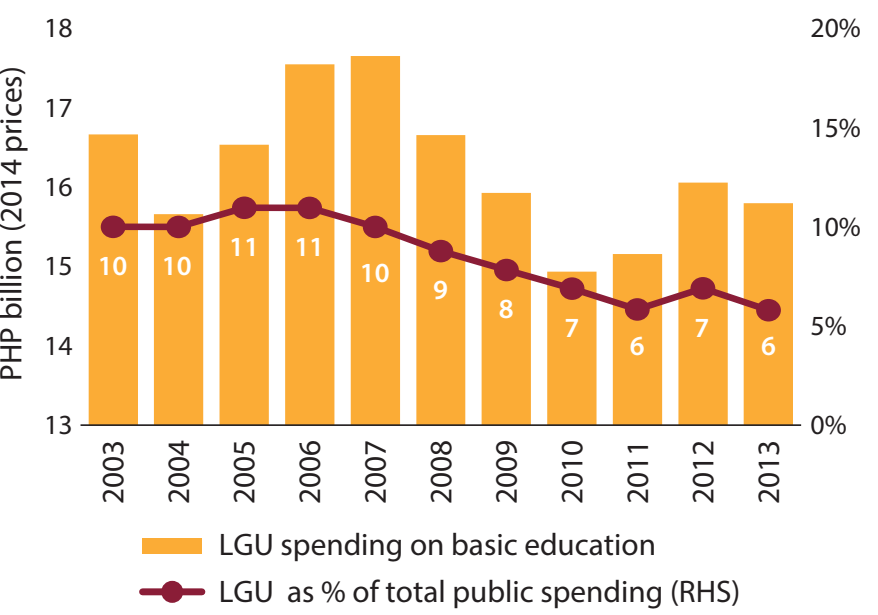

Public spending per student

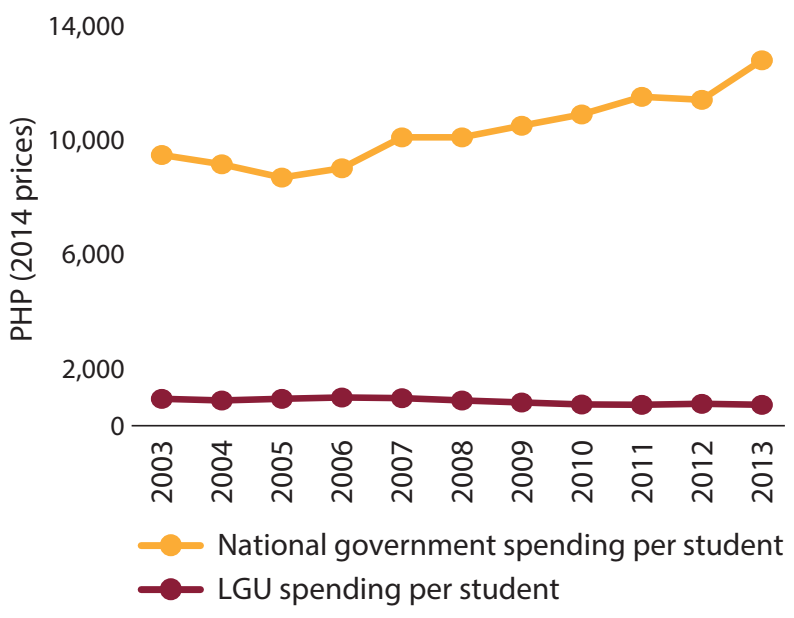

Sources: National government spending - DBM National Expenditure Program. Local government education spending - Bureau of Local Government Finance. Enrollment - DepEd FACT sheet. GDP and GDP deflator - Philippines Statistics Authority.

Notes: Student numbers include kindergarten. 
Figure 2: There are Large Differences in the Amounts that Local Governments Spend on Education

Total and per student local government education spending by region, 2013

Total LGU spending

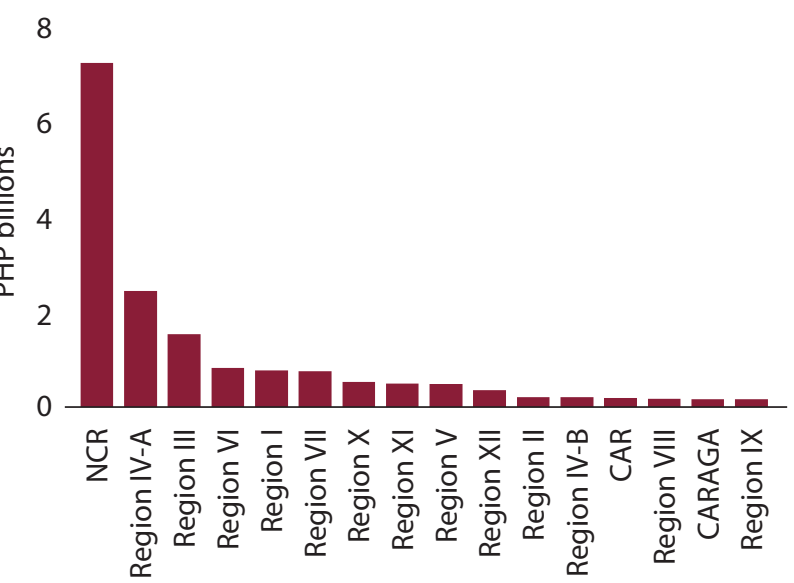

LGU spending per student

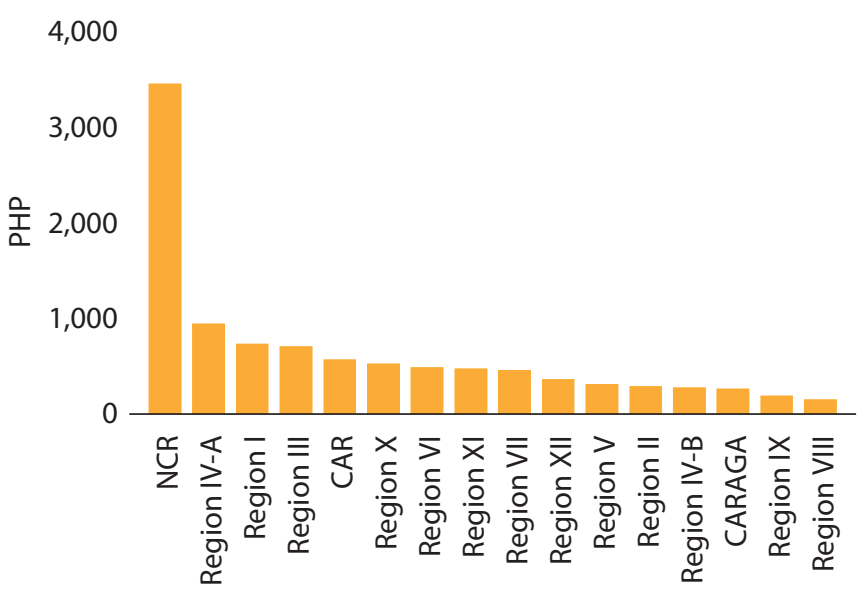

Sources: Bureau of Local Government Finance. Enrollment rates from DepEd FACT sheet.

Notes: Student numbers include kindergarten.

The aggregate patterns of local government education spending mask large disparities among regions, which are administrative units that do not have their own elected governments but encompass provinces, cities, and municipalities (Figure 2). The National Capital Region (NCR), the region with the highest overall levels of property tax revenue, accounts for over 44 percent of total local government education funding in the Philippines. This is a very large and significant source of additional funding for the school system, equivalent to approximately PHP 3,500 in additional funding for each basic education student in the region or about 28 percent over and above per student funding from the national government. Disparities between other regions are not as stark but still exacerbate funding inequalities between schools in different locations.

\section{Local Government Support for Public Schools}

Within each province, city, and municipality, a local school board (LSB) is responsible for the allocation and use of local government education funds (see Box 1). Its main function is to develop an overall plan and budget for local government funding of basic education in their locality, including funding from the SEF. ${ }^{4}$ The LSB is supposed to meet on a monthly basis and to make decisions on the basis of majority voting, including the approval of the budget. The national government sets broad priorities for how local government funding should be used, largely related to supporting public schools falling under the jurisdiction of the LSBS.

Interviews with members of local school boards conducted as part of the PETS-QSDS study revealed that they meet less frequently than outlined in the Local Government Code. The study found that boards meet, on average, every quarter rather than every month as the code suggests. These meetings often focus on the overall finances of the board and the needs of schools, but the outcomes of these meetings are rarely communicated to schools and their principals. For example, it became clear from the study team's interviews with elementary and high school principals that more than one-third of them were not even aware when or how often the school board meets. Moreover, it did not appear that school principals and other stakeholders are given an opportunity to provide feedback to their boards.

Obtaining reliable and accurate information on the amount of financial support that schools receive from local governments is difficult. While local governments report information on aggregate education spending in their 


\section{Box 1: Legal Framework for the Role Played by LGUs and their Local School Boards in Basic Education}

The Local Government Code (LGC) issued in 1991 (Republic Act 7160) set out the legal framework for the role of LGUs in basic education. It initiated the creation of provincial, city, and municipal local school boards (LSBs) as the main bodies for making decisions over the use of local government education funds. Each LSB is co-chaired by the head of the local government and either the DepEd's School Division Superintendent (for provincial and city LSBs) or the Public School District Supervisor (for municipal LSBs). Members of the parent-teacher associations and representatives of teachers and non-teaching staff are also represented on the LSB.

The main functions of the LSBs are: (i) to develop the annual school board budget in accordance with the amount of revenue in the SEF and with their determination of the supplementary maintenance and operating needs of public schools covered by the LSB; (ii) to authorize SEF disbursements; (iii) to act as an advisory committee for the local council; and (iv) to recommend school name changes.

The LGC and a series of joint circulars from DepEd, the Department of Management and Budget, and the Department of the Interior and Local Government have set out the main priorities for the Special Education Funds, including the provision of additional teachers, the construction and repair of school buildings, other capital investments for schools, educational research, the purchase of books and instructional materials, equipment purchases, sports, and other extracurricular activities.

Sources: Government of the Philippines Republic Act 7160, (1991). "An Act Providing for a Local Government Code." Manila; Manasan, R. G., A.B. Celestino, and J.S. Cuenca (2011). "Mobilizing LGU Support for Basic Education: Focus on the Special Education Fund," Philippine Institute for Development Studies, Manila.

annual accounts, these reports do not contain any detailed information on the type and level of support given to individual schools. This makes it impossible to assess how funds are being used and how much local government education funding directly benefits public schools.

To overcome this constraint, the PETS-QSDS study collected detailed information on all sources of school revenue and expenditure from a nationally representative sample of elementary and high schools. Based on the World Bank's prior experience of collecting this information in the Philippines and other countries, the study team developed a questionnaire that would capture all cash and in-kind contributions received by schools from all national and local governments (provincial, city, and municipal LSBS and barangays), members of Congress, parent-teacher associations (PTAs), NGOs and any other sources. The study also collected information on contributions from parents as well as funds received from income-generating projects like the school canteen. ${ }^{5}$

\section{Incidence and Overall Level of Local Government Support to Basic Education}

The findings of this detailed exercise revealed that fewer than 50 percent of schools receive any kind of direct funding from local governments (Figure 3). On the whole, local governments tend to provide direct financial support to a slightly greater proportion of elementary schools than high schools. These differences were large in urban areas where 53 percent of all elementary schools receive support compared to only 28 percent of high schools. Although a greater proportion of elementary schools receive LGU support, a much greater share of total LGU funding goes to high schools. Direct funding of high schools by LGUs is equivalent to PHP 331,000 for every high school compared to only PHP 206,000 for each elementary school.

Levels of direct support to education from local governments tend to be higher in highly urbanized cities (HUCs) than in other cities and municipalities, particularly in the case of high schools (Figure 3). LGUs in HUCs provide approximately PHP 1.6 million for each high school while LGUs in municipalities spend only PHP 256,000 per high school. This is not surprising given that LGUs in highly urbanized cities include the National Capital Region, which has the largest SEF revenues (see Figure 2).

On average, LGU contributions make up a very small share of overall public school funding across the Philippines. A comparison of school revenue from all sources shows that public schools receive the majority of their funding from the national government through the Department of Education 
Figure 3: Fewer than Half of All Schools Receive LGU Support, and the Amount of Funding Provided is Small Percentage of schools that report receiving cash or in-kind contributions from local governments and average levels of support, 2013-14
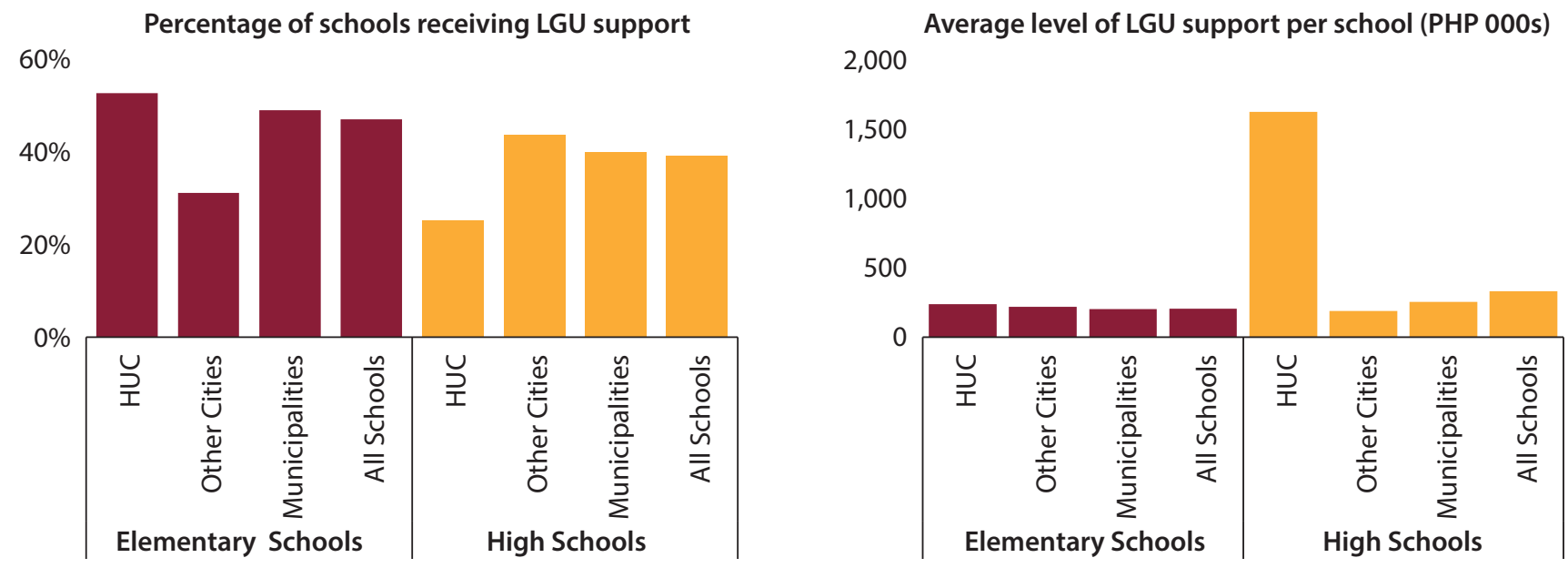

Source: PETS-QSDS national survey - school level.

Note: The average level of support is only for schools that received LGU contributions in 2013-14

(Figure 4). Other sources such as contributions from private individuals, NGOs, and school-level income-generating projects (such as school canteens) are significant sources of funding for elementary schools, having made up around 5 percent of their total funding in 2013/14. LGU funding, on the other hand, represent less than 4 percent of the cash and inkind funding that schools receive directly from all sources.

A comparison between levels of LGU direct school funding and total LGU education spending reported at the national

Figure 4: The Contribution of LGUs to Direct School Funding is Also Low

Composition of school funding for all schools and only schools that receive some LGU support, 2013-14

Composition of all school funding (PHP 000s)

10,000

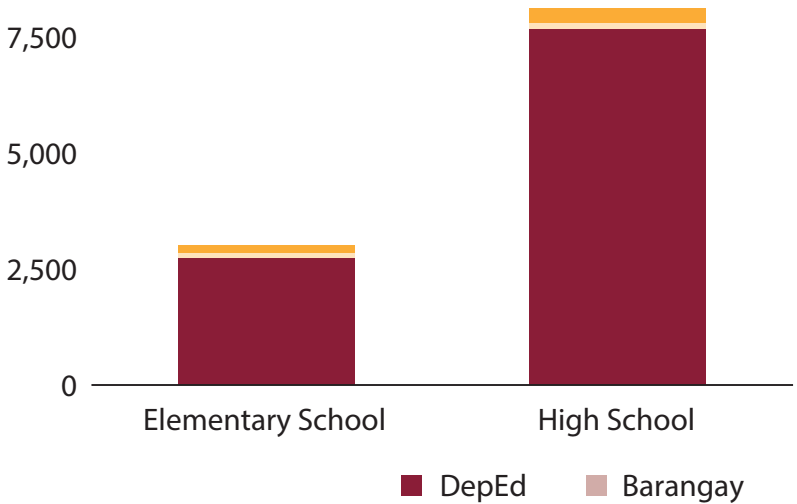

10,000

7,500

5,000

2,500

0

Composition of funding only in schools reporting LGU support (PHP 000s)

Source: PETS-QSDS national survey - school level.

Note: The left hand panel reports the composition of school funding across all schools while the panel on the right reports the composition only for schools that reported receiving LGU funding. 
level suggests that significant amounts are not being spent on activities that directly benefit schools. Rough estimates by the PETS-QSDS study team using carefully collected finance data from school visits suggest that LGU spending on schools amounts to approximately PHP 9 billion. This represents only 58 percent of the PHP 16 billion that LGUs reported spending on education in 2013 (see Figure 1).

There is little information on how the LGU funds that are not spent at the school level are being used. The study team made considerable efforts to collect such information from the local governments directly and from the DepEd supervisors who sit on local school boards. However, little information was available and, even where it was, the data were patchy and did not correlate with the official aggregate spending figures reported by the LGUs. The study found that one destination for this indirect spending was additional allowances or bonuses provided by the LGUs to DepEd teachers; one-quarter of provincial LGUs and 15 percent of city and municipal LGUs reported making these payments. These payments are unlikely to have been recorded in the official school financial records. While this may account for the differences between actual and reported LGU spending, it is not possible to estimate the magnitude of this kind of expenditure. The study also found that around one-quarter of local governments had paid the utility bills of some of the schools in their jurisdiction. However, once again, the magnitude of this support often went unrecorded, which makes it difficult to discover exactly where the majority of the reported LGU spending went.

\section{Use of LGU Support by Schools}

The bulk of local government support for schools is provided in the form of goods and services rather than cash (Figure 5). In-kind contributions account for 90 percent of total LGU support for elementary schools and 98 percent of LGU support for high schools. In providing specific in-kind support, local governments must have detailed knowledge of what schools need and of what support they are already receiving from other sources. For example, in the area of construction and rehabilitation activities, local governments need to ensure that their efforts supplement rather than duplicate DepEd's plans for school infrastructure development. When there is an overlap, this constitutes inefficient use of education funding. The alternative to local governments providing schools with in-kind contributions is to give them cash that could be factored into their annual improvement and procurement plans. However, less than 10 percent of LGU contributions are provided in this form. ${ }^{6}$

\section{Figure 5: Most LGU Funding is Provided In Kind}

Composition of LGU cash and in-kind contributions to schools (PHP), 2013-14

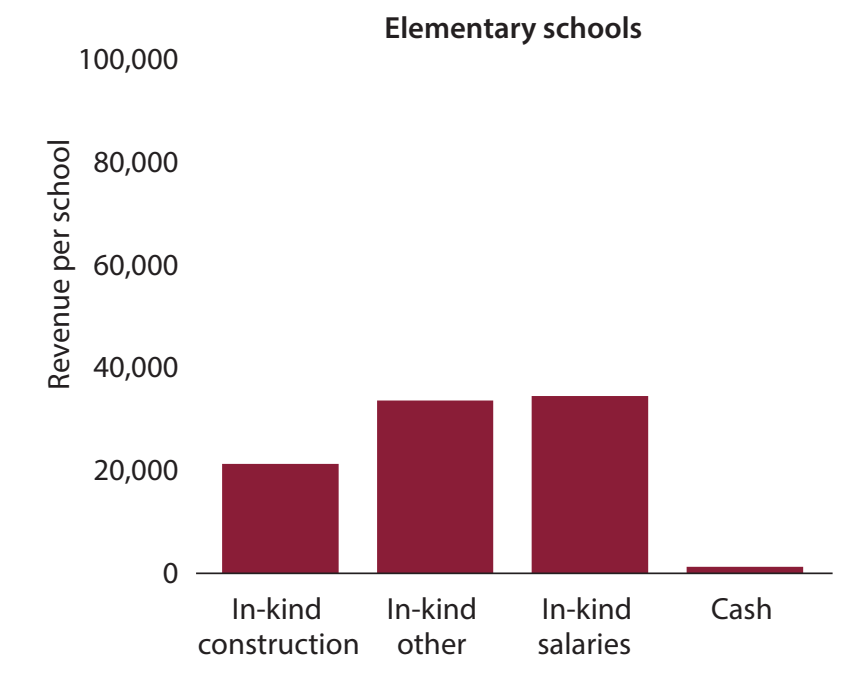

100,000

High schools

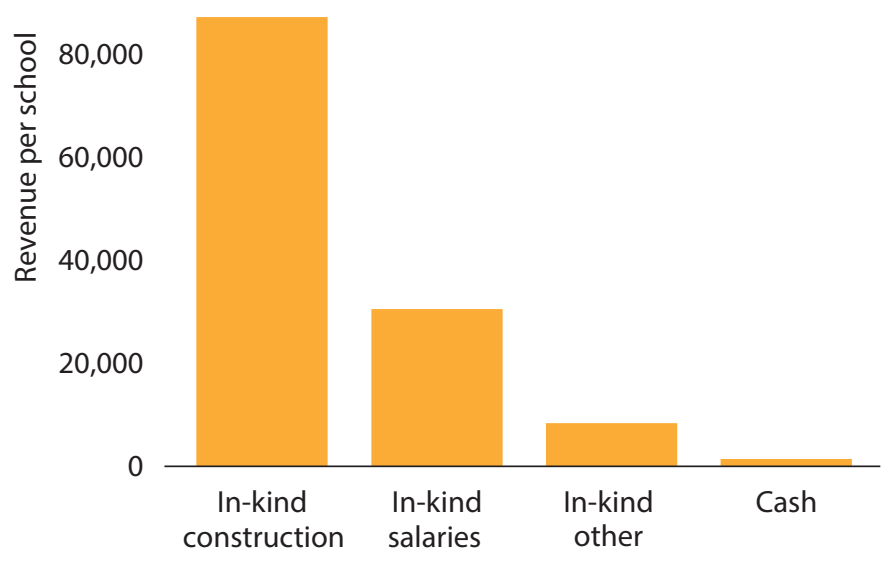

Source: PETS-QSDS national survey - school level.

Note: In-kind contributions refer to goods or services given to schools directly rather than as cash grants for the school to purchase the goods and services for themselves. Other in-kind contributions include school supplies, books, and instructional materials. 
Few of these local government in-kind contributions relate to the provision of teachers and other staff. In 2014, the government decided to incorporate all local government funded teachers into the national teacher workforce funded directly by the national government. When the study team fielded their survey at the end of 2014, a significant number of local government teachers had already been absorbed into the national network, and fewer than 2 percent of teachers in elementary and high schools were funded by local governments. However, local governments continue to provide some support to schools to fund the provision of ancillary staff such as janitors and security guards.

The construction and rehabilitation of school infrastructure absorbs a much larger share of total LGU funding for high schools than of total funding for elementary schools. Around three-quarters of all LGU funding in high schools is devoted to construction and rehabilitation compared to only one-third for elementary schools. Of all projects undertaken by local governments in 2013 and 2014, 68 percent involved the new construction of classrooms or water and sanitation facilities, with the repair of existing infrastructure accounting for the remaining projects. Most of the projects were completed on time, but satisfaction rates were relatively low with 54 percent of school principals saying that they were dissatisfied with these projects largely because of delays in implementation and the poor quality of the completed projects?

\section{Equity and Local Government Support}

Local government education support is unevenly distributed across regions and is highly inequitable. Comparing regional poverty rates and local government spending shows that, on the whole, poorer regions spend less on supporting basic education (Figure 6). For example, less than 10 percent of the population is poor in Region IV-A in Luzon, and it spends an average of PHP 950 per basic education student. In contrast, over 35 percent of the population is poor in Region XII in Visayas, and it spends only around PHP 370 per student. These large differences are primarily the result of differences in the amount of property tax revenue that local school boards are able to collect for their Special Education Funds. These findings are worrying since schools serving poorer children tend to need higher levels of funding in order to compensate for the more limited support that disadvantaged children tend to receive outside the school.

Looking at the per-student distribution of local government funding within regions reveals a different picture. Schools located in rural municipalities tend to receive significantly more per-student funding from LGUs than schools in urban

\section{Figure 6: The Distribution of Local Government Education Spending is Inequitable}

Total and per student LGU spending on basic education by region and poverty incidence, 2012-13
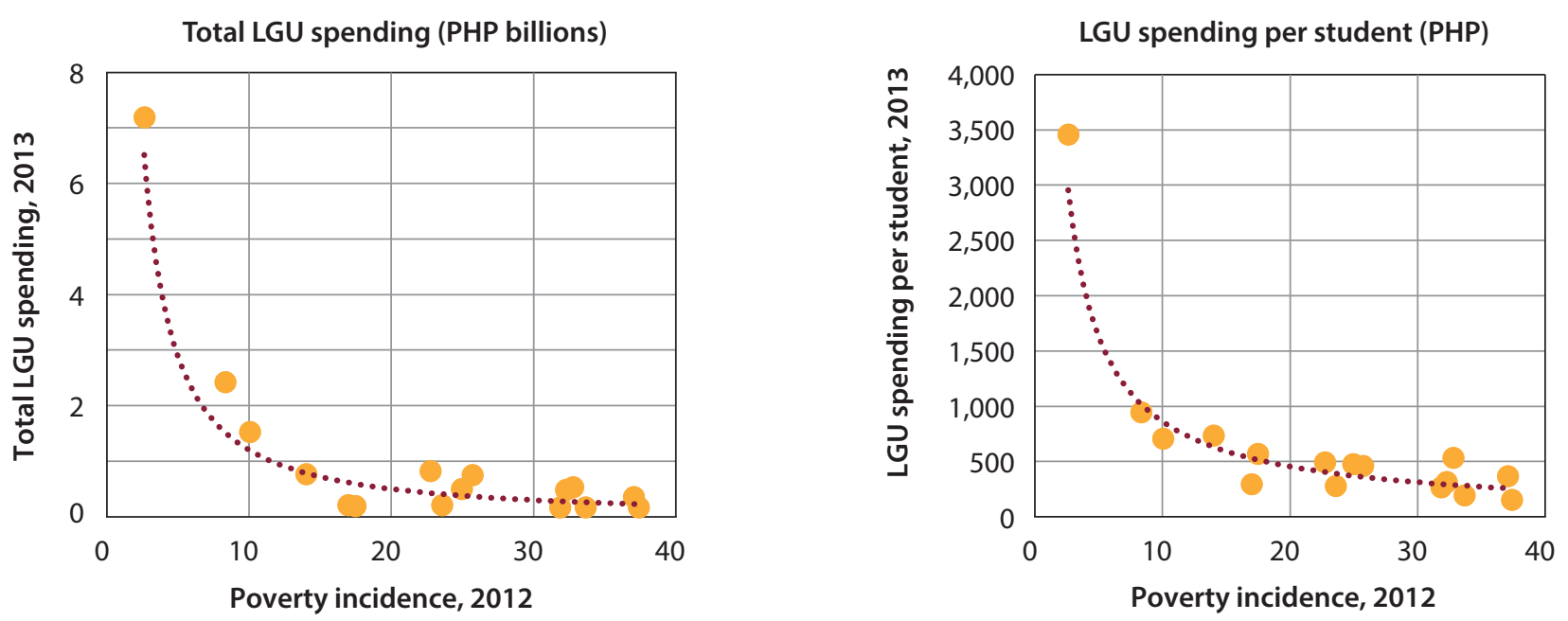

Sources: Poverty incidence data from the Philippines Statistical Authority, LGU spending from the Bureau of Local Government Finance. 
Figure 7: Patterns of Local Government Funding are Inequitable Average per-student LGU funding (PHP), 2013-14
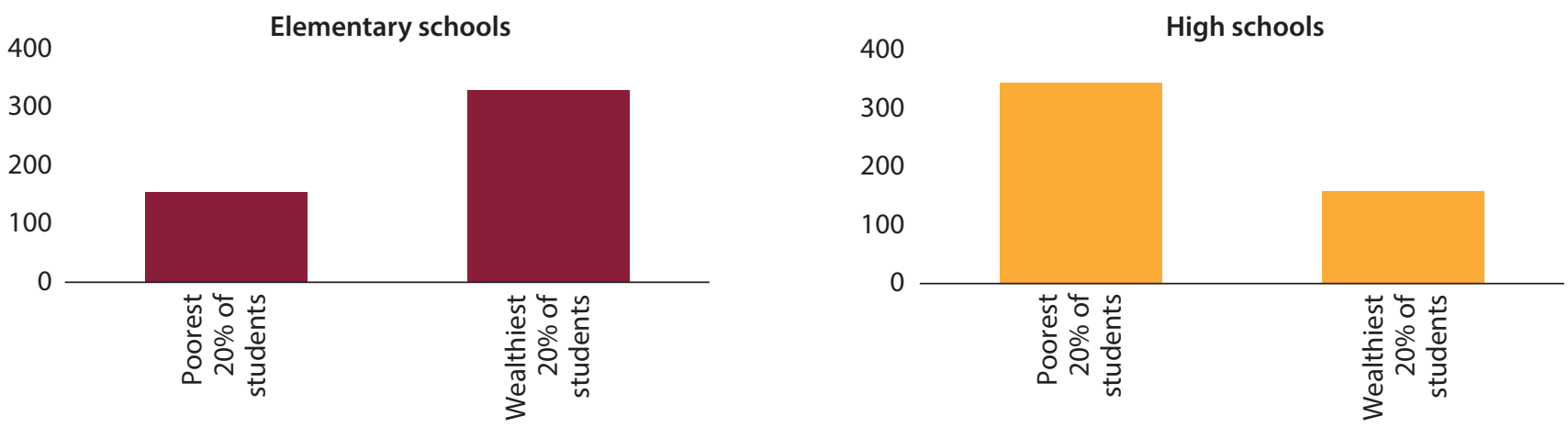

Source: PETS-QSDS national survey - school and student household levels.

areas. For example, the average LGU per-student contribution to high schools in highly urbanized areas is PHP 245 compared with PHP 369 to high schools in municipalities. The key driver of this is the smaller size of rural schools. ${ }^{8}$

LGU contributions vary according to the socioeconomic status of students in very different ways in elementary schools and in high schools (Figure 7). The PETS-QSDS survey included a nationally representative sample of households of public elementary and high school students. Using information collected by the survey on consumption and asset ownership, it is possible to rank these student households by their estimated levels of household consumption per capita. ${ }^{9}$ This ranking shows that students from poorer households tend to attend elementary schools that receive less LGU per-student funding than is received by the elementary schools attended by students from wealthier households. In contrast, poor high school students tend to attend high schools that have higher levels of per-student funding than is received by the high schools attended by their wealthier counterparts..$^{10}$ Taken as a whole, the findings suggest that local government funding tends to widen funding inequalities in elementary schools and to narrow them in high schools. However, given that LGUs provide relatively low levels of education funding, their impact on overall funding remains small.

\section{Transparency and Accountability of Local School Boards}

Information on overall levels of annual local government education spending was often unavailable to the survey team at the local level, and what little data they were able to find were inconsistent. This clearly limits the ability of stakeholders to hold local governments accountable. The PETS-QSDS study collected financial data on the Special Education Funds (SEFs) from the Bureau of Local Government Finance (BLGF) at the national level and from LSB offices in cities, municipalities, and provinces. The team then attempted to match these two sets of data, which revealed significant inconsistencies between the nationally and locally reported spending aggregates. The team found that the information reported at the national and local levels was consistent in the case of only 16 percent of $L S B s$, while, for 22 percent of $L S B s$, there were inconsistencies in the levels of spending reported at the national and local levels and one-half of all LSBs did not report any SEF expenditure at the local level to compare with national data. 
The information on those schools that received local government support and on the kind of support that they received also revealed discrepancies. The PETS-QSDS study tracked the spending that local governments had reported providing to elementary and high schools within the schools themselves. Depending on the type of funding in question, local governments reported providing funding to a large number of schools under their jurisdiction. However, when the team checked this information at the school level, a significant proportion of schools reported that they had not received these funds. For example, 24 percent of elementary schools to which local governments claimed to have provided in-kind support for salaries denied ever having received this support (Figure 8 ).

The team found additional inconsistencies in reporting between schools and local governments. For example, of all the elementary schools that reported having received support from their local government, the LGUs themselves only reported providing support to approximately 40 percent of them.

These findings demonstrate that local government reporting and accounting procedures for the use of education funds are weak. This hampers the ability of schools, parents, and other stakeholders to assess the fairness and effectiveness of spending priorities and resource allocations and to hold local governments accountable.

\section{Policy Directions for Improving Local Government Support for Basic Education}

This note has shown that, in recent times, local governments have failed to spend the revenue that they have collected in their Special Education Funds. Other studies have shown that existing levels of public education spending are inadequate to deliver the quality of services outlined in existing national norms and standards. While local government funding constitutes a small percentage of overall education spending in the Philippines, it is imperative that all of these funds should be used to support education improvements. The national government needs to strengthen its monitoring of local government SEF surpluses and to consider putting a cap on the level of these surpluses to ensure that the vast majority of these funds is spent on education.

While reporting deficiencies prevented the study team from making a completely accurate assessment, it is clear that a relatively low share of local government education spending reaches schools. The funds that do reach schools are largely provided in-kind, which limits the control and flexibility that schools have to use the support according to their own priorities. Providing a greater proportion of local government funding to schools in the form of cash, as is the case with the nation-

Figure 8: Comparing Expenditures between LGUs and Schools Revealed Many Discrepancies

Percentage of schools where LGUs reported providing some funding but schools reported receiving none
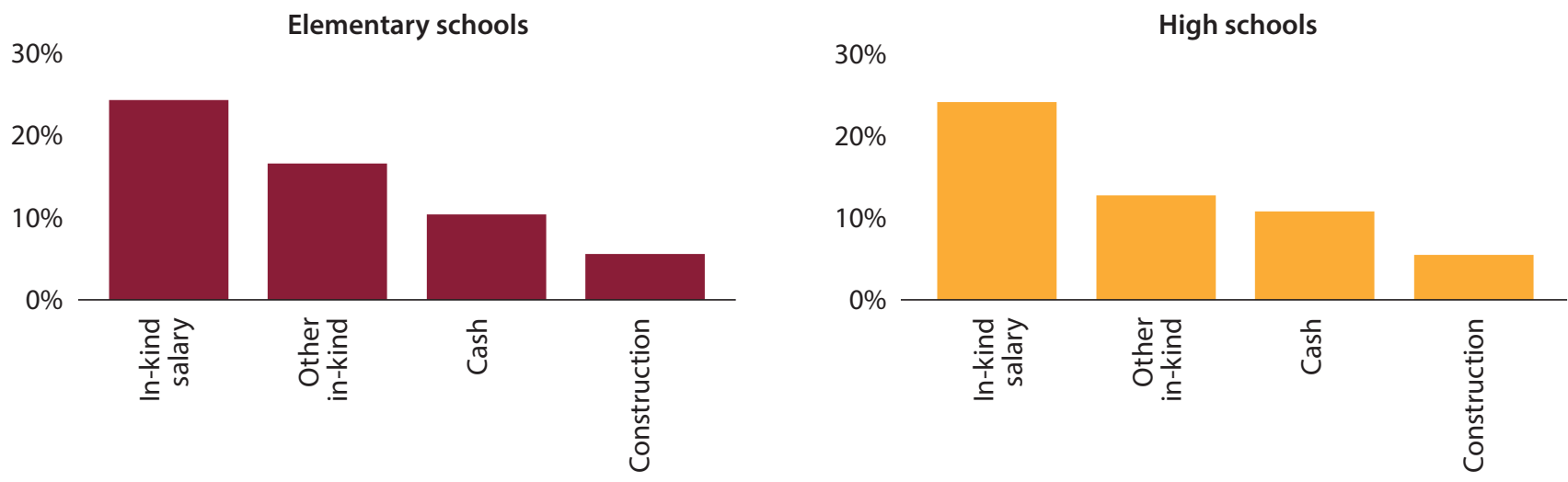

Source: PETS-QSDS national survey - provincial, city and municipality local school boards. 
al government's funding for school maintenance, operating, and other expenses (MOOE), would increase the autonomy of schools and provide them with greater flexibility and predictability, all of which would increase the positive impact of local government funding on educational outcomes.

Both the revenue base and the allocations of local government education funding are inequitable. This policy note has shown that the revenues available to local governments vary widely and are negatively correlated with poverty rates and other markers of disadvantage. Addressing this issue will be difficult, but the national government should consider adjusting its own funding allocations to compensate for the inequalities arising from these differences at the local government level. For example, the national funding formula for school maintenance, operating, and other expenses (MOOE) could be adjusted to account for differences in SEF revenues between localities."

This note has shown that local government spending tends to favor better-off schools, at least in terms of support for facilities. Therefore, it is vital that the allocation of local government funding is improved to ensure a closer fit between funding levels and needs at the school level. Introducing a simple and transparent funding formula, similar to the national funding formula for MOOE, could go a long way towards making the allocation of local government funding more equitable. The guidelines for LSBs on using local government funds also need to be consistent with national guidelines to ensure that there is no duplication and that local government spending complements national government funding.

The findings of the study also show that schools and school principals are rarely involved in local government funding decisions. Unless LSBs take into account school planning processes, there is a significant risk that local government funding will not help schools to meet their most pressing needs. Increasing coordination between LSBs and schools themselves would mitigate this risk and provide LSBs with more information on which to base their allocations of support to basic education. Moreover, it would allow for greater coordination between local governments and other sources of school funding, which would prevent any potential overlaps and enable more efficient and equitable use of all sources of funding.

The outcomes of the funding decisions of LSBs are not transparent, which makes it difficult for education stakeholders to hold local governments accountable. There are no consistent reporting formats to document the amount of funds that LSBs allocate to schools, the amount that the schools receive, and the amount that the LSBs allocate to other education-related activities. Developing a simple reporting format, to be issued as part of a revision of SEF guidelines by the national government, and the passing of regulations requiring that these reports are published on LSB bulletin boards and school notice boards would also increase transparency.

A recent initiative by the Department of the Interior and Local Government (DILG) to encourage greater accountability and transparency has been an important first step. LGUs that perform well in several areas receive the Seal of Good Local Governance as well as additional performance-based funds, and this scheme has provided LGUs with a strong incentive to increase transparency and to improve the use of SEF funds (Box 2). While the awarding of the Seal is already conditional on whether the annual plan of the LSB is aligned with the plans of the schools themselves, it could also be used to address

\section{Box 2: The Seal of Good Local Governance}

Building on earlier attempts to promote greater local government transparency and accountability in the use of public funds, the national government introduced the Seal of Good Local Governance in 2014. In order to receive the Seal, local governments must demonstrate good performance in three core areas (good financial housekeeping, disaster preparedness, and social protection) and in at least one essential area (business friendliness and competitiveness, peace and order, and environmental management).

Support for basic education falls under social protection. In order for a local government to receive the seal, it must demonstrate that it has completed 70 percent of the local school board's annual plan and that the plan is aligned with schools' own improvement programs. The DepEd superintendent currently certifies the achievement of these two conditions.

Recipients of the Seal are also eligible for the Performance Challenge Fund (PCF), which provides additional funding for local governments to pursue their own priorities. In 2015, 41 of the 80 provinces, 28 of the 143 cities, and 170 of the 1,491 municipalities were awarded the Seal.

Source: Department of the Interior and Local Government (2014). "Seal of Good Local Governance." Circular No. 2014-39. Manila. 
some other issues highlighted in this note. For example, the category of "good financial housekeeping" could be expanded to include more detailed reporting and the publication of how SEF funds are used and to set targets for the proportion of funds that should reach schools.

Any changes in the way in which local governments use their SEFs will require agreement between DepEd, the Department of Management and Budget (DBM), and the DILG, an updating of the existing joint circular on the SEFs, and a set of clear operational guidelines. These guidelines will need to clearly articulate priorities for the use of SEF funds, to devise ways to record the outcomes of school-level improvement plans, and to document clearly any elements of an LSB school funding formula to allocate resources. Moreover, the guidelines should stress the need for local governments to devote the majority of their funding to school-level activities and should include indicators to measure this.

Table 1: Improving Local Government Support for Basic Education

\begin{tabular}{|c|c|}
\hline Findings & Policy suggestions \\
\hline $\begin{array}{l}\text { A low share of local government } \\
\text { funding reaches schools and } \\
\text { most is provided in-kind }\end{array}$ & $\begin{array}{l}\text { - Raise the share of local government funding provided directly to schools } \\
\text { - Introduce a formula-based funding model to allocate more cash directly to schools } \\
\text { to support their annual improvement plans }\end{array}$ \\
\hline $\begin{array}{l}\text { Local government funding is } \\
\text { inequitable }\end{array}$ & $\begin{array}{l}\text { - Reduce inequalities between local school board areas by adjusting the national } \\
\text { funding formula } \\
\text { - Introduce a simple and transparent local government funding formula to strengthen } \\
\text { the link between funding and school needs }\end{array}$ \\
\hline $\begin{array}{l}\text { Schools are rarely involved in } \\
\text { funding decisions }\end{array}$ & $\begin{array}{l}\text { - Make better use of schools' annual improvement and procurement plans in LSB } \\
\text { planning } \\
\text { - Ensure that the link to school improvement planning in the Seal of Good Local } \\
\text { Governance is properly measured and monitored }\end{array}$ \\
\hline $\begin{array}{l}\text { Transparency and accountability } \\
\text { for the use of funds is weak }\end{array}$ & $\begin{array}{l}\text { - Improve reporting formats for the use of SEF funds and ensure that the results are } \\
\text { publicly disseminated } \\
\text { - Build on the Seal of Good Local Governance and associated performance-based funding } \\
\text { by, for example, requiring LSBs to report planned school level funding allocations. }\end{array}$ \\
\hline
\end{tabular}




\section{Endnotes}

1 Barangays (or villages) are the smallest administrative unit in local government in the Philippines. Above them come the municipalities and above municipalities come provinces/cities.

2 In 2014, SEFs were the source of approximately 85 percent of municipality spending and 70 percent of province and city spending on basic education.

3 Manasan, R. G., A.B. Celestino, and J.S. Cuenca (2011). "Mobilizing LGU Support for Basic Education: Focus on the Special Education Fund," Philippine Institute for Development Studies, Manila.

4 Within cities, the LSB allocates all of the funds within the SEF, whereas municipal LSBs are required to give 50 percent of their SEF revenue to their provincial LSB to provide resources for provincial spending. Some local governments also allocate money from their own General Fund (GF) and other sources to provide additional support to education.

5 A full description of the information collected in the PETS-QSDS study and the approach used to calculate total school revenue and expenditure is included in a set of additional annexes and tables accompanying the main PETS-QSDS report.

6 The effectiveness of school-level planning and implementation mechanisms is discussed in more detail in a separate note Assessing School-based Management in the Philippines.

7 The quality of school infrastructure and of national and local government projects is discussed in more detail in a separate note - Building Better Learning Environments in the Philippines.
8 Average school-level funding is indeed higher in urban areas. For example, the average high school in a highly urbanized city receives PHP 458,000 compared with the average of approximately PHP 107,000 received by high schools located in municipalities.

9 The household questionnaire included a short module on consumption and a set of questions on assets that have been used by the Department of Social Welfare and Development (DSWD) to undertake a proxy means testing (PMT) approach to estimating household consumption per capita. The results reported here are based on information gathered using the PMT approach, and a full description is included in a separate note.

10 These findings are supported by the study team's analysis of school facilities. Elementary schools receiving LGU support tend to have better school facilities (such as IT equipment, playgrounds, clinics, and libraries) than those that receive no funding. The opposite is true for high schools.

11 A fuller discussion of national government funding of schools through the maintenance, operating, and other expenses (MOOE) budget is provided in a separate note- Providing Schools with Adequate Operating Expenses to Deliver Quality Education in the Philippines. 


\section{Policy Note 7: Understanding the Drivers of Public School Performance and Efficiency}

\section{Introduction}

After a long period of stagnation, public spending on education in the Philippines has increased significantly. Between 2005 and 2015, education spending more than doubled in real terms, with much of it being devoted to increasing the number of teachers and improving school infrastructure. As a result, student-teacher and studentclassroom ratios have improved significantly. For example, the average student-teacher ratio in high schools fell from 40:1 in 2005 to $27: 1$ in 2014.

Despite increased spending and improvements in key input ratios, improvements in learning outcomes have been relatively modest so far. Studies have shown this to be the case in many other countries as well. Clearly spending is only one of a host of factors that can affect the ability of schools to improve the academic outcomes of their students. Some of these factors fall within the control of the education system and schools such as the provision and quality of education inputs and the effectiveness of school-based management. Others such as the characteristics of students and their households are beyond the control of schools, but all of these factors affect the efficiency of resource use and education outcomes.

This note attempts to identify the factors associated with differences in overall school performance and efficiency. It draws on data from the Philippines Public Education Expenditure Tracking and Quantitative Service Delivery Study (PETS-QSDS), which tracked public education spending and assessed the quality of the systems governing the use of these funds. The note also draws on the findings from other policy notes in this series to identify the key factors that determine the links between public spending and education outcomes

The note found that school performance is related to several of these key factors incluidng school governance and

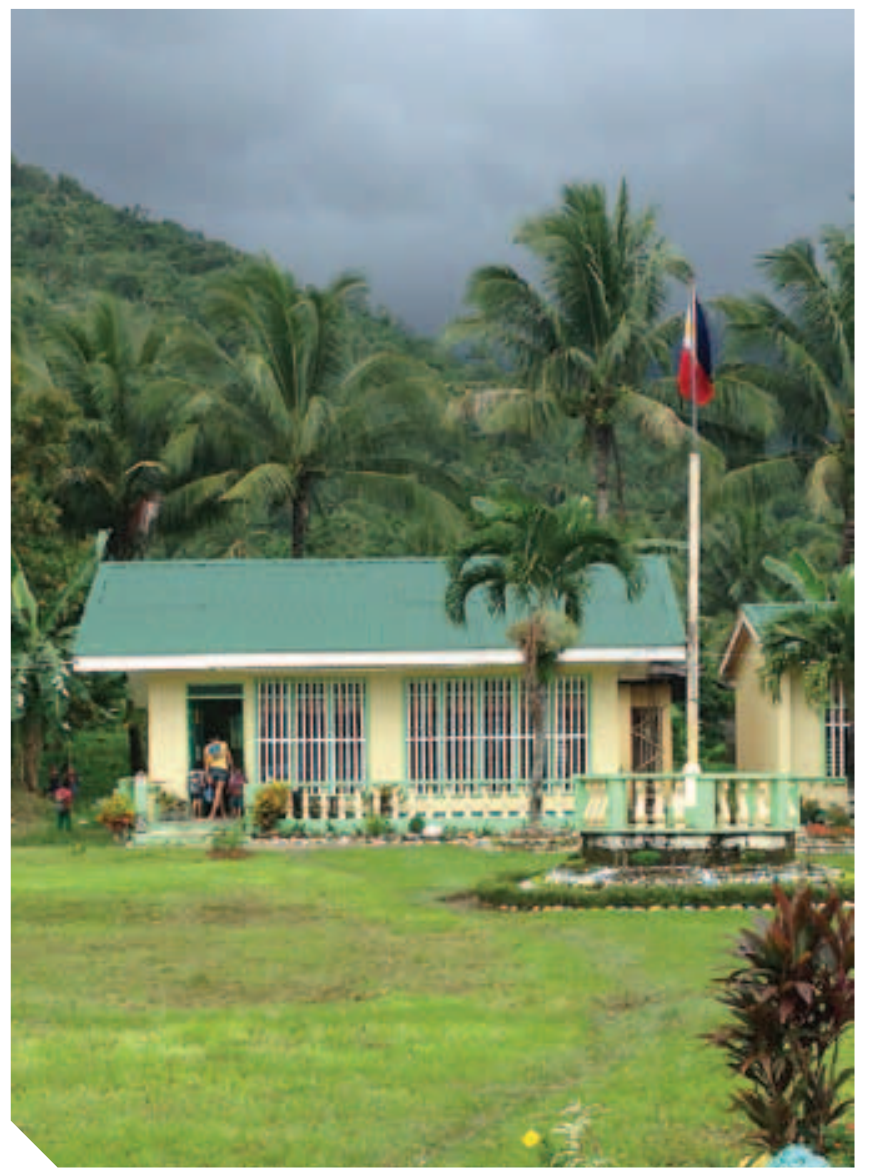

school infrastructure. It also found that student and school characteristics, school-level accountability mechanisms, and some teacher characteristics are associated with how efficiently schools can convert their financial, physical, and human resources into improved education outcomes. However, given the limitations of using cross-sectional data, the findings are not strong, and factors associated with good performance tend to vary a lot according to the level of education and the performance measures that were being analyzed. While more rigorous research is needed, the policy note provides tentative evidence that the factors often associated with better performance are not functioning effectively in the Philippines. 


\section{Approach to Assessing School Performance}

This policy note used the average National Achievement Test (NAT) score for each school as a measure of its performance. Specifically, it used a school aggregate of the different subject tests that individual students took in 2014 at the end of elementary school (Grade 6) and high school (Grade 10). The NAT scores of municipal schools tended to be higher than those of schools in urban areas (Table 1). For example, the average NAT score for Grade 6 students in municipalities was 75 percent compared with 66 percent in highly

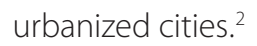

Student attendance was used as an additional measure of school performance. The data on attendance were collected as part of the PETS-QSDS survey directly from student attendance registers. The specific measure used in this note was average attendance in all grades on four specific dates in the last six months of 2014. ${ }^{3}$ The school averages showed that student attendance is generally high in the Philippines with relatively little variation between rural and urban schools (Table 1).

In order to develop a framework for understanding the factors affecting the performance of individual schools, the study team consulted several international studies. ${ }^{4}$ These studies broadly looked at three main categories of factors associated with school effectiveness and good education outcomes (Figure 1).

1. Household and Student Characteristics. The early childhood care received by children, their development

Table 1: School National Achievement Test Results and Student Attendance Rates, 2014

\begin{tabular}{|c|c|c|c|c|c|c|c|c|}
\hline & \multicolumn{4}{|c|}{ Elementary Schools } & \multicolumn{4}{|c|}{ High Schools } \\
\hline & $\begin{array}{c}\text { High } \\
\text { Urbanized } \\
\text { Cities }\end{array}$ & $\begin{array}{l}\text { Other } \\
\text { Cities }\end{array}$ & Municipalities & $\begin{array}{c}\text { All } \\
\text { schools }\end{array}$ & $\begin{array}{c}\text { High } \\
\text { Urbanized } \\
\text { Cities }\end{array}$ & $\begin{array}{l}\text { Other } \\
\text { Cities }\end{array}$ & Municipalities & $\begin{array}{c}\text { All } \\
\text { schools }\end{array}$ \\
\hline \multicolumn{9}{|c|}{ National achievement score (\%) } \\
\hline Average (mean) & 66.2 & 70.6 & 75.4 & 74.3 & 54.5 & 57.7 & 57.6 & 57.3 \\
\hline $\begin{array}{r}\text { Variation (standard } \\
\text { deviation) }\end{array}$ & 11.9 & 13.8 & 13.6 & 13.7 & 7.7 & 8.4 & 12.6 & 11.7 \\
\hline Minimum & 38.8 & 36.7 & 32.1 & 32.1 & 41.5 & 41.7 & 34.8 & 34.8 \\
\hline Maximum & 83.4 & 91.5 & 94.2 & 94.2 & 72.6 & 80.8 & 85.9 & 85.9 \\
\hline \multicolumn{9}{|c|}{ Student Attendance (\%) } \\
\hline Average (mean) & 87.5 & 93.8 & 88.4 & 89.0 & 88.5 & 92.9 & 89.3 & 89.8 \\
\hline $\begin{array}{r}\text { Variation (standard } \\
\text { deviation) }\end{array}$ & 14.1 & 4.4 & 12.7 & 12.2 & 9.4 & 3.3 & 10.3 & 9.6 \\
\hline Minimum & 19.7 & 78.1 & 34.8 & 19.7 & 39.6 & 81.4 & 56.6 & 39.6 \\
\hline Maximum & 99.0 & 100.0 & 99.6 & 100.0 & 99.6 & 99.4 & 99.6 & 99.6 \\
\hline
\end{tabular}

Source: PETS-QSDS national survey - school level. NAT scores of PETS-QSDS sampled schools - National Education Testing and Research Center of DepEd. Notes: Attendance rates were calculated using the average of student attendance on four specific days in the second half of 2014. NAT scores were calculated as the averages of all subjects for Grade 6 (elementary) and Grade 10 (high school) students in PETS-QSDS sampled schools who took the national examination in 2014. 
Figure 1: A Framework for Understanding School Performance

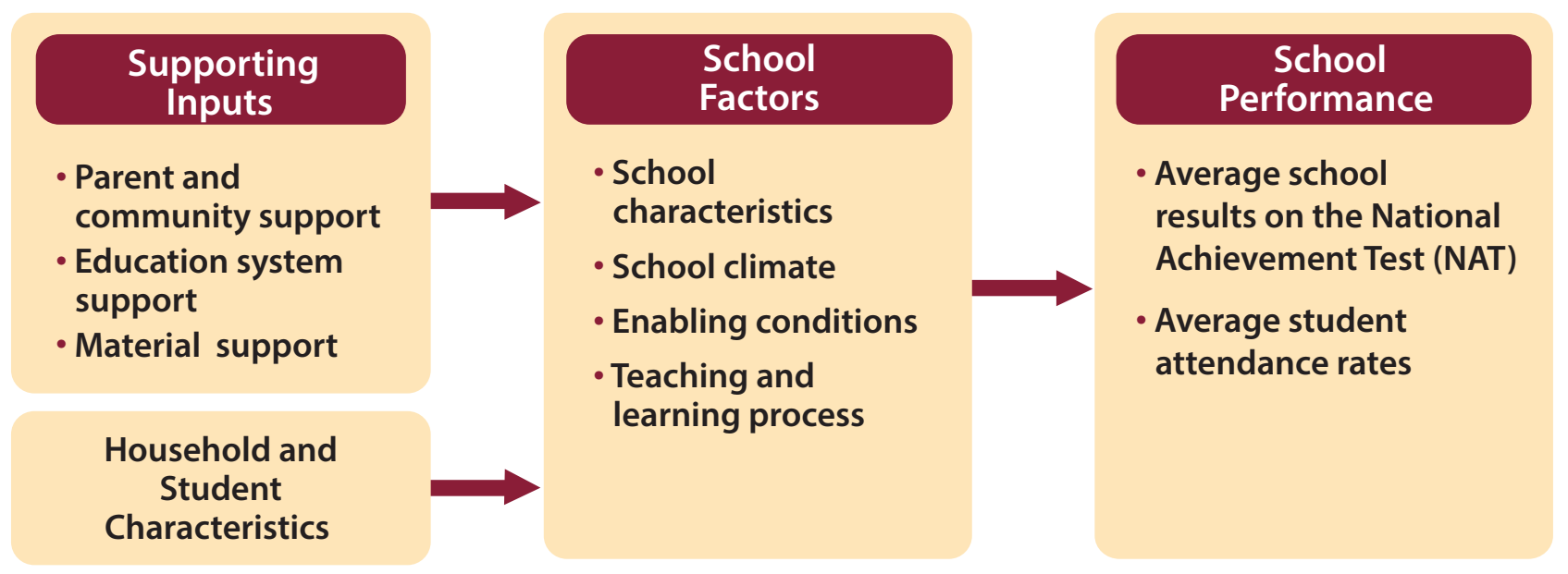

history, and the investments made by their household in their education influence the performance of the schools that they attend. The level and type of financial and academic support that children receive outside of school depends crucially on the socioeconomic status of their parents.

2. School Factors. How the school itself is organized to provide learning opportunities for its students critically affects their academic achievement. This includes the motivation, attitudes, and competency of teachers, the quality of the teaching and learning process, the amount of learning time that the school provides, and the systems used for student assessment. The quality of school leadership is another important school-level factor that affects the school's performance.

3. Supporting Inputs. In order for schools to perform well, they need the appropriate inputs and resources to operate effectively. This includes sufficient classrooms of good quality to teach children in groups that are not too large and the availability of other education inputs such as textbooks and discretionary funds to support school improvement plans. They also need support from parents, the community, and, in the case of the Philippines, local school boards (LSBs). Schools in the Philippines also depend on the DepEd division and district offices for support on administration, financing and teaching.
The PETS-QSDS study team compiled a large number of variables from the PETS-QSDS survey data for each of the categories in the framework. They then reduced this list to a smaller group that they judged to be the best measures of each particular factor and that had been identified as important in the other policy notes in the PETS-QSDS series (Table 2).

This note explores the association between these important explanatory factors and school performance in a number of ways. First, the note compares differences in these factors between high-performing and low-performing schools. Schools with scores in the top 20 percent on the NAT were classified as high performers whereas schools with scores in the bottom 20 percent were classified as low performers. A similar definition was used to rank school performance in terms of student attendance rates. Second, the note explores the extent to which the factors in Table 2 explain differences in efficiency. ${ }^{5}$ Finally, it looks directly at the relationship between the explanatory factors and school performance using a multivariate regression approach. ${ }^{6}$

While this exercise highlighted some important associations, the approach had a number of limitations. Given the crosssectional nature of the data and the lack of any strategy for addressing selection bias, it was not possible to establish causality between the explanatory factors and the selected performance measures. School performance is also not only determined by the current status of household 
Table 2: Characteristics Used to Measure the Key Aspects of the Performance Framework

\begin{tabular}{|c|c|c|}
\hline Household Characteristics & School Factors & Supporting Inputs \\
\hline $\begin{array}{l}\text { Average per capita } \\
\text { household consumption }\end{array}$ & $\begin{array}{l}\text { Material support: Revenue per student } \\
\text { by source, MOOE funds received per } \\
\text { student, textbooks per student, adequacy } \\
\text { of classrooms, days of teacher training, } \\
\text { infrastructure and condition of classrooms. } \\
\text { Parent and community support: Frequency } \\
\text { of meetings of the school governing council } \\
\text { and the PTA, parental participation in school } \\
\text { decision-making, transparency board } \\
\text { available in a public space. } \\
\text { Effective support from education system: } \\
\text { frequency of supervision visits from the } \\
\text { DepEd Division office. }\end{array}$ & $\begin{array}{l}\text { School characteristics: the school's location, } \\
\text { enrollment rates, school feeding program, } \\
\text { the principal's years of experience, time spent } \\
\text { by the principal in the classroom observing } \\
\text { classes, the school's SBM self-assessment } \\
\text { level, whether the principal develops a school } \\
\text { plan for professional development. } \\
\text { Capable teaching force: teacher } \\
\text { competency test scores, teacher attendance, } \\
\text { teacher qualifications. } \\
\text { Teacher learning process: the percentage } \\
\text { of parents who receive a report card for their } \\
\text { child's performance, proportion of students } \\
\text { that report doing homework. }\end{array}$ \\
\hline
\end{tabular}

characteristics, school factors, and supporting inputs but also by how those factors have evolved over time. It is unlikely that the current state of the education system is a good reflection of its past, given the large amounts of money that have recently been invested. The lack of any information on the status of key indicators in earlier years will affect the overall results. Also, the analysis focused on performance at the school level, which did not take into account any possible variations between different classes and teachers within the schools. These issues were compounded by the small sample of teachers and households for each school that was used in the study, which may have introduced some measurement error. In addition, while the PETS-QSDS survey collected information on many important areas related to school performance, there were some important gaps. For example, very little information was available on the amount of real learning time available in schools or on the quality of classroom teaching. This may have led to biased estimates of the importance of the measured factors where they were correlated with omitted variables. It is important to keep these limitations in mind when interpreting the results presented in this note.

\section{Characteristics of School Performance}

\section{Household Factors}

Students who attend higher performing schools tended to be from slightly better-off families than those who attended low-performing schools, but these differences were not large and were rarely statistically significant. For example, annual per capita household consumption was approximately PHP 16,300 for students in those elementary schools ranked in the top 20 percent for student attendance compared with PHP 14,700 for students in schools ranked in the bottom 20 percent. Schools that had better average NAT scores also tended to include students who were slightly wealthier than average, but again the differences were relatively small and not statistically significant. 


\section{School Factors}

It is clear from looking at differences between highperforming and low-performing schools that schools in urbanized areas tended to perform less well than those in municipalities. For example, a higher proportion of poorly performing elementary and high schools were located in highly urbanized cities than in municipalities, whereas good performing schools tended to be located more frequently in municipalities (Figure 2). ${ }^{8}$ Related to this finding, schools with higher enrollments also tended to have lower levels of student achievement than smaller schools. ${ }^{9}$ For example, the high schools ranked in the top 20 percent in terms of NAT scores had an average of 446 students compared with an average of 833 students in schools in the bottom 20 percent.

More elementary schools with high student attendance rates had school feeding programs than schools with the lowest rates of student attendance. For example, 25 percent of elementary schools in the bottom quintile of student attendance had a school feeding program compared with 71 percent of schools in the top quintile of student attendance. This suggests that school feeding programs may provide families with an incentive to send their children to school.

The quality of school leadership also appears to be associated with better school performance. Indicators associated with school principals and the processes for which they are responsible tended to be better for high-performing schools (Table 3). High-performing schools tended to have principals who spent more time in classrooms and who were more likely to have developed teacher professional development plans. However, these differences were not generally statistically significant.

Simple comparisons of high-performing and low-performing schools did not reveal any statistically significant differences in the capacity of the teaching force..$^{10}$ The PETS-QSDS study tested a sample of Grade 6 and Grade 10 teachers in all sampled schools. However, there was no clear or consistent pattern in the relationship between the performance ranking of the sampled teachers in a school and the performance ranking of the school itself.

\section{Supporting Inputs}

Simple comparisons between high-performing and low performing schools yielded some differences in terms of the quality of school infrastructure. Only 6 percent of elementary schools in the highest quintile in terms of NAT scores operated multiple shifts compared to 9 percent of schools in the bottom quintile. However, a similar pattern was not observed for high schools, which may reflect the differences in shift patterns between elementary and high

\section{Figure 2: Lower Performing Schools Tend to be Bigger and Are More Likely to Be Located in Highly Urbanized Cities}

Average student enrollment and location for schools ranked in the bottom and top 20 percent of NAT scores, 2014

Percentage of schools in HUCs

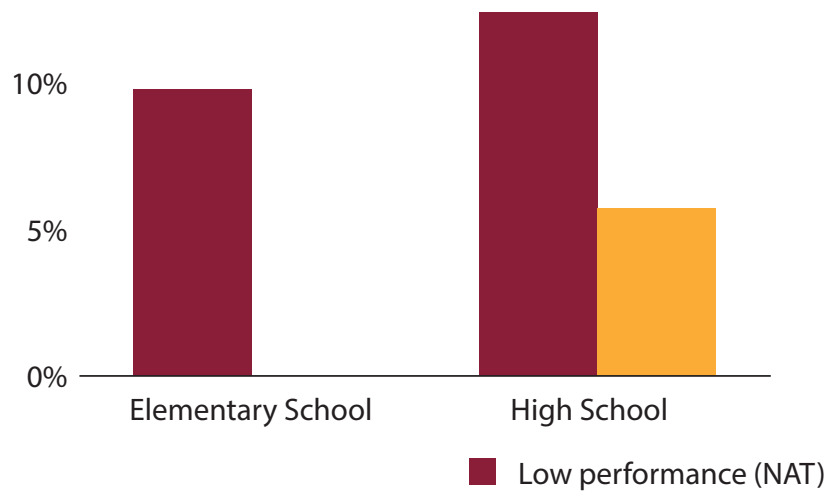

1,000

Total school enrollment

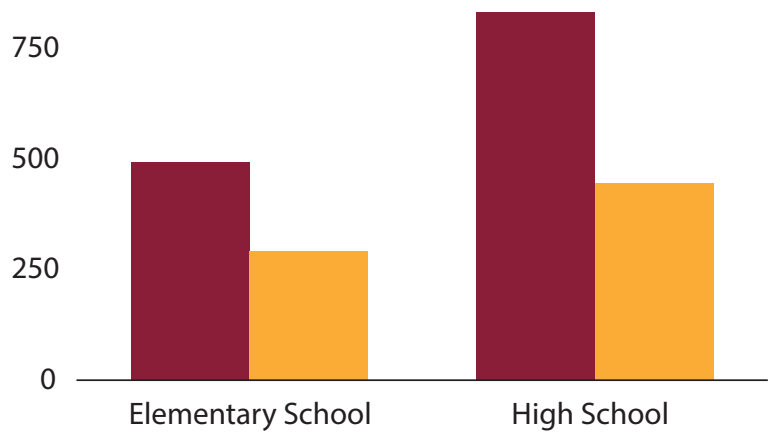

High performance (NAT)

Source: PETS-QSDS national survey - school-level data. 
Table 3: School Performance and Leadership Indicators

\begin{tabular}{|c|c|c|c|c|c|c|c|c|}
\hline & \multicolumn{4}{|c|}{ Elementary Schools } & \multicolumn{4}{|c|}{ High Schools } \\
\hline & \multicolumn{2}{|c|}{ Attendance } & \multicolumn{2}{|c|}{ NAT scores } & \multicolumn{2}{|c|}{ Attendance } & \multicolumn{2}{|c|}{ NAT scores } \\
\hline & $\begin{array}{l}\text { Low } \\
\text { perf. }\end{array}$ & $\begin{array}{l}\text { High } \\
\text { perf. }\end{array}$ & $\begin{array}{l}\text { Low } \\
\text { perf. }\end{array}$ & $\begin{array}{l}\text { High } \\
\text { perf. }\end{array}$ & $\begin{array}{l}\text { Low } \\
\text { perf. }\end{array}$ & $\begin{array}{l}\text { High } \\
\text { perf. }\end{array}$ & $\begin{array}{l}\text { Low } \\
\text { perf. }\end{array}$ & $\begin{array}{l}\text { High } \\
\text { perf. }\end{array}$ \\
\hline $\begin{array}{l}\text { Number of hours principal } \\
\text { observes classes }\end{array}$ & 2.6 & 7.1 & 2.9 & 4.8 & 3.7 & 5.5 & 3.8 & 5.8 \\
\hline $\begin{array}{l}\text { Principal's number of years } \\
\text { of experience }\end{array}$ & 2.6 & 3.3 & 3.7 & 3.0 & 2.7 & 3.6 & 2.9 & 2.7 \\
\hline $\begin{array}{l}\text { School plan for teacher } \\
\text { professional development exists }\end{array}$ & 54.0 & 97.3 & 61.3 & 84.5 & 53.5 & 67.8 & 72.3 & 82.5 \\
\hline SBM self-assessment level & 1.4 & 1.6 & 1.5 & 1.4 & 1.5 & 1.8 & 1.6 & 1.7 \\
\hline
\end{tabular}

Source: PETS-QSDS national survey - school level.

Notes: Hours of observation are over a typical school week. School based management self-assessment is based on a three point scale (Level 1 = developing, Level 2 = maturing, and Level 3 = advanced).

schools. For example, it is more common in elementary schools to operate independent shifts, which may reduce the amount of instructional time received by each student. Subject-based teaching is implemented in high schools, so shifting is more likely to be associated with the organization of timetables and to have less impact on each student's learning time.

The availability of key facilities such as electricity and water supply and the quality of classrooms (their state of repair) also tended to be positively related to school performance. Thus, schools with better facilities tended to have better attendance and NAT scores, although this was significant only for elementary schools and in the case of attendance for high schools.

Student-teacher ratios also tended to be lower in schools that had better NAT scores although the differences were not very large. High schools that ranked in the top quintile of NAT scores had an average student-teacher ratio of 24:1 compared with an average of 26:1 in schools in the bottom quintile of NAT scores. In contrast, schools with low student attendance tended to have lower student-teacher ratios than schools with better student attendance. This may have been a function, in part, of differences in attendance between rural and urban areas, which also had large differences in studentteacher ratios. School attendance tended to be better in municipal schools, which also tended to have lower student numbers and lower student-teacher ratios.

There is some evidence that better performing schools had greater support from the local community and from the education system generally. Participation rates in parentteacher associations (PTAs) were much higher in better performing schools (Figure 3). A similar pattern was also found between school performance and the frequency of its school governing council meetings. However, differences between high-performing and low-performing schools in terms of SGC meetings were rarely statistically significant. Whether DepEd division offices provide schools with their full allocations for maintenance and other operating expenses (MOOE) is a good measure of the amount of funds over which schools have discretion to spend on their own improvement plans and a good indicator of the support that division offices provide to schools. If division offices do not fulfill their obligation to download all of a school's allocation of MOOE funds, then it may not be providing much other support. Simple comparisons did show that better performing schools were more likely to be located in divisions that downloaded their full MOOE allocations (Figure 3). 


\section{Figure 3: Schools with Higher NAT Scores Have More Parental Participation and Receive More of their Funding from DepEd Division Offices}

Average proportion of parents who are members of the PTA and percentage of schools that do not receive all of their MOOE funds from the DepEd division offices

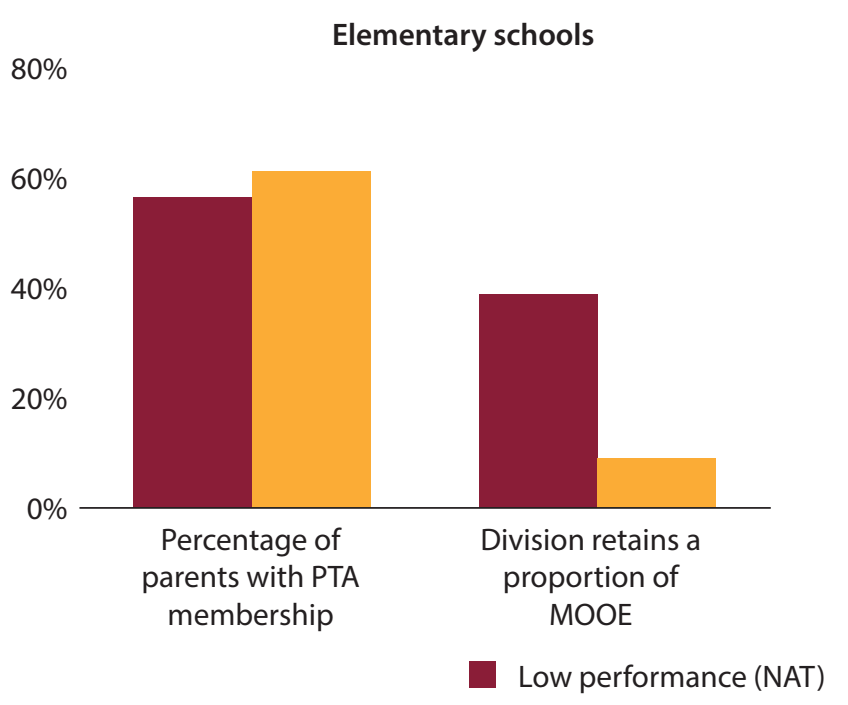

Source: PETS-QSDS national survey - school-level data.

There did not appear to be a consistent pattern between schools' levels of revenue and their performance. As part of the framework outlined in the previous section, the team used a number of different measures of annual school revenue to explore differences in school performance. They found no consistent association between revenue and performance. In some cases, schools with lower than average revenues per student had better than average performance indicators. These results point to the weak relationship between spending and school performance and the likelihood that other factors (such as how well funds are managed at the school level) influence the efficiency of school spending.

\section{Efficiency of School Spending}

The previous section showed that schools vary considerably in their ability to translate their revenues into positive education outcomes. The PETS-QSDS study collected detailed information on all sources of school revenue from a nationally representative sample of elementary and high schools. On the whole, the higher the annual level of school funding, the better the school's performance, but this relationship was not very strong (Figure 4 ).

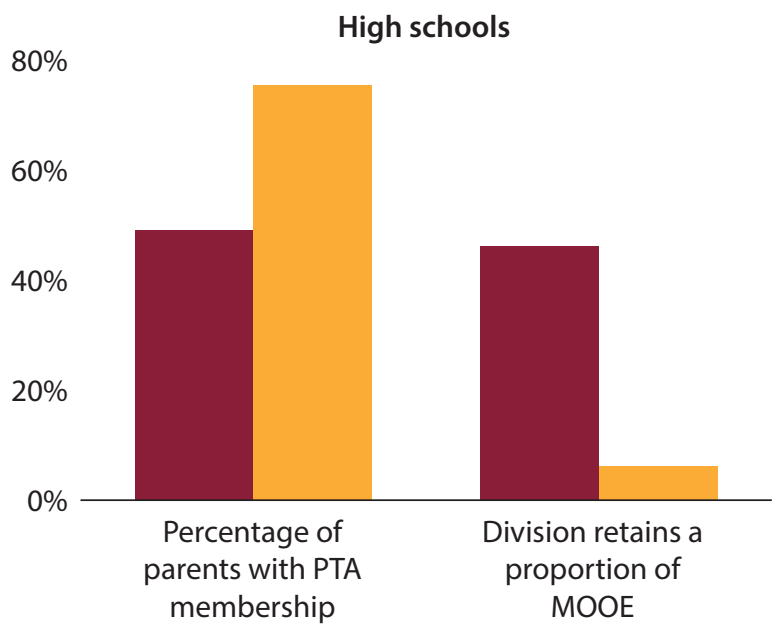

High performance (NAT)
Some schools appeared to use their resources more effectively than others to improve student learning outcomes. In Figure 4, each panel is divided into quadrants that show where schools fell in relation to the average achievement score and average annual school spending per student. Schools in quadrant A were the most efficient as they spent less than the average school every year but had better than average outcomes. The schools in quadrant $B$ were the least efficient, with levels of spending that were higher than average but with below average performance. Levels of efficiency varied greatly between schools that had similar levels of either performance or spending.

The team's estimates of school efficiency suggest that education outcomes could be significantly improved without the need for any additional funding. Using data envelopment analysis (DEA), the team estimated efficiency scores for school performance (as measured by attendance and NAT scores) to measure the relative effectiveness of schools in transforming their annual per-student spending into better education outcomes. ${ }^{12}$ The results revealed considerable variation among schools in their ability to translate resources into better education outcomes. The estimated efficiency scores can be interpreted as the percentage increase in output that a school could achieve with its current 
Figure 4: There Are Large Differences in Performance Even Among Schools with Similar Levels of Funding National achievement test scores and school annual revenue per student, 2013-14
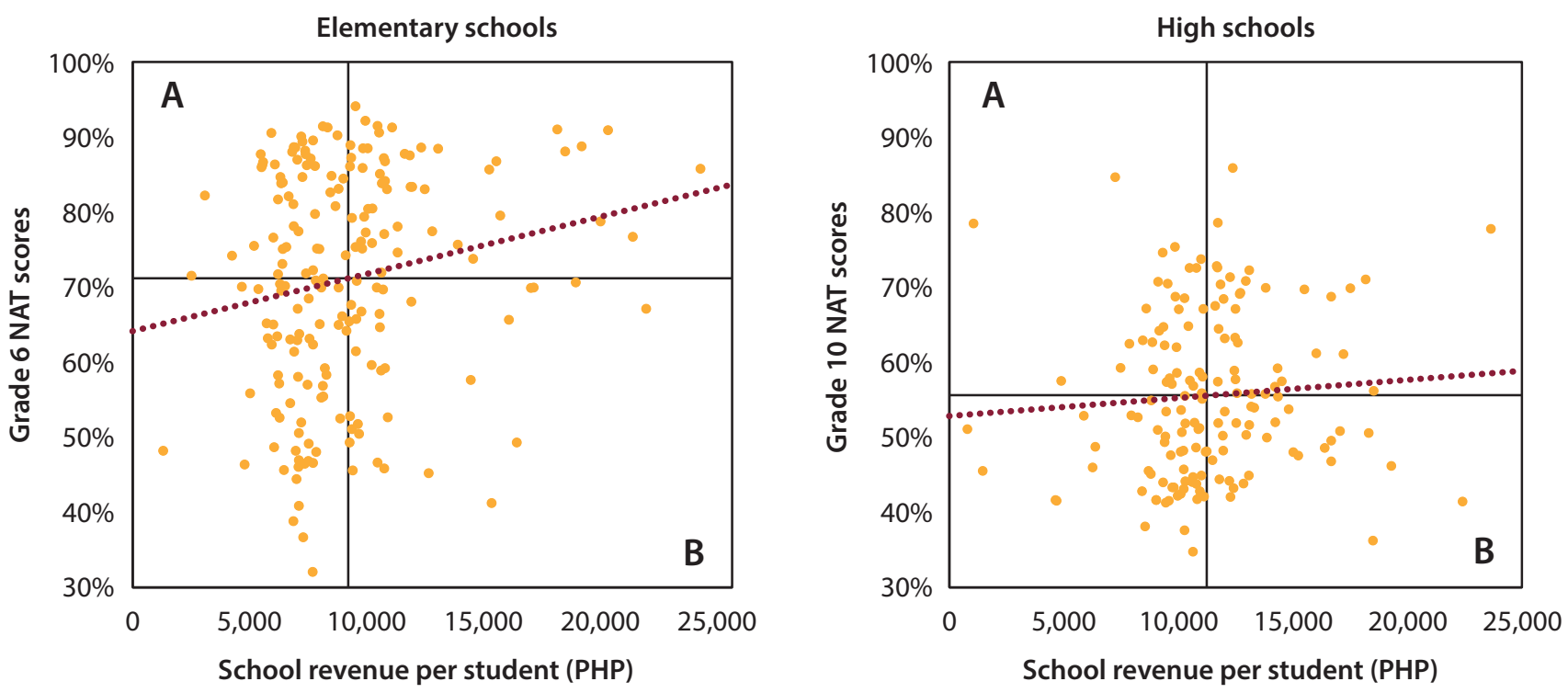

Source: PETS-QSDS national survey - school-level data.

Note: The horizontal line in the figure represents the average school NAT score while the vertical line marks the average school revenue per student.

resources. The estimates revealed that school efficiency varied considerably and there is considerable potential for improving education outcomes if schools were able to use their resources more effectively (Figure 5). For example, the average efficiency score for elementary school NAT results was 77 percent. This suggests that Grade 6 NAT scores could be improved by around 23 percent if all schools were able to use their resources as efficiently as the most efficient schools in the system (Figure 5). While not too much should be read into the exact magnitude of these estimated improvements,

Figure 5: Increasing School Efficiency Can Improve Education Outcomes

Average estimated efficiency scores and standard deviations for school attendance and NAT results in elementary and high schools

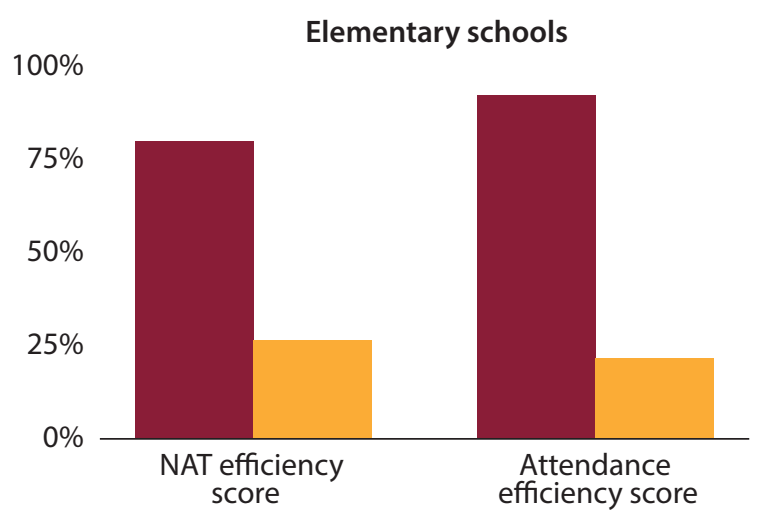

Source: PETS-QSDS national survey - school-level data.

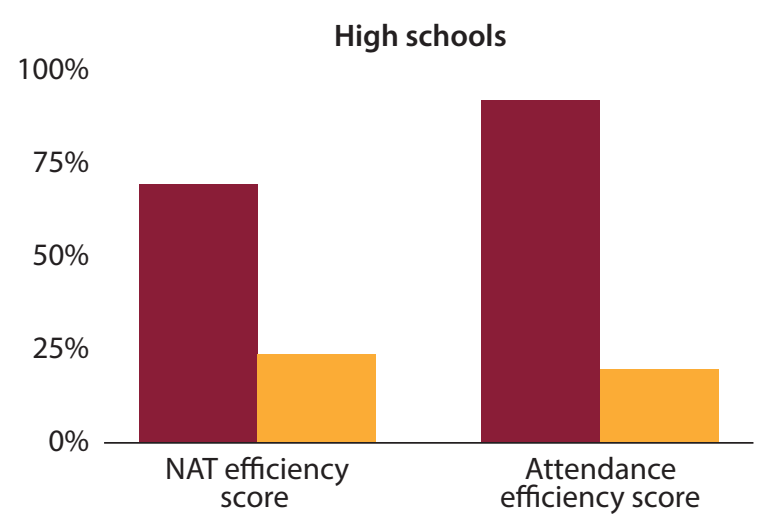

Standard deviation

Note: The efficiency score shows the average efficiency of schools relative to the most efficient schools in the system. Efficiency scores were estimated using data envelopment analysis. School attendance and NAT scores were the output measures used, and the input measure was total annual school revenue per student. 
this exercise does demonstrate the potential benefits that might accrue from more effective resource use.

Schools' levels of efficiency are affected by some factors that they can influence and some that they cannot, such as the characteristics of the communities and households to which their students belong. The team used regression analysis to explore the associations between the estimated efficiency scores and the explanatory factors in the framework outlined in Figure $1 .^{13}$ The results of this second stage analysis highlighted some of the same explanatory factors that were revealed in the comparison of high-performing and lowperforming schools in the previous section.

Schools in urban areas tended to be less efficient than rural schools in using their resources to deliver better NAT scores. For example, elementary schools located in cities were less efficient than schools in municipalities or in highly urbanized cities. Larger schools, and particularly high schools, also tended to be less efficient even after controlling for school location. This is likely to reflect the difficulties involved in the management and organization of larger schools. However, the differences in efficiency between schools in different locations and of different sizes were not always statistically significant.

While school leadership factors were associated with greater efficiency, the results were not always statistically significant. Similar to the high and low performance comparisons, schools with more experienced principals who spent more time observing teaching and who developed plans for teacher professional development tended to be more efficient. However, these factors were rarely statistically significant on their own.

Teacher characteristics also did not appear to be associated with levels of school efficiency. A number of factors such as qualifications and test results were included to understand whether teacher characteristics were associated with efficiency. ${ }^{14}$ However, these factors did not appear to play much of a role in determining the efficiency of either elementary or high schools in terms of either NAT scores or attendance. Meanwhile, better teacher performance on subject matter tests, while statistically significant for efficiency in high schools as measured by attendance, appeared to actually reduce school efficiency in some cases.

Differences in the sources of school funding did not appear to be strongly associated with school efficiency. It might have been expected that schools with more discretionary funding would be more efficient because they were able to use these funds to more effectively address their needs. However, the results did not show this. Frequently, the relationship between the amount of discretionary funds and the source of those funds was not statistically significant. And in some cases, the size of discretionary funds received by a school appeared to be associated with lower levels of school efficiency.

There is some evidence that the availability of key school facilities and the condition of the existing stock of classrooms affected efficiency. For example, better learning environments, measured by an index of classroom conditions such as the state of repair, were positively associated with school efficiency. However, this association was only statistically significant for elementary school NAT scores and high school attendance rates.

Factors associated with greater parental and community participation tended to be related to better efficiency, but the results were rarely statistically significant. More frequent PTA and SGC meetings and greater parental participation were associated with greater efficiency in terms of NAT scores. However, only the frequency of SGC meetings in elementary schools was statistically significant. The frequency of PTA meetings and the proportion of parents participating in these meetings were associated with lower efficiency as measured by attendance. It is unclear what was driving these results.

Schools located in divisions where the DepEd offices provided schools with their full MOOE allocations tended to be more efficient. To the extent that this factor was a proxy for more effective and transparent division-level management, it highlights the important role played by education system governance in increasing school efficiency. 


\section{Determinants of School Performance}

The team tried taking a third approach to analyzing school performance by extending the simple bivariate approach reported in Section 2 to some simple multivariate regression analysis. School performance in terms of attendance and NAT scores was regressed against the set of explanatory variables outlined in Table 2 . The results of this final approach were very similar to the efficiency score results and highlighted similar associations between explanatory factors, levels of school attendance, and national examination scores..$^{15}$

\section{Conclusion}

This policy note has shown that many schools in the Philippines are not using the resources at their disposal in the most efficient way to improve their performance. The analysis has found that many schools could improve their performance quite substantially by using their existing level of resources more effectively.

Understanding the factors that underlie existing levels of efficiency using the information from the PETS-QSDS survey was more challenging. The cross-sectoral nature of the data and the relatively small sample sizes made it difficult to identify the main factors that could drive improvements in efficiency. And while the study team made considerable efforts to collect information on the broadest possible set of explanatory factors, there were still significant gaps. In particular, the lack of any information on the teaching and learning process within classrooms may have affected the validity of the results.

Notwithstanding these limitations, the note does provide some tentative evidence that participation by parents and community members in school affairs can influence the efficiency with which schools use their resources and overall school performance. The frequency of SGC meetings had a positive and sometimes statistically significant association with school efficiency and performance in the multivariate analysis. However, factors associated with greater participation and support from PTAs tended to be negatively related to efficiency in school outcomes. Further research is needed to understand the factors underlying these results but strengthening the relationships between schools and their local communities, particularly through the institutions (such as the SGCs) and processes (such as the school improvement plans) related to the implementation of school-based management could be beneficial.

The note has shown that school leadership may be a key explanatory factor for differences in performance among schools. Schools where the principals observed classroom teaching regularly and developed professional development plans for their teaching force were often more efficient and had better performance indicators than schools where this did not happen.

There is also some tentative evidence to suggest that schools within the jurisdiction of the better managed DepEd divisions tended to perform better themselves. Division offices are obligated by DepEd regulations to transfer all MOOE funds to schools, and it can be assumed that those that do not do so are less well managed. The evidence reported in this note has shown that schools that fall within the jurisdiction of those divisions also tended to be inefficient and to perform poorly compared to schools in better managed divisions.

It is surprising that teacher characteristics were not associated consistently with overall school performance. The PETS-QSDS study included a detailed assessment of teacher's subject knowledge, and the results were not associated strongly with school performance. It is possible that this was because only a small proportion of each school's teachers took the test or it may be that levels of teacher competency are universally low in the Philippines and do not vary significantly across schools.

Finally, the note's findings suggest that larger schools in urban areas are inefficient and perform less well than smaller schools in municipalities. Other policy notes based on the PETS-QSDS data have highlighted the fact that large schools in urban areas are under significant amounts of stress. The results presented here tend to confirm that these schools are also less efficient. Schools in highly urbanized cities tended to have higher than average levels of funding but lower than average levels of performance. Given that the socioeconomic status of children in these schools did not appear to be significantly different from the status of those in other public schools, this suggests that the inefficiency stemmed from the challenges associated with managing very large schools and the very intensive use of limited school infrastructure. 


\section{Endnotes}

1 A detailed description of the methodology and the full results are available in World Bank (2016). "Understanding the Drivers of School Efficiency/Performance in the Philippines." Washington, D.C.

2 Highly urbanized cities are cities with populations of more than 200,000 and with average revenues of at least PHP 50 million in 1991 prices. Other cities are defined as cities that do not meet the criteria to be classified as highly urbanized. Municipalities are administrative units for all other areas in the Philippines.

3 Other performance indicators such as a school's dropout and completion rate were also analyzed, but these school-reported rates did not seem to be very accurate.

4 See for example, Glewwe, P.W., E. A. Hanushek, S.D. Humpage, and R. Ravina (2011). "School Resources and Educational Outcomes in Developing Countries: A Review of the Literature from 1990 to 2010" NBER Working Paper No. 17554, National Bureau of Economic Research, Cambridge, MA and Heneveld, W. and H. Craig (1996) "Schools Count: World Bank Project Designs and the Quality of African Primary Education." World Bank, Washington, D.C.

5 Data envelopment analysis was used to explore school efficiency. See, for example, Coelli, T. J., Rao, D. S. P., O'Donnell, C. J., and Battese, G. E. (2005) An Introduction to Efficiency and Productivity Analysis, Springer Science \& Business Media, New York and Herrera, S. and G. Pang (2005) "Efficiency of Public Spending in Developing Countries: An Efficiency Frontier Approach" Policy Research Working Paper. No. 3645, World Bank, Washington, D.C.

6 A hierarchical modelling (HLM) approach was used when appropriate to account for the grouping of schools in the PETS-QSDS study under DepEd division and regional offices.

7 Average elementary (high) school attendance for the bottom 20 percent of schools was 71 (75) percent and 98 (98) percent for the top performing 20 percent of schools. Average elementary (high) school national achievement test score for the bottom 20 percent of schools was 52 (42) percent and 90 (75) percent for the top performing 20 percent of schools. The full results are available in a set of additional tables accompanying the main PETS-QSDS report.
8 The proportion of highly urbanized schools in the poor performing quintile was much higher than the proportion of highly urbanized schools in the population as a whole.

9 Differences were statistically significant at the 1 percent level.

10 Differences in teacher attendance were also explored but no statistically significant differences were found between high and low performing schools.

11 A full description of the information collected and the approach that the PETS-QSDS study took to calculating total school revenue and expenditure is included in additional annexes and tables accompanying the main PETS-QSDS report.

12 Efficiency scores were estimated for each of the performance measures. An output-oriented approach that assumes variable returns to scale was used to estimate efficiency scores. Full details of the approach and results are available in World Bank (2016) "Understanding the Drivers of School Efficiency/Performance in the Philippines."Washington, D.C.

13 Efficiency scores cannot exceed 100 percent so a Tobit model was used to estimate associations between efficiency scores and explanatory factors.

14 Teacher attendance did not have a significant impact on efficiency scores. In the final analysis teacher attendance was dropped because it allowed more school observations to be used.

15 The full results are not presented here but are included in additional annexes and tables accompanying the main PETS-QSDS report. 


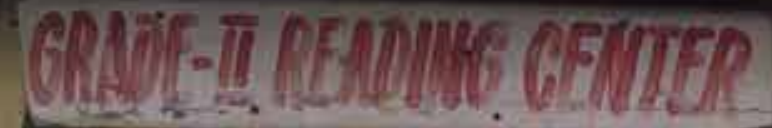
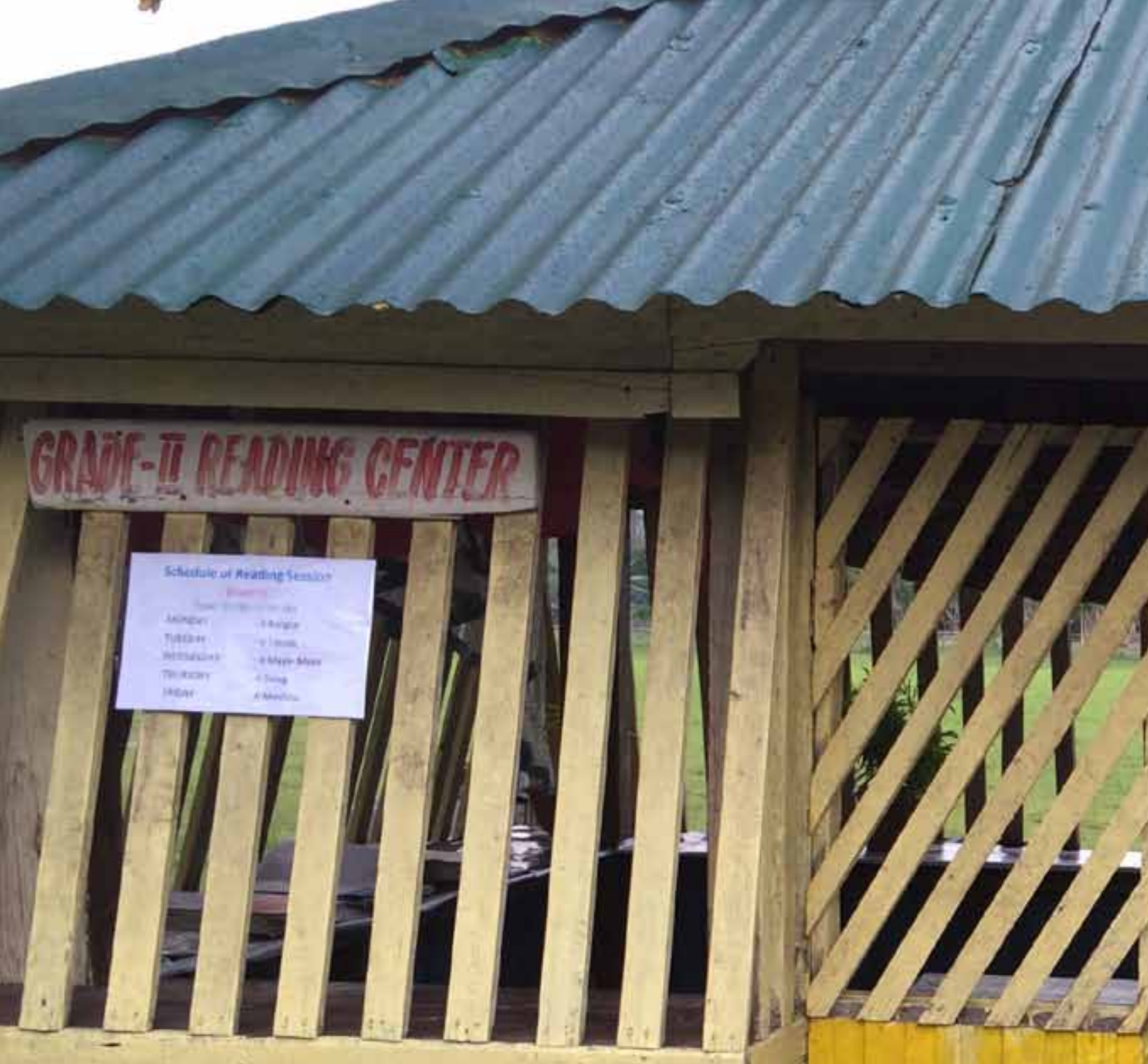

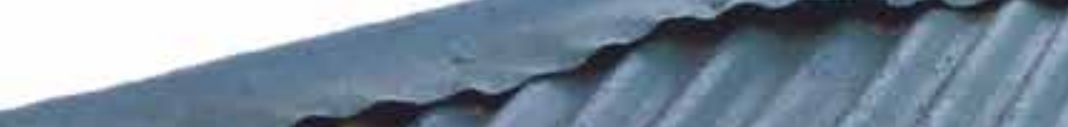




\section{Conclusions and Policy Directions}

The study has shown that, despite a renewed focus on basic education by the Philippines government, further increases in both capital and recurrent public spending are needed. The study has shown that there have been significant improvements in the learning environment that Filipino children experience every day but more still needs to be done. Many schools, particularly in urban areas, have insufficient and poor quality facilities and a shortage of teachers. Operational funding still falls short of the amounts that schools need to pay bills, undertake basic repairs, and provide the day-to-day materials their students need. And there is rarely anything left over to fund schoollevel initiatives to improve student learning achievement. The study has also highlighted the lack of good quality opportunities for teachers to improve their skills. Addressing these challenges will require further investments in the education sector.

It also appears that the bulk of this funding will need to be provided by the national government. The study has shown that local government funding, except in the National Capital Region, is very small and that funding from other sources, including parent-teacher associations, is also negligible. Detailed estimates suggest that over 90 percent of school funding comes from the national government. Unless there are significant policy changes in the future, this means that increases in spending will need to be found from the national government budget, either through greater revenue-raising efforts and/or by increasing the share of basic education in the overall government budget from its existing level of 15 percent.

However, the study also highlights some limitations in the existing systems that manage public basic education funds. Allocation systems have managed to target funds reasonably well, but there are still many examples of needy schools missing out on additional support while other, better-equipped schools continue to receive additional support. Moreover, delays in identifying school needs and in the budget allocation process have meant that a significant amount of funding goes unspent or has to be spent quickly or at times that disrupt school operations. Even when schools benefit from improvement projects or resources, the study has also shown that they are frequently unhappy about the quality of the resources supplied.

In the absence of efforts to address these limitations, further increases in funding are likely to have only limited impact on the challenges faced by the education sector. Moreover, the successful introduction of the senior high school program in 2016 will be jeopardized if systems managing the allocation and use of public funds are not made more effective.

Through a series of policy notes, this report has identified some of the key challenges and potential policy responses in key areas of resource management. Instead of repeating these recommendations in full, this section draws together some common policy directions that have emerged from the findings of the study as a whole.

\section{Improve Allocation Mechanisms Through Better Planning}

The report makes clear that the systems currently used to allocate resources to schools could be strengthened by improved planning. While these allocation systems generally target schools with greater need, they could be improved further. For example, school infrastructure improvement projects are planned on an annual basis and project lists are frequently finalized late. This shortens the time available to implement them and compromises the ability of DepEd and DPWH offices to monitor projects adequately. Developing a two- or three-year plan that would forecast need and list all school improvement projects in each DepEd division would reduce the work involved in putting together the annual project list and accelerate the transmission of funds to the responsible implementing offices. It would also give implementing offices time to do some advance planning and thus avoid some of the difficulties associated with inadequate funding and site availability that were commonly cited as reasons for implementation delays. A similar approach could be adopted for teachers and the planning of other important school inputs. 
More input from division offices and schools in planning could also improve allocation decisions. Funding decisions are largely taken at the central level and frequently do not take into account local conditions. For example, in the PETSQSDS study, a considerable number of school principals and school division superintendents (SDSs) felt that existing procedures for allocating new teachers was suboptimal, and some SDSs felt that they had not been adequately consulted. Similarly, schools had only limited input into the planning and implementation of infrastructure projects. This contributes to an impression that division offices and schools have limited influence on education decisionmaking. Strengthening the processes for consulting schools and division offices about the decisions that affect them and making information publicly available on the decisions that are made would improve planning.

\section{Give Schools Greater Authority and Simplify Reporting Requirements}

Increasing the role played by schools and local DepEd offices in deciding on the use of education funding may also improve the quality of public education spending. The study has highlighted the limited authority that schools have over the implementation of school infrastructure projects. It has also shown the weak links between the individual professional development needs of teachers and the types of in-service training offered. Providing schools and division offices with more authority during the implementation of both infrastructure projects and teacher training could yield significant benefits. For example, giving school principals the authority alongside DepEd and DPWH officials for certifying that infrastructure projects have been satisfactorily completed might improve their quality. School principals in the Philippines have taken on roles of this kind in the past and with appropriate training could become a major driving force in improving the quality of school infrastructure projects.

Over recent years, schools have been given ever increasing amounts of discretion over how to spend their funding. This has primarily been done to support school-based management reforms by providing schools with the funds to implement their own school improvement plans. Evidence from the Philippines and other countries supports the idea that giving schools more autonomy can improve education outcomes.
However, the study found that the existing system for managing school operational funding is too onerous on school principals and that there is a risk that the benefits from reforms of this kind will not materialize. Simplifying the existing requirements for the management of these funds would reduce the significant burden that this currently puts on schools. It would also give school principals more time to focus on providing academic leadership in their schools, which is their primary responsibility. One approach that has been adopted in other countries would be to treat operational funds as a grant. For example, this is the case in Indonesia, where these funds have much less onerous reporting requirements than required by the usual government budget and implementation systems. Schools use simplified reporting templates to report on their use of the funds and submit these forms to district offices (the equivalent of division offices in the Philippines) every quarter. Developing a similar system adjusted to take account of the specific context of the Philippines could reduce the burden that using these funds currently puts on schools.

However, if division offices, schools, and even local communities are to get more involved in decisions about how education resources are allocated and used, these spending decisions need to be more transparent. Across all of the spending areas that the PETS-QSDS survey covered, information on the transfer and use of funds was frequently missing, inaccessible, or in formats that were not easy to understand. Even where information was available, it frequently was not consistent between different administrative levels. For example, there was a discrepancy of about 8 percent between the funds that division offices reported having downloaded to schools for operational expenses and the amounts that the schools reported receiving. In most cases, it was not possible for the study team to judge accurately the extent to which these discrepancies arose from misappropriation of funding and/or incomplete reporting.

\section{Improve Transparency of Fund Allocation and Resource Use}

Local government funding was an area that was particularly concerning. The study estimated that only around 60 percent of local government funding reached schools directly. However, records on which schools received funds and what the funds were provided for were very weak. For 
example, 24 percent of elementary schools to which local governments claimed to have provided in-kind support for salaries denied ever having received this support. In contrast, LGUs themselves reported providing support to only approximately 40 percent of all of the elementary schools that reported having received support from their LGU. Information on the 40 percent of funds that did not go directly to schools was even less reliable.

Developing simple reporting formats in which to record the funds allocated to divisions and schools and how these institutions use these funds would go a long way to increasing transparency. A recent initiative by the Department of the Interior and Local Government (DILG) to encourage greater accountability and transparency is one useful example of what could be done. The DILG awards the Seal of Good Local Governance to local governments that perform well in several areas as well as providing them with additional performance-based funds. This scheme has given LGUs a strong incentive to increase transparency and to improve their use of the Special Education Funds. While the awarding of the Seal is already conditional on whether the annual plan of local school boards is aligned with the plans of the schools themselves, it could also be used to encourage better reporting. For example, the category of "good financial housekeeping" could be expanded to include more detailed reporting, a requirement to publish details of how SEF funds are used, and a requirement to set targets for the proportion of funds that should reach schools.

Introducing and widely disseminating a set of standards for elementary and high schools would also increase transparency and encourage greater accountability for the use of public funds. DepEd has a number of different guidelines that set standards for elementary and high schools, which the PETS-QSDS study used to assess the adequacy of existing resource allocations. However, these guidelines are scattered across different DepEd orders and regulations, and many stakeholders are unaware of their existence.

Setting basic standards for basic education provision and ensuring that information about these standards is widely disseminated would enable parents and other stakeholders to judge the fairness of allocations and to hold the government more accountable for the provision of key education inputs like classrooms and teachers. It would also enable schools and other stakeholders to seek redress for unfair allocations or poor project implementation. Policymakers should explore the feasibility of introducing a formal grievance system that schools could use to express dissatisfaction with decisions related to all school funding, including school infrastructure projects, as this would help to make government education spending more effective and improve education services.

\section{Strengthen the Role of School Governing Councils and Parent Teacher Associations}

Parents and other community members can also play a role in improving school decision-making and overseeing how schools use public funds and resources. However, the study found that, while SGCs had been established in nearly all schools, their role was fairly limited. Giving SGCs greater responsibility for monitoring how schools use public funds could usefully complement DepEd's own oversight role. For example, SGCs could become jointly responsible with the DepEd division offices for signing off on schools' fund utilization reports. However, if the SGCs are to take on an expanded role, then their members will need to receive more training and support from DepEd. Schools also need to encourage greater participation from parents and others in the SGC to strengthen their planning and oversight activities as the PETS-QSDS study found that most parents of students were unaware of the existence of SGCs or of their school's improvement plan.

A campaign to increase the awareness of parents and other education stakeholders of the role of SGCs and school improvement plans is needed. Recent evaluations in Indonesia and Pakistan have shown that it is possible to use old and new technologies to disseminate information. In Indonesia, an impact evaluation study showed that well-designed information campaigns using simple SMS text messages or school meetings can significantly increase public knowledge about schools' funding levels and responsibilities. It also found that this increased knowledge led to higher levels of parental participation in school affairs. In Pakistan, a similar strategy was used in a successful pilot program to disseminate information about school councils. The pilot set up a call center and used inbound and outbound calls, robot calls, and SMS text messages to 
transmit important information about the role played by school councils and their members. An assessment of the pilot showed that school council members' knowledge about their roles and responsibilities had increased, while school principals reported the councils had increased their participation in school affairs.

\section{Address Funding and Quality Inequalities}

The study has shown that there are substantial differences in the quality of education services across the Philippines. The factors associated with the distribution of quality vary, and there is no clear and consistent pattern. However, schools in highly urbanized areas, particularly high schools, tend to be very large and, despite getting higher levels of funding, tend to have more stressed learning environments and poorer levels of performance. The forthcoming extension of high school by two extra years is only going to add to the pressure that these schools face. A concerted effort by DepEd to address the specific issues of these schools by, for example, establishing a task force to develop a complete program of support for these schools could be an important step forward.

In some cases, the distribution of education quality reinforces existing inequalities. For example, poorer students tended to go to high schools that had teachers with more limited knowledge of their subject areas. They also tended to go to schools with lower levels of discretionary funding and those that reported having implemented only a minimal amount of school-based management.

The Philippines has a well-established funding formula for school operational funding that could be extended to include an equity component. This would be one way to reduce the large school-level funding inequalities highlighted in this report. In order to compensate those schools that receive lower funding from non-DepEd sources such as local governments, an equity component could be introduced in the allocation formula. This could go some way towards equalizing school funding and providing schools in poorer areas with the additional resources that they need to support the learning needs of marginalized students. Many other countries, like the United Kingdom, have introduced funding components of this kind. The allocations of MOOE funds could also be adjusted to take into account price differences between regions so that schools operating in high-cost areas such as remote locations where travel and transportation costs are high are able to purchase similar amounts of goods and services as those in lower-cost locations.

\section{Further Research}

The study has highlighted a number of areas where current and existing resources could be used more effectively. However, there are a number of important gaps that further research could clarify. In particular, the PETS-QSDS study was not able to look at individual student performance and some of its important determinants. In particular, the study did not explore the quality of classroom instruction and other important factors associated with the teaching and learning process. The quantitative approach used in the PETS-QSDS study is not best suited to exploring issues of this kind, but qualitative work would be an appropriate way to add to what is known about the quality of education in the Philippines and to help DepEd to develop appropriate pre-service and in-service training.

The PETS-QSDS study collected very detailed information on the status of education service delivery across the Philippines. The report analyzed a wide range of priority issues, but the data collected in the study could provide the basis of future research into an even wider range of issues. For example, further analysis of the teacher competency assessments would be useful to provide further insights into the professional development needs of teachers. The data could also be used to categorize schools for further research. For example, schools that have better school-community relationships could be identified in the PETS-QSDS data as a starting point for more detailed qualitative work to understand why these schools have been successful in this respect. Finally, the data represent an important baseline for tracking future progress in increasing the effectiveness of public education spending and improving student learning outcomes in the Philippines. 


\section{Annex 1}

This annex outlines the approach taken to designing the PETS-QSDS study and describes the survey instruments and sampling strategy used to collect nationally representative data to answer the study's main research questions. In addition, it documents the details of the fieldwork and data processing phases of the study's implementation. The process of designing the study began in November of 2013 and the survey was implemented from August to December of 2014.

\section{Developing the Study Design}

The PETS-QSDS study sought to answer four main research questions related to: (i) the flow, management, and control of resources; (ii) how resources were used at the school level; (iii) how the availability and use of resources influence school performance; and (iv) whether the availability and management of resources differ among regions and socioeconomic groups. The study tracked over 80 percent of the national education budget.

The study was designed by the World Bank in response to requests from the DBM and DepEd for a study to track public expenditure in the basic education system. Prior to designing the study, the Bank held consultations with key government agencies to identify the main issues to be covered as well as the most important budget items to be tracked. Specifically, an advisory group was set up consisting of officials from DepEd, the DBM, the National Economic and Development Authority (NEDA), and the Affiliated Network for Social Accountability (ANSA) and of various academics working on the Philippines education system. This group reviewed the overall approach of the study before seeking approval of the study's concept note and methodology by the government. In designing the study, the team and the advisory group referred to guidelines posted on the World Bank's PETS/QSDS web portal that were drawn from other countries' experiences in implementing similar studies. It also drew significantly from the design of a PETS and QSDS study undertaken in Bangladesh in 2005. 'Therefore, the broad approach adopted in the design of this study is similar to PETS and QSDS studies that have been undertaken in other countries.

In order to answer the main research questions, the team developed a detailed analysis plan with a list of key information and indicators to be collected. The study tracked the following items in the central government budget.

- New teachers and teacher salaries.

- Teacher training resources, specifically those from the Human Resource Training and Development Fund (HRTD) and In-Service Training (INSET).

- School maintenance and other operating expenses (MOOE).

- Infrastructure spending from the Basic Education Facilities Fund and the School Building Program.

In addition to looking at central government resource flows, the study also tracked the flow of local government education funds to schools, including the Special Education Fund (SEF). ${ }^{2}$

A set of funding maps was created that outlined the various steps in the planning, budgeting, and implementation of each budget line to be tracked in the study to help the team to understand fund flow mechanisms and design the expenditure tracking elements of the study. ${ }^{3}$ The analysis plan also identified the different levels of government offices and the other respondents that would need to be surveyed to gather such information as follows:

- Department of Budget and Management regional offices (DBMR)

- DepEd regional, division, and district offices

- Local government units (LGU) at the province and city/ municipality levels

- Schools

- Teachers

- General parent-teacher associations (GPTA)

- Student households 


\section{Survey Instruments}

Questionnaires were developed corresponding to each institution that covered all of the information needed to answer the main research questions. In order to track the flow of funds from central government offices to schools, it was necessary to understand the procedures and documentation used for receiving, allocating, and disbursing funds at each administrative level. Therefore, the team conducted exploratory field visits in CAR region ${ }^{4}$ in November, 2013. The purpose of these visits was to understand the type of records that existed on the relevant budget items and to identify key respondents within each office or school for different modules of the surveys. The field visits covered all levels of the institutions where staff would be interviewed for the study.

After the questionnaires had been designed, the team conducted several rounds of pre-testing in different regions before finalizing them to ensure that they were able to track the timing and flow of these funds from source to final destination. Pilot interviews of all levels of the questionnaires were conducted in Region III and were followed by further checks for some questionnaires. Details of the sites visited for the exploratory visits, testing and pilots are shown in Table 1.
Since an important aspect of the study was to explore how effectively schools use their available resources to deliver good quality learning opportunities, the questionnaires were designed to gather considerable information on the characteristics of the sampled schools, such as their available facilities and management systems. The study also collected information on education inputs and outcomes such as student attendance and dropout rates to supplement the main indicators commonly used to measure school quality in the Philippines such as students' scores on the National Achievement Test. Information was also collected on the current management system used and monitoring and coordination activities at the division, district, and regional institutions.

The survey instrument for teachers included a teacher assessment module that was designed by the study team in partnership with the Philippines National Research Center for Teacher Quality (RCTQ). Each questionnaire included a quality control section to be filled in by the enumerator before and after the interview. The school and government-level surveys were conducted using a combination of English and Filipino. The household questionnaire was translated into Filipino. Table 2 presents details of the types of information collected from respondents in each questionnaire.

Table 1: Details of the Field Visits Carried Out during the Development of the Survey Instruments

\begin{tabular}{|c|c|c|c|}
\hline Region & Office & Interviewee & Dates \\
\hline \multicolumn{4}{|c|}{ Exploratory field visits } \\
\hline \multirow{8}{*}{ CAR } & CAR DepEd regional office & $\begin{array}{l}\text { Regional director, accountant, payroll } \\
\text { services unit officers }\end{array}$ & \multirow{8}{*}{$\begin{array}{l}\text { November 17-21, } \\
2013\end{array}$} \\
\hline & DepEd division office, Benguet & $\begin{array}{l}\text { School division superintendent (SDS), } \\
\text { accountant, supply/planning officers }\end{array}$ & \\
\hline & DepEd division office, Baguio & SDS, accountant, COA auditor & \\
\hline & DPWH, Benguet & District Engineer & \\
\hline & Benguet municipal LGU & Mayor, budget officer in charge of the SEF & \\
\hline & Longlong Elementary School in Benguet & Principal & \\
\hline & Lucban Elementary School in Baguio & Principal & \\
\hline & Benguet National High School & Principal, accountant & \\
\hline
\end{tabular}


Table 1 continued: Details of the Field Visits Carried Out during the Development of the Survey Instruments

\begin{tabular}{|c|c|c|c|}
\hline Region & Office & Interviewee & Dates \\
\hline \multicolumn{4}{|c|}{ Field Visits to Test Questionnaires } \\
\hline \multirow{3}{*}{ NCR } & DepEd division office, Taguig city & SDS, accountant, planning officer & \multirow{3}{*}{$\begin{array}{l}\text { February 22-28, } \\
2014\end{array}$} \\
\hline & Bagumbayan National High School & Principal & \\
\hline & Sta. Teresa Elementary school & Principal & \\
\hline \multirow{2}{*}{ Region IV-A } & DepEd division office, Cainta & $\begin{array}{l}\text { SDS, accountant, cashier, planning officer, } \\
\text { human resources officer, supplies officer }\end{array}$ & \multirow{2}{*}{ April 11-14, 2014} \\
\hline & Sipsipin Elementary School & Principal & \\
\hline \multicolumn{4}{|c|}{ Pilot Interviews } \\
\hline Region IV-A & DBM regional office & $\begin{array}{l}\text { Chief budget management specialist in } \\
\text { charge of DepEd }\end{array}$ & \multirow{8}{*}{ June 23-27, 2014} \\
\hline \multirow[t]{7}{*}{ Region III } & DepEd regional Office & $\begin{array}{l}\text { Regional director, human resources } \\
\text { manager, physical facilities officer, } \\
\text { accountant, payroll officer }\end{array}$ & \\
\hline & DepEd division office, Bulacan & $\begin{array}{l}\text { SDS, accountant, cashier, human resources } \\
\text { officer, supplies officer, physical facilities } \\
\text { supervisor, planning officer }\end{array}$ & \\
\hline & DepEd division office, Angeles City & $\begin{array}{l}\text { SDS, accountant, cashier, human resources } \\
\text { officer, supplies officer, physical facilities } \\
\text { supervisor, planning officer }\end{array}$ & \\
\hline & $\begin{array}{l}\text { Pampanga DPWH 2nd district engineering } \\
\text { office }\end{array}$ & District engineer, accountant & \\
\hline & Angeles City LGU & City accountant & \\
\hline & $\begin{array}{l}\text { Dulong Malabon Elementary School, } \\
\text { Bulacan }\end{array}$ & $\begin{array}{l}\text { Principal, selected teachers, selected } \\
\text { households, PTA President }\end{array}$ & \\
\hline & Nepomuceno High School, Angeles City & $\begin{array}{l}\text { Principal, accountant, bookkeeper, selected } \\
\text { teachers, selected households, PTA } \\
\text { President }\end{array}$ & \\
\hline \multicolumn{4}{|c|}{ Further Checks of Implementing Unit High Schools, DPWH, and LGU questionnaires } \\
\hline \multirow{3}{*}{ NCR } & Valenzuela National High School & Principal, accountant, property custodian & \multirow{3}{*}{ August 19, 2014} \\
\hline & Valenzuela DPWH district office & District engineer, accountant & \\
\hline & Valenzuela City LGU & $\begin{array}{l}\text { Councilor in charge of education, } \\
\text { budget officer }\end{array}$ & \\
\hline
\end{tabular}


Table 2: Description of Questionnaires

\begin{tabular}{|c|c|c|c|c|}
\hline Level & Questionnaire & Respondents & $\begin{array}{c}\text { General Information } \\
\text { Collected }\end{array}$ & $\begin{array}{l}\text { Tracking Information } \\
\text { Collected }\end{array}$ \\
\hline \multirow[b]{2}{*}{ Region } & $\begin{array}{l}\text { Department } \\
\text { of Budget and } \\
\text { Management }\end{array}$ & $\begin{array}{l}\text { Chief Budget } \\
\text { Specialist(s) in charge } \\
\text { of the Department of } \\
\text { Education }\end{array}$ & $\begin{array}{l}\text { - Overall regional } \\
\text { allocations to DepEd }\end{array}$ & $\begin{array}{l}\text { - Amount and timing of allotment } \\
\text { releases and cash allocations } \\
\text { (MOOE, new teacher items, SBM } \\
\text { grants, HRTD funds, and SBP and } \\
\text { BEF funds) to DepEd regional } \\
\text { offices and sampled DepEd } \\
\text { division offices and implementing } \\
\text { unit (IU) high schools. }\end{array}$ \\
\hline & $\begin{array}{l}\text { Department of } \\
\text { Education }\end{array}$ & $\begin{array}{l}\text { Regional director, } \\
\text { payroll officer, and } \\
\text { accountant }\end{array}$ & $\begin{array}{l}\text { - Education } \\
\text { management } \\
\text { - Monitoring and } \\
\text { coordination activities } \\
\text { - Opinions on adequacy } \\
\text { of budget and } \\
\text { efficiency of programs } \\
\text { (such as SBP, BEF, and } \\
\text { new teacher items) } \\
\text { - Financial reporting } \\
\text { procedures and } \\
\text { feedback }\end{array}$ & $\begin{array}{l}\text { - Amount and timing of allotments } \\
\text { received for HRTD, SBP, and BEF } \\
\text { funds from DepEd central office } \\
\text { and cash allocations from the } \\
\text { DBM regional office. } \\
\text { - Amount and timing of allotment } \\
\text { releases (new teacher items, } \\
\text { HRTD funds, and SBP and BEF } \\
\text { funds) to DepEd division offices } \\
\text { and implementing unit high } \\
\text { schools. }\end{array}$ \\
\hline \multirow[b]{2}{*}{$\begin{array}{l}\text { Division, } \\
\text { Province, and } \\
\text { District }\end{array}$} & \multirow[b]{2}{*}{$\begin{array}{l}\text { Department } \\
\text { of Education } \\
\text { division office }\end{array}$} & $\begin{array}{l}\text { School division } \\
\text { superintendent }\end{array}$ & $\begin{array}{l}\text { - Interview with division } \\
\text { superintendent } \\
\text { on education } \\
\text { management issues, } \\
\text { coordination with } \\
\text { local governments, } \\
\text { monitoring, and } \\
\text { budget management }\end{array}$ & - No tracking. \\
\hline & & $\begin{array}{l}\text { Division supplies officer, } \\
\text { planning officer, human } \\
\text { resources officer, and } \\
\text { education program } \\
\text { supervisors }\end{array}$ & $\begin{array}{l}\text { - Division office facilities } \\
\text { and personnel } \\
\text { - Size of school-level } \\
\text { workforce and teacher } \\
\text { transfers } \\
\text { - Teacher training } \\
\text { activities }\end{array}$ & $\begin{array}{l}\text { - Number of new teacher posts } \\
\text { received from DepEd central } \\
\text { office and DBM regional office } \\
\text { for the division and for the } \\
\text { sampled elementary and non- } \\
\text { implementing unit high schools. } \\
\text { - Information on enrollment } \\
\text { and teacher numbers in } \\
\text { sampled elementary and non- } \\
\text { implementing unit high schools. }\end{array}$ \\
\hline
\end{tabular}


Table 2 continued: Description of Questionnaires

\begin{tabular}{|c|c|c|c|c|}
\hline Level & Questionnaire & Respondents & $\begin{array}{c}\text { General Information } \\
\text { Collected }\end{array}$ & $\begin{array}{c}\text { Tracking Information } \\
\text { Collected }\end{array}$ \\
\hline \multirow{4}{*}{$\begin{array}{l}\text { Division, } \\
\text { Province, and } \\
\text { District }\end{array}$} & & $\begin{array}{l}\text { Division accountant, } \\
\text { bookkeeper, cashier, } \\
\text { physical facilities } \\
\text { coordinator, and } \\
\text { resident Commission } \\
\text { On Audit (COA) auditor }\end{array}$ & $\begin{array}{l}\text { - Management and } \\
\text { allocation of MOOE and } \\
\text { SBM funds } \\
\text { - Auditing and financial } \\
\text { reporting }\end{array}$ & $\begin{array}{l}\text { - Amount and timing of allotments } \\
\text { releases, and cash allocations for } \\
\text { MOOE, SBM, and new teacher } \\
\text { items received from the DBM } \\
\text { regional office. } \\
\text { - Amount and timing of allotment } \\
\text { releases and cash allocations } \\
\text { for HRTD, SBP, and BEF funds } \\
\text { received from DepEd central and } \\
\text { regional offices. } \\
\text { - Amount and timing of } \\
\text { downloading of MOOE and SBM } \\
\text { funds to sampled elementary } \\
\text { and non-implementing unit high } \\
\text { schools. } \\
\text { Amount and description of } \\
\text { construction, repair, and water } \\
\text { and sanitation projects in } \\
\text { sampled elementary and non- } \\
\text { implementing high schools using } \\
\text { SBP, BEF, and SEF funds. }\end{array}$ \\
\hline & $\begin{array}{l}\text { Provincial } \\
\text { government }\end{array}$ & $\begin{array}{l}\text { Board member in } \\
\text { charge of education for } \\
\text { provincial local school } \\
\text { board and budget } \\
\text { officer in charge of SEF } \\
\text { and other education } \\
\text { spending }\end{array}$ & \multirow{2}{*}{$\begin{array}{l}\text { - Support through SEF } \\
\text { and other local funds } \\
\text { supporting education } \\
\text { (such as the General } \\
\text { Fund) } \\
\text { - Uses of LGU funds for } \\
\text { education (for example, } \\
\text { for teachers and } \\
\text { sports) } \\
\text { - Coordination with } \\
\text { DepEd }\end{array}$} & \multirow{2}{*}{$\begin{array}{l}\text { - Cash and in-kind resources } \\
\text { provided to sampled elementary } \\
\text { and non-implementing unit high } \\
\text { schools. }\end{array}$} \\
\hline & $\begin{array}{l}\text { City/ } \\
\text { municipality } \\
\text { government }\end{array}$ & $\begin{array}{l}\text { Councilor for education } \\
\text { for city/municipality } \\
\text { local school board } \\
\text { and budget officer in } \\
\text { charge of SEF and other } \\
\text { education spending }\end{array}$ & & \\
\hline & $\begin{array}{l}\text { Department of } \\
\text { Public Works } \\
\text { and Highways } \\
\text { district } \\
\text { engineering } \\
\text { office }\end{array}$ & $\begin{array}{l}\text { Engineer in charge of } \\
\text { DepEd projects and } \\
\text { accountant }\end{array}$ & $\begin{array}{l}\text { - Management and } \\
\text { coordination with } \\
\text { DepEd }\end{array}$ & $\begin{array}{l}\text { - Amount and timing of allotment } \\
\text { releases and school project } \\
\text { information on SBP and BEF funds } \\
\text { from DPWH central office. } \\
\text { - Amount, description, and } \\
\text { status of projects in all sampled } \\
\text { elementary and high schools. }\end{array}$ \\
\hline
\end{tabular}


Table 2 continued: Description of Questionnaires

\begin{tabular}{|c|c|c|c|c|}
\hline Level & Questionnaire & Respondents & $\begin{array}{c}\text { General Information } \\
\text { Collected }\end{array}$ & $\begin{array}{c}\text { Tracking Information } \\
\text { Collected }\end{array}$ \\
\hline $\begin{array}{l}\text { Division, } \\
\text { Province, and } \\
\text { District }\end{array}$ & $\begin{array}{l}\text { DepEd district } \\
\text { offices }\end{array}$ & $\begin{array}{l}\text { Public schools district } \\
\text { supervisor }\end{array}$ & $\begin{array}{l}\text { - Coordination and } \\
\text { effectiveness of local } \\
\text { school boards } \\
\text { - Management and } \\
\text { oversight of textbook } \\
\text { and learning materials }\end{array}$ & $\begin{array}{l}\text { - Quantity and timing of teacher } \\
\text { guides and learner materials from } \\
\text { DepEd central office. } \\
\text { - Allocations and delivery } \\
\text { schedules of learner materials } \\
\text { and teacher guides to sampled } \\
\text { elementary and high schools. }\end{array}$ \\
\hline & $\begin{array}{l}\text { Public } \\
\text { elementary, } \\
\text { IU and non-IU } \\
\text { high schools }\end{array}$ & School principal & $\begin{array}{l}\text { - School characteristics, } \\
\text { condition, performance, } \\
\text { management, and gov- } \\
\text { ernance (for example, } \\
\text { the quality of SBM) } \\
\text { - Principal career } \\
\text { information } \\
\text { - Teacher characteristics, } \\
\text { attendance, and } \\
\text { management } \\
\text { - Student absenteeism } \\
\text { - Selection of teachers } \\
\text { from sample and } \\
\text { selection of students } \\
\text { from Kindergarten, and } \\
\text { Grades } 6 \text { and } 10 \\
\text { samples }\end{array}$ & $\begin{array}{l}\text { - Information on school } \\
\text { characteristics to compare with } \\
\text { EBEIS information at DepEd } \\
\text { division and central offices. } \\
\text { - Information on absenteeism and } \\
\text { learner materials for sampled } \\
\text { students. }\end{array}$ \\
\hline $\begin{array}{l}\text { Schools } \\
\text { and their } \\
\text { communities }\end{array}$ & $\begin{array}{l}\text { Public } \\
\text { elementary, } \\
\text { IU and non-IU } \\
\text { high schools }\end{array}$ & $\begin{array}{l}\text { School principal and, } \\
\text { for Section C custodian } \\
\text { and physical facilities } \\
\text { officer }\end{array}$ & $\begin{array}{l}\text { - School revenue and } \\
\text { expenditure from PTA, } \\
\text { canteen, donations, } \\
\text { barangay, private } \\
\text { sector, student charges } \\
\text { etc. }\end{array}$ & $\begin{array}{l}\text { - Amount and timing of allotment } \\
\text { releases and cash allocations for } \\
\text { MOOE, SBM, and new teacher } \\
\text { items received from DepEd } \\
\text { district office and DBM regional } \\
\text { office (for IUs). } \\
\text { - Amount and timing of in-kind } \\
\text { transfers from local government } \\
\text { units. } \\
\text { - Training activities from DepEd } \\
\text { district office and HRTD and SEF } \\
\text { training funds. } \\
\text { - School SBP, BEF, and SEF } \\
\text { construction project description } \\
\text { and status to check with DPWH } \\
\text { district office, DepEd regional } \\
\text { office (for IUs) and division office } \\
\text { records. } \\
\text { - Receipt of learner materials and } \\
\text { teacher guides from sampled } \\
\text { DepEd district office. }\end{array}$ \\
\hline
\end{tabular}


Table 2 continued: Description of Questionnaires

\begin{tabular}{|c|c|c|c|c|}
\hline Level & Questionnaire & Respondents & $\begin{array}{l}\text { General Information } \\
\text { Collected }\end{array}$ & $\begin{array}{l}\text { Tracking Information } \\
\text { Collected }\end{array}$ \\
\hline \multirow{3}{*}{$\begin{array}{l}\text { Schools } \\
\text { and their } \\
\text { communities }\end{array}$} & $\begin{array}{l}\text { Teachers } \\
\text { (DepEd and } \\
\text { LGU teachers } \\
\text { teaching } \\
\text { kindergarten } \\
\text { and Grades } 6 \\
\text { and 10) }\end{array}$ & Teachers & $\begin{array}{l}\text { - Education, experience, } \\
\text { training } \\
\text { - Career and training } \\
\text { history } \\
\text { - Income } \\
\text { - Strengths and needs } \\
\text { assessment and } \\
\text { subject-specific } \\
\text { assessment for Grade } 6 \\
\text { and } 10 \text { teachers }\end{array}$ & - No tracking information \\
\hline & $\begin{array}{l}\text { General } \\
\text { Parent-Teacher } \\
\text { association }\end{array}$ & General PTA President & $\begin{array}{l}\text { - Activities and support } \\
\text { to school } \\
\text { - Contributions } \\
\text { and charges for } \\
\text { membership } \\
\text { - Revenue and } \\
\text { expenditure accounts }\end{array}$ & $\begin{array}{l}\text { - Cash and in-kind contributions to } \\
\text { school }\end{array}$ \\
\hline & $\begin{array}{l}\text { Student } \\
\text { households }\end{array}$ & Household head & $\begin{array}{l}\text { - Socioeconomic } \\
\text { background } \\
\text { - Student education } \\
\text { background } \\
\text { - Education direct and } \\
\text { indirect costs }\end{array}$ & $\begin{array}{l}\text { - Verify school registers by } \\
\text { identifying a random sample of } \\
\text { students } \\
\text { - Receipt of learner materials }\end{array}$ \\
\hline
\end{tabular}




\section{Sampling Approach and Final Sample}

The sampling approach for this study was based on the need to collect information on a nationally representative sample of public elementary and high schools. The team developed the sampling approach in consultation with an international expert on sampling who had considerable experience of designing appropriate samples for the Living Standards Measurement surveys and other public expenditure tracking studies of this kind. The Autonomous Region in Muslim Mindanao (ARMM) was excluded from the study based on a review of recent studies and after consultations with the advisory board.

Since the main purpose of the study was to assess whether schools receive their budgeted resources and use them effectively, ensuring that an adequate number of schools were in the sample was crucial in order to yield accurate estimates of key indicators at the school level (for example, the share of schools receiving their full MOOE allocation). The study also aimed to examine the extent to which local governments and DepEd administrative offices influence the performance of schools. For example, do schools in DepEd divisions who receive their full MOOE allocations in timely manner perform better? Therefore, a further consideration was to include in the sample schools in the jurisdiction of a wide range of local governments and DepEd divisional offices.

Based on these requirements, the study adopted a stratified clustered sampling approach in which the primary sampling units were municipalities and cities. A sample of schools was then selected within each sampled municipality or city. The team concluded that a sample size of 250 elementary schools and 250 high schools was financially feasible and would provide the necessary precision for some of the key indicators to be studied. In addition, a random sample of teachers and student households within the sampled schools was selected to be interviewed by survey teams with the relevant questionnaires. Table 3 presents the planned and final samples for each questionnaire. A detailed description of the sampling approach taken at various levels is given in Table 4.

\section{Table 3: Planned and Final Samples}

\begin{tabular}{lcc}
\hline Questionnaire & $\begin{array}{c}\text { Planned } \\
\text { Sample }\end{array}$ & $\begin{array}{c}\text { Final } \\
\text { Sample }\end{array}$ \\
\hline DBM Regional & 16 & 16 \\
DepEd Regional & 16 & 16 \\
DepEd Divisions & 50 & 51 \\
DepEd District & $* *$ & 113 \\
DPWH District & $* *$ & 54 \\
Provincial LGU* & 30 & 27 \\
City/Municipal LGU & 50 & 47 \\
Elementary Schools & 250 & 249 \\
High Schools & 250 & 200 \\
Teachers (Kindergarten and grade 6) & Max(1,250) & 608 \\
Teachers (grade 10) & Max(1,500) & 946 \\
GPTA & 500 & 449 \\
Student households & 2,500 & 2,189 \\
\hline
\end{tabular}

Notes: * Since HUCs and other cities do not have a provincial-level LGU, 30 provincial LGUs were sampled. ** The sampling of district level offices was driven by the schools selected. All DepEd and DPWH offices associated with the sampled schools were identified and interviewed. The final sample size indicates the number of observations that can be used for analysis after accounting for adjustments and non-responses. 


\section{Sampling of Cities and Municipalities, and Associated Agencies}

Cities and municipalities in 16 regions were selected within strata of highly urbanized cities (HUCs), other cities, and municipalities. ${ }^{5}$ A total of 30 municipalities, 10 other cities, and 10 HUCs were sampled with probability proportional to population size. ${ }^{6}$ These numbers were determined by the need to ensure an adequate sample of schools from different types of location. In addition, following the team's consultations with DepEd, three HUCs from the National Capital Region (NCR) were sampled with certainty given the region's large population and the high share of basic education funds spent in the NCR.

All division offices and LGUs that had at least one sampled elementary or high school under their jurisdiction were selected. There was some attrition due to key officials refusing to be interviewed or being unavailable, and this resulted in final samples sizes of 27 provincial LGUs and 47 city/municipality LGUs.

While most cities and municipalities are under the jurisdiction of a single division, DepEd's decision in 2014 to split a particular division in two meant that a city in the study sample came under the jurisdiction of both divisions.

\section{Sampling of Schools}

Random samples of five public elementary schools offering the full $\mathrm{K}$ to 6 grades and five public high schools were chosen with equal probability within each sampled city or municipality. However, some cities and municipalities had fewer than five high schools. In such cases, all of the high schools in the city or municipality were included in the sample. Private schools were excluded from the sampling frame because, on the whole, the public funds tracked by the study do not flow to these types of schools. The funds tracked in the study represented over 80 percent of the total central government education budget in 2014 and were mainly used to support public schools. Integrated schools and incomplete schools (in other words, elementary schools not offering all $\mathrm{K}$ to 6 grades) were also excluded. ${ }^{8}$ In addition, 350 special high schools that follow a different curriculum and 84 high schools that were new and did not offer grade 10 classes were not included in the sample frame.
The final sample included 249 elementary and 200 high schools. One sampled elementary school could not be accessed for an interview because the school was closed because of security concerns. In addition, an incorrect high school that was not in the original sample had to be dropped. ${ }^{9}$

The samples of DepEd and DPWH district offices were determined by the schools that had been selected. All DepEd and DPWH district offices that were associated with the 250 elementary schools and 201 high schools in our original sample were identified and visited for interviews. The original and final sample sizes for the survey of general parent-teacher associations (GPTA) were also based on the sample of schools.

\section{Sampling of Teachers and Student Households}

The sampling of teachers and student households was done in the field by survey teams. Within each elementary school, up to three DepEd-funded teachers and up to two LGU-funded teachers were sampled. Among the DepEd-funded teachers, up to two Grade 6 teachers and one kindergarten teacher were selected from each school. In order to select Grade 6 teachers, two Grade 6 sections were first randomly sampled from the pool of all Grade 6 sections within each elementary school, and from those sections, up to two DepEd-funded teachers were then selected. However, if there was only one DepEd-funded Grade 6 teacher in the sampled sections to choose from, then an additional teacher was selected from among DepEd-funded teachers in the other non-sampled Grade 6 sections. If there were no DepEd-funded Grade 6 teachers in the other sections, then a DepEd-funded teacher from another grade was sampled. If the selected sections had LGU-funded or locally hired teachers, then one LGU-funded teacher was sampled from this pool. If there were no LGUfunded teachers in the selected Grade 6 sections, then an LGU-funded teacher was chosen either from the pool of all LGU-funded Grade 6 teachers or from all LGU teachers in the school depending on the availability of LGU-funded teachers in other Grade 6 sections.

High school teachers were also sampled from a pool of teachers teaching in two randomly selected Grade 10 sections in each school, but they did not need to be LGUfunded. Emphasis was placed on sampling at least one teacher specializing in Math, Science, English, and Filipino. 
There were significantly fewer teachers in the final sample than had been estimated. A number of factors contributed to the gap between the planned and final samples. Some schools had only one section per grade or, in the case of high schools, had one teacher teaching multiple subjects, which reduced the actual size of the teacher sample. Some elementary schools did not have any LGU-funded teachers or DepEd-funded kindergarten teachers. The size of the high school teacher sample was also lower than planned as the original estimate was based on 250 high schools instead of the 201 that were actually sampled. In addition, only teachers in Grades 6 and 10 were used in the analyses.

For the household questionnaire, four Grade 6 students were selected from the sampled sections in each school.
Two of these students were selected from the pool of students who attended school on the first day of the survey while the other two students were chosen from among the students who were not at school that day. A total of two kindergarten students were also selected from each elementary school, one from among those attending school on the first day of the survey and the second from among those who were absent. Four Grade 10 students from each high school were also sampled using the same approach.

Attrition in the household sample was a result of the smaller final size of the school samples as well as of some people refusing to be interviewed or the team's inability to contact some households. Moreover, in some cases, security concerns prevented field teams from visiting the households. ${ }^{10}$

\section{Table 4: Outline of the PETS-QSDS Sampling Strategy}

\begin{tabular}{|c|c|c|c|c|c|c|}
\hline $\begin{array}{l}\text { Sampling } \\
\text { Units }\end{array}$ & Stage & Domain & Strata & $\begin{array}{c}\text { Number of } \\
\text { Units Selected }\end{array}$ & $\begin{array}{l}\text { Selection } \\
\text { Method }\end{array}$ & Total \\
\hline \multirow{5}{*}{$\begin{array}{c}\text { City and } \\
\text { municipalities }\end{array}$} & \multirow{5}{*}{1} & NCR & Cities & 3 & $\begin{array}{l}\text { Systematic sampling } \\
\text { with probability } \\
\text { proportional to } \\
\text { population size }\end{array}$ & 3 \\
\hline & & \multirow{4}{*}{$\begin{array}{l}\text { All other regions } \\
\text { excluding ARMM }\end{array}$} & Davao City & 1 & $\begin{array}{l}\text { Selected with } \\
\text { certainty }\end{array}$ & 1 \\
\hline & & & $\begin{array}{l}\text { All other highly } \\
\text { urbanized cities }\end{array}$ & 6 & \multirow{3}{*}{$\begin{array}{l}\text { Systematic sampling } \\
\text { with probability } \\
\text { proportional to } \\
\text { population size }\end{array}$} & 6 \\
\hline & & & Other cities & 10 & & 10 \\
\hline & & & Municipalities & 30 & & 30 \\
\hline $\begin{array}{l}\text { Complete (all- } \\
\text { grade) public } \\
\text { elementary } \\
\text { schools (including } \\
\text { kindergarten) }\end{array}$ & 2 & $\begin{array}{l}\text { All } 50 \text { cities and } \\
\text { municipalities }\end{array}$ & Government & $\begin{array}{l}5 \text { per city/ } \\
\text { municipality }\end{array}$ & $\begin{array}{c}\text { Systematic } \\
\text { equal-probability } \\
\text { sampling }\end{array}$ & 250 \\
\hline $\begin{array}{l}\text { Elementary } \\
\text { Grade } 6 \text { sections }\end{array}$ & 3 & $\begin{array}{c}\text { All } 250 \text { selected } \\
\text { complete } \\
\text { elementary schools }\end{array}$ & All Grade 6 sections & 2 & $\begin{array}{l}\text { Simple random } \\
\text { sample }\end{array}$ & $\sim 500$ \\
\hline
\end{tabular}


Table 4 continued: Outline of the PETS-QSDS Sampling Strategy

\begin{tabular}{|c|c|c|c|c|c|c|}
\hline $\begin{array}{l}\text { Sampling } \\
\text { Units }\end{array}$ & Stage & Domain & Strata & $\begin{array}{c}\text { Number of } \\
\text { Units Selected }\end{array}$ & $\begin{array}{l}\text { Selection } \\
\text { Method }\end{array}$ & Total \\
\hline \multirow[b]{2}{*}{$\begin{array}{l}\text { Elementary school } \\
\text { teachers }\end{array}$} & \multirow{2}{*}{$3 a$} & \multirow[b]{2}{*}{$\begin{array}{c}\text { All } 250 \text { selected } \\
\text { complete } \\
\text { elementary schools }\end{array}$} & $\begin{array}{l}\text { At least two DepEd } \\
\text { Grade } 6 \text { teachers in } \\
\text { selected sections }\end{array}$ & $1-2$ & $\begin{array}{l}\text { Selected with } \\
\text { certainty }\end{array}$ & $\sim 500$ \\
\hline & & & $\begin{array}{l}\text { At least one LGU/ } \\
\text { locally hired teacher }\end{array}$ & 1 & $\begin{array}{l}\text { Simple random } \\
\text { sample (select } \\
\text { Grade } 6 \text { teacher in } \\
\text { selected section } \\
\text { where possible) }\end{array}$ & 250 \\
\hline \multirow{2}{*}{$\begin{array}{l}\text { Elementary } \\
\text { school student } \\
\text { households }\end{array}$} & \multirow[t]{2}{*}{$3 b$} & \multirow{2}{*}{$\begin{array}{c}\text { All } 250 \text { selected } \\
\text { complete } \\
\text { elementary schools }\end{array}$} & $\begin{array}{c}\text { Grade } 6 \text { students } \\
\text { in selected section } \\
\text { attending school } \\
\text { on first day of the } \\
\text { survey }\end{array}$ & 2 & $\begin{array}{l}\text { Simple random } \\
\text { sample }\end{array}$ & 500 \\
\hline & & & $\begin{array}{l}\text { Grade } 6 \text { students } \\
\text { in selected section } \\
\text { absent on the first } \\
\text { day of the survey }\end{array}$ & 2 & $\begin{array}{l}\text { Simple random } \\
\text { sample }\end{array}$ & 500 \\
\hline \multirow{2}{*}{$\begin{array}{l}\text { Kindergarten } \\
\text { teachers }\end{array}$} & \multirow{2}{*}{$3 c$} & \multirow{2}{*}{$\begin{array}{c}\text { All } 250 \text { selected } \\
\text { complete } \\
\text { elementary schools }\end{array}$} & $\begin{array}{c}\text { DepEd Kindergarten } \\
\text { Volunteer Program } \\
\text { (KVP) teacher }\end{array}$ & 1 & $\begin{array}{l}\text { Simple random } \\
\text { sample }\end{array}$ & 250 \\
\hline & & & $\begin{array}{l}\text { LGU/locally hired } \\
\text { teachers }\end{array}$ & 1 & $\begin{array}{l}\text { Simple random } \\
\text { sample }\end{array}$ & 250 \\
\hline \multirow{2}{*}{$\begin{array}{l}\text { Kindergarten } \\
\text { school } \\
\text { households }\end{array}$} & \multirow[t]{2}{*}{$3 d$} & \multirow{2}{*}{$\begin{array}{l}\text { All } 250 \text { selected } \\
\text { complete } \\
\text { elementary schools }\end{array}$} & $\begin{array}{l}\text { Kindergarten } \\
\text { students attending } \\
\text { school on the first } \\
\text { day of the survey }\end{array}$ & 1 & $\begin{array}{l}\text { Simple random } \\
\text { sample }\end{array}$ & 250 \\
\hline & & & $\begin{array}{c}\text { Kindergarten } \\
\text { students absent on } \\
\text { the first day of the } \\
\text { survey }\end{array}$ & 1 & $\begin{array}{l}\text { Simple random } \\
\text { sample }\end{array}$ & 250 \\
\hline $\begin{array}{l}\text { Complete public } \\
\text { high schools }\end{array}$ & 4 & $\begin{array}{l}\text { All } 50 \text { cities and } \\
\text { municipalities }\end{array}$ & Government & $\begin{array}{l}5 \text { per city/ } \\
\text { municipality }\end{array}$ & $\begin{array}{l}\text { Systematic equal- } \\
\text { probability sampling }\end{array}$ & $\sim 250$ \\
\hline $\begin{array}{l}\text { High school } \\
\text { section }\end{array}$ & 5 & $\begin{array}{c}\text { All } 250 \text { selected } \\
\text { secondary schools }\end{array}$ & $\begin{array}{l}\text { All Grade } 10 \\
\text { sections }\end{array}$ & 2 & $\begin{array}{l}\text { Simple random } \\
\text { sample }\end{array}$ & $\sim 500$ \\
\hline
\end{tabular}


Table 4 continued: Outline of the PETS-QSDS Sampling Strategy

\begin{tabular}{|c|c|c|c|c|c|c|}
\hline $\begin{array}{l}\text { Sampling } \\
\text { Units }\end{array}$ & Stage & Domain & Strata & $\begin{array}{l}\text { Number of } \\
\text { Units Selected }\end{array}$ & $\begin{array}{l}\text { Selection } \\
\text { Method }\end{array}$ & Total \\
\hline $\begin{array}{l}\text { High school } \\
\text { teachers }\end{array}$ & $5 a$ & $\begin{array}{l}\text { All } 250 \text { selected } \\
\text { secondary schools }\end{array}$ & $\begin{array}{l}\text { Grade } 10 \text { teachers in } \\
\text { selected sections }\end{array}$ & $\begin{array}{l}\text { Grade } 10 \\
\text { teachers in } \\
\text { math, science, } \\
\text { English and } \\
\text { Filipino } \\
\text { teaching } \\
\text { selected } \\
\text { sections }\end{array}$ & $\begin{array}{l}\text { Selected with } \\
\text { certainty }\end{array}$ & $\sim 1500$ \\
\hline \multirow{2}{*}{$\begin{array}{l}\text { High school } \\
\text { student } \\
\text { households }\end{array}$} & \multirow[t]{2}{*}{$5 b$} & \multirow{2}{*}{$\begin{array}{l}\text { All } 250 \text { selected } \\
\text { secondary schools }\end{array}$} & $\begin{array}{l}\text { Grade } 10 \text { students } \\
\text { in selected section } \\
\text { attending school on } \\
\text { the first day of the } \\
\text { survey }\end{array}$ & $\begin{array}{l}2 \text { from selected } \\
\text { section }\end{array}$ & $\begin{array}{l}\text { Simple random } \\
\text { sample }\end{array}$ & 500 \\
\hline & & & $\begin{array}{l}\text { Grade } 10 \text { students } \\
\text { in selected section } \\
\text { absent on the first } \\
\text { day of the survey }\end{array}$ & $\begin{array}{l}2 \text { from selected } \\
\text { section }\end{array}$ & $\begin{array}{l}\text { Simple random } \\
\text { sample }\end{array}$ & 500 \\
\hline
\end{tabular}

\section{Survey Implementation}

After the survey instruments had been finalized, the study was implemented between August and December of 2014 by a Philippines-based survey firm, Tylor, Nelson, and Sofres (TNS), which was also responsible for data encoding. Several steps were taken to ensure the quality of the interviews and the resulting outputs, including providing enumerators with comprehensive training and building in many quality control checks. In addition, TNS secured authorization from the relevant school division superintendents before conducting the school interviews.

\section{Enumerator Training}

The survey enumerators underwent extensive training in how to administer each module of the questionnaires and in how to record the information obtained during the interview from verbal responses, official records, and personal observation. They were also given detailed instructions on the sampled grade sections, teachers, and student households before administering the teacher and household questionnaires. Enumerators were specifically trained to conduct the interviews in a respectful manner and to mitigate any potential biases in the responses.

Two batches of 10-day training sessions were held in September before the launch of the actual fieldwork. The training sessions were split into five days of classroom training and five days of training in the field. The classroom training included an overview of the project and its design, a discussion of each question in the questionnaires, and instruction on the proper way to use skips and to document responses. Role playing and mock interviews and recording of responses were also used to prepare enumerators for fieldwork. In the training held in the field, enumerators participated in test runs of interviews during which they were accompanied by a field supervisor. Finally, sessions were held to discuss and resolve any difficulties that were encountered during test runs before the launch of the actual fieldwork.

A comprehensive fieldwork manual was prepared for the enumerators to use. The manual provided them with background information on the Philippines' education system as well as an overview of how DepEd is organized. It also included a description of each stage of the budgeting 
process to give enumerators an overview of the flow of basic education funds in the Philippines. It also contained detailed instructions for completing each module of the PETS-QSDS questionnaires as well as decision trees to facilitate the sampling of teachers and student households.

In addition, the World Bank team prepared a manual on the public financial management system in the Philippines, which explained all phases of the government's budget process. The manual included a detailed description of the flow of public funds tracked in the survey starting from appropriation and allotment to spending guidelines as well as brief descriptions of funds that schools often receive from other sources such as school canteen funds and other nongovernment sources such as Parents Teachers Association funds. The manual also contained relevant government orders and guidelines associated with public fund flows in the education sector.

\section{Fieldwork Organization}

The field interviews began on September 24, 2014 and were conducted in two phases. The schedule and coverage of the two phases are shown in Table 5.

The field team was led by a field manager and three field coordinators who each covered one of the three island groups in the Philippines - Luzon, Visayas, and Mindanao. The field coordinators were in charge of monitoring the survey implementation and of creating field reports on a weekly basis. Each region was assigned two to three field survey teams to conduct the interviews, with each team consisting of about three members. Each team comprised a field team leader (FTL) who was responsible for conducting quality checks and ensuring that interviews were carried out and documented properly. FTLs were also responsible for carrying out sampling of grade sections, teachers, and student households.

In addition, each region was assigned an executive enumerator. These executive enumerators have experience in conducting these types of interviews so were appointed to interview senior officials in the regional, province, and district offices of the relevant government departments. The executive enumerators also interviewed the school division superintendents. These senior enumerators were also accompanied by an assistant enumerator on any visits that entailed documenting a lot of information from official records. Interviews at the school and household levels were conducted by the field survey teams. The survey teams also administered sections of the division questionnaires that were not covered by the executive enumerator.

In case an interview was not possible at the time of the first visit, the enumerators scheduled another visit to conduct the interview.

\section{Quality Control}

The utmost care was taken to ensure quality by carrying out checks at various points during the implementation of the study. Quality control checks were conducted by field coordinators (FC), field team leaders (FTL), a team of back checkers, and by each enumerator. In order to facilitate systematic checks in the field, questions related to survey quality were embedded in the questionnaires themselves. A core survey management team handled any quality control issues and reviewed the weekly progress reports submitted from the field. In addition, the World Bank team conducted survey monitoring visits as did the RCTQ (for the teacher assessments). Furthermore, any completed questionnaires with a lot of missing data were identified during the data

\section{Table 5: Schedule and Coverage of Field Visits}

\begin{tabular}{|c|c|c|c|}
\hline Field Visits & Regions & No. of Cities/Municipalities & Schedule \\
\hline \multirow{2}{*}{ 1st Phase } & Luzon and NCR & 19 & September 24-November 13 \\
\hline & Visayas and Mindanao & 9 & September 30-November 13 \\
\hline \multirow{2}{*}{ 2nd Phase } & Luzon & 7 & November 12-December 9 \\
\hline & Visayas and Mindanao & 5 & November 17-December 9 \\
\hline
\end{tabular}


processing phase, and the school or agency in question was revisited to get complete responses to the extent possible."

The quality checks by each type of fieldwork member are as follows:

- Field Coordinator (FC). A field coordinator was assigned to each of the three island groups. FCs were responsible for supervising their field teams and executive enumerators to ensure that they complied with interview protocols, including proper data collection and encoding during interviews and proper sampling of teachers and households in the field. FCs also consolidated and submitted weekly progress reports from the field to TNS central office.

- Field Team Leader (FTL). FTLs were generally responsible for ensuring the quality of the interviews conducted by their team and the information that they collect. Immediately after their teams conducted the interviews, while still in the field, the FTLs checked the completed questionnaires for correctness, completeness, and consistency and took steps to rectify any errors. For example, they verified information obtained from official records against the original sources (such as MOOE records) or ensured that the skips in the questionnaires had been followed or checked whether information recorded multiple times in the survey is fairly consistent (such as whether totals add up correctly). In order to ensure that these checks are carried out systematically, each questionnaire includes a quality control section for FTLs to fill in after the completion of the interview. FTLs also observed a number of interviews conducted by other enumerators in the team and provided them with appropriate feedback. In addition, FTLs were required to follow up on a random selection of interviewed households to cross-check some of the basic information with the respondents.

- Back Checkers. A team of nine back checkers was appointed to conduct further cross-checks of the quality controls carried out by the FTLs on a sample of questionnaires. These back checkers re-checked approximately 30 percent of questionnaires in TNS central office and during field visits. They were provided with a separate form to assist in the checking of questionnaires and to identify inconsistencies. Similar to FTLs, back checkers also made follow-up visits to a random sample of households and observed some original interviews, including some conducted by FTLs. The back checkers also ensured that all levels of questionnaires were completed in each city or municipality after the completion of the fieldwork.

- Other Enumerators. Each enumerator carried out a quality check on each interview that they conducted themselves by filling in the quality control section included in each questionnaire. Prior to the beginning of the interview, enumerators followed the instructions on choosing the correct respondent and entered the respondent's details in the quality control section. After the interview was completed, the enumerators were required to check and document whether each module in the questionnaire was completed and whether any relevant information or identifiers (such as school identification codes) had been transferred from one questionnaire to another (for example, transferring data on specific teachers from the teacher observation module in the school questionnaires to the teacher and RCTQ assessment questionnaires).

\section{Processing Data for Analysis}

The data collected during the fieldwork were encoded by TNS using automated data entry scripts that had been pretested. The World Bank team gave regular feedback to the data entry team regarding the need for any corrections of the data. TNS submitted a complete set of data to the World Bank in July of 2015.

\section{Data Cleaning}

After the World Bank received the datasets from TNS, some further cleaning and verification was required. The major changes and follow-ups for verifications are outlined in Box 1.

\section{Creation of Sample Weights}

In order to strengthen the external validity of the findings of the policy notes, the analyses used sampling weights based on the probability of being selected from the relevant populations and sub-populations. The World Bank team calculated the sampling weights using the finalized datasets after the completion of adjustments described in Box 1. Details of how the weights for each dataset were calculated are provided in a set of additional tables and annexes accompanying the report. 


\section{Box 1: Finalizing Datasets for Analysis}

The World Bank study team made the following revisions to the datasets when conducting preliminary analyses using the data submitted by TNS in July 2015. All of the final analyses for the policy notes were conducted using the revised datasets.

- Six non-implementing high schools were accidentally administered the HSIU2 questionnaire meant for implementing (IU) high schools. For variables that overlap between the HS2 and HSIU2 questionnaires, the data from the HSIU2 questionnaire for these six schools were appended to the HS2 data. All information in the HSIU2 dataset for these six schools were then removed.

- An IU high school that was not in the sample was accidentally interviewed in place of Baguio High School of Agriculture - Tambobong Annex (which was in the original sample). All of the variables corresponding to this school in the high school, teacher, GPTA, and household questionnaires were set to missing.

- Non-zero values for MOOE amounts in the division-level data were recorded for five IU high schools. Following phone calls to verify their IU status and whether they had received any MOOE funds from the division office or from the DBM, the study team set the variables for MOOE amounts in the division data for four of these schools to missing as they did not report receiving any MOOE from divisions.

- Adjustments were made to the teacher and RCTQ assessment datasets. Teachers who do not teach kindergarten, Grade 6, or Grade 10 were dropped as the analyses on teachers were focused on teachers who teach these grades. In addition, some teachers who had not been included in the "teacher roster" in the school questionnaires but had been interviewed were also dropped.

\section{Use of Other Data Sources}

While most of the analysis was conducted using the datasets from this PETS-QSDS study, the study team often had to use other data sources to supplement the information gathered in the study. Table 6 lists all of these other data sources that were used in all seven policy notes.

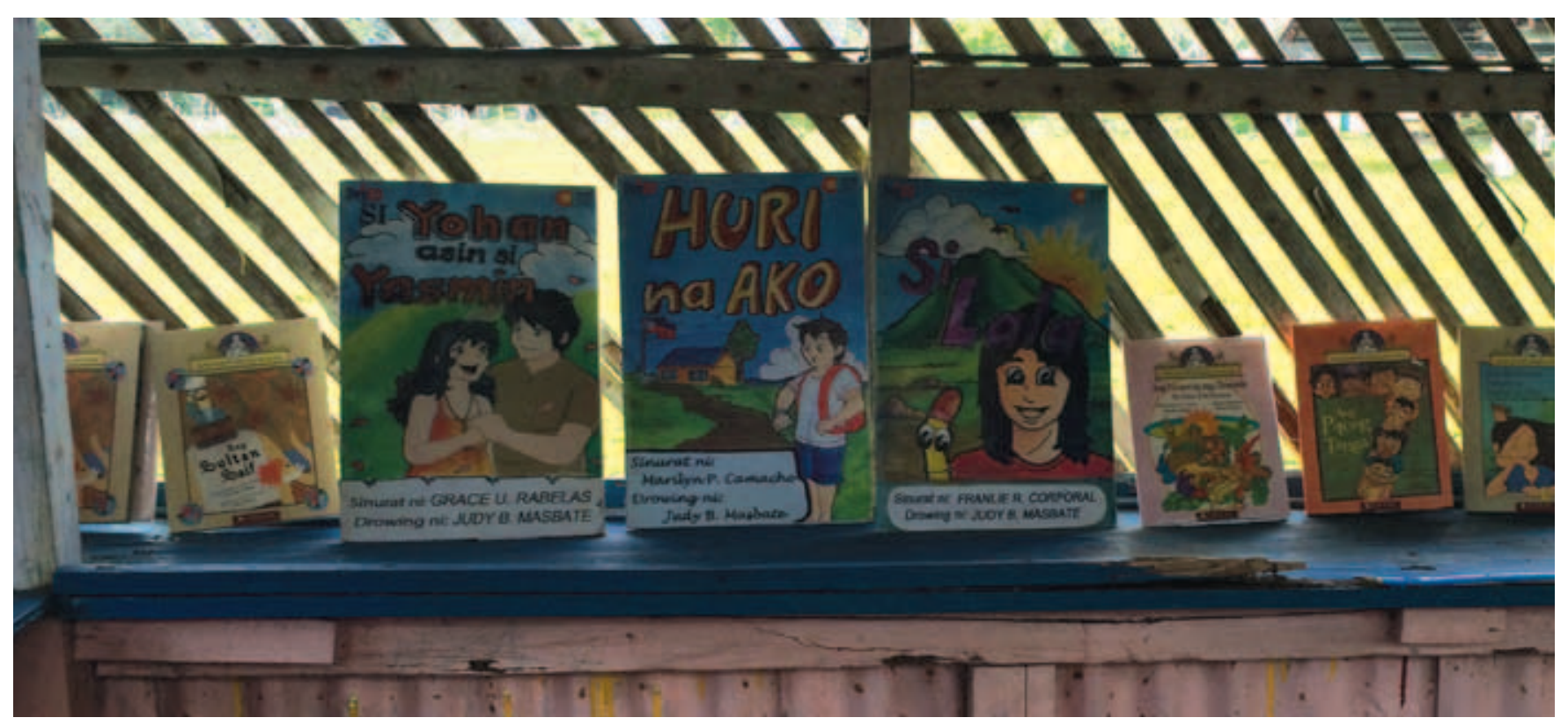




\section{Table 6: Other Data Sources Used in the Policy Notes}

\begin{tabular}{|c|c|c|}
\hline Data Source & Year(s) & Description/use \\
\hline $\begin{array}{l}\text { DepEd's Fact Sheet on Basic } \\
\text { Education Statistics }\end{array}$ & $\begin{array}{l}2011,2013 \\
2015\end{array}$ & $\begin{array}{l}\text { Enrollment figures for kindergarten, elementary and high school, and } \\
\text { teacher ratios in all public schools }\end{array}$ \\
\hline DepEd eBEIS & $\begin{array}{l}2011,2012 \\
2013\end{array}$ & $\begin{array}{l}\text { Enrollment figures by grade (2003 to 2014), number of classrooms and } \\
\text { number of teachers for all public schools }\end{array}$ \\
\hline DBM General Appropriations Act & 2013 & MOOE allocations for each public high school in the Philippines \\
\hline DepEd (Correspondence) & 2013-2016 & $\begin{array}{l}\text { Elementary school MOOE allocations 2013, parameters of MOOE funding } \\
\text { formula 2013-2016. }\end{array}$ \\
\hline DepEd (Correspondence) & & $\begin{array}{l}\text { Standard regional costing estimates for classroom construction and water } \\
\text { and sanitation units }\end{array}$ \\
\hline $\begin{array}{l}\text { DepEd Staffing Summary } \\
\text { Document }\end{array}$ & $2012-2016$ & DepEd obligations for teacher salaries \\
\hline DepEd Order 12, s.2014 & 2014 & Implementing guidelines for school MOOE \\
\hline DepEd Order 77, s.2010 & 2010 & $\begin{array}{l}\text { Guidelines on the Allocation/Deployment of New Teaching, Teaching- } \\
\text { related, and Non-teaching Positions for FY } 2010\end{array}$ \\
\hline DepEd Order 102, s. 2011 & 2011 & Benchmark dates on new teacher allocations and deployment \\
\hline DepEd Order 54, s. 2009 & 2009 & Guidelines governing PTAs at the school level \\
\hline $\begin{array}{l}\text { DepEd Statement of Allotments } \\
\text { and Obligations }\end{array}$ & 2005-2014 & $\begin{array}{l}\text { Allotments and obligations for Human Resources and Training } \\
\text { Development funds, school MOOE funds. }\end{array}$ \\
\hline $\begin{array}{l}\text { DepEd Basic Education Facilities } \\
\text { Fund data }\end{array}$ & 2013 & $\begin{array}{l}\text { School-level details of each classroom construction project and water/ } \\
\text { sanitation unit construction project }\end{array}$ \\
\hline National Expenditure Program & & $\begin{array}{l}\text { Total government spending, total education spending, DepEd's spending } \\
\text { obligations }\end{array}$ \\
\hline $\begin{array}{l}\text { Bureau of Local Government } \\
\text { Finance }\end{array}$ & 2009-2014 & Data on Special Education Funds \\
\hline Philippines Statistics Authority & $\begin{array}{l}\text { Various } \\
\text { years }\end{array}$ & GDP deflator \\
\hline $\begin{array}{l}\text { ADB Teacher Absenteeism } \\
\text { Survey - Indonesia }\end{array}$ & 2014 & Teacher absenteeism rates in Indonesia \\
\hline $\begin{array}{l}\text { OECD Teaching and Learning } \\
\text { International Survey }\end{array}$ & 2013 & Survey on the professional development of teachers in different countries \\
\hline World Development Indicators & $\begin{array}{l}\text { See policy } \\
\text { note } 1\end{array}$ & \\
\hline UNESCO Institution for Statistics & 2012 & Teacher salaries in various countries \\
\hline PETS - Cambodia & 2004 & Absenteeism rates for primary school teachers \\
\hline
\end{tabular}




\section{Endnotes}

1 FMRP (2006) "Social Sector Performance Surveys: Primary Education in Bangladesh: Assessing Service Delivery" Oxford Policy Management and Financial Management Reform Program, Dhaka.

2 The SEF comes from a 1 percent property tax surcharge and is managed by local government units.

3 The funding map along with the relevant regulations and guidelines were collated into a single report used to train survey enumerators.

4 The CAR region, the two division offices visited, and other sites visited to pre-test the questionnaires were selected largely because of convenience as determined by the sites' proximity to Manila.

5 The stratification followed the legal classification of cities and municipalities based on population size and annual income.

6 Population data used to select the sample was from the 2010 Census.
7 The bulk of government funding to private schools is given through the Government Assistance for Students and Teachers in Private Education (GASTPE), which only represented about 3 percent of new appropriations in 2014. The study team decided not to track these resources given their relatively small share of the overall budget and the fact that other studies were planning to look at the GASTPE program in more detail.

8 As of 2013 school year, there were 164 integrated elementary schools and 568 integrated high schools in the Philippines. Thirteen percent of all elementary schools were incomplete.

9 Instead of Baguio High School of Agriculture-Tambobong Annex, another IU high school was interviewed by mistake.

10 Some areas where sampled households were located were known to harbor insurgents.

11 Revisits were completed for 35 out of the 58 institutions or interviewees that had been identified as needing a revisit. In some cases where only one school in a municipality or city was identified, no revisit was carried out. 
The World Bank

1818 H Street, N.W.

Washington, D.C. 20433 USA

www.worldbank.org/ph 